\title{
PM-I NUCLEAR POWER PLANT PROGRAM PARAMETRIC STUDY REPORT
}

September 1959

Martin Company Nuclear Division

Baltimore, Maryland

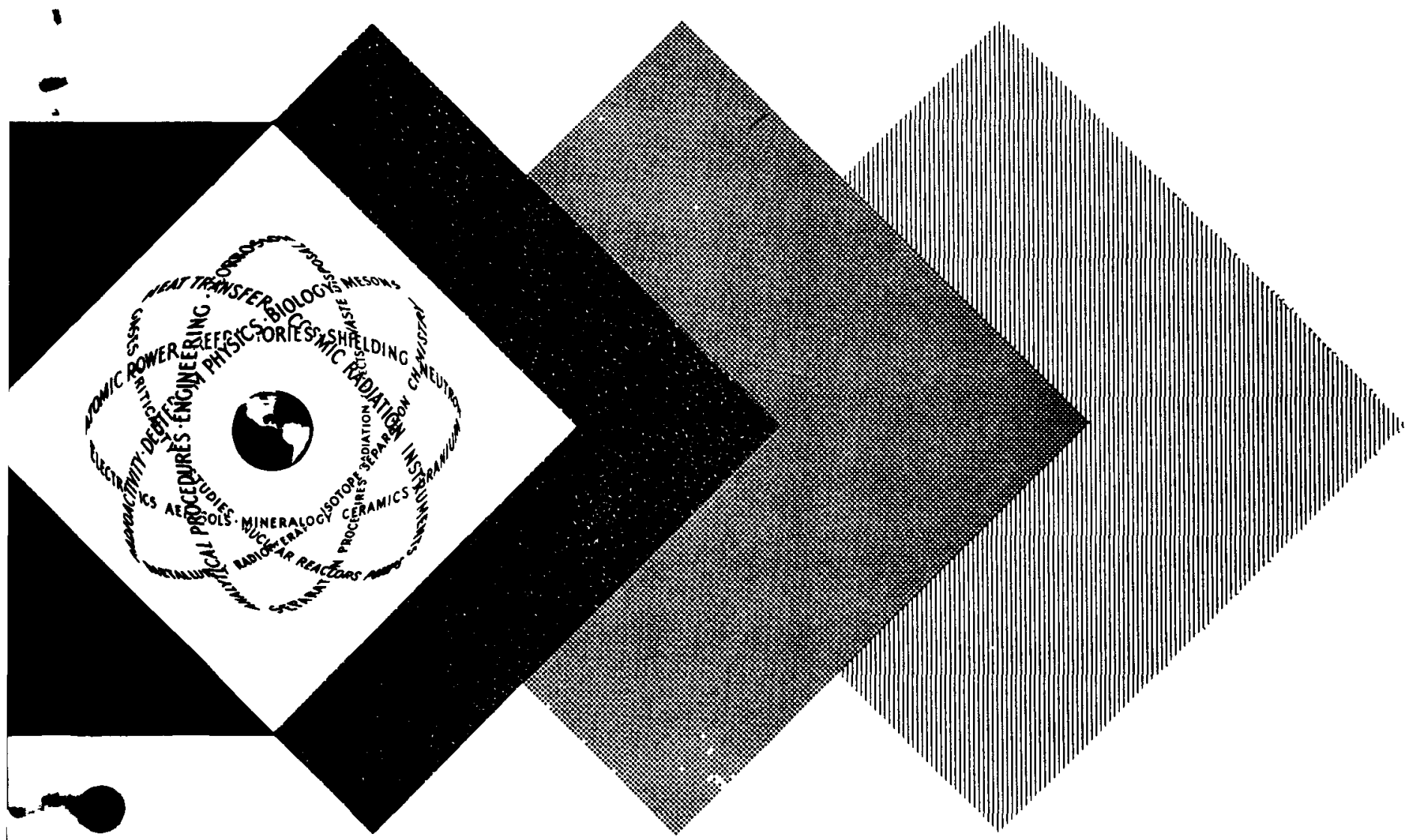




\section{DISCLAIMER}

This report was prepared as an account of work sponsored by an agency of the United States Government. Neither the United States Government nor any agency Thereof, nor any of their employees, makes any warranty, express or implied, or assumes any legal liability or responsibility for the accuracy, completeness, or usefulness of any information, apparatus, product, or process disclosed, or represents that its use would not infringe privately owned rights. Reference herein to any specific commercial product, process, or service by trade name, trademark, manufacturer, or otherwise does not necessarily constitute or imply its endorsement, recommendation, or favoring by the United States Government or any agency thereof. The views and opinions of authors expressed herein do not necessarily state or reflect those of the United States Government or any agency thereof. 


\section{DISCLAIMER}

Portions of this document may be illegible in electronic image products. Images are produced from the best available original document. 


\section{LEG A L NOTICE}

This report was prepared as an account of Government sponsored work. Nelther the United States, nor the Commission, nor any person acting on behalf of the Commission:

A. Makes any warranty or representation, expressed or implied, with respect to the accuracy, completeness, or usefulness of the information contained in this report, or that the use of any information, apparatus, method, or process disclosed in this report may not infringe privately owned rights; or

B. Assumes any liabllities with respect to the use of, or for damages resulting from the use of any information, apparatus, method, or process disclosed in this report.

As used in the above, "person acting on behalf of the Commission" includes any employee or contractor of the Commission, or employee of such contractor, to the extent that such employee or contractor of the Commission, or employee of such contractor prepares, disseminates, or provides access to, any information pursuant to his employment or contract with the Commission, or his employment with such contractor.

This report has been reproduced directly from the best available copy.

Printed in USA. Price $\$ 3.50$. Available from the Office of Technical Services, Department of Commerce, Washington 25, D. C.

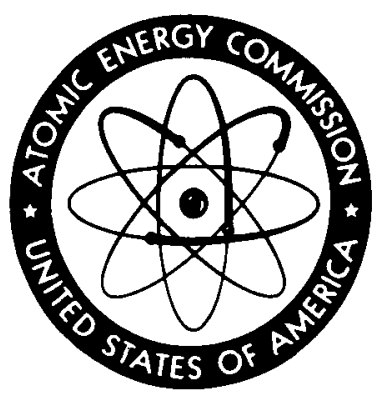


MND-M-1852

PM-1 Nuclear Power Plant Program

PARAMETRIC STUDY REPORT

September 1959

Contract $\operatorname{AT}(30-1)-2345$

Prepared By:

Approved By:
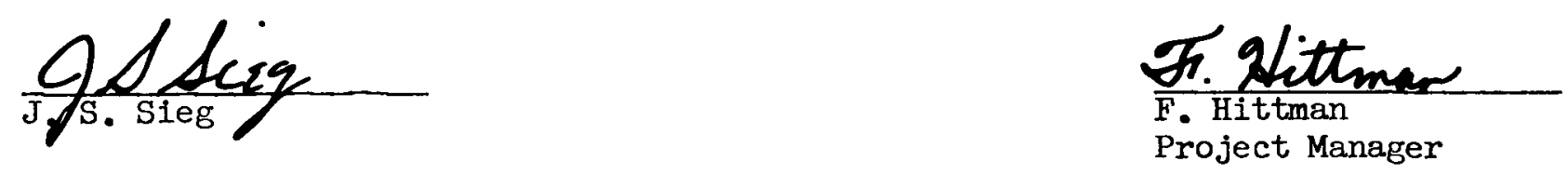
This task report is submitted to the U.S. Atomic Energy Comission under Contract $\operatorname{AT}(30-1)-2345$. It covers the PM-1 Parametric Studies. 


\section{ABSTRACT}

This report describes the parametric study performed by The Martin Company for the USAEC as a part of Contract AT (30-1)-2345. The study deals with narrowing the range of parameters prior to preliminary design of the PM-1--a factory prepackaged, alr-transportable, pressurized water, nuclear power plant. The plant is to produce $1000 \mathrm{kw}$ of net electrical power and $7,000,000 \mathrm{Btu} / \mathrm{hr}$ of space heat that is suitable for use with a central heating system. The plant is to be operational, at a government site, by 9 March 1962 .

The principal conclusions of the study were that the optimum plant design should incorporate the following:

(1) Local boiling in the core

(2) A 1300-psia primary system pressure

(3) A single turbine-generator set

(4) A direct air-to-steam con' 'nsing system.

The report is divided into the following main areas:

(1) Primary loop

(2) Secondary system

(3) Configuration

(4) Plant synthesis and description of selected design.

The data and conclusions resulting from the parametric study will provide the basis for the preliminary design of the PM-1 power plant. 
- 
Page

Foreword ...................... . . . . . ii

Abstract ..................... . . . . i ii

I. Introduction . . . . . . . . . . . . . . . . . I I-I

II. General Scope of Parametric Studies . . . . . . . . . . II-I

A. Division of Efforts................. II-I

B. Range of Operating Variables . . . . . . . . . . II-2

III. Primary Loop . . . . . . . . . . . . . . . . . III-I

A. General ................... III-I

B. Nuclear Studies. . . . . . . . . . . . III-2

C. Heat Transfer Studies. . . . . . . . . . . III-2I

D. Core and Pressure Vessel Design Studies. . . . . . . . III-38

IV. Secondary System . . . . . . . . . . . . . IV I

A. Scope of Study . . . . . . . . . . . . . IV $\quad$ I

B. Turbine-Generator Studies. . . . . . . . . . IV-2

c. Condenser studies. ............... IV-II

D. Cycle Studies. . . . . . . . . . . . . IV -16

E. Power quality Studies. . . . . . . . . . . . IV-19

F. Steam Generator Studies. . . . . . . . . . . IV-23

G. Summary of Equipment Selection . . . . . . . . . . IV-26

v. Configuration. . . . . . . . . . . . . . . . V V-1

A. General Considerations .............. . . V V-1

B. Primary Loop Configuration . . . . . . . . . . . V V-1 


\section{CONTENTS (continued)}

Page

C. Primary Loop Containment . . . . . . . . . . V V-10

D. Shielding................. . . V

E. Packaging and Shelter.............. V V-30

VI. Plant Synthesis and Description of Selected Design . . . . . . VI-I

A. Plant Synthesis Studies. . . . . . . . . . . . VI-l

B. Plant Description. ............... . . VI -35

Appendix A . . . . . . . . . . . . . . . . A A-1

Appendix B . . . . . . . . . . . . . . . . B B

Appendix C ......................... $\mathrm{c}-1$

Appendix D . . . . . . . . . . . . . . . . D D

References ..................... . . . R-1

References-- Chapter III . . . . . . . . . . . R R-2

Nomenclature .................... . . . . N-1

List of Nomenclature--Chapter III. . . . . . . . . . N-2 
I. INTRODUCTION

The objective of the parametric study of the overall PM-1 power plant was to provide, by engineering analysis, the data required to select a power plant design that would meet all of the PM-1 design requirements and as many of the design objectives as possible. Preparation of a preliminary plant design will follow, and will be based upon, the results of the parametric study.

This report presents the parametric study, key results, and key supporting data. Work began on March 9, 1959 and was completed on June 19, 1959.

The areas investigated during the parametric study were those set forth in the PM-I Program Plan, Contract AT(30-1)-2345, and are described in Chapter II of this report. In addition to the individual studies conducted in the designated technical areas, an overall plant synthesis was performed and a preferred design concept established, as summarized in Chapter VI, B.

The selection of the "best" or "optimum" system design requires comparison of various possible design features on the basis of predetermined objectives. The system design most closely meeting these objectives becomes the so-called "optimum" design. For the PM-1, there are a large number of criteria which must be considered in the selection of an optimum design. These include: number of packages, system weight, system reliability, ease of installation, ease of operation, plant efficlency, and economics. These criteria, along with other plant requirements and objectives, must be approached in a realistic manner. In some areas, engineering compromises must be made since the optimization of some parameters conflicts with the optimization of others.

To determine the basls for selection, the following facts are worthy of consideration:

(1) The definition of "optimum" is necessarily arbitrary and depends on the proper weighting of many of the features of plant environment and operation. It involves, for example, methods for evaluating the economic desirability of certain design alternatives. Any subsequent change of method can invalidate the previously selected optimum design.

Emphasis has been placed on a realistic appraisal of the more important PM-I goals that are not subject to change in the near future. These provided the real guide to the selection of the preferred design. Emphasis has been placed, therefore, on the simplest, most reliable design concepts. It has been found that low weight, low cost, and reliability are nearly symonymous.

The details of the plant synthesis and selection are presented in Chapter VI, A of this report.

(2) A number of conditions which might normally have been varied to yield alternative designs are PM-1 design requirements which must be met by all designs conaidered. These are summarized in Table I-l. All comparisons must be made on systems which meet these stated requirements to an equal degree. 
(3) The major PM-1 plant design objectives shown in Table I-2, are the keys to the selection of the optimum plant design. These objectives are, to a certain extent, incompatible with each other. Ease of operation can, for instance, lead to difficulty in maintenance; high power quality leads to additional cost; low capital cost leads to low plant efficiency.

\section{TABLE I-1}

$\underline{\text { Item }}$

Net Electrical Production

( $3 \varphi, 60 \mathrm{cps}, 4160 \mathrm{v}$ )

Process Heat (low pressure steam)

Plant Type

Fuel Element Type

Core Replacement Time

Design Conditions

Design Life

Down Time

Air-transportable

Relocation of Plant

Erection time

Control Components

Temperature Coefficient

Climatic Range:
PM-1 Requirements

\section{$\underline{\text { Requirement }}$}

1000 kwe

$7 \times 10^{6} \mathrm{Btu} / \mathrm{hr}$

Pressurized water, with steam-electric conversion system

Tubular, $\mathrm{UO}_{2}$ dispersion in SS, highly

Enriched fuel, burnable poisons .

4 days

$70^{\circ} \mathrm{F}$, sea level to $6500 \mathrm{ft}$, no wind, $70 \%$ relative humidity, full sunlight

$20 \mathrm{yr}$

21 days $/ \mathrm{hr}$ maximum

C-130 A, 1000-mi range

Maximum possible

90 days maximum

Fail safe

Negative--assured stabllity

$100 \mathrm{mph}$

125 to $-60^{\circ} \mathrm{F}$

$-55^{\circ} \mathrm{F}$

$30 \mathrm{psf}$ 


\section{TABLE I-2}

PM-I Objectives

Item

Voltage Regulation

Harmonics

Frequency Regulation

Reactor Vessel

Heat Transfer

Actuators

Afterheat removal.

Control Repairs

Controls

Shielding

Vapor Containment design

Core Life

Installation Time

Maintenance Efforts

Relocation

Operation

Cost
Objectives

$\pm 1 / 2 \%$ steady state

$\pm 2 \%$ maximum, during $30 \%$ step transient

rms $\pm 2 \%$ maximum, $\pm 0.75 \%$ single

harmonic

$\pm I / 4 \%$, steady state, $\pm 2 \%$ maximum during $30 \%$ step transient

To allow for core variations

Local boiling permitted if stability can be assured

Maintainable at pressure

Convection cooling

Maximum use of plug-in components, carded subassemblies

Solid state, high reliabllity

Use local materials

Air-transportable, no field welding

$2 \mathrm{yr}$

Minimum

Minimum

Greatest extent possible by $\mathrm{C}-130 \mathrm{~A}$

Minimum crew

Minimum

Although weighing the relative merit of various objectives is attractive, no system appears sufficiently realistic. Attempts to define exact methods become extremely complex and usually degenerate into a series of judgments based upon experience. It is not feasible, for example, to put relative weighing factors on power quality and on system weight and then to pick an optimum point of compromise. One way to reduce this problem is to place all features on a common cost basis. However, costs must be evaluated in terms of consumption of time, men, and strategic materials as well as in terms of dollars. How many dollars is it worth to cut installation time in half? The assumptions involved in answering such a question are too broad to permit a single realistic answer. 
The end result of these considerations is to design the "best" plant possible, for the given cost, meeting all the requirements and the greatest number of the objectives of the PM-I plant. Within this framework, lowest cost still determines preferences of design--other things being equal. Where other things are not equal, a choice is available between weight and power quality, between short installation time and ease of operation, etc. The facts must be assembled and engineering judgment applied separately to each choice involving a conflict of objectives.

In addition to these considerations, there are several practical relationships in the PM-1 System that should be noted. First, the plant is quite small and the cost effects of such variables as system pressure are correspondingly small. The prime objectives of reliability, air transportability and rapid on-site installation place emphasis on obtaining a simple system with a minimum number of plant modules. This in turn places emphasis on reduced system and component weights. Fortunately, light weight means low cost in most cases (e.g., steam generator, system piping, etc.). Second, a number of design features may be determined with little or no effect on the rest of the plant. Thus the choice between one- and two-turbine systems may be made without seriously affecting reactor design. Third, a number of design variables are very closely related, especially the thermodynamic conditions of the plant. For these reasons, this report separates the discussion of parametric study results into the following categories:

(1) General Scope

(2) Primary Loop

(3) Secondary System

(4) Configuration

(5) Plant Synthesis and Description of the Selected Design.

In numerous sections of the report, equipment costs and weights are treated as dependent variables to give the reader a feeling for the effect of varying design parameters. In most cases, the cost and weight figures are determined only for these equipment components which vary with the design parameters and represent, therefore, relative rather than absolute values. It must also be recognized that the time available for the parametric study was limited and that cost estimates had to be prepared using such general methods as cost per pound factors for pressure vessels, pressurizers, etc.

The Project Engineers responsible for various areas of the parametric study are identified; the engineers and scientists who have made significant contributions are identified by sections. 


\section{GENERAL SCOPE OF PARAMETRIC STUDIES}

\section{A. DIVISION OF EFFORTS}

Work on the parametric study program was accomplished by The Martin Company and its subcontractors, Westinghouse Electric Corporation and Gibbs and Hill. The areas of effort were as follows:

(1) Primary Loop--Martin

(1) Nuclear studies, including effects of core loading, core size, core life, fuel tube size, control rods and burnable poisons, structural materials, and nuclear stability with local boiling in the core.

(2) Heat transfer studies, including relationship of flow, system pressure, and water temperature, the effect of the number of coolant passes, hot channel factors and hydrodynamics for both non boiling and local-boiling cores.

(3) Design studies, including core configurations, reactor pressure vessel and control rod actuators.

(4) System studies covering pumps, piping, pressurizer, and auxiliary equipment as affected by system temperature, pressure, and flow.

(2) Secondary System Follow-up--Martin

(1) Effects of throttle, extraction and exhaust pressures on system performance, weight, cost, etc.

(2) Effects of type of cycle on system performance, weight, cost, etc.

(3) Effects of different secondary system equipment on meeting plant requirements and objectives.

(3) Configuration Studies--Martin

(1) Design studies of primary system arrangements for contained and uncontained plants.

(2) Shielding studies, including effects on configuration, relocation, and activation.

(3) Secondary system housing and configuration studies.

(4) Westinghouse Electric Corporation

(1) Studies on the effect of various steam pressures, turbine exhaust pressures, feedwater heating systems, and types of condenser system on cycle efficiency, component weight, number of packages, ease of installation, reliability, ease of operation, and maintenance requirements. 
(2) Steam generator studies, 1ncluding the effects of fluid temperatures, primary system pressure, steam pressure, materials, and type of steam generation on size, weight, cost, and operation.

(3) Turbine generator studies, including effects of generator voltage and frequency, number of units and use of static excitation, lightweight materials and planetary gears on unit weight, size, performance, and cost.

(4) Studies of switchgear, motor control center and transformer designs to minimize weight.

(5) Studies of the effects of heat transfer apparatus design variation on size, weight, ease of operation, and cost.

(6) Studies of secondary system piping and wiring requirements, interconnections, etc., concerning ease of installation and maintenance.

(7) Studies of system and equipment arrangement within plant modules.

(8) Studies of various types of auxiliary power units for plant startup and emergency power.

(5) Gibbs and Hili

(1) General secondary system consultants to The Martin Company.

(2) Study of the feasibility of various condenser types.

(3) Study of methods of attaining required power quality.

\section{B. RANGE OF OPERATING VARIABLES}

Figure II-1 presents a PM-I plant schematic on which the operating variables and their ranges of study are noted. These may be briefly summarized as follows:

Primary loop pressure
Primary loop average temperature
Primary loop flow
Secondary loop steam pressure
Turbine extraction pressure
Turbine exhaust pressure
Steam flow rate
Turbine-generator units
Condenser system type

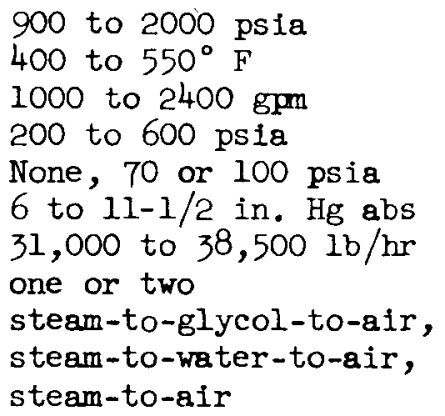

Details on additional variables studied and the ranges considered are presented in Chapters II and III of this report. In general, equipment studies were conducted over the entire range of the operating variables. Reactor core analysis and design studies covered the entire range of feasible tube sizes and applicable core dimensions. 


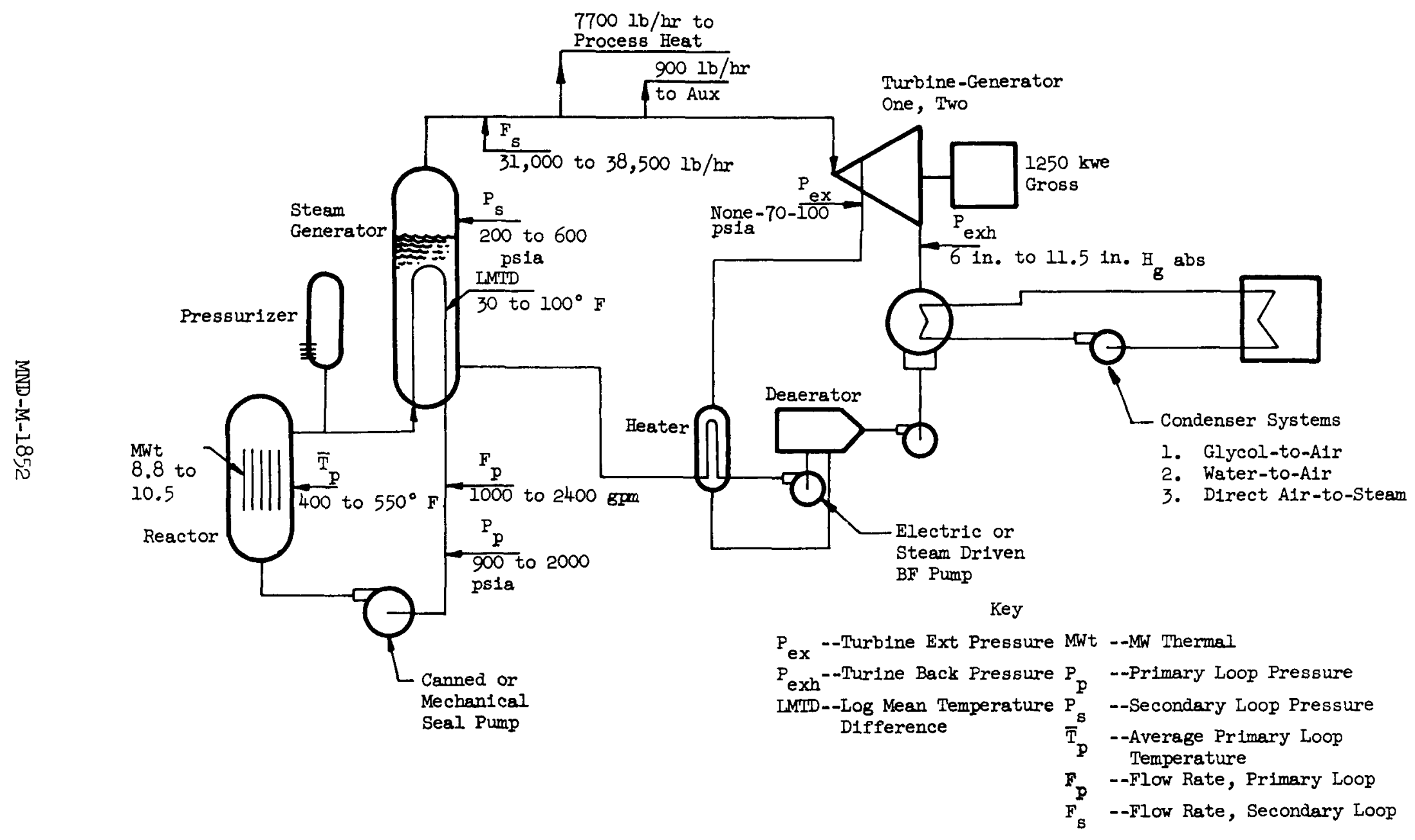

Fig. II-1. PM-l Plant Schematic 


\section{PRIMARY LOOP}

Project Engineer: R. Akin

A. GENERAL

Primary loop studies were divided into four sections:

(1) Nuclear studies

(2) Heat transfer studies

(3) Core and pressure vessel design studies

(4) Primary system equipment studies.

The nuclear studies were further subdivided into three sections. The first of these was a general evaluation of stainless steel, water and uranium dioxide systems. This study revealed that, a given inventory, varlations, within practical limits, of fuel element diameter, fuel element thickness, fuel concentration in the cermet, length-to-diameter ratio of the core, tube pitch length or initial boron loading had little effect on core life. Core diameter and mean temperature had some effect on core life, but only about $15 \%$ over the range studied. The second of these was an evaluation of seven rod control systems in a typical PM-1-type core. The results indicate that " $\mathrm{Y}$ " and cruciform rods are interchangeable--since their effectiveness per unit surface is the same--that small diameter cores give more control, that there is a radial position for maximum rod effectiveness and that core length does not affect rod worth. The third of these was a preliminary study of lumped burnable poison systems. The results of this study indicated that burnable poisons can be expected to improve the reactivity characteristics of the PM-I core and may make it possible to remove the burnable poison from the fuel elements.

The heat transfer studies were further subdivided into two sections. The first of these was a study of possible PM-1 cores in which local boiling is not permitted. The second was a study of possible PM-1 cores where local boiling is permitted. The studies yielded the following general results:

(1) Local-boiling is feasible for the PM-I.

(2) Local boiling cores require approximately half the number of tubes that nonlocal boiling cores require.

(3) Single-pass local boiling cores are superior to nonlocal boiling cores of two-pass design because their design is less complex and they need only one size fuel element rather than the two required by optimized nonlocal boiling cores.

The design studies were further subdivided into two sections. The first was a study to determine the fuel element diameter, length, and pitch most suitable for the PM-1 design. 
The following values were selected as most suitable:

$$
\begin{array}{ll}
\text { Fuel element diameter } & 0.500 \mathrm{in.} \\
\text { Fuel element length } & 30 \mathrm{in} . \text { (active) } \\
\text { Fuel element pitch length } & 0.65 \mathrm{in} .
\end{array}
$$

The second was a study (tube center-to-center distance) of the feasibility of using various materials for the pressure vessel. The results indicated ferritic steels to be preferable for small vessels. The use of austenitic steels and nonferrous materials was limited to larger vessels. Austenitic steels may, however, have to be used to overcome radiation damage problems.

The systems studies were further subdivided into separate sections for each major component or subsystem in the primary loop. Each was evaluated on a weight and cost basis for various design conditions in the primary loop.

\section{B. NUCLEAR STUDIES}
R. Hoffmeister
E. Scicchitano
F. Todt

\section{Scope of Studies}

A preliminary parametric core design study was undertaken to determine the more promising areas of interest for the PM-1 plant. To this end, an evaluation of the effects of eight independent design variables on core life and other pertinent core parameters was undertaken. The eight independent variables considered and the range investigated for each of the variables are given in Table III-I.

Table III-1

Independent Variables for Parametric Core Design Studies

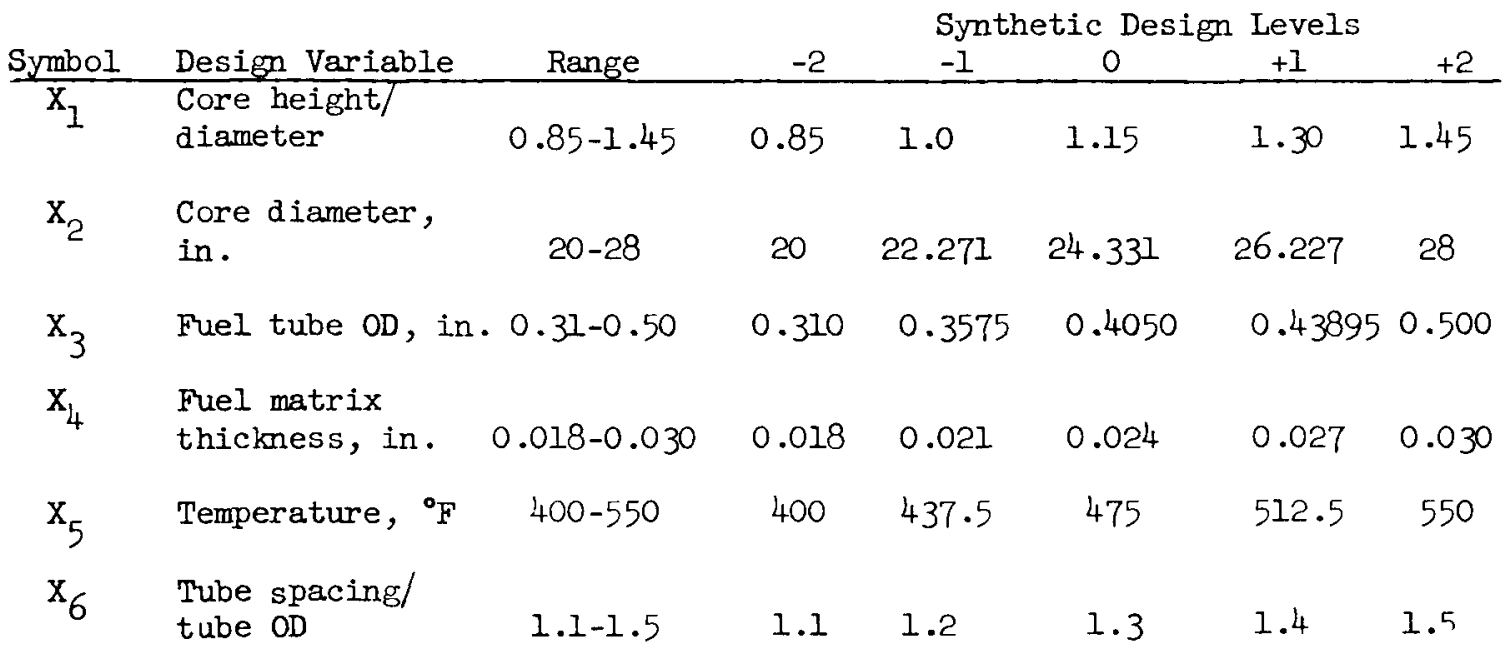


Table III-1 (continued)

\begin{tabular}{cllllllll} 
& & \multicolumn{6}{c}{ Synthetic Design Levels } \\
Symbol & Design Variable & Range & -2 & -1 & 0 & +1 & +2 \\
\hline $\mathrm{X}_{7}$ & $\begin{array}{l}\text { Grams of boron } \\
\text { gm U-235 }\end{array}$ & $0.0-0.013$ & 0.0 & 0.00325 & 0.0065 & 0.00975 & 0.013 \\
$\mathrm{X}_{8}$ & $\begin{array}{l}\text { Weight } \% \mathrm{UO}_{2} \text { in } \\
\text { matrix }\end{array}$ & $23-30$ & 23 & 24.75 & 26.5 & 28.25 & 30
\end{tabular}

Using appropriate machine codes and statistical techniques, core life, initial $\mathrm{K}_{\text {eff }}$ and fuel inventory were obtained as functions of the eight variables. Curves were plotted defining a series of desion cores, each yielding the required 2-yr life. Data evaluation consis ted of determining the fuel inventory as a function of the number of fuel elements for the 2-yr core designs, the relative effects of the different variables on core life, and the variation of core life with deviation from the optimum level in the range investigated for the different variables. Sufficient data were generated to narrow the range of the variables to be considered during preliminary design.

The parametric study was performed using uniformly-loaded cores that were assumed to burn out uniformly.

Reactivity calculations were performed using the IBM-704 machine three-group diffusion code, Program C-3..$^{1}$ Thermal disadvantage factors, calculated using Program I-2, and calculated reflector savings were used to account for heterogeneity and the presence of reflectors. Uniform burnup, using the Fuel Recycling Program ${ }^{1}$, was assumed. An average nonuniform burn-up correction (calculated using the Nonuniform Burn-up Code ${ }^{l}$ in both radial and axial directions) was applied using middle range ("O" level, see Table III-2) variables.

Statistical experiment design techniques, Synthetic Design Program (Syd II) ${ }^{1}$, made it possible to plot core lives from calculations of far fewer points (81) than would be determined by all combinations of the eight independent variables. Each of the 81 points were calculated and the group was statistically correlated by the synthetic design procedure.

Detalled nonuniform burn-up studies were made for three cases; these cases and results are described in Table III-2.

$I_{\text {See Appendix A of this report }}$ 
$\underline{\text { Table III-2 }}$

Core Designs Evaluated in Nonuniform Burn-up Studies

Core height/diameter

Core diameter, in.

Fuel tube $O D$, in.

Fuel matrix thickness, in.

Temperature, ${ }^{\circ} \mathrm{F}$

Tube s pacing/tube oD

*Effective tube spacing/tube OD

**Grams of boron/gm U-235

Weight $\%_{\mathrm{UO}_{2}}$ in matrix

Fuel tubes, no.

Fuel inventory (U-235), kg

Core life (at $9.4 \mathrm{mw}$ ), mo

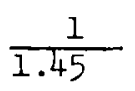

20

0.50

0.030

475

1.3

1.430

0.0132

28.25

709

28.9

42

\section{$\frac{2}{1.046}$}

22

0.50

0.030

475

1.3

1.405

0.0136

28.25

889

28.8

42

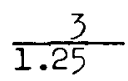

24

0.50

0.030

475

1.3

1.387

0.0151

23.00

1086

36.7

52

The nonuniformburn-up studies were performed using the Nonuniform Burn-up Code. $^{l}$ six regions in the core were considered in both the radial and axial directions. Curves similar to Fig. III-I were obtained showing reactivity versus time for both a hot, dirty and a cold, clean core.

To properly evaluate the data obtained, the validity, or degree of accuracy, of the data generated had to be established. To this end, several studies were completed which gave a measure of the error to be expected in generating synthetic design curves.

A series of 20 check points defined by middle-range variables were calculated and compared to points established through synthetic design; the differences between the points calculated and the points established by synthetic design were less than the error to be expected in reading the graphs. The graphical results of the parametric study may, therefore, be considered to be accurate for all cases. in which the independent variables lie between the levels of -1 and +1 .

*Allowance was made for fuel elements removed for control rod channels **Amount of boron necessary to reduce initial $\mathrm{K}_{\mathrm{eff}}$ with equilibrium Xe-135 to 1.015 . 


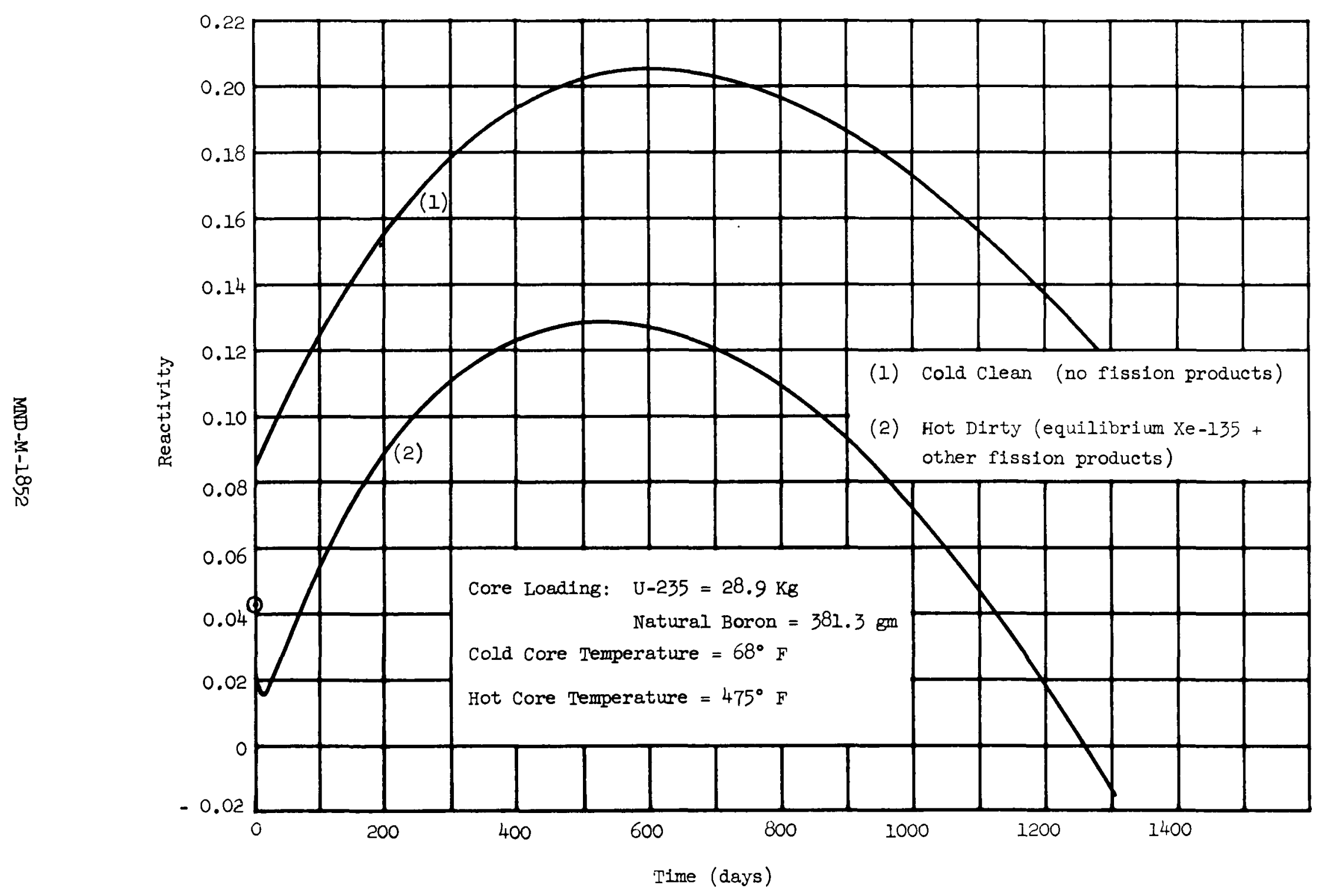

Fig. III-1. Reactivity vs TIme, Nonuniform Burnup (Case 1, Table III-2) 
An additional series of 16 check point cases defined by combinations of extreme levels of the independent variables in the range of interest were run. Maximum error was approximately 15\%.

The analyses indicate that the nuclear data obtained by the synthetic design method comprise a reasonably good guide for the later selection of a preliminary design.

As stated previously, an average nonuniform burn-up factor was calculated from a middle-range core design and applied to all cases. This was done to conserve machine time in calculating core life. Although not strictly accurate, this assumption was believed to be satisfactory for the parametric studies. Results of the nonuniform burn-up cases, described in TableIII-2, showed that the core lives calculated assuming uniform burn-up were 20,10 and $14 \%$ less respectively than the core lives calculated assuming nonuniform burnup. Since these cases considered as many as four of seven variables at extreme levels, this agreement is reasonably good.

A series of core designs, each of which gives the required 2-yr life, are available. Results shown in the curves of Number of Fuel Elements vs Fuel Inventory indicate that the initial fuel inventory will be 24 to $27 \mathrm{~kg}$ of

U-235 (A typical curve is shown in Fig. III-2.). The nonlinear slope of the curves results from the fact that both inventory and the number of tubes are functions of two variables $\mathrm{x}_{2}$ and $\mathrm{x}_{6} \cdot$ Average fuel depletion calculated from the nonuniform burn-up studies is $1.32 \mathrm{gm} \mathrm{U}-235 / \mathrm{mw}$ day. This amounts to the burnup of $9.0 \mathrm{~kg}$ of U-235 during 2-yr of rull-power operation at $9.4 \mathrm{mw}$.

The variation of reactor lifetime as a function of each of the independent variables for constant values of the other variables was also determined. Typical curves resulting from these studies are shown in Figs. III-3 and III-4. For a constant inventory, as shown by the points superimposed on the first graph of Fig. III-3, the variation of core life over the entire range of all variables except core diameter and mean core temperature was small. These data appear to exhibit minima or maxima, but, since the curves are relatively flat, this effect is not too important.

A typical representation showing the effect of varying $x_{2}, x_{3}, x_{4}$ and $x_{6}$ on reactor lifetime is presented as Fig. III-5. In this particular case, $x_{1}$, $\mathrm{x}_{5}, \mathrm{x}_{7}$, and $\mathrm{x}_{8}$ are held constant. Twenty-six other representations were prepared which indicated the effects on reactor lifetime of varying combinations of the other independent variables. To simplify reading the graph, only the extreme values of variable $X_{3}$ were plotted as surfaces; polnts for the middle surface are plotted but not interconnected.

The dashed lines appearing on some of the surfaces of Fig. III-5 represent the intercept of a 24-mo reactor plant core life plane and the surface. It may be noted that the intercept is not precisely 24-mo (on the ordinate scale) above the surface of the base plane in any case. This is because certain effects were considered in plotting the intercepts of reactor plant core life which were not taken into account in the basic plot of reactor lifetime, namely:

(1) An across-the-board correction of $25 \%$ was applied to account conservatively for the effects of nonuniform burn-up. (This is in 


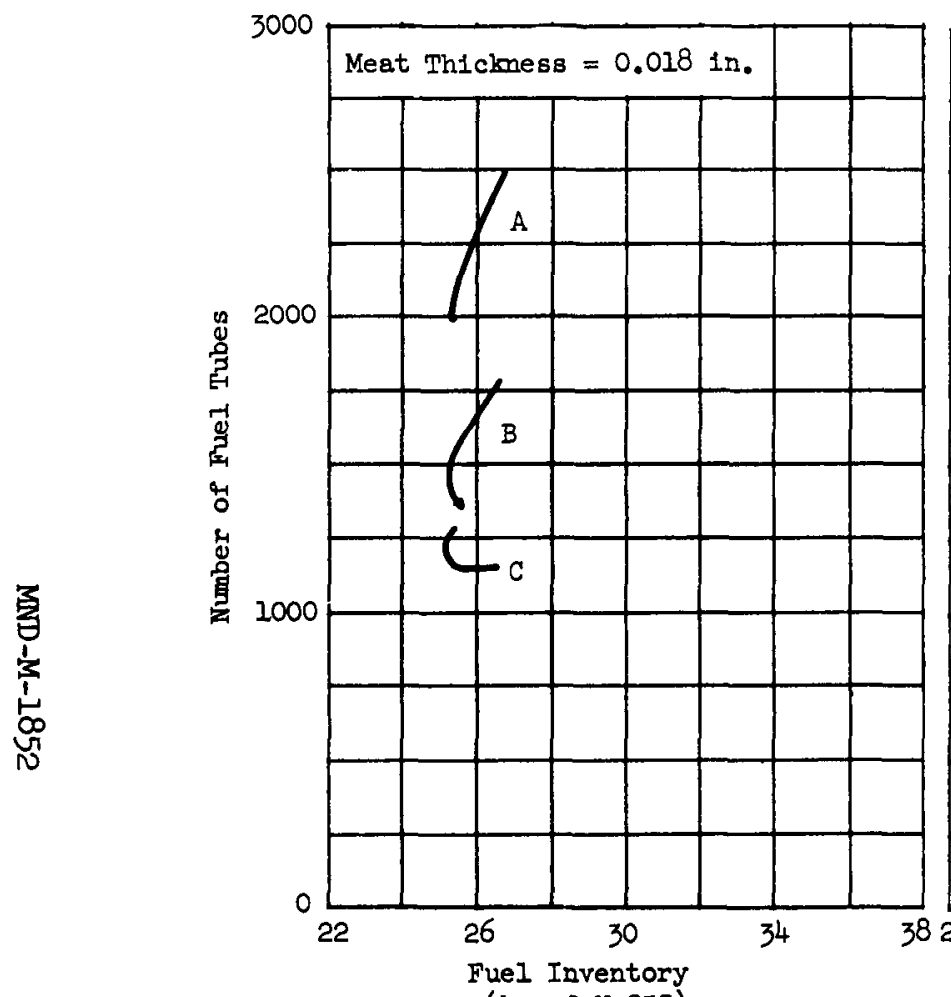

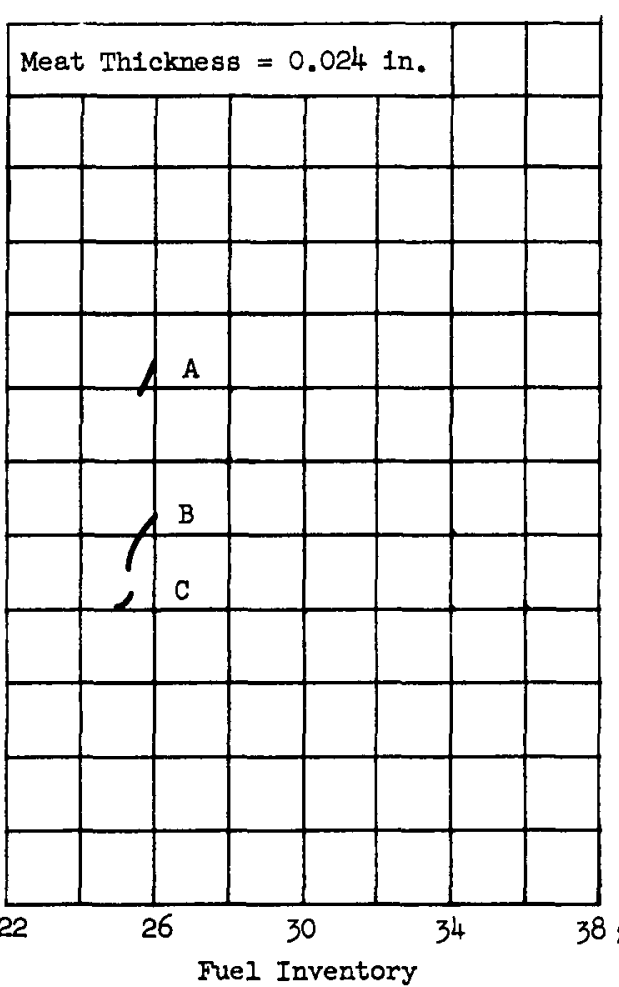

( $k g$ of U-235)

Core He1ght/Diameter $=1.15$

Tube $\mathrm{OD}=\mathrm{A}-0.310, \mathrm{~B}-0.405, \mathrm{C}-0.500$ in.

Temperature $=475^{\circ} \mathrm{F}$

gm Boron/gm U-235 $=0.0$

Wt $\% \mathrm{UO}_{2}$ in Meat $=26.5 \%$

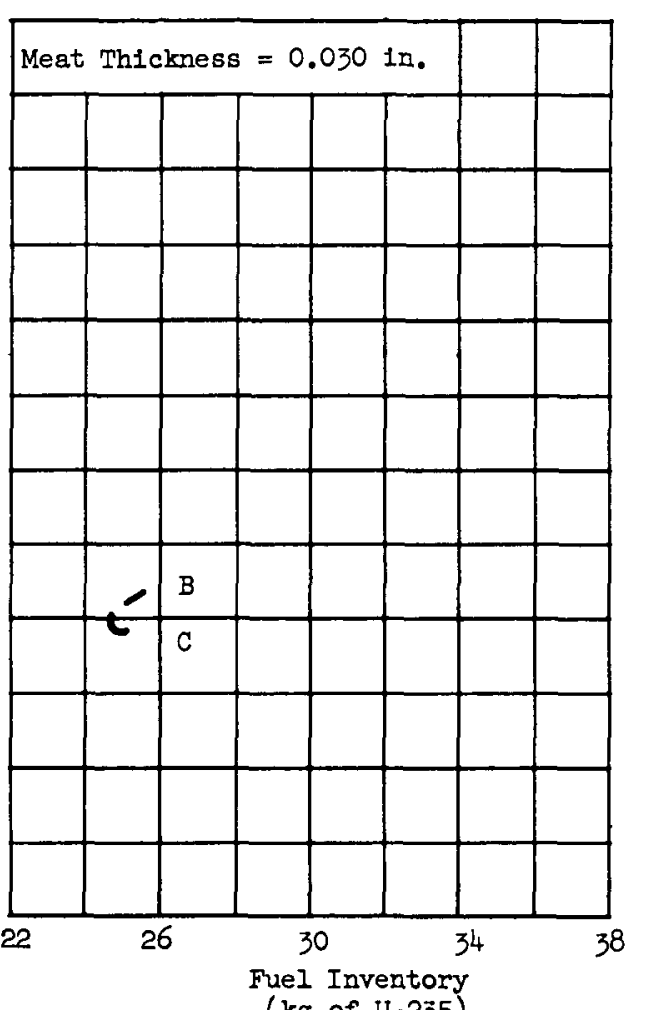

(kg of U-235)

(4o of v-235) 
0

0 


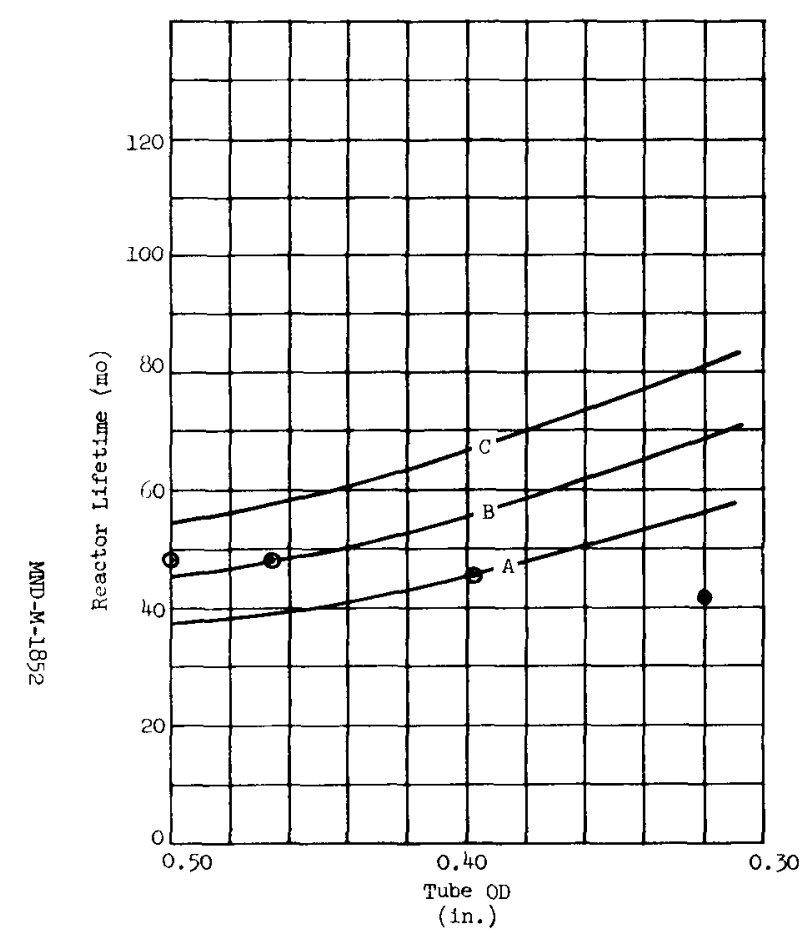

Core lleight $/$ Diameter $=1.15$

Core Diameter $=24.331 \mathrm{in}$.

Fuel Matrix Thickness $=0.024$ in

Temperature $=475^{\circ} \mathrm{F}$

Tube Spacing/Tube oD $=1.3$
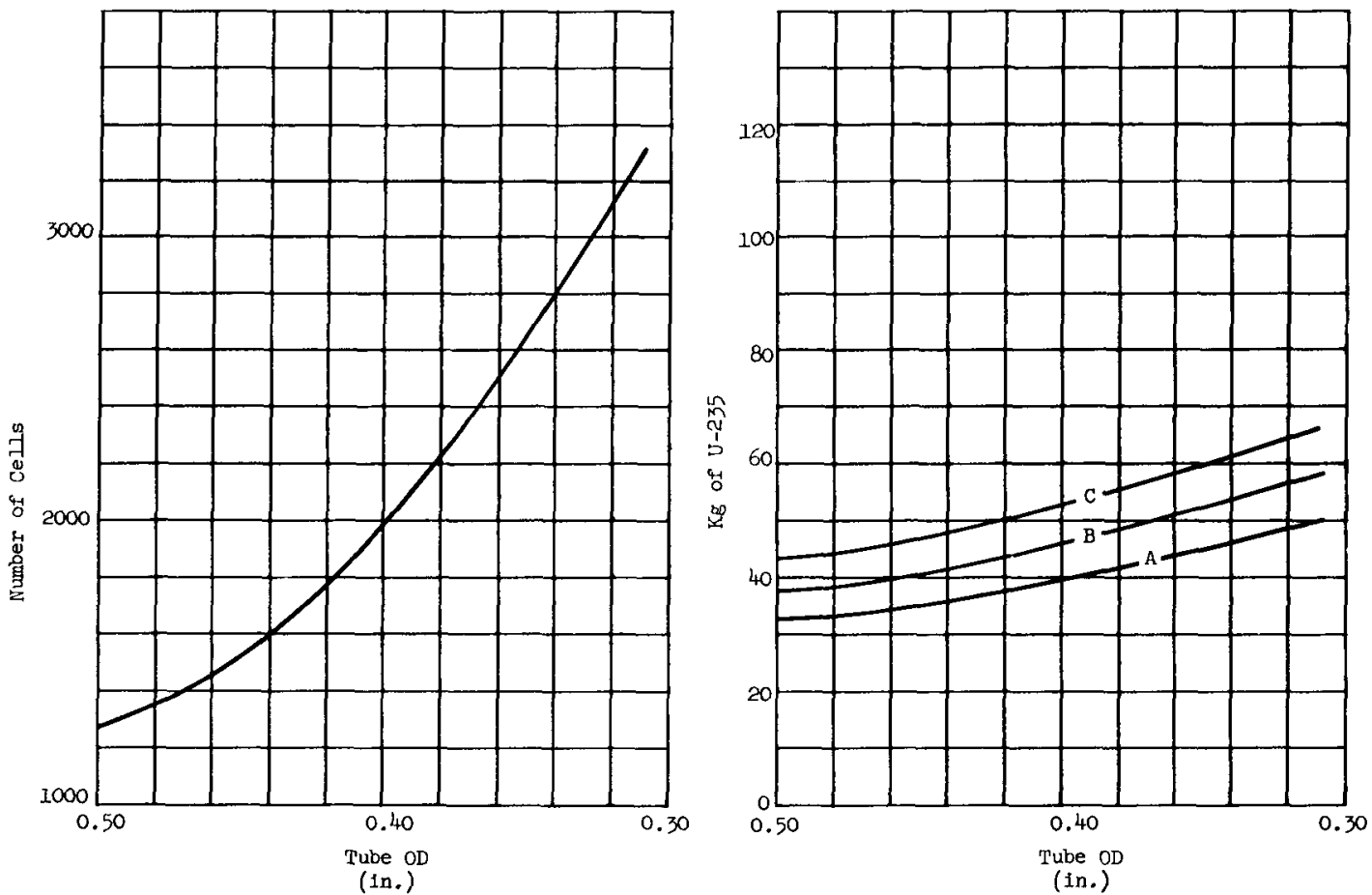

GM Boron/gm U-235 $=0.0065$

Wt $\% \mathrm{UO}_{2}$ in Matrix:

$\mathrm{A}=23 \%, \mathrm{~B}=26.5 \%, \mathrm{C}=30 \%$

O Fuel Inventory Constant $=40 \mathrm{~kg}$ of U-235

F18. III-3. Fuel Tube OD vs L1fetime, Cells, and Fuel Inventory--Uniform Core Loading 

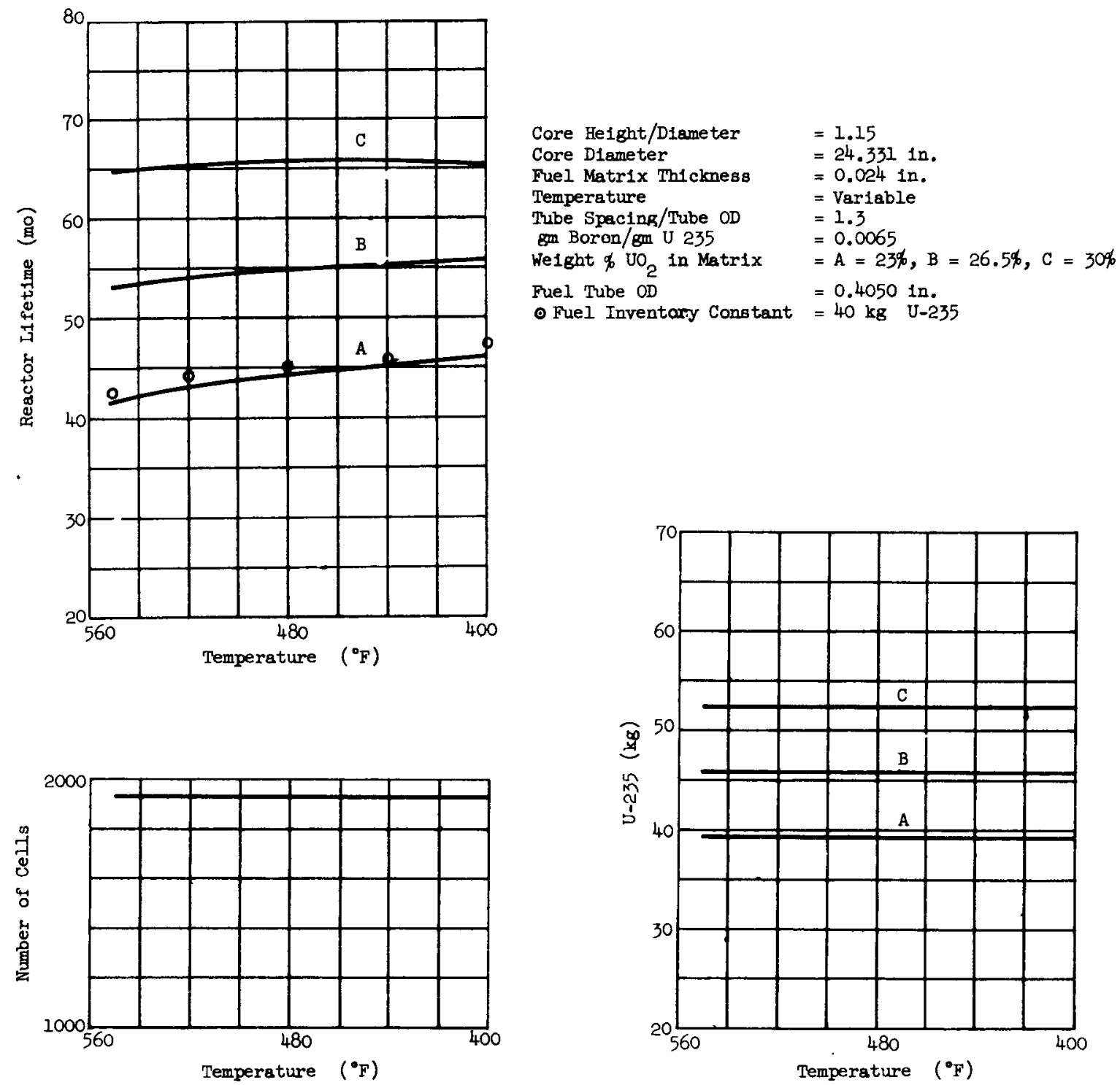

Fig. III-4. Temperature vs Lifetime, Cells, and Fuel Inventory-Uniform Core Loading 


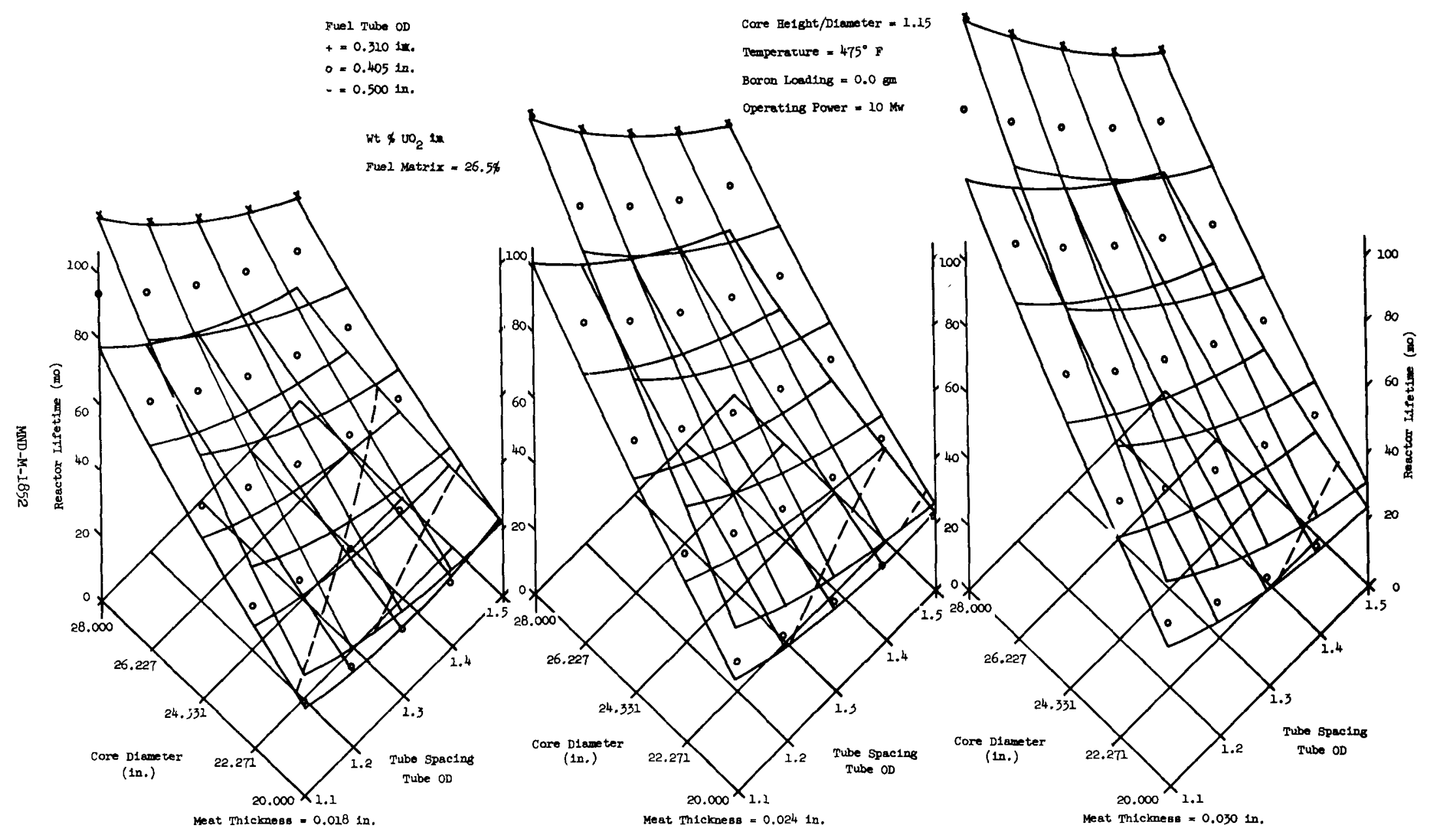


addition to the correction applied in the computer code.) As a result of this, the 24-mo core life curve would be parallel to the base plane at a height corresponding to an ordinate reading of 30 mo.

(2) The effect of operating temperature on required reactor power was included by making allowance for the increase of plant thermal efficiency (Rankine Cycle) which accompanies an increase in operating temperature. Since the reactor operating power necessary to meet plant requirements at $475^{\circ} \mathrm{F}$ is somewhat less than the $10 \mathrm{mw}$ power criteria used in the computer codes, a downward shift of the 24-mo core life curve from 30 to about 28 mo results.

Figure III-6 is a typical representation of the effect of varying $x_{2}, x_{3}$, $\mathrm{x}_{4}$, and $\mathrm{x}_{6}$ on $\mathrm{U}-235$ inventory. In this particular case, $\mathrm{x}_{1}, \mathrm{x}_{7}$, and $\mathrm{x}_{8}$ were held constant.

To simplify interpretation of the results in special cases, alternate graphical presentations have been compiled. These graphs, obtained by cross-plotting information from the 27 representations, of which Fig. III-5 is typical, show the effect of each individual variable on either reactor lifetime or initial $\mathrm{K}_{\mathrm{eff}}$ while all other variables are held at their mean and/or extreme levels. Figure III-7, for example, shows reactor lifetime as a function of core diameter, fuel concentration and temperature. In graph 1, all other variables are held at the -2 level; in graph 2, all other variables are held at the 0 level; and in graph 3 , all other variables are held at the +2 level.

In general, the overall conclusion is that the effect of all the variables, except for operating temperature (hence cycle efficiency) and core diameter, on reactor lifetime is small over the range considered.

Control rod studies.- Control requirements may pose one of the more difficult problems to be solved in the PM-1 system. Since the core is physically small, the use of a large number of individually-actuated rods is impractical. The following study was made to determine the most effective way to use control rods. Comparisons were made to the reference design for PM-1. The following evaluations were made:

(1) A system made up of seven "Y" rods was evaluated. Three possible variables were: the pitch circle diameter of the eccentric rods; the arm length of a rod and the diameter of the core. Each of these was varied while the other two quantities were held constant. The results are listed as Items 1, 2, and 3 in Table III-3 and in Fig. III-8.

(2) Studies were also made using a system of seven cruciform rods. The only parameter that was varied in this system was core length. The results are listed as Item 4 in Table III-3 and in Fig. III-8.

Additional studies will be performed as necessary in the preliminary and final design phases of the core. 


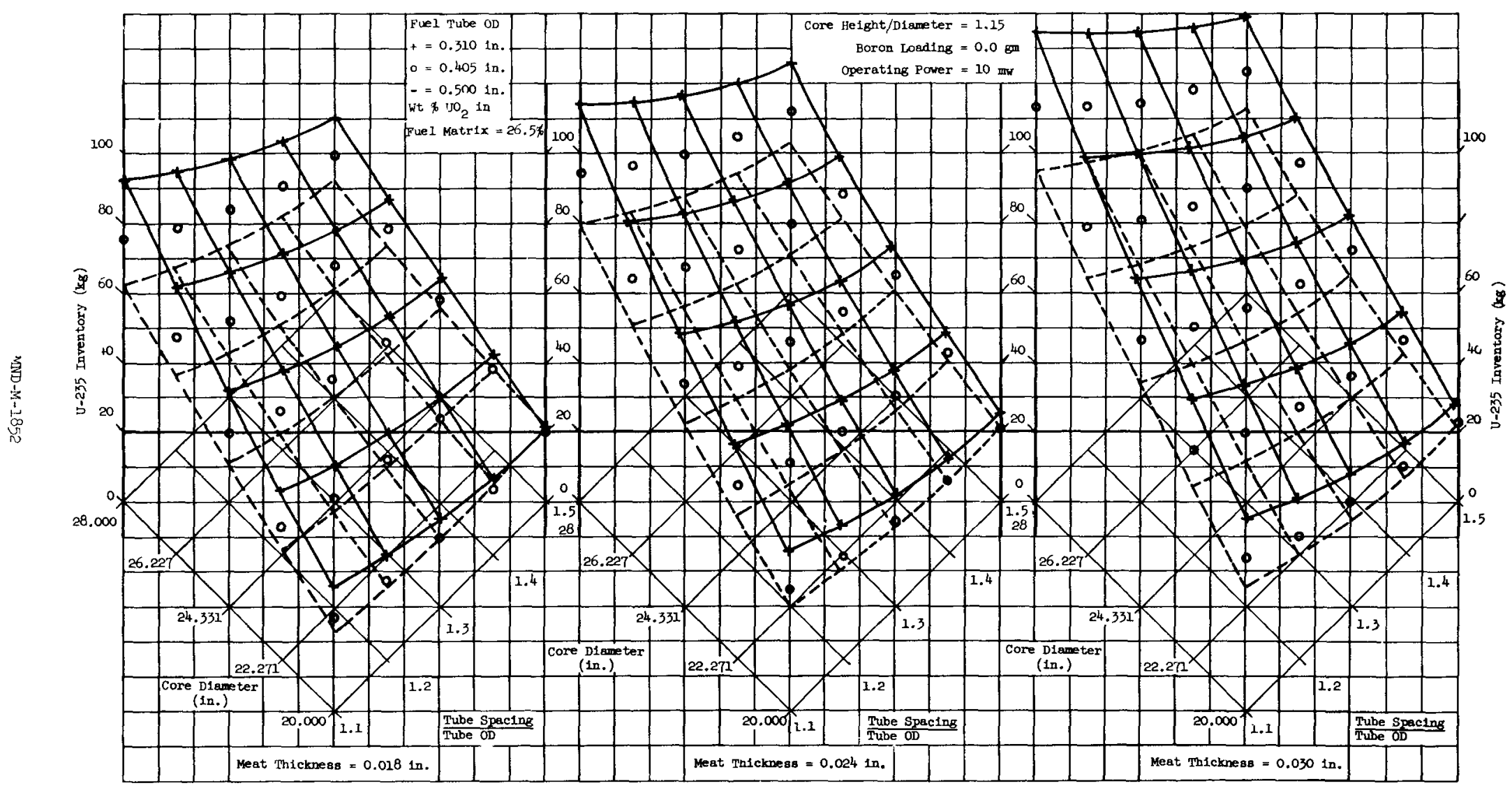



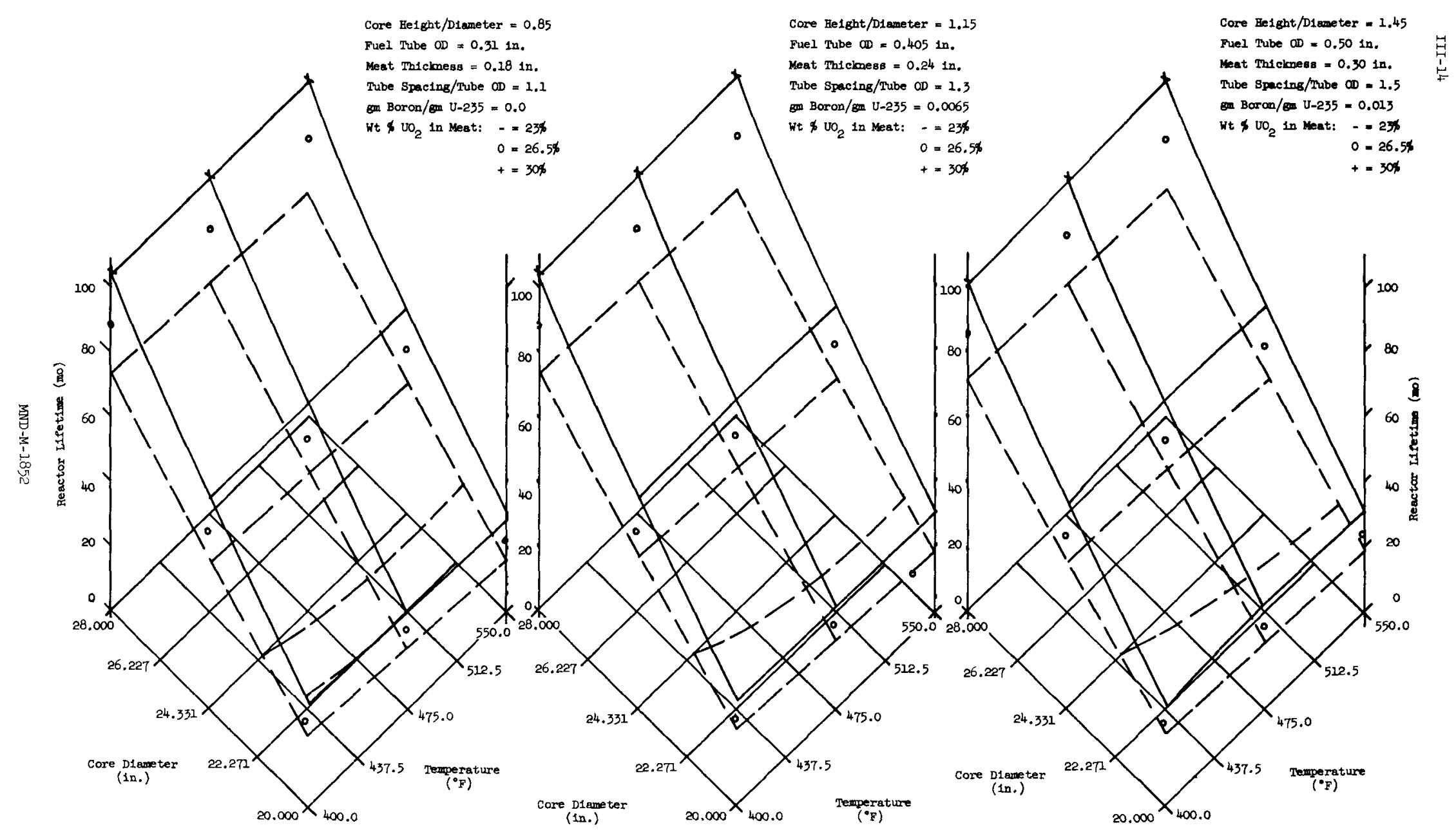

F1g. III-7. Reactor Lifetime--Un1form Core Loading 


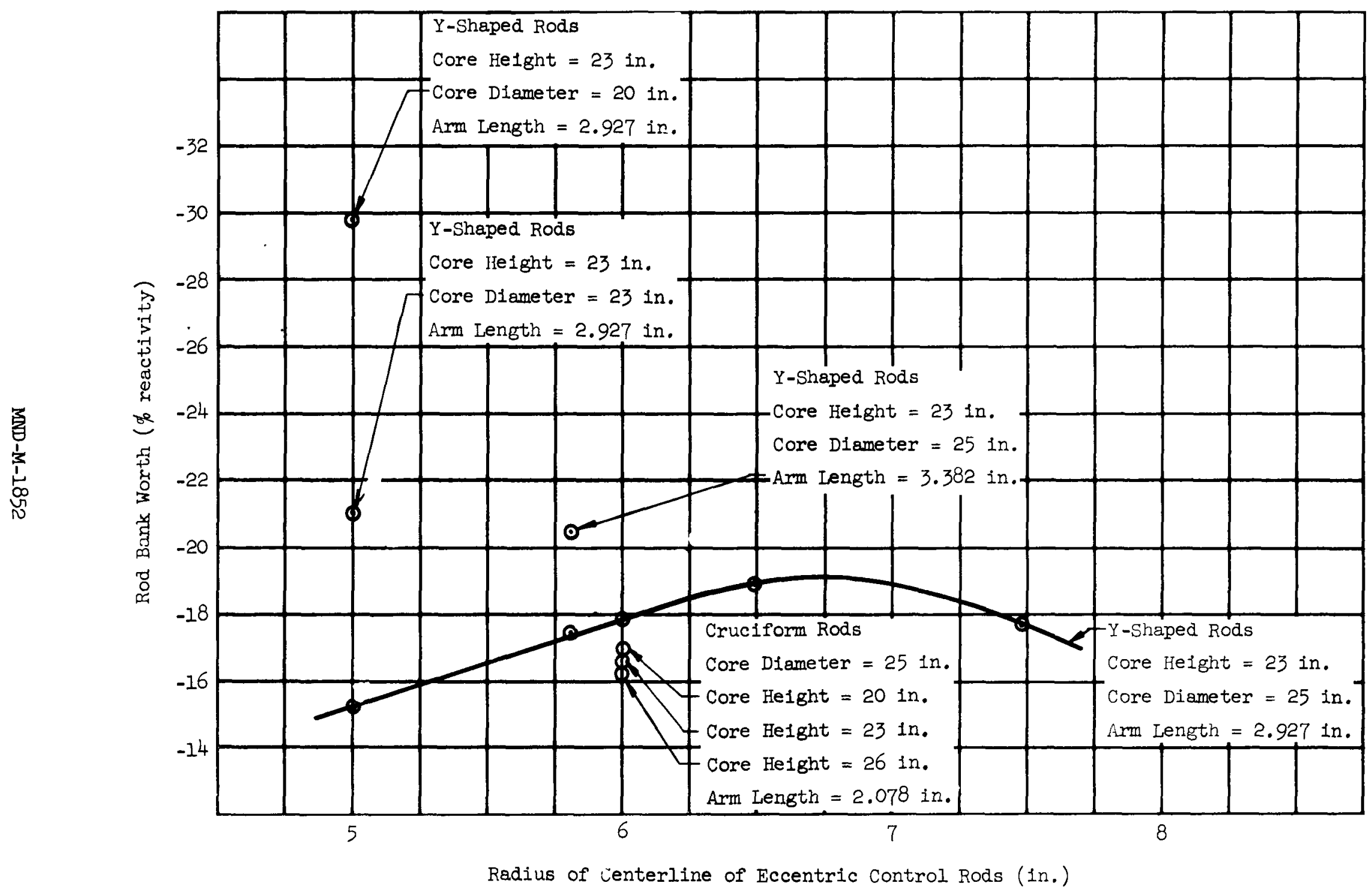

Fig. III-8. Results of Control Rod Studies for a Seven-Rod Bank 
Table III-3

Results of Seven-Rod Bank Worth Studies Core

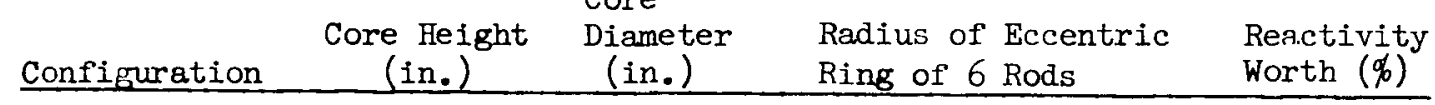

$\begin{array}{rllll}\text { (1) Y (Fig. III-9) } & 23 & 25 & 5.0 & -15.3 \\ \text { Y (Fig. III-9) } & 23 & 25 & 6.0 & -17.9 \\ \text { Y (Fig. III-9) } & 23 & 25 & 6.5 & -18.9 \\ \text { Y (Fig. III-9) } & 23 & 25 & 7.5 & -17.7\end{array}$

(2) Y (Fig. III-9)

with rod width

$=3.382$ in.

instead of

$2.927 \mathrm{in}$.

$$
23
$$

(3) Y (Fig. III-9)

25

5.8

$-20.5$

Y (Fig. III-9)

23

20

5.5

$-29.6$

Y (Fig. III-9)

23

23

5.5

$-20.9$

Cruciform (Fig. III-9)

20

25

6.0

$-17.1$

Cruciform (Fig. III-9)

25

6.0

Cruciform (Fig. III-9)

26

25

6.0

The results of Item 1 show that the maximum rod bank worth for the eccentric ring occurs at a radius of 6.75 in. The relative increase of worth obtained by increasing the radius to $6.75 \mathrm{in}$. is believed due to decreased effects of rod shadowing .

From Item 2, an increase of 0.455 in. in rod width was shown to result in an increase of $3 \%$ in rod bank worth. A 17\% increase in relative rod bank worth resulted from changing the arm width by $15.5 \%$.

Variation in core diameter, Item 3, had a significant effect on rod bank worth. The core height was found to have no significant effect on rod bank worth.

The relative worth of cruciform versus $Y$-shaped rods is also indicated from Case 2 of studies 1 and 4. The cruciform rods with arm widths of 2.078 in. were worth $-16.86 \%$ as compared to $-17.93 \%$ worth of the $Y$-shaped rods with arm widths of 2.927 in. Since the $Y$ rods evaluated contain $5.6 \%$ more absorber area than the cruciform rods and the difference in rod worth is $5.9 \%$, it appears that both shapes of rods are about equally effective. 


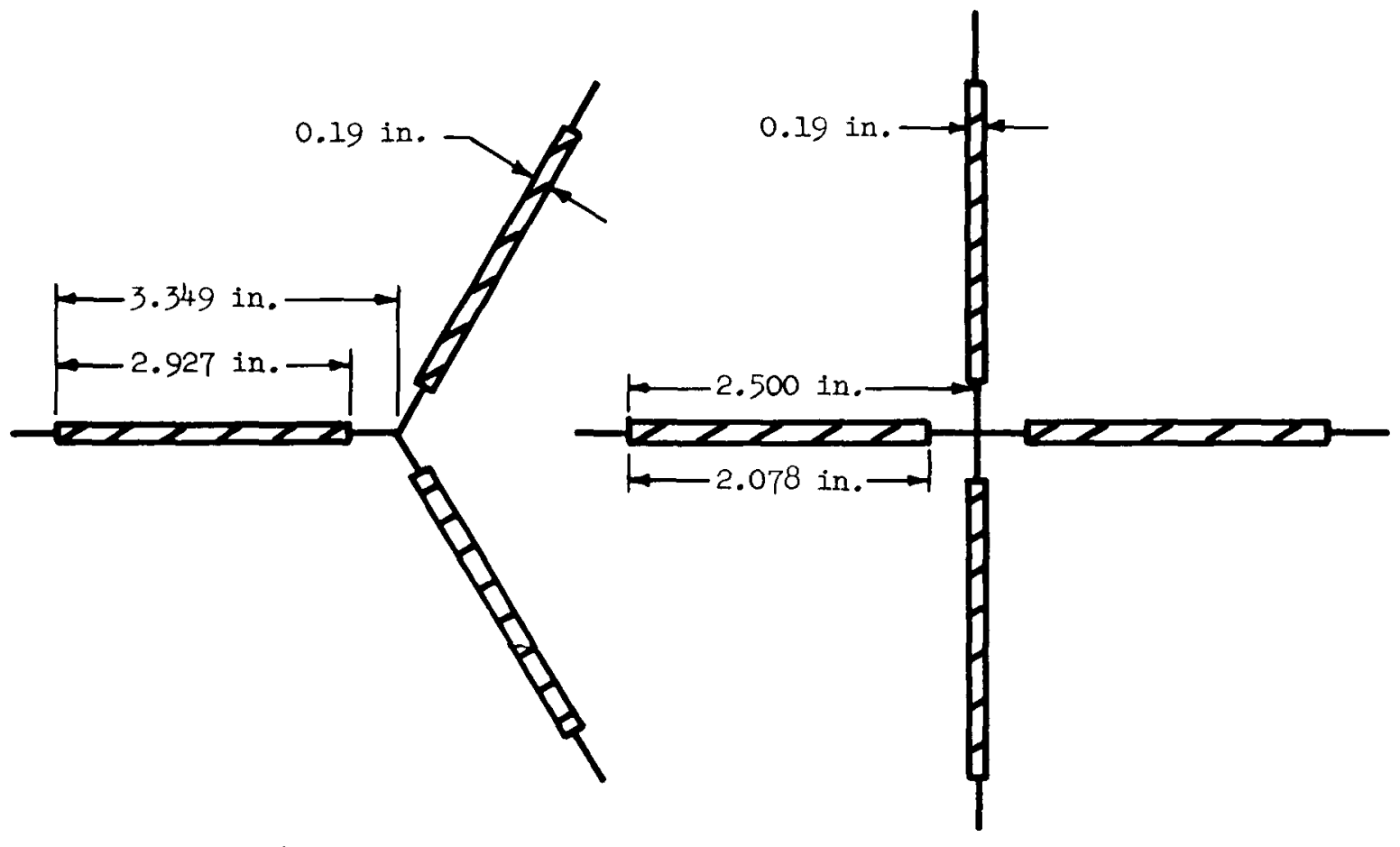

2 Control Rod Absorber Material: Boron Steel, 2.5 Wt \% B -10 Control Rod Configuration Showing Absorber Section

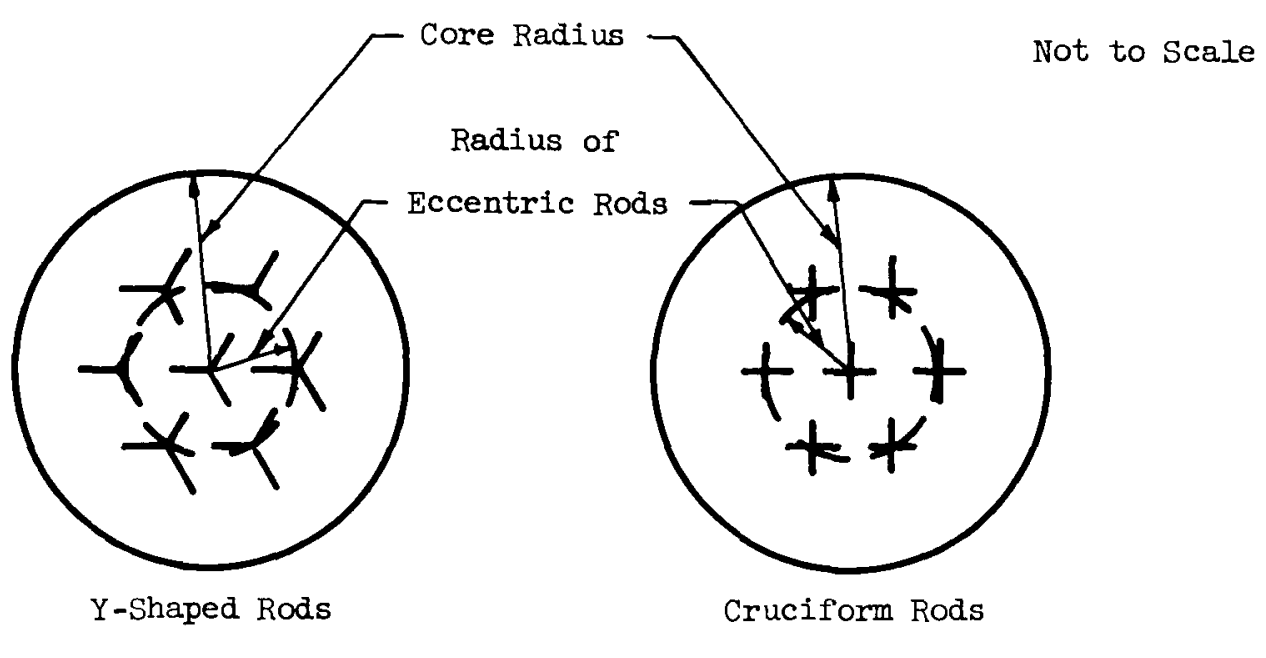

Control Rod Location

Fig. III-9. Rod Configuration and Location 
The following conclusions can be drawn from this study:

(1) Either Y- or cruciform-shaped rods may be used interchangeably since the effect of geometry is negligible.

(2) The height of the core has little effect upon rod worth.

(3) A linear change in rod worth can be effected by a linear change in absorber surface.

(4) If the pitch of the rods is optimized for any set core and rod size, an increase of several percent in reactivity worth can result.

(5) The rod effectiveness increases quite sharply as the core diameter is decreased.

(6) The placement of rods should be optimized for any particular design configuration and the diameter of the core should be kept as small as possible, even if an increase in length is required.

Control rod worths were calculated using the two-dimensional, three-group, IBM-704 machine code $P D Q{ }^{8}$ in X-Y geometry as described in Refs. 1 and 2 . The calculated rod bank worths, $i . e .$, the difference between core reactivity with and without rods, were corrected for the effect of the step approximation required in mapping two of the three arms of the " $Y$ " shaped rods in $X-Y$ geometry. (Note that no geometric correction is required for the cruciform rod analysis.) Comparison of analytical results obtained using this technique with experimental results of previous studies (Chapter VIII, Ref. I) indicated that the analytical results

obtained are good within $\pm 10 \%$. For rod design studies, the calculated worth was assumed to overestimate the worth by $10 \%$. This assumption was considered in presenting the data in Table III-3.

AIl indications to date have been that the peak reactivity in the PM-I core will be approximately 15 to $20 \%$ at the maximum value. The use of burnable poison to aid the control rods in suppressing this reactivity peak is being considered.

Lumped burnable poisons.- The feasibility of using burnable poisons to reduce peak control requirements is well known. For reactors having relatively short lives, a homogeneous distribution of a burnable poison is adequate for keeping the peak reactivity at a relatively low level. However, for reactors having longer core lives and in which the maximum poison loading is such that the reactor is just critical at initial operating conditions, the peak value of reactivity with time may be hightr than desired. By lumping some or all of the poison the selfshielding of the poison so changes its burnout characteristics that larger quanti-

8 Reactor code abstract 8 in Section $D$.

Ref. 1: "Zero Power Test Engineering Report," MND-MPR-1646, Dec 1958.

Ref. 2: "Core and Control Rod Studies for the Martin Power Reactor," R. A. Hoffmeister, W. P. Kutz, E. A. Scicchitano, Trans Am Nuc Society 2,223 Jun 1959. 
ties of poison may be loaded initially, thereby resulting in a lower reactivity peak. If the effect on core life is negligible, or if the lowering of peak reactivity is more desirable than eliminating the additional fuel inventory, the use of lumped poisons is justified.

A preliminary study to determine the feasibility and worth of lumping was poisons in the PM-l core was completed. The effective multiplication factor, $\mathrm{K}_{\text {eff }}$, was calculated as a function of operating time. Figure III-10 shows the results for a core with no burnable poison, Curve 1; for a core with homogeneously distributed poison, Curve 2; for a core with homogeneously distributed lumped poisons, Curve 3; for several cases involving lumped poisons of different initial concentrations (i.e., different initial self-shielding factors) Curves 4, 5, 6 and 7 ; and for a combination of the previous loadings, Curve 8 . The initial poison concentrations for all cases are such that initial $\mathrm{K}_{\text {eff }}$ is $\approx 1.015$.

The approach to the problem used in the preliminary analysis was to calculate $\mathrm{K}_{\mathrm{eff}}$ as a function of time for the cases described from the two-group equation:

$$
\mathrm{K}_{\mathrm{eff}}=\frac{\frac{v \Sigma_{\mathrm{s}_{1}}}{\bar{\Sigma}_{\mathrm{a}_{1}}}\left(1-\mathrm{P}^{\prime}\right)}{\left(1+\mathrm{L}_{1}{ }^{2}+\mathrm{B}^{2}\right)\left(1+\mathrm{L}_{2}{ }^{2}+\mathrm{B}^{2}\right)}+\frac{\frac{v \mathrm{~s}_{2}}{\overline{\mathrm{a}}_{2}} \mathrm{P}^{\prime}}{\left(1+\mathrm{L}_{2}{ }^{2} \mathrm{~B}^{2}\right)}
$$

where:

$$
\begin{aligned}
& \bar{\Sigma}_{a_{1}}=\text { fast group macroscopic absorption cross section } \\
& \bar{\Sigma}_{a_{2}}=\text { thermal group macroscopic absorption cross section } \\
& \Sigma_{f_{1}}=\text { fast group macroscopic fission cross section } \\
& \Sigma_{f_{2}}=\text { thermal group macroscopic fission cross section } \\
& v=\text { number of neutrons per fission }(=2.46 \text { for U-235) } \\
& P^{\prime}=\frac{\Sigma_{f_{1}}}{\Sigma_{f_{1}}+\Sigma_{a_{1}}}
\end{aligned}
$$

where:

$$
\begin{aligned}
& \Sigma_{f_{1}}=\text { fast group slowing-down probability per unit path length } \\
& \mathrm{L}_{1}^{2}=\text { fast group diffusion area } \\
& \mathrm{L}_{2}^{2}=\text { thermal group diffusion area }
\end{aligned}
$$




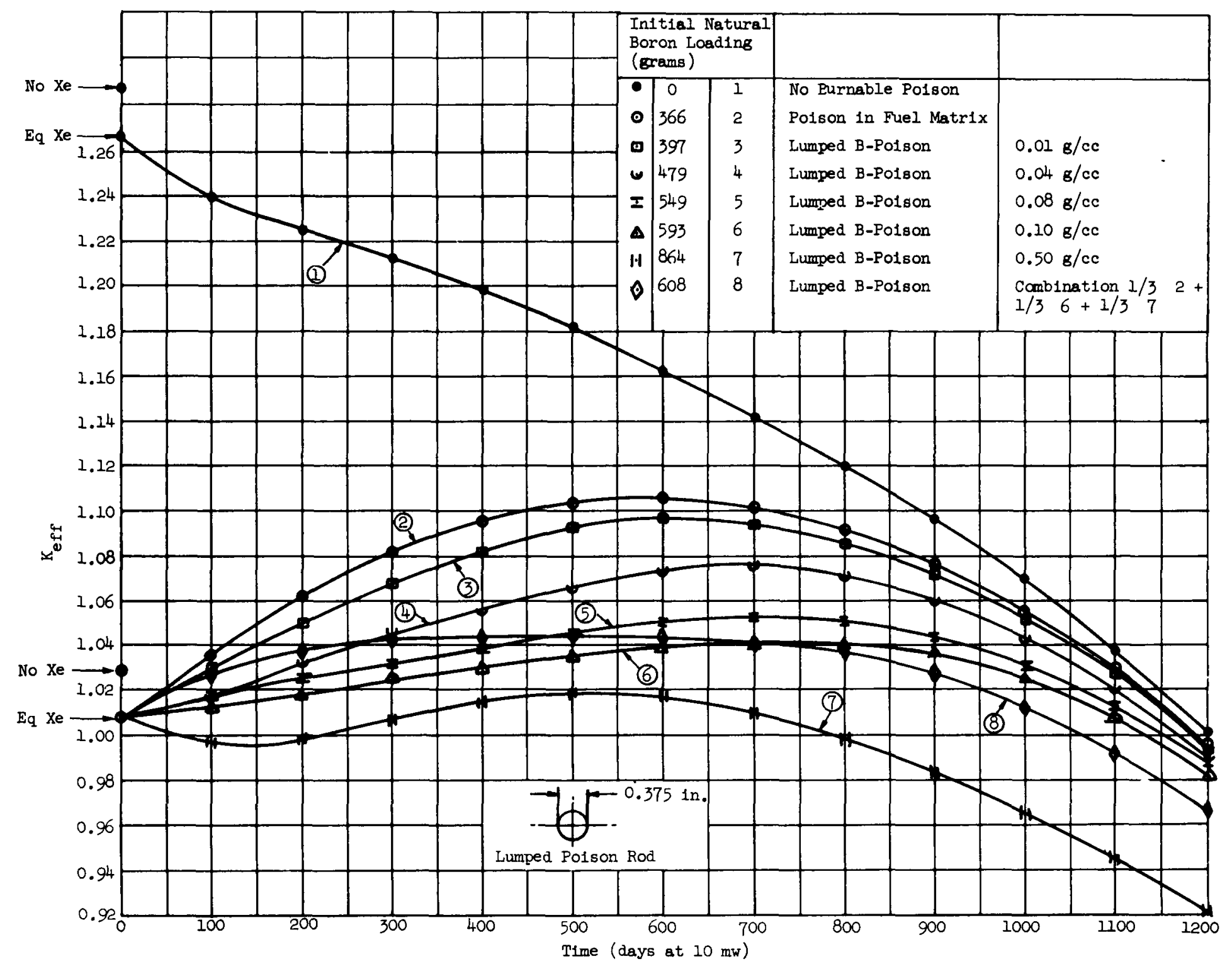

F18. III-10. Study of Effects of Lumping Burnable Poisons 


$$
B^{2}=\text { total geometric buckling }
$$

and:

$$
\Sigma=\sum_{i=1}^{i=n} N^{i} \delta^{i}
$$

with:

$$
\begin{aligned}
& N^{i}=\text { atomic density for material } i \\
& \delta^{i}=\text { microscopic cross section for material } i
\end{aligned}
$$

The time-dependent quantities are $\mathrm{N}^{\mathrm{U}-235}$ in $\Sigma_{\mathrm{f}}=\mathrm{N}^{\mathrm{U}-235} \delta_{\mathrm{f}} \mathrm{U}-235$, $N^{U-235}$ and $N^{B-10}$ in $\Sigma_{a}=\Sigma N^{\frac{1}{\delta}}{ }_{a}^{i}$, and $g(t)$ the thermal self-shieldins factor. Other quantities are assumed to remain constant but will be included later if found to have a significant effect due to energy spectral shifts. The timedependent atomic densities are being calculated from the equation:

$$
N(t)=N(t-1)-N(t-1) \Delta\left(\delta_{a_{1}} \Phi_{1}+(t-1)\right) \delta_{a_{2}} \Phi_{2}
$$

where:

$$
\begin{aligned}
& \Delta=\text { time internal in seconds } \\
& \Phi=\text { group flux at time } t
\end{aligned}
$$

The time-dependent self-shielding factor, $g(t)$, is essentially a function of atomic density, $i . e ., g(t)=g(N)$. This function is obtained by calculating the ratio of the flux in the poison to the unperturbed flux using multiregion, onedimensional diffusion theory. More precise calculations for obtaining the selfshielding factor will be performed later for detailed work.

Completion of the preliminary study indicated that the use of burnable poisons is practical for the PM-I system. Although the analytical techniques are quite involved, it is believed that, with the aid of the results of past and future zero power tests, reliable techniques will be evolved. Results to date indicate that good control of the reactivity transient can be attained through proper selection of the burnable poison system or systems.

\section{HEAT TRANSFER STUDIES}

R. Baer

A. Carnesale

Both nonboiling and local boiling cores were investigated in the heat transfer studies. The more pertinent results are: 


\section{Nonboiling Pressurized Water Cores}

The pressure required to prevent boiling in a core is a function only of the maximum fuel element surface temperature occurrins in the core. An analytical study was made, therefore, to determine the value of this temperature over the range of significant parameters.

Since reactor power varies only slightly for various secondary loop configurations, reactor power was held constant at $10 \mathrm{mw}$ thermal throughout the study Core diameters of 22.5 and 25 in. were studied. The smaller of these diameters represents about the smallest feasible core size for a pressurized water reactor producing $10 \mathrm{mw}$. The larger core was selected so that the variation of power plant cost and weight with core diameter could be obtained when the primary and secondary loops are integrated. Two values of the ratio of core lensth-to-core diameter, 1.00 and 1.25 , were included in the study.

Fuel element inside diameters of 0.25 to 1.0 in. were covered in the study. This range is sufficient to include all feasible cores for the ranje of other parameters studied. The overall fuel element thickness was held constant at $0.030 \mathrm{in.}$ This is permissible since the maximum fuel element surface temperature is insensitive to element thickness for all reasonable values. Two values of the ratio of tube pitch-to-tube OD, 1.2 and 1.5 , were investigated.

The primary coolant flow rate was varied from 1400 to $2600 \mathrm{gpm}$. Considering the variation of primary loop pressure drop with flow and the consequent pump cost, weight, and motor power, this represents the full range of feasible flow rates.

Only two coolant pass cores were included in the study since extensive early investigation of one- and two-pass cores demonstrated conclusively that the latter is thermodynamically superior. The major advantages of the two-pass system are the inherent power flattening in each pass and the increased fluid velocity, for a given flow rate, in each pass. For a fixed reactor power output, a reduction in primary loop flow rate of the order of $50 \%$ may be obtained by selecting a twopass over a single-pass core configuration.

The average heat flux is higher in the inner pass than in the outer pass. Therefore, there is a slight thermodynamic advantage in making the inner region the first pass. However, nuclear considerations dictate that all the control rods be in the inner pass. Thus, if the inner pass is the first pass, the shaft of each control rod would have to pass through the flow baffle and require an individual seal. This additonal design complexity is not warranted by the slight decrease in flow rate which may be obtained with suck a design. Flow stability in the core under all thermal conditions is also more easily obtained if the flow is vertically upward in both passes. In view of this reasonin̈, all pressurized water core configurations investigated had a general flow pattern up the outer region of the core, down between the thermal shield and pressure vessel, and up the inner region of the core (see Fig. III-II).

All steady-state core thermal calculations were made using the IBM-704 digital computer. The assumptions used in the analysis are:

(1) Coolant flow channels are well defined.

(2) Coolant mixing may be neglected. 


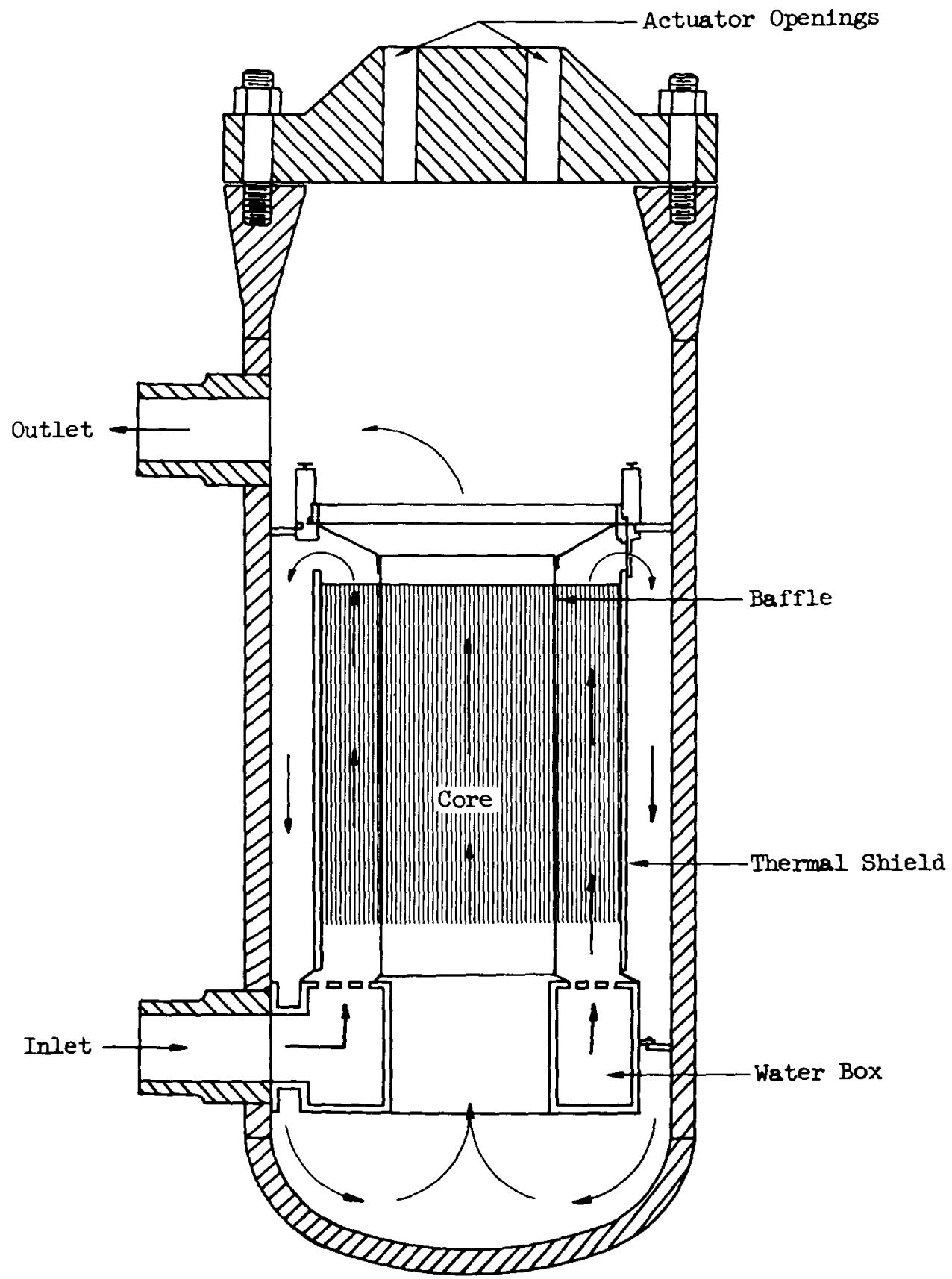

Fig. III-11. Flow Pattern--Typical Two-Coolant Pass Reactor 
(3) Axial heat conduction in the fuel elements and coolant may be neglected.

(4) Thermal properties of the fuel element and coolant may be assumed constant.

(5) Perfect bonding exists between the meat and cladding.

(6) Axial symmetry exists over the active length of the fuel element.

(7) A heat transfer film coefficient, representing the resistance to heat transfer between the fuel element surface and the coolant, may be predicted.

Since the nuclear and thermal analysis parametric studies were performed concurrently, exact heat production distribution data were not available. The distribution used in this study was based on a PM-1 type core. Pertinent information concerning this distribution is as listed:
(1) Peak-to-average flux ratio in first pass
2.24
(2) Peak-to-average flux ratio in second pass (including local flux perturbations)
(3) Fraction of total power produced in first pass
0.50
(4) Fraction of total power produced in second pass
0.50

For parametric design purposes, hot spot factors are used in the analysis. The estimated variations and the resultant hot spot factors for a reactor of the PM-1 type are presented in Table III-4.

The methods of analysis used in the IBM-704 code are given in the Appendix. The results, plotted in terms of the maximum surface temperature minus the coolant inlet temperature, are shown in Figs. III-12 to III-19. The symbols used on these figures are as follows:

$$
\begin{aligned}
D_{C} & =\text { core diameter, } \text { in } . \\
\frac{L}{D_{C}} & =\text { length-to-diameter ratio of core } \\
T_{\max } & =\text { fuel element maximum surface temperature, }{ }^{\circ} \mathrm{F} \\
\theta_{\text {in }} & =\text { coolant inlet temperature, }{ }^{\circ} \mathrm{F} \\
\mathrm{k} & =\text { fuel element pitch-to-diameter ratio } \\
\mathrm{D} & =\text { inside diameter of fuel element, in } . \\
O D & =\text { outside diameter of fuel element, in. } \\
N & =\text { number of fuel element tubes }
\end{aligned}
$$


The information of some of these curves was replotted in a form for use in the system integration study (see Fig. III-20).

\section{Table III-4}

Hot Spot Factors

$$
\text { Variation }(\%)
$$

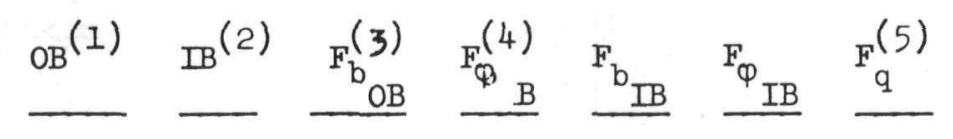

Plenum Chamber

12

$$
7 \quad 1.137
$$$$
\begin{array}{llll}
1.117 & 1.078 & 1.081 & -
\end{array}
$$

Velocity Variation due to Channel Dimension Uncertainty

$$
\begin{array}{lllllll}
1 & 1 & 1.040 & 1.024 & 1.024 & 1.036 & -
\end{array}
$$

Velocity Variation due to Fnd Spacer Dimension Uncertainty

Variation in Meat

Thickness

$$
3
$$

Fuel Concentration

3

1.030

$1.030 \quad 1.030 \quad 1.030$ -

Inability to Predict Heat Transfer Film

Coefficient

Inability to Predict Neutron Flux Distribution

Uncertainty in Power Requirements

10

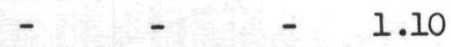

Total

\section{$\begin{array}{lllll}1.326 & 1.622 & 1.243 & 1.600 & 1.210\end{array}$}
(1) Outside Baffle
(2) Inside Baffle
(3) Hot Spot Factor to Account for Variations in Bulk Coolant Temperature Rise
(4) Hot Spot Factor to Account for Variations in the Temperature Drop Across the Film
(5) Hot Spot Factor to Account for Variations in Power 


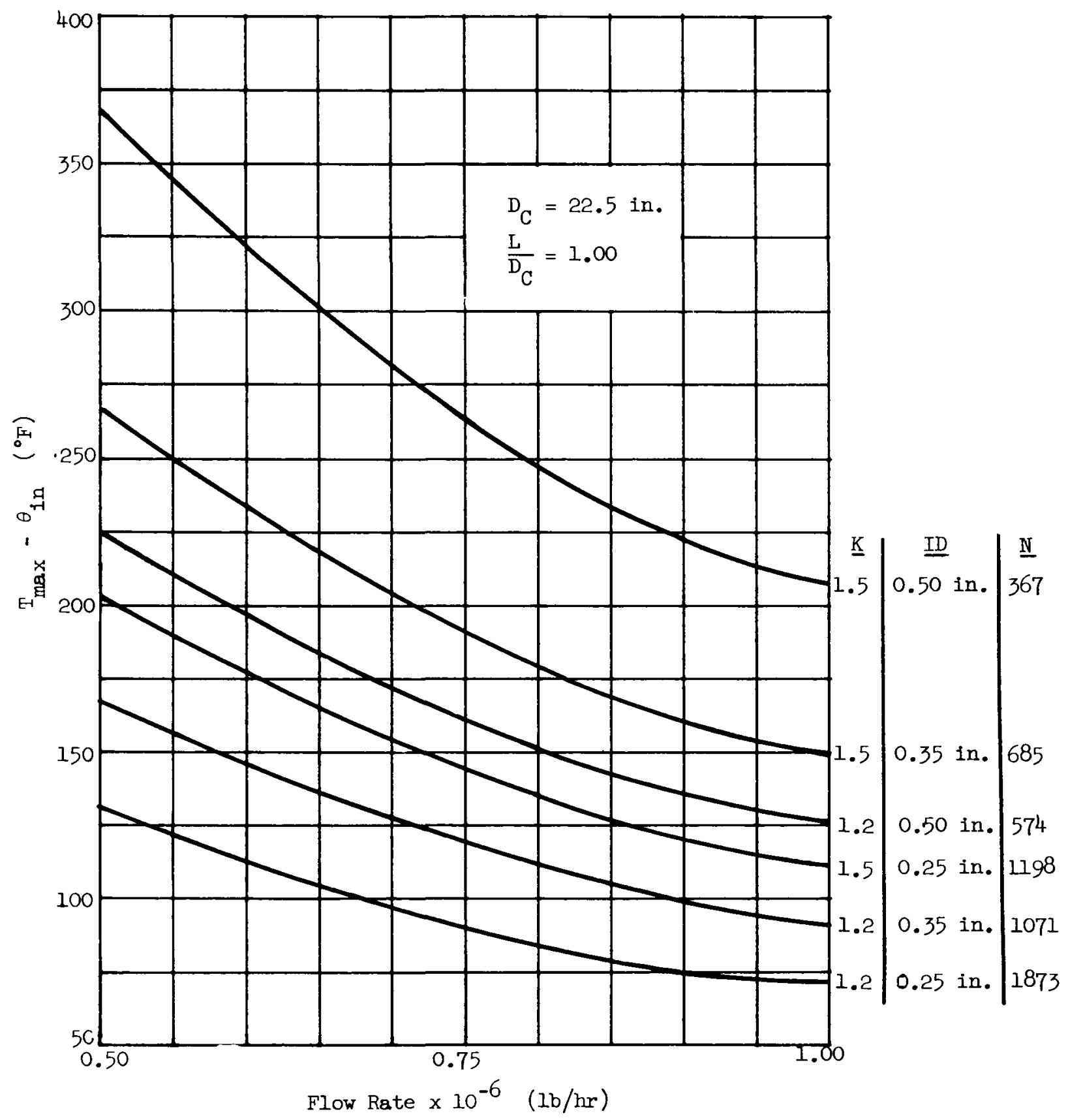

Fig. III-12. Maximum Fuel Surface Temperature Minus Coolant Inlet Temperature as a Function of Coolant Flow Rate and Core Parameters Outside of Flow Baffle 


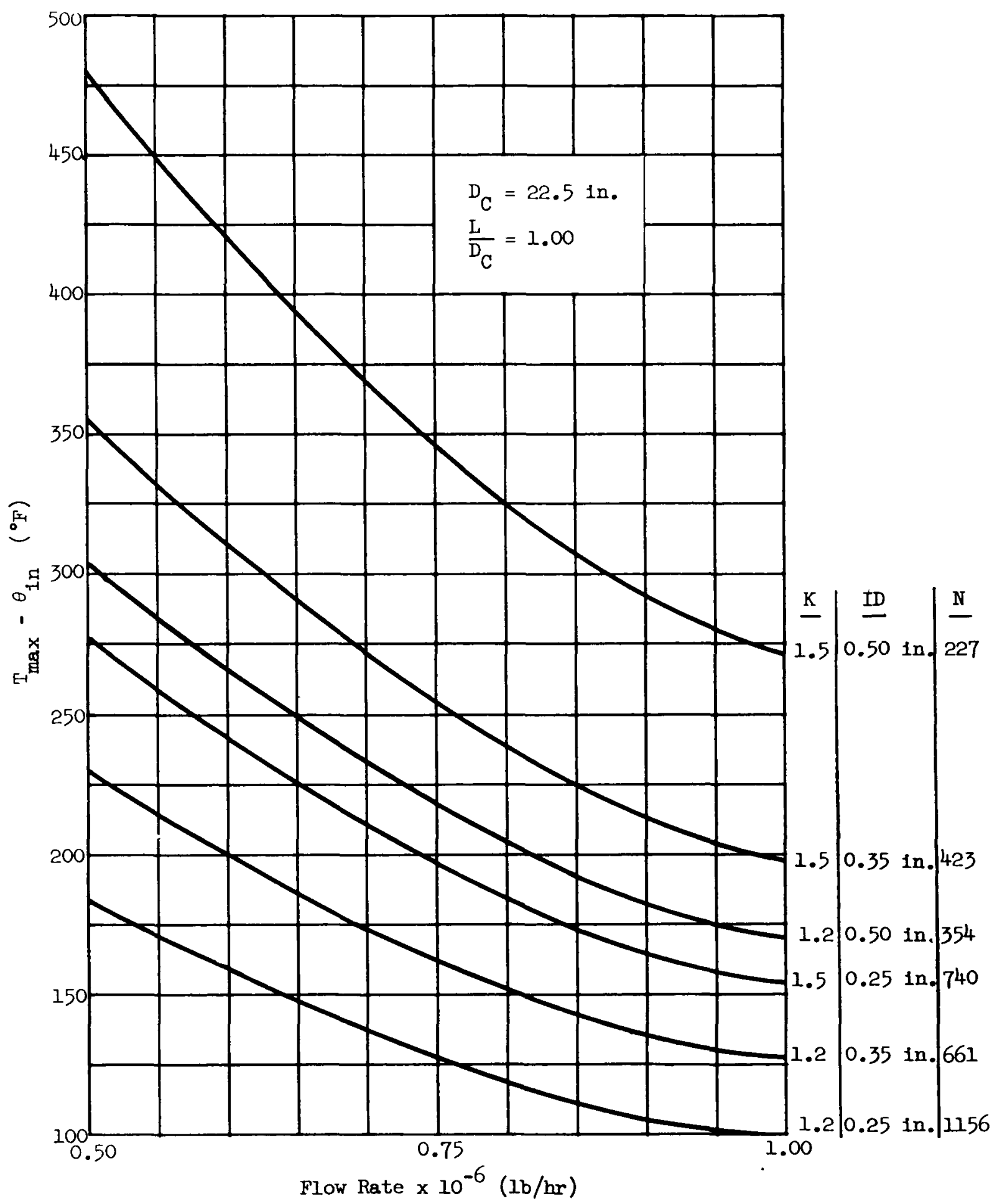

Fig. III-13. Maximum Fuel Surface Temperature Minus Coolant Inlet Temperature as a Function of Coolant Flow Rate and Core Parameters--Inside of Flow Baffle 


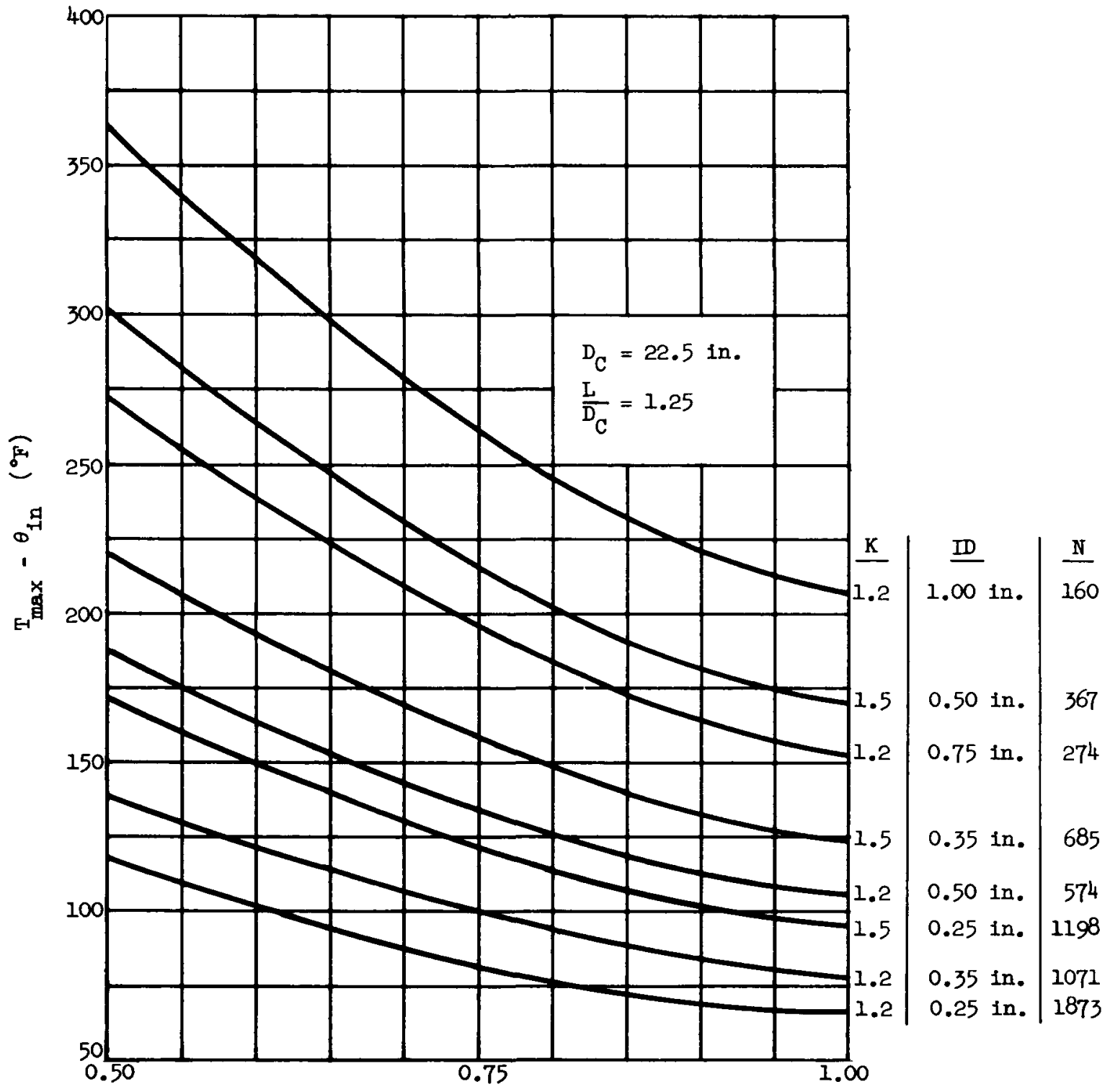

Flow Rate $\times 10^{-6}(1 \mathrm{~b} / \mathrm{hr})$

Fig. III-14. Maximum Fuel Surface Temperature Minus Coolant Inlet Temperature as a Function of Coolant Flow Rate and Core Parameters--Outside of Flow Baffle 


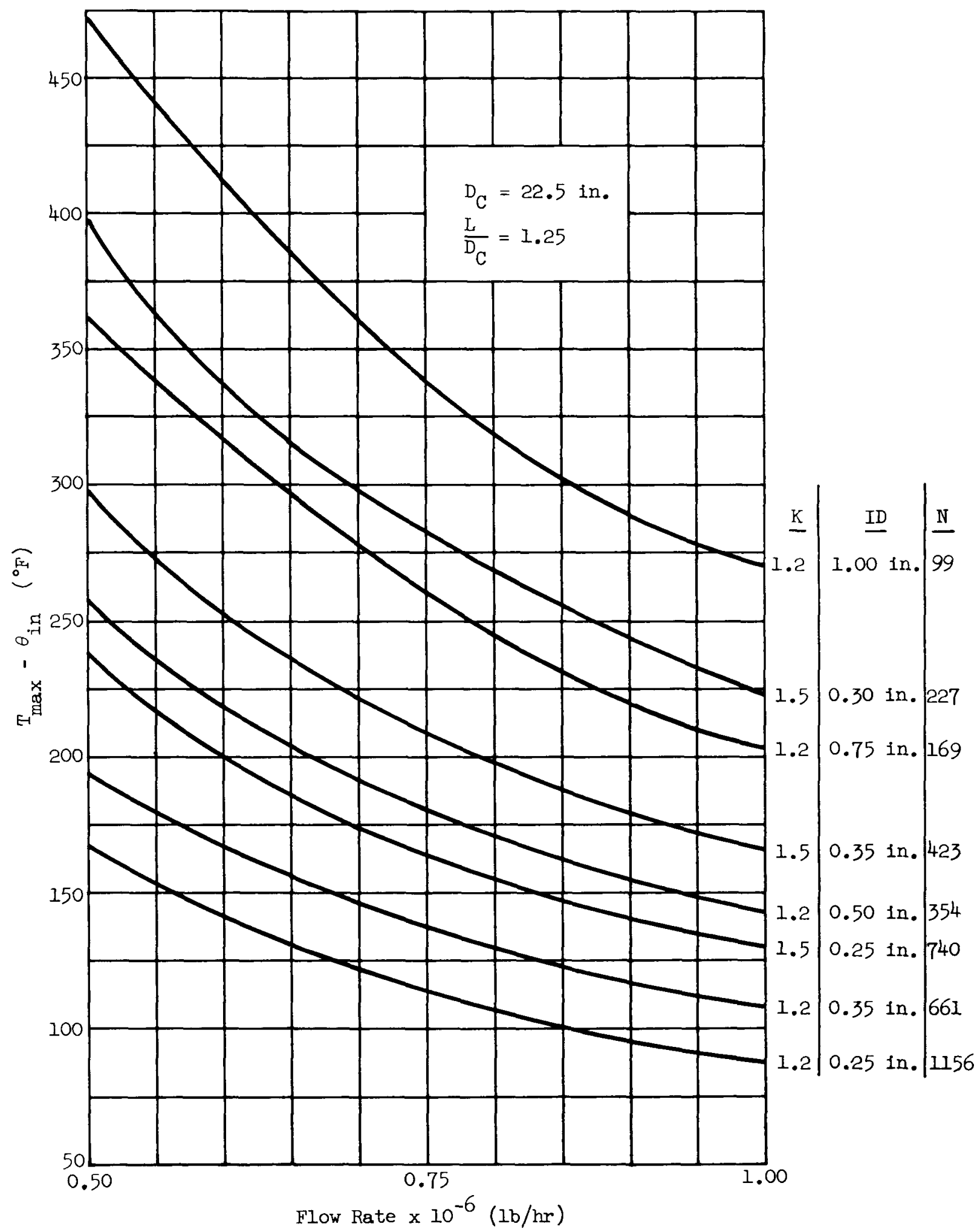

Fig. III-15. Maximum Fuel Surface Temperature Minus Coolant Inlet Temperature as a Function of Coolant Flow Rate and Core Parameters--Inside of Flow Baffle 


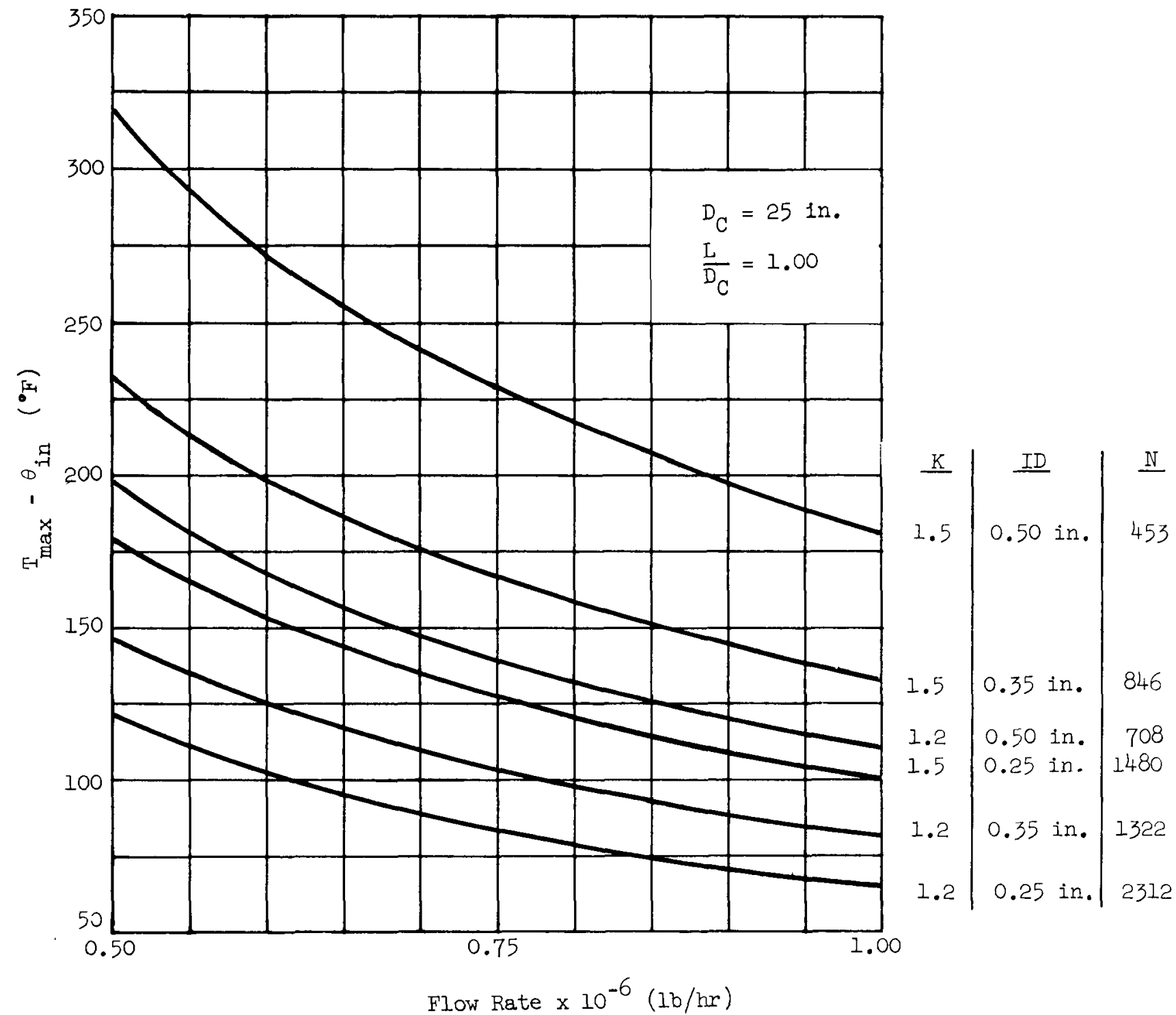

Fig. III-16. Maximum Fuel Surface Temperature Minus Coolant Inlet Temperature as a Function of Coolant Flow Rate and Core Farameters--Outside of Flow Baffle 


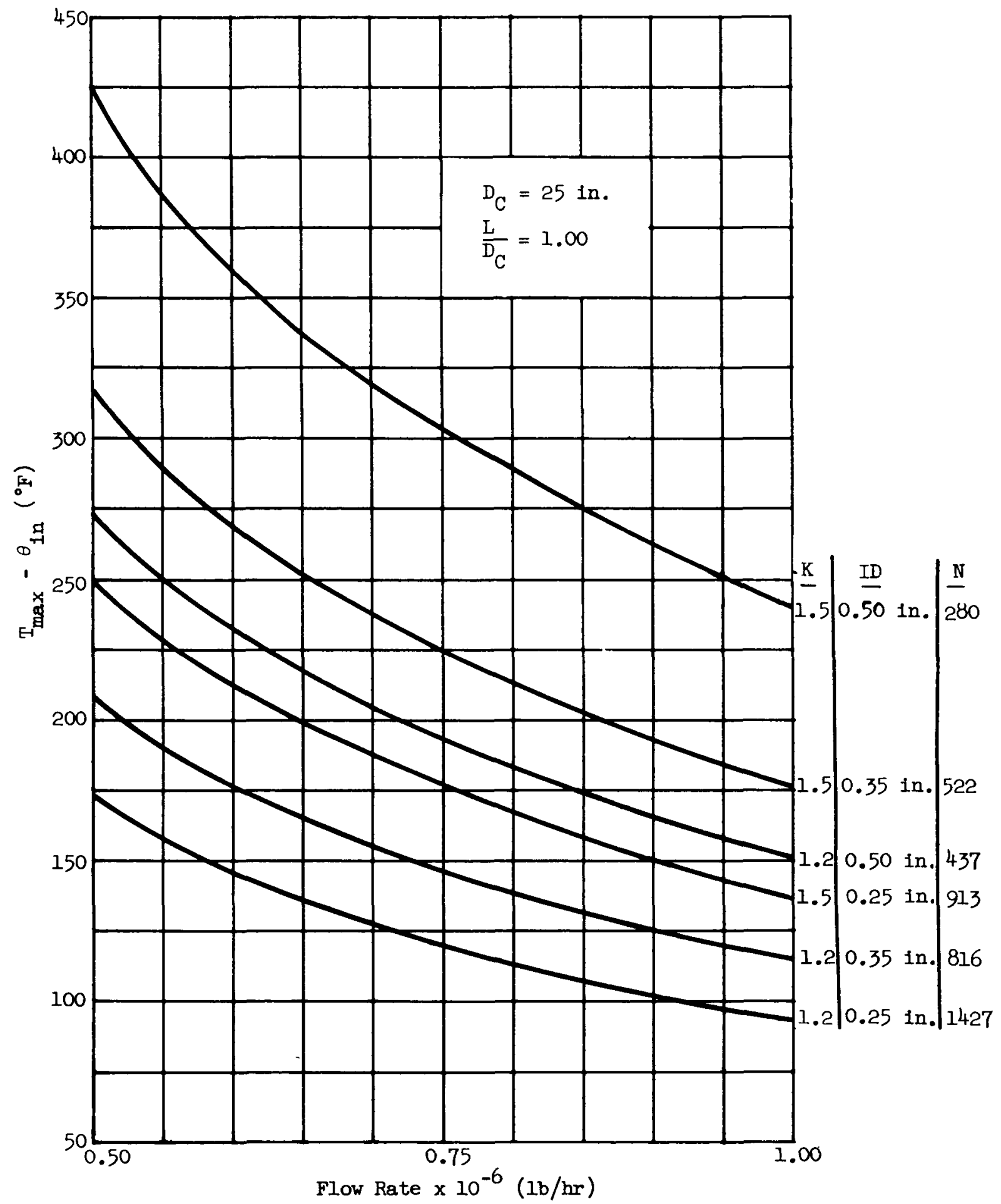

Fig. III-17. Maximum Fuel Surface Temperature Minus Coolant Inlet Temperature as a Function of Coolant Flow Rate and Core Parameters--Inside of Flow Baffle 


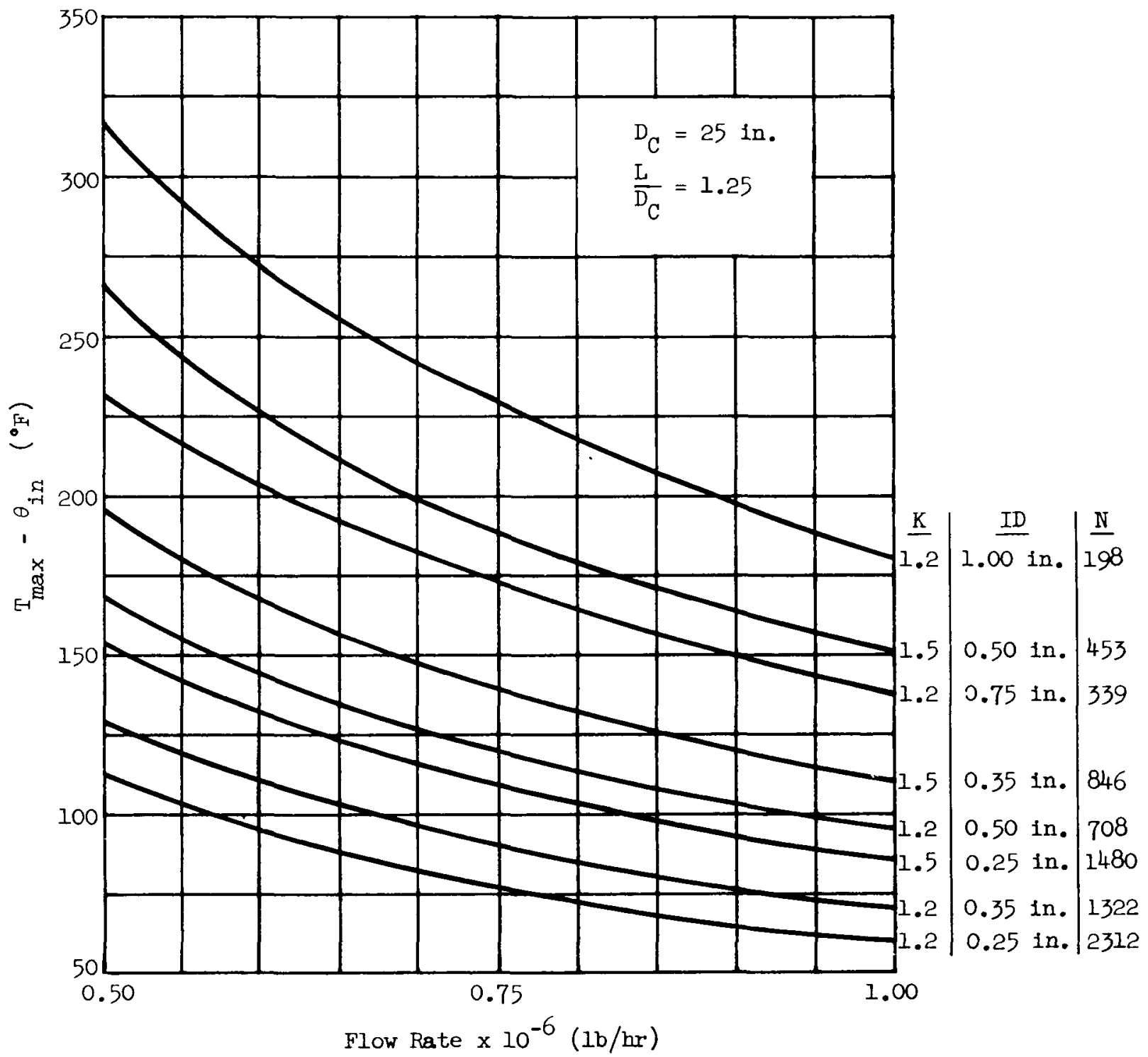

Fig. III-18. Maximum Fuel Surface Temperature Minus Coolant Inlet Temperature as a Function of Coolant Flow Rate and Core Parameters--Outside of Flow Baffle 


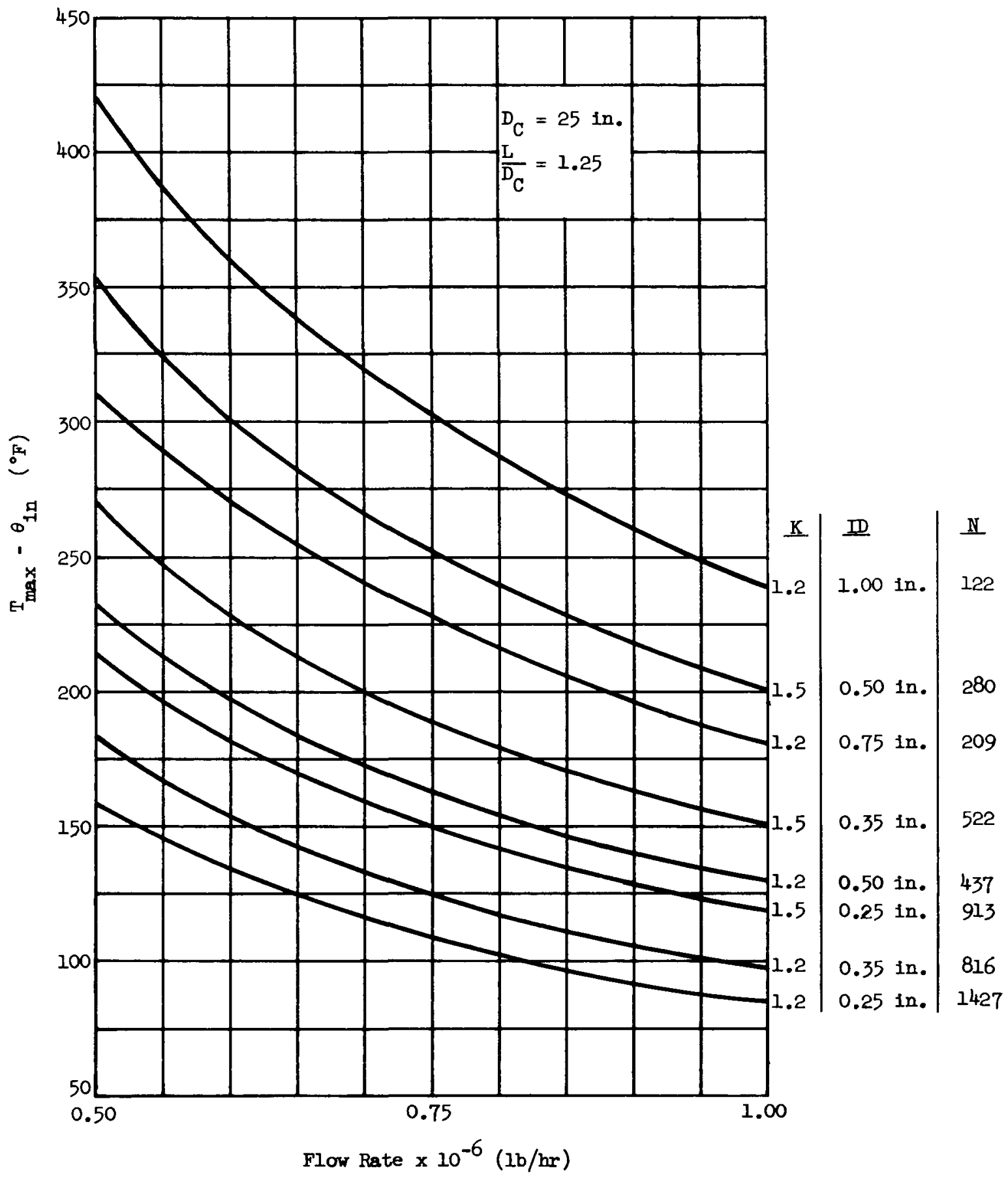

Fig. III-19. Maximum Fuel Surface Temperature Minus Coolant Inlet Temperature as a Function of Coolant Flow Rate and Core Parameters--Inside of Flow Baffle 


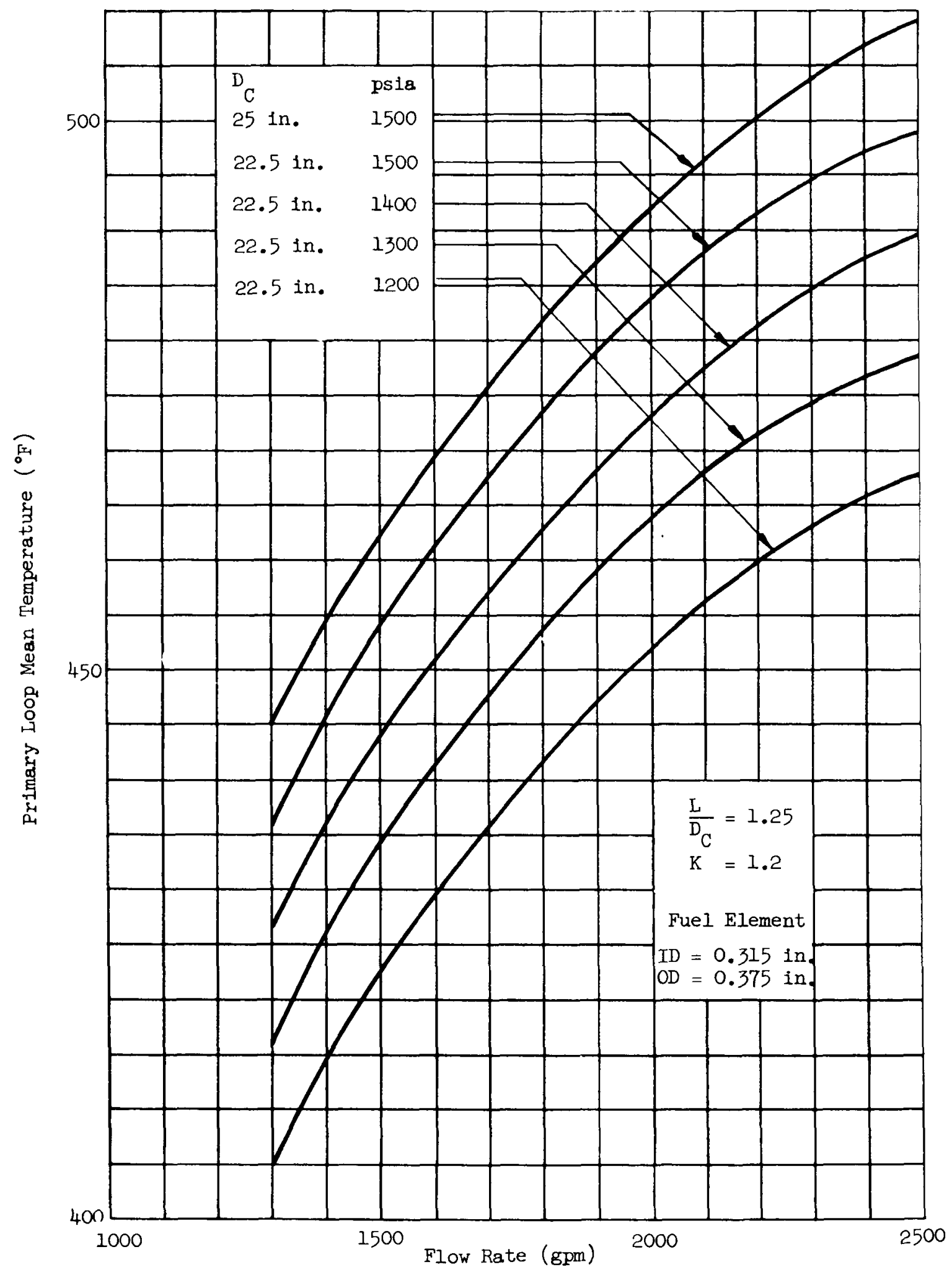

Fig. III-20. Primary Loop Mean Temperature as a Function of Coolant Flow Rate, Pressure, and Core Diameter--Inside of Flow Baffle 


\section{Local Boiling Cores}

A study was performed to determine the maximum value of the ratio of actual heat flux to burnout heat flux over the range of significant parameters.

The parameters studied were identical to those considered for pressurized water cores, except that pressure was added as an independent variable. Pressures between 900 and 2000 psia were included to treat the entire range of interest. Since smaller core diameters are feasible with local boiling, core diameters as small as $20 \mathrm{in}$. were investigated. The effects of 2.11 other parameters were studied over essentially the same range covered in the pressurized water investigation.

In local boiling operation, the heat transfer rate from the fuel element to the fluid is independent of the coolant velocity. The single remaining advantage of a two-pass core is its inherent power flattening. Since the effect of bulk boiling in the first pass would cause severe design problems, the benefits to be gained from a two-pass design did not seem to warrant the problems that would "be encountered. Only one-pass cores were, therefore, included in the local boiling study .

A cursory analytical technique was programmed for the IBM-704 and was employed in this study. The basic assumptions used in the analysis were that:

(1) The radial peak-to-average power distribution ratio is 2 .

(2) The axial power distribution may be represented as a chopped cosine function with an extrapolated length of 1.3 times the active fuel element length.

(3) The maximum fraction of burnout heat flux occurs at a point $65 \%$ of the way up the core.

(4) The velocities inside and outside the tubes are equal.

(5) The heat fluxes inside and outside the tubes are equal.

(6) A $50 \%$ power increase would create incipient bulk boiling at the exit of the hot tube.

(7) Twenty-five percent of the coolant flows through empty control rod channels.

(8) Coolant flow channels are well defined.

(9) Coolant mixing may be neglected.

(10) Axial heat conduction may be neglected.

(11) Thermal properties are constant.

The code was used to determine the inlet, exit, and mean coolant temperatures; the point at which local boiling begins; and the burnout heat flux. The equations used in the code are given in the Appendix. 
It was found that, for the range of parameters investigated, the highest percentage of burnout heat flux obtained was 29\%. In most cases the percentage was between 5 and 15\%. Since burnout heat flux is the only essentially geometrydependent thermal performance parameter, it appears that the thermal performance of the local boiling cores studied are independent of core configuration. In other words, the mean coolant temperature attainable is a function of the coolant flow rate and the operating pressure only and not of the heat transfer characteristics of the core. This relationship is shown graphically in Fig. III-2l. The mean temperatures of the primary loop required to obtain various steam pressures with various logarithmic mean temperature differences in the steam zenerator are shown.

The problem of flow stability is of extreme importance in this type of system. Although the final determination can only be made through operation, preliminary studies indicate that, for the selected system under consideration, no serious effects will result from local boiling and that maximum variations in reactor coolant flow are not severe.

In the limiting case for flow within the tubes, when the coolant temperature approaches the saturation temperature, the ratio of tube wall friction factor during local boiling to the friction factor with no boiling is 1.6. Since the greater value was used throughout the analysis, results quoted are probably conservative.

The coolant flow outside of the tubular elements is not confined to a single flow path. The extremes in the possible flow pattern outside of the elements would occur when the resistance to flow normal to the elements is either zero or infinite.

When this resistance is zero, the pressure drop per unit length is equal outside of all the elements at any axial location. Relationships for the pressure drop per unit length occurring in two channels-one in local boiling and the other not--were equated and solved for the relative values of velocity. This calculation showed a reduction in velocity of $23 \%$ in the channel having local boiling. Preliminary calculations indicate that for this decrease in velocity the burnout heat flux is lowered by $14 \%$ at the location where the ratio of operating heat flux to burnout heat flux is a maximum.

The other extreme in possible flow pattern outside of the elements occurs when the resistance to flow normal to the elements is infinite. In that event, the coolant is restricted to a single flow path similar to the coolant flow inside of the elements and orificing may be used to control the flow. The orifice pressure drop is a function of flow rate only, and not the heat transfer characteristics of the fuel elements. Hence, orifices will tend to stabilize the flow. For example, if the orifice pressure drop is set at four times the friction pressure drop which would occur without boiling, local boiling would result in only a $6 \%$ decrease in velocity and a negligible decrease in burnout heat flux.

From these results it was concluded that large changes in flow distribution will not occur and that these can be minimized by proper design. 


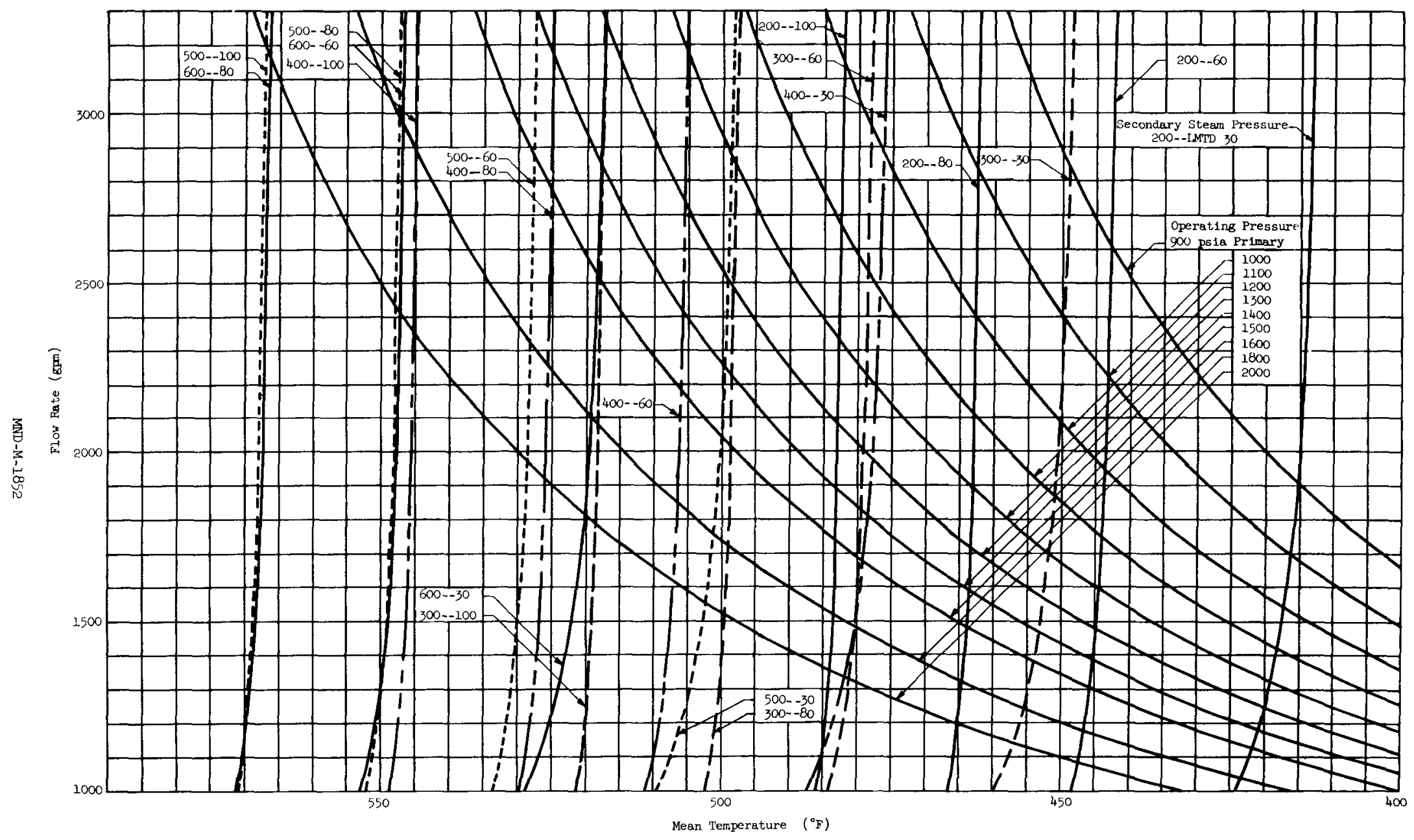

Fig. III-21. Primary Coolant Mean Temperature as a Function of Primary Coolant
Flow Rate, LMTD, and Secondary System Pressure--Local Boiling 


\title{
D. CORE AND PRESSURE VESSEL DESIGN STUDIES
}

\section{H. Brainard}

\author{
J. Goeller
}

R. Phipps

The core and pressure vessel design studies consisted of: selection of the fuel element diameter, lensth, and pitch; and prelimary evaluation of different pressure vessel materials and determination of their suitability to the PM-l design.

The PM-1 will use tubular fuel elements. A fuel element of $1 / 2-i n$. diameter and $30-i n$. active length was chosen as the reference design element. This selection was made as a result of the following considerations:

(1) From an economic point of view, the number of fuel elements should be as small as possible.

(2) The length of the fuel element should be as great as possible to incorporate maximum surface area and fuel cermet volume without increasing the number of tubes.

(3) Tubes as large as 1 in. in diameter and 30 in. in active length can be made by the present fuel element process and equipment.

(4) The length-to-diameter ratio for a fuel element should be limited to 75 , since some may be used as colum-loaded structural elements-- such tubes may not contain fuel.

(5) If local boiling is allowed, the volume of fuel-containing cermet will be the criterion which determines the number of tubes. If local boiling is not allowed, an additional criterion, surface area, must be added.

(6) Manufacturing considerations limit the maximum fuel-containing cermet thickness to 0.030 in.

(7) The preferred design concentration of uranium dioxide in the cermet is 25 wt $\%$. It is felt that 30 wt $\%$ cermet can be fabricated, but, to be conservative, the lower limit has been selected for preliminary design purposes.

(8) The control rod gap increases and the effectiveness of lumped burnable poison decreases as fuel element diameter increases.

(9) Although the fuel element size does not affect the required fuel inventory to any great amount, a slight minimum in fuel inventory does exist at a tube diameter of 0.48 in.

(10) A gap of 0.10 to $0.15 \mathrm{in}$. between fuel elements is required as a result of structural and heat transfer considerations.

Considering these points, the following conclusions were drawn:

(1) Although sarmle fuel elements have been made with diameters of up to $I$ in., the only large-scale experience is with 3/8-in. elements. The 
closer the selected element is to this size, the more benefit can be derived from previous fabrication experience.

(2) Application of structural criteria, giving due consideration to clearcut dead ends and the desirability of maximizing active length, yields minimum fuel element diameters of 0.45 to 0.50 in.

(3) In nonlocal boiling cores, two sizes of fuel elements are required; one of these should be at least 0.45 to $0.50 \mathrm{in}$. for structural reasons.

As a result of these conclusions and those of the nuclear and heat transfer studies, a l/2-in. diameter fuel element of 30 -in. active length was selected.

Using tubular fuel elements, many different types of pitches can be used. The two considered for this study were the triangular and the square pitch. The following conclusions were reached from a study of each:

(1) The core diameter using square pitch is greater than the core diameter using triangular pitch if the length of pitch and number of tubes are the same. The two diameters differ by about $7 \%$.

(2) If orifices are used each tube must be orlficed and the space surrounding each must be orfficed. In triangular pitch this means approxinately $3 \mathrm{~N}$ orifices, where $\mathrm{N}$ is the number of tubes. In square pitch this means $2 \mathrm{~N}$ orifices, approximately. The size of orifices outside of tubes on a triangular pitch will be smaller by $30 \%$ than those outside of tubes on a square pitch.

The orifices used should be at least $1 / 4$ in. in diameter. To provide enough space to fit these in and still have a sufficiently sound plate, the pitch length has been fixed at $0.65 \mathrm{in}$. for preliminary design. Since this gives a pitch length-to-tube diameter of 1.3 , there are no serious effects from nuclear considerations.

\section{Pressure Vessel Evaluation}

An evaluation was made of the effects of various water gaps and thermal shield thicknesses on pressure vessels fabricated from different materials. Some materials were corrosion resistant, others were not--the latter would be clad if selected, but the effect of the cladding was not considered in determining strength.

The following design conditions were assumed:

Core diameter

Average temperature of pressure vessel wall

Weld efficiency

The following materials were investigated:

SA-167, Grade 6,Type 347

$S A-302 B$
23 in.

$600^{\circ} \mathrm{F}$

$100 \%$. 


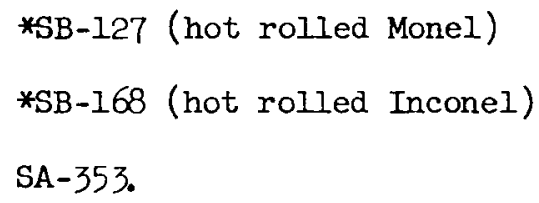

Using these materials and conditions stated, the allowable thermal stresses were calculated for:

(1) Different water gaps between the core and the pressure vessel.

(2) Different thicknesses of thermal shields.

(3) Different internal pressures.

(4) Different allowable mechanical stresses for a specific material. This was considered because the worst mechanical stress occurs at nozzles or other discontinuities rather than at the point of maximum thermal stress. Larger thermal stresses are, therefore, permissible.

Neither the effects of cladding nor the effects of neutron flux damage were taken into account in this investigation.

The computed thermal stresses versus water gap for various materials are plotted in Fig. III-22. The allowable tension is also shown so that the minimum water gap for each material considered can be easily picked from the curve.

Using the two materials, SA-302B and SA-167, Grade 6, Type 347, which have known technology and that appear to have the best and poorest stress qualities, and assuming external stresses of either 0 or 3000 psi, a second plot of thermal stress versus water gap was made (Fig. III-23).

Figure III-24 is a plot of the same two materials with thermal shield thickness as a variable.

Figure III-25 is a plot of calculated thermal stresses versus water gap with internal pressure as a variable.

The computed total stress versus the wall thiclmess is plotted in Fif. III-26 and Fig. III-27 for SA-302B material and water gaps of 13.5 in. and 6 in., respectively.

The allowable thermal stress is shown on all of the figures, and is computed under the rules of the ASME Boiler Code, Section VIII, as amended by case rulings.

* Since the annealing temperatures of these materials are about 1000 to $1400^{\circ} \mathrm{F}$, and this temperature would never be reached in service, it was felt that the hot-rolled condition could safely be used. However, a complete investigation was not conducted; additional problems such as the effects of welding will be considered if these materials are seriously considered during preliminary design. 


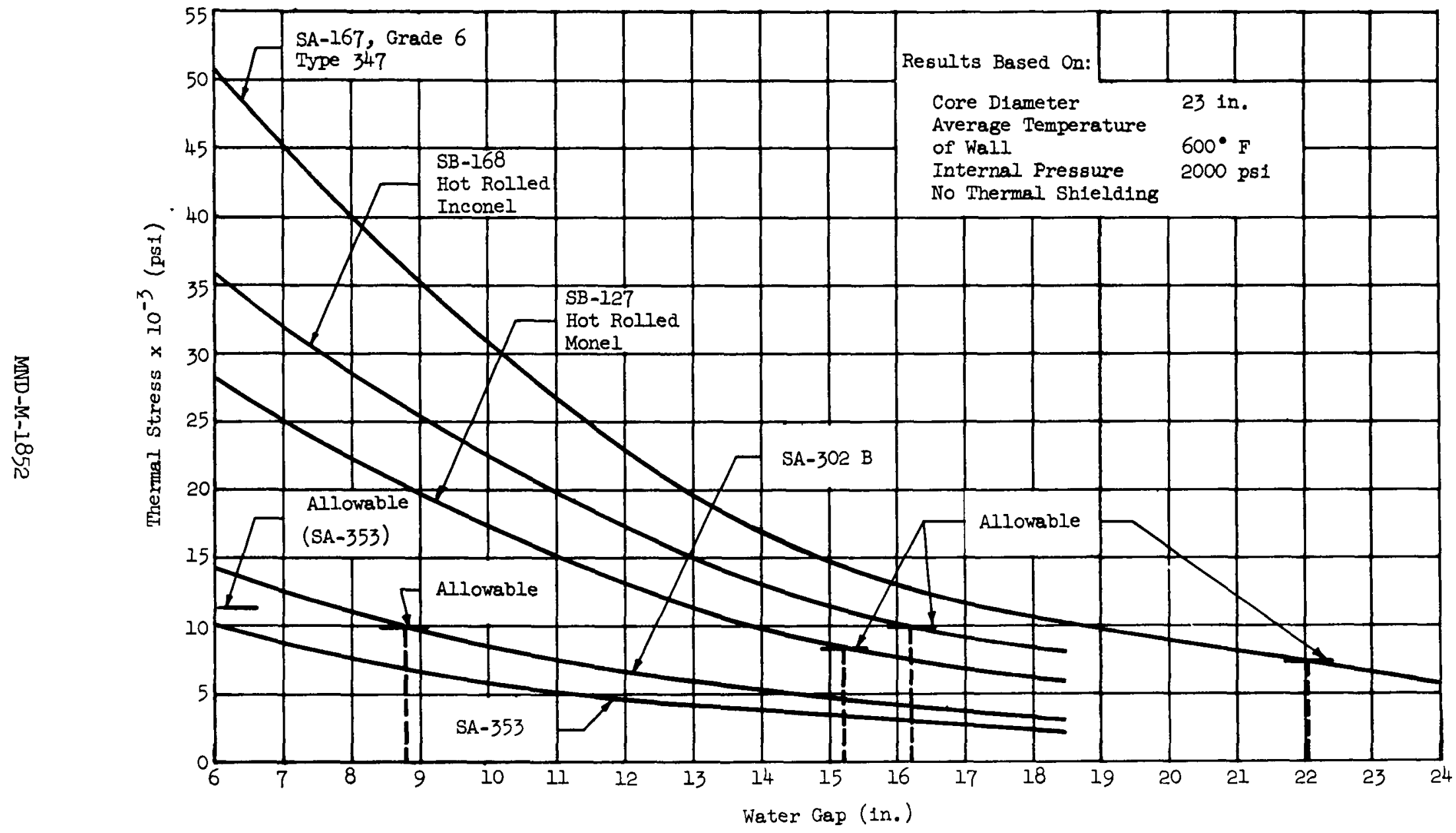

Fig. III-22. Thermal Stress as a Function of Water Gap for Varlous Materials 


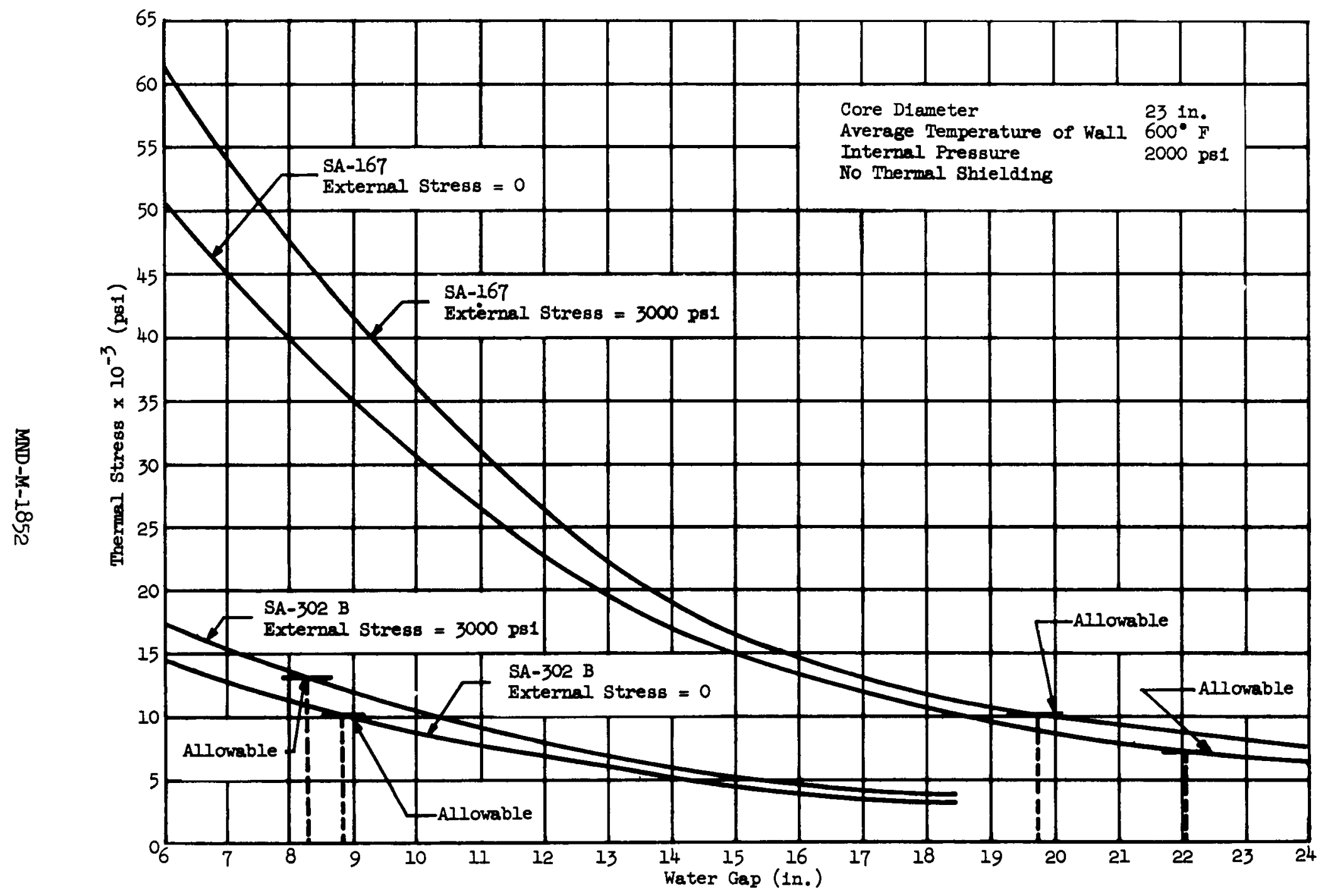

Fig. III-23. Thermal Stress as a Function of Water Gap for Various External Stresses 


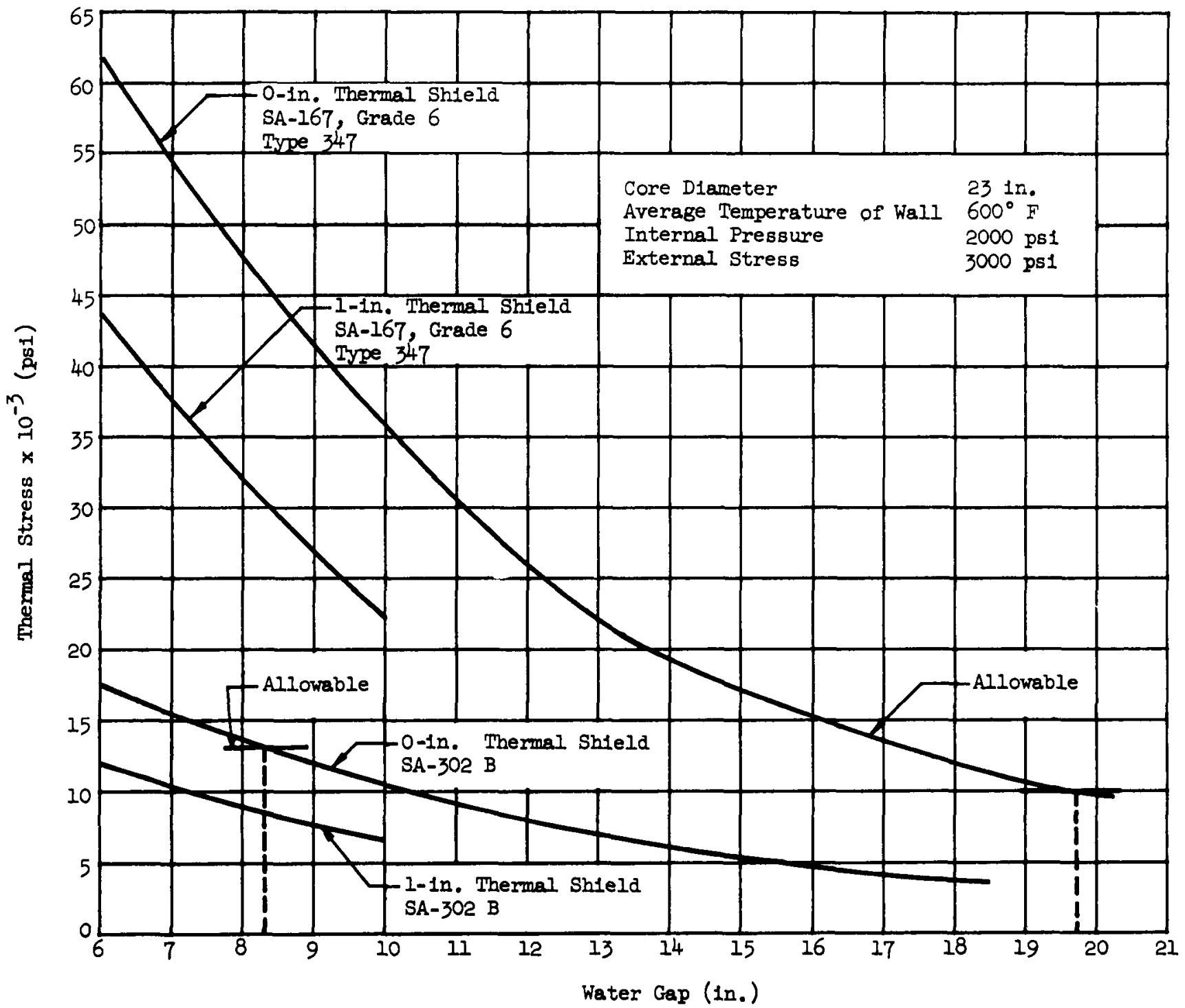

F1g. III-24. Thermal Stress as a Function of Water Gap for Varlous Thermal Shlelds 


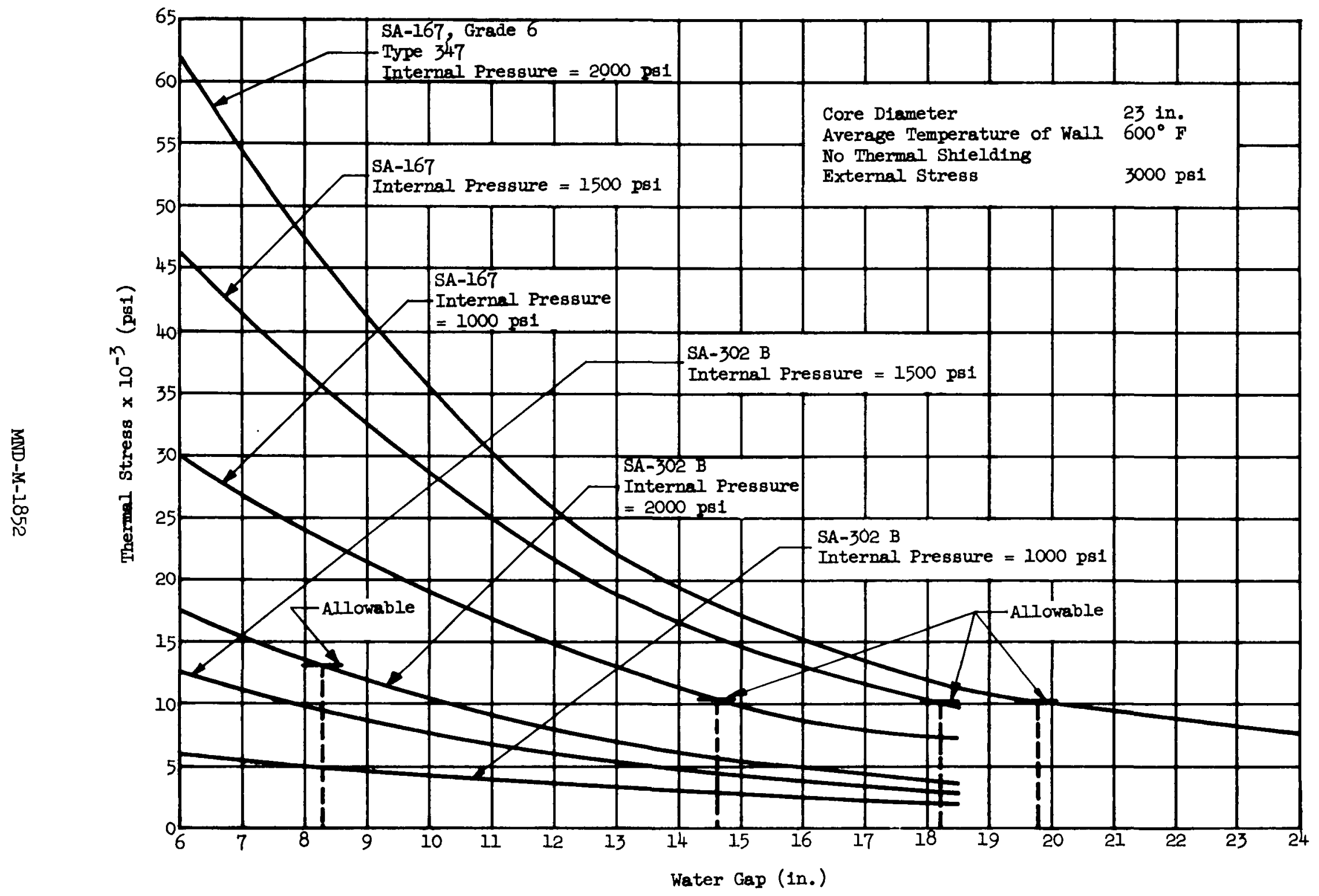

Fig. III-25. Thermal Stress as a Function of Water Gap for Various Internal Pressures 


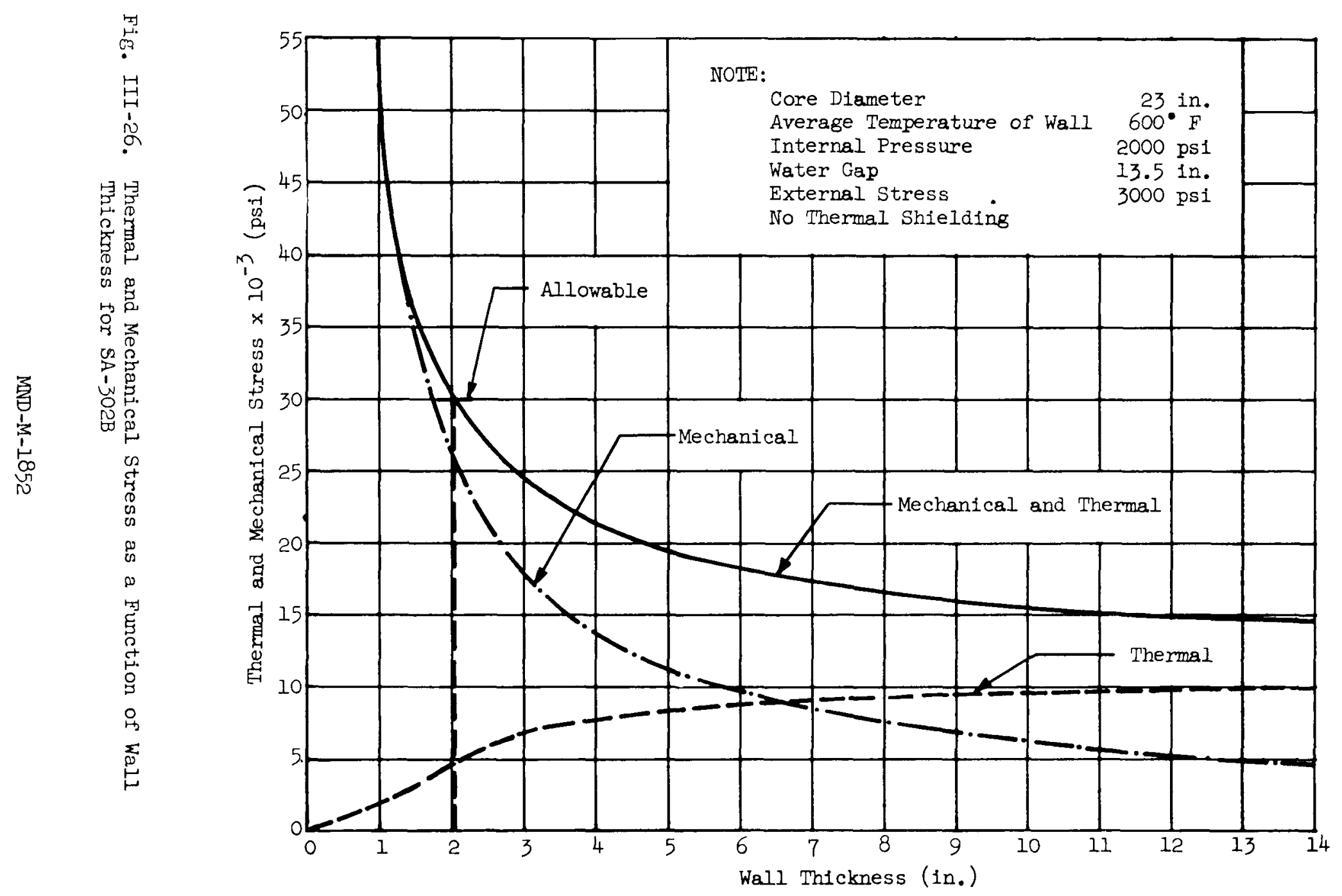


External Stress

6 in.

No Thermal Shielding

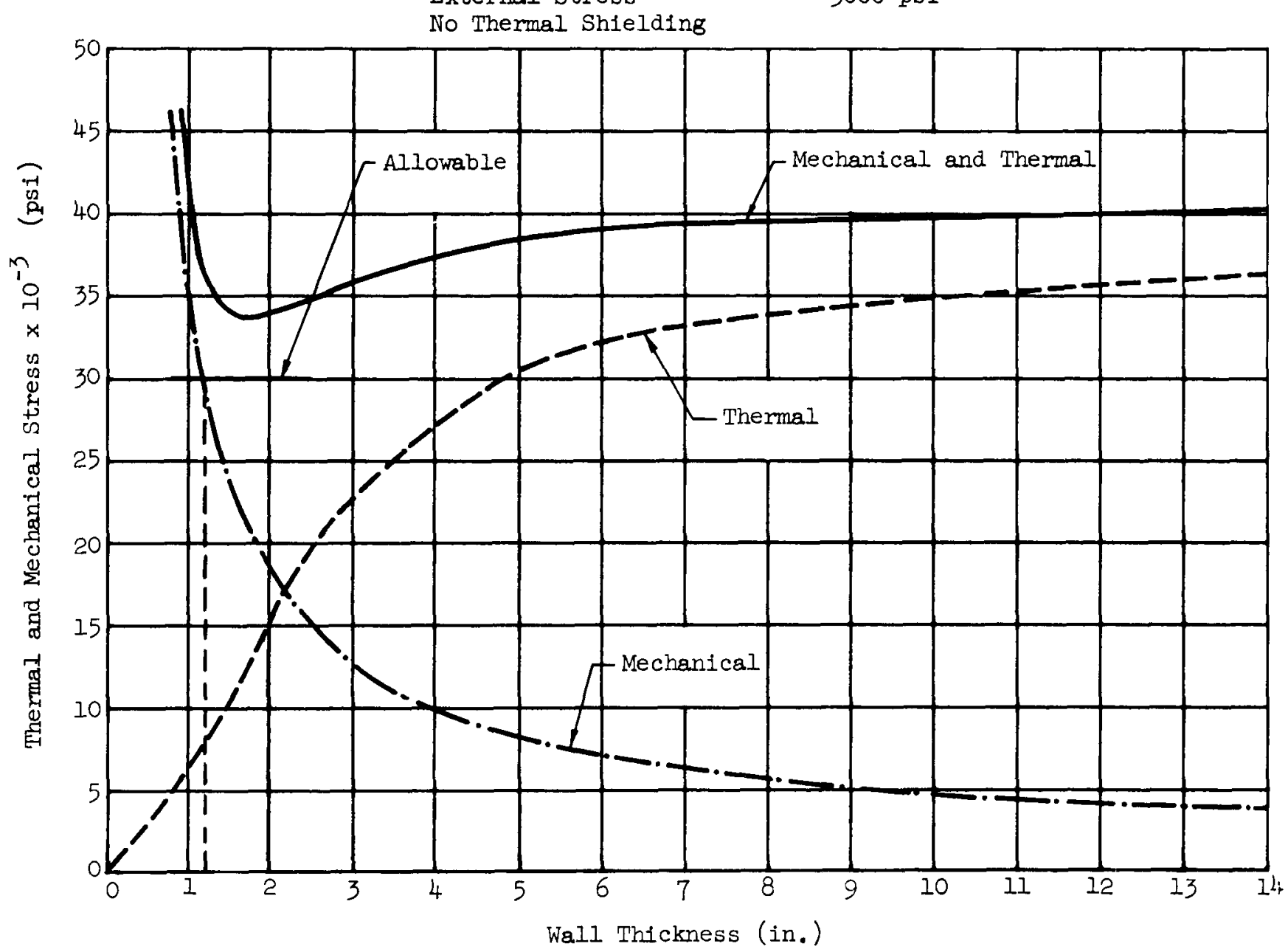

Fig. III-27. Thermal and Mechanical Stress as a Function of Water Gap for SA-302 B 
The following relations were used:

(1) Internal pressure stress + external stresses = total mechanical stress.

(2) Total mechanical stress $\leq$ allowable stress in the code.

(3) Total mechanical + total thermal stress $\leq 1.5$ allowable stress in the code.

The following assumptions were made during this investigation:

(1) SA-353 material

$$
\begin{aligned}
& E=25.4(10)^{6} \text { at } 600^{\circ} \mathrm{F} \\
& \mu=0.30 \text { at } 600^{\circ} \mathrm{F}
\end{aligned}
$$

Note: See list of nomenclature at end of report for definitions of terms.

(Values for SA-167, Grade 6, Type 347 and for SA-302B steels were available in the literature.)

(2) The static tension allowables given in the ASME Boiler Code apply to plates, no matter what the thickness (see Table III-5).

(3) It is permissible to use a design allowable of 1.5 times the static tension allowable when combining thermal stresses with mechanical stresses (Ref. 6).

\section{Table III-5}

Tension Allowables

Material

SA-167, Grade 6, Type 347

$\mathrm{SA}-302 \mathrm{~B}$

SB-127 (hot rolled Monel)

SB-168 (hot rolled Inconel)

SA -353
Static Allowables at $600^{\circ} \mathrm{F}$

14,900 (Ref. 1, p 94)

20,000 (Ref. 1, p 74)

17,000 (Ref. 1, p 87)

$20,000(\operatorname{Ref} .1$, p 89)

22,500 (Ref. 1, p 74)

Two cases were considered:

\section{Case 1}

If external stresses (piping, fittings, etc.) are assumed to be zero, one-half the static tension allowable is used up by thermal stresses. 


\section{Case 2.}

If external stresses are assumed to be $3000 \mathrm{psi}$, the followinis is true:

For SA-167 Grade 6 Type 347 material, these stresses are allowable:

11,900 psi-mechanical loads

10,450 psi-thermal loads

For $\mathrm{SA}-3 \mathrm{O} 2 \mathrm{~B}$ material, these stresses are allowable:

17,000 psi-mechanical loads

13,000 psi-thermal loads

Only the tensile stresses at the inside surface were considered as they are maximum at this point.

Thicknesses of the vessel for various materials, external stresses, and water gaps were computed by the following formula:

$$
t=\frac{P R}{S E_{W}-0.6 P} \quad(\operatorname{Ref} .1, p 7, E q 1)
$$

Thermal stresses for the inside surface of the vessel where tension occur for the various materials, pipin; stresses, and water gaps were computed using the following formula:

$$
\delta_{h}=\frac{12 E_{\alpha} Q_{0}}{(1-\mu) K \beta^{2}}\left[1-\frac{1}{\beta^{t}}+\frac{1}{\beta^{t}}-\frac{\beta^{t}}{2}-\beta^{t}\right](\operatorname{Ref} .2, p 40, E q 20)
$$

\section{Discussion}

It is interesting to note that both the Monel and Inconel materials appear to be competitive with the alloy steels. Although SA-353 appears to be the most promising alloy steel, cladding difficulties were anticipated.

Allowing 3000 psi for external stresses and assuming that these stresses are local in nature, is believed to be a good approximation of the actual case. This results in a higher allowable thermal stress and reduced water gap, but also in a much thicker vessel.

The use of a thermal shield, as expected, tends to reduce the needed water gap (Fig. III-24). Lowering the internal pressure produce the same effect. (Fig. III-25).

Although final vessel design will depend on many variables, including the effects of radiation damage, the present study indicates that the use of austenitic stainless steel or nonferrous materials does not minimize required pressure vessel diameter to the extent possible using ferritic steels. The stainless steels and nonferrous materials do not, however, exhibit a nil ductility transition temperature. At high values of nvt, the nil ductility temperature of the 
ferritic steels is greatly affected (raised). Selection of the final pressure vessel material, required water gap, thermal shield and pressure vessel diameter must, therefore, await evaluation of other than mechanical and thermal stress effects.

\section{E. PRIMARY SYSTEM EQUIPMENT}

J. Beam

C. Smith

\section{Pressurizer}

The analysis of the pressurizer included the derivation of formulae for predicting pressurizer performance; for determining the design-to-operating pressure ratio; and for estimating the effect on pressurizer size, weight, and cost of changes in primary system pressure, volume, and mean temperature. The following simplifying assumptions were made:

(1) Heaters and spray nozzles were inoperative durins transients.

(2) Expansion and compression of the steam was isentropic.

(3) Expansion of the liquid in the pressurizer was isentropic.

(4) Pressurizer volume is equally divided between water and steam.

(5) Pressurizer water was saturated throushout.

(6) The loop mean temperature was $100^{\circ} \mathrm{F}$ below the saturation temperature of water in the pressurizer.

Using these assumptions, it was found that, under the same loop volume and temperature conditions, a pressurizer outsurge resulted in a pressure drop of only appruximately one-sixth of the magnitude of a pressurizer insurge. For this reason the remainder of the parametric study concentrated on the insurge behavior of the pressurizer.

The derivations of the expressions for predicting the performance of the pressurizer are shown in Appendix A. The changes in pressurizer volume and shell weights withvarious primary system operating and surge pressures were plotted as Fig. III-28. Since the weight and cost of the reactor vessel, steam generator, primary loop piping, etc., increase with an increase in design pressure, a value of 1.15 (design-to-operatind pressure ratio) was chosen as a good compromise between design conservatism and weight minimization.

The pressurizer size (or volume) was then plotted (Fig. III-29) versus operating pressure, assuming a primary loop volume of $75 \mathrm{cu} \mathrm{ft}$ and a mean temperature variation of $15^{\circ} \mathrm{F}$. Corrections for actual loop volume and mean temperature variation are linear (Fig. III-29). The weight of the pressurizer shell was calculated, assuming an $L / D$ of 3 , and the cost was found by multiplyinf weight by $\$ 2.70 / 1 b--a n$ average cost figure determined from previous price estimates. Results are presented in Fig. III-30. The discontinuity is due to changes in the size of the pressurizer flanges. 


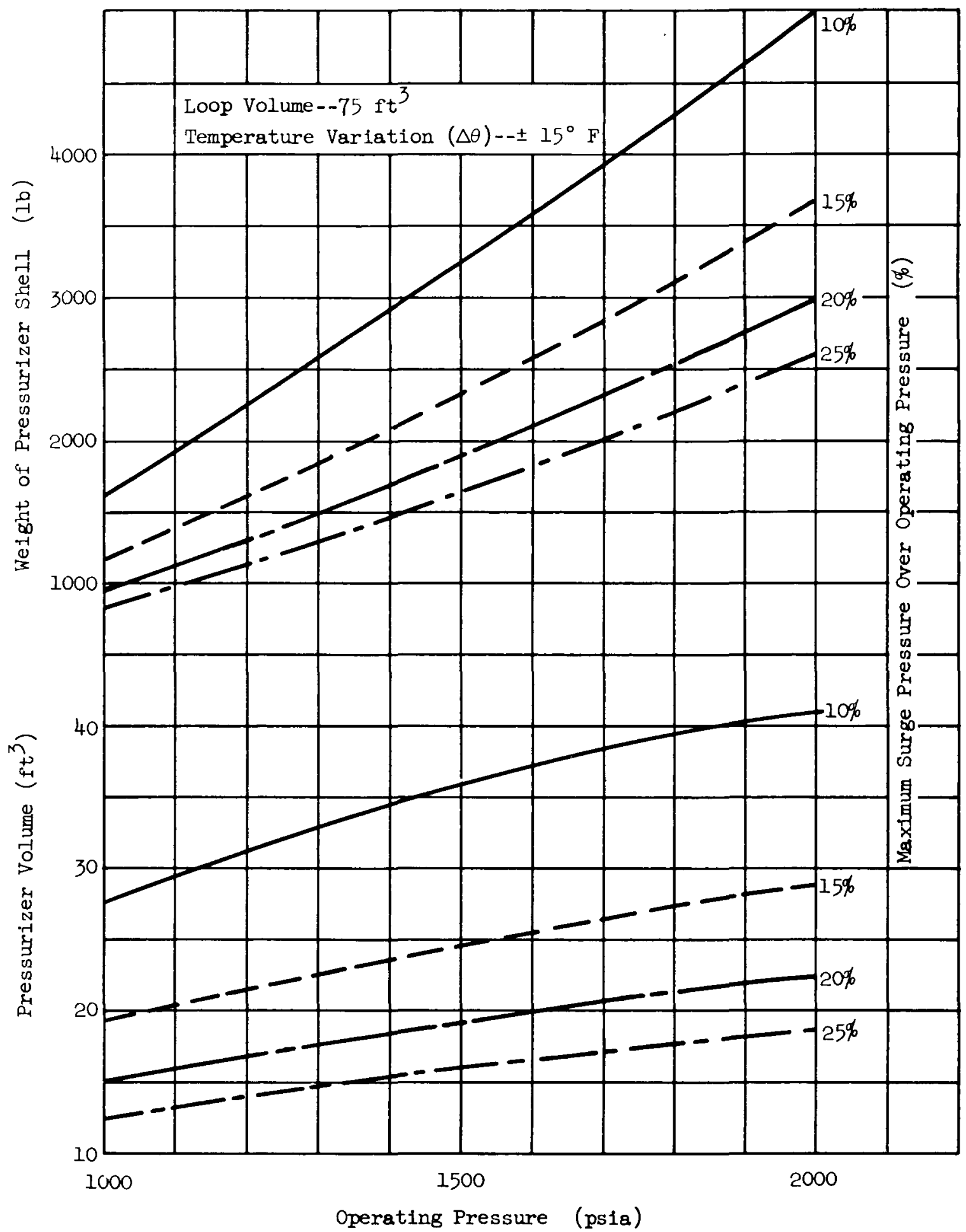

Fig. III-28. Pressurizer Size as a Function of Operating and Surge Pressure 

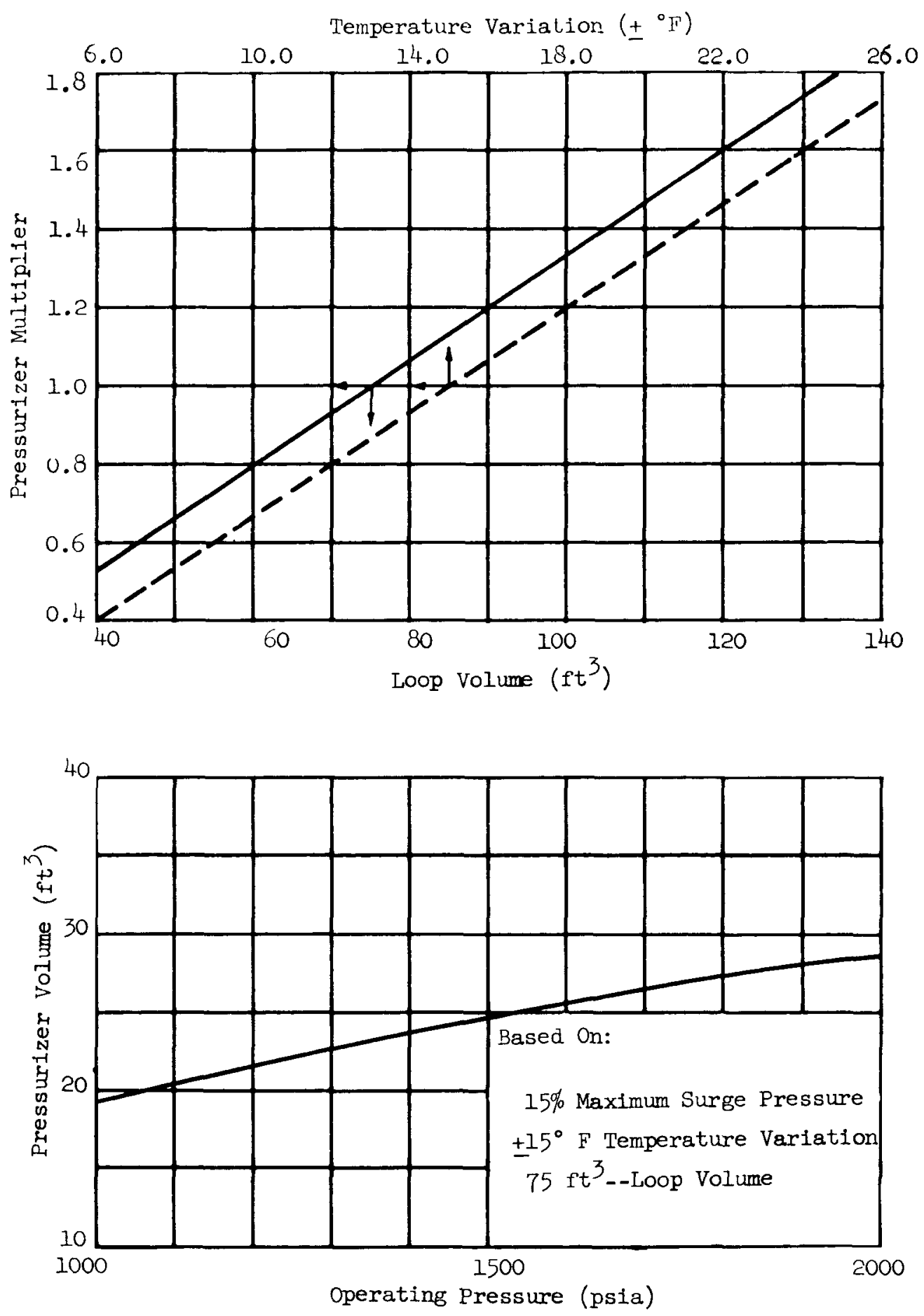

Fig. III-29. Pressurizer Size vs Operating Pressure, Loop Volume and Temperature Variation 


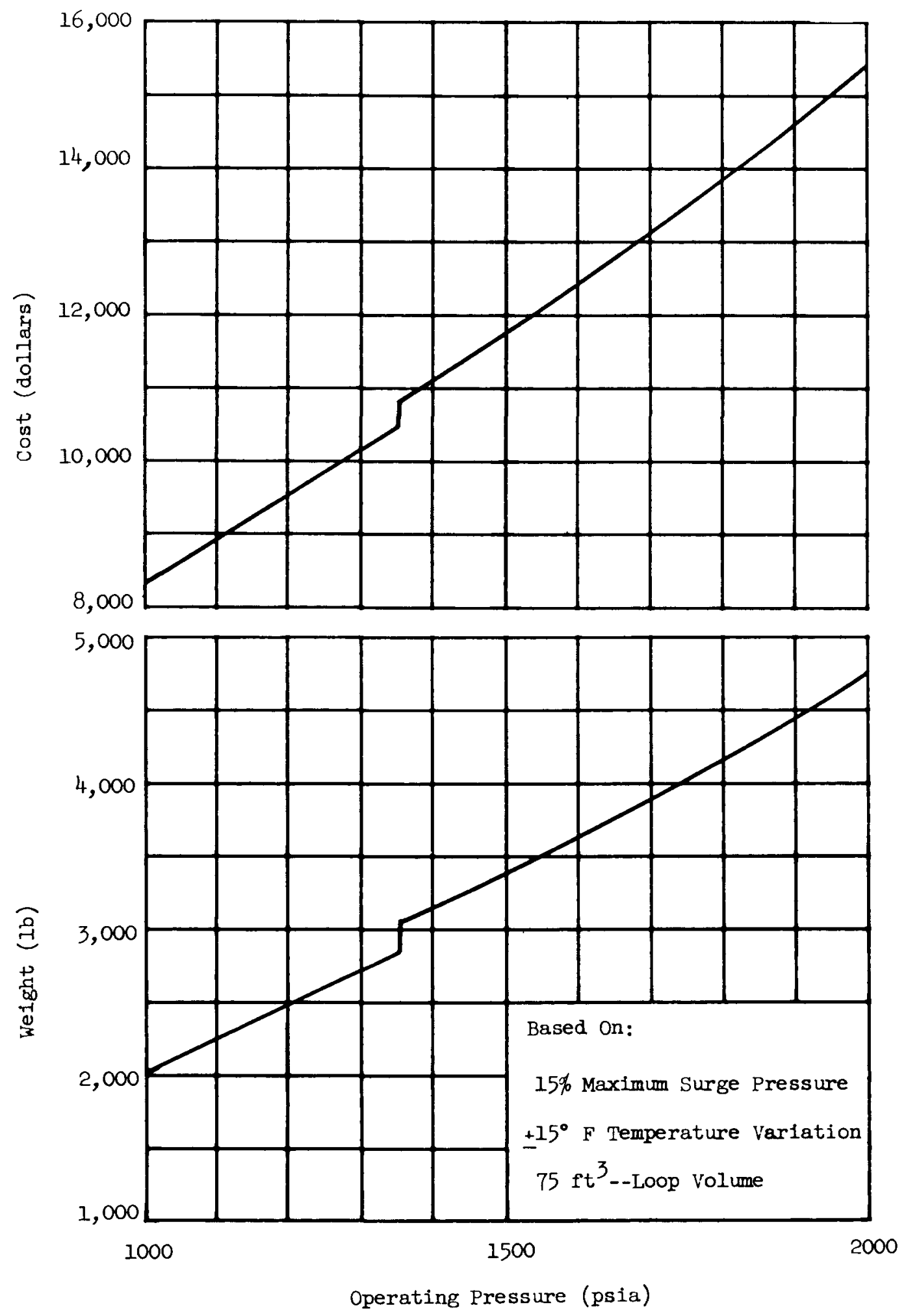

Fig. III-30. Pressurizer We1ght and Cost vs Operating Pressure 


\section{Reactor Vessel}

For parametric study purposes, a reference design reactor vessel consisting of a right circular cylinder with a hemispherical end and flat flanged head was used. The vessel was assumed to be constructed of ASTM Type A 303, Grade B, clad with AISI Type 304L stainless steel. (Allowable workin stress for this material is 20,000 psi at operating temperature.)

The size and weight of the vessel werecalculated for various values of internal diameter, core height and system operating pressures. The cost was calculated using as a basis a vendor-proposed price of $\$ 2.80 / 1 \mathrm{~b}$ for the referenced design reactor vessel. The results are shown in Fig. III-3I.

\section{Primary Coolant Pump}

For parametric study purposes, it was assumed that one primary coolant circulating pump would be required. Information obtained from vendors on the canned motor, mechanical seal, and controlled leakage types of pumps was used to make comparisons which are here tabulated:

\section{Canned Motor}

Cost

Weight

Overall

efficiency

Operating pressure

Size range

\section{Mechanical Seal}

$60 \%$ of comparable canned unit

Increases $500 \mathrm{lb}$ over canned unit

$70 \%$

Complete pressure 1500 and below

Approx length-$4 \mathrm{ft}$ Approx diameter-15 in.

\section{Controlled Leakage}

$75 \%$ of comparable canned unit Increases 2000 Ib over canned unit

$70 \%$ (approx $10 \mathrm{kw}$ required for pressurizing purmp)

2500 and below

Length will increase 2 ft over canned unit. Additional $2 \times 3$ ft space required for pressurizing purmp

The canned motor and mechanical seal type pumps were used in the parametric study. Due to the additional weight and space requirements of the controlledleakage pump, and the increased operational problem, the use of this type of pump was not considered. The break-point between the canned motor and mechanical seal pumps is arbitrarily taken at 1500 psia operating pressure. Therefore, for pressures below $1500 \mathrm{lb}$, only a mechanical seal-type unit was considered; for pressures above $1500 \mathrm{lb}$, only a canned motor unit was considered. Experimental data were available from the mechanical seal pump vendor which indicated that operating pressures of up to 2500 psia were feasible; however, a conservative approach was taken and the maximum value was limited to 1500 psi.

A break-point in pump weight occurs at a system head of approximately 130 ft. At this point, the transition is made from a four - to a two-pole motor representing a reduction in unit weight of approximately $40 \%$. 


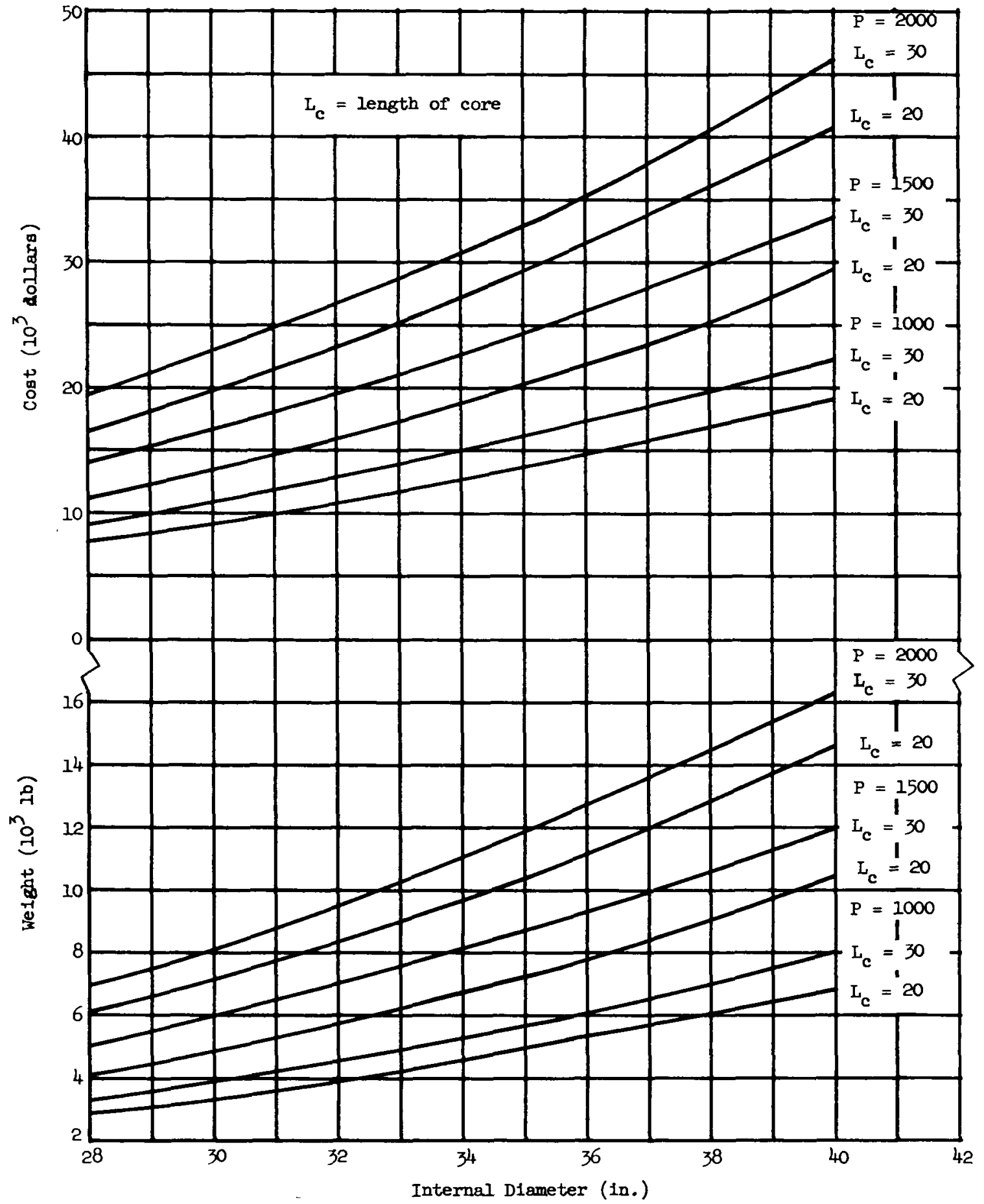

Fig. III-31. Reactor Vessel Weight and Cost Varlation 
Figures III-32 and III-33 show the cost and weight of canned motor pumps for various flow rates, system heads, and system operating pressures.

4. Auxiliary Systems

A study was made of the variation of auxiliary system cost and weight with system pressure. Included in the study were the following systems: primary coolant purification; primary coolant blowdown; shield water; heat ejection from the steam pressurizer blowoff; and storage and purification of liquid waste. Cost and weight data for stainless steel piping, fittinss, and valves in sizes from $1 / 4$ to 2 in. were obtained from vendors.

Results of the study are presented in Fig. III-34, which shows that the variation in auxiliary system weight and cost is small. This finding has been confirmed by similar stud res made by the Gibbs and Hill Company .

\section{Primary Loop Piping}

A study was made of the variation of primary loop piping weight, cost and head loss with system flow and operating pressure. The study, which considered 5-, 6-, and 8-in. pipe, was based on the following conditions:

(1) Material is stainless steel, Type 304.

(2) Fifty feet of seamless pipe is used.

(3) There are 12 long sweep elbows.

(4) There are five flanged connections.

(5) Design pressure is $15 \%$ above the operating pressure.

(6) Maximum allowable stress is $15,000 \mathrm{psi}$. (ASA Code for pressure piping.)

(7) The corrosion allowance is 0.065 in.

(8) The friction factor is 0.012 in.

(9) Maximum fluid velocity is 30 fps.

The cost and weight of the piping was plotted versus system operating pressure in Fig. III-35. The head loss of the piping versus flow rate appears in Fig. III-36 which shows that for flows up to about 2500 gpm a 6-in. pipe can be used without exceeding $30 \mathrm{fps}$ maximum velocity. For flows below $1700 \mathrm{gpm}$, a 5 -in. pipe could be used without exceeding $30 \mathrm{fps}$. However, in most instances where a choice could be made between 5- and 6-in. pipe, it was found that, in the interest of reduced capital investment and pumping power, it was more economical to use a 6-in. pipe size.

\section{Reactor Pressure Drop}

The reactor pressure drop from the inlet flange to the outlet flange versus flow was calculated for local boiling and nonlocal boiling cores. For both types 


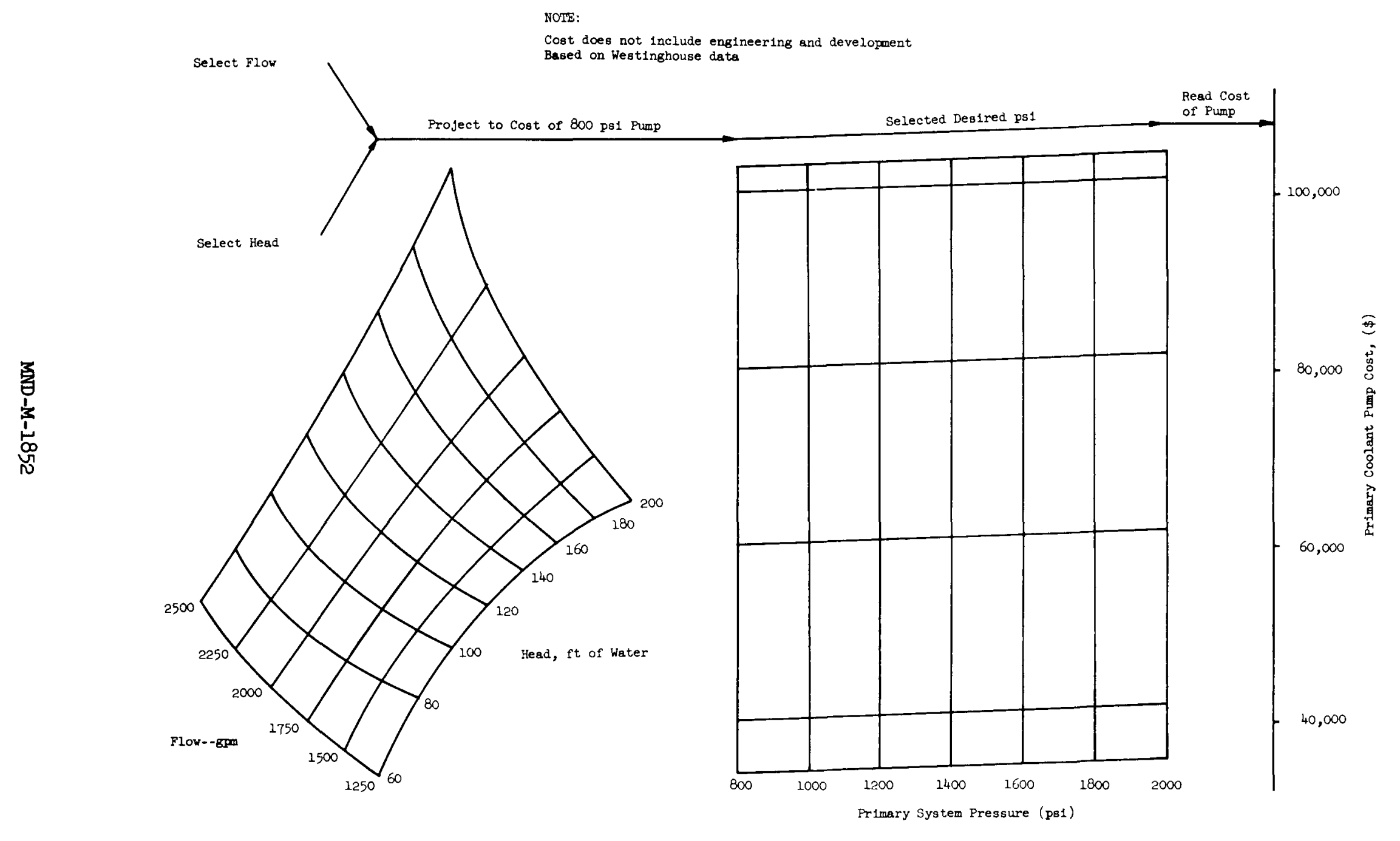

Fig. III-32. Primary Coolant Pump Cost as a Function of System Flow, Head, and Pressure--Canned Motor 


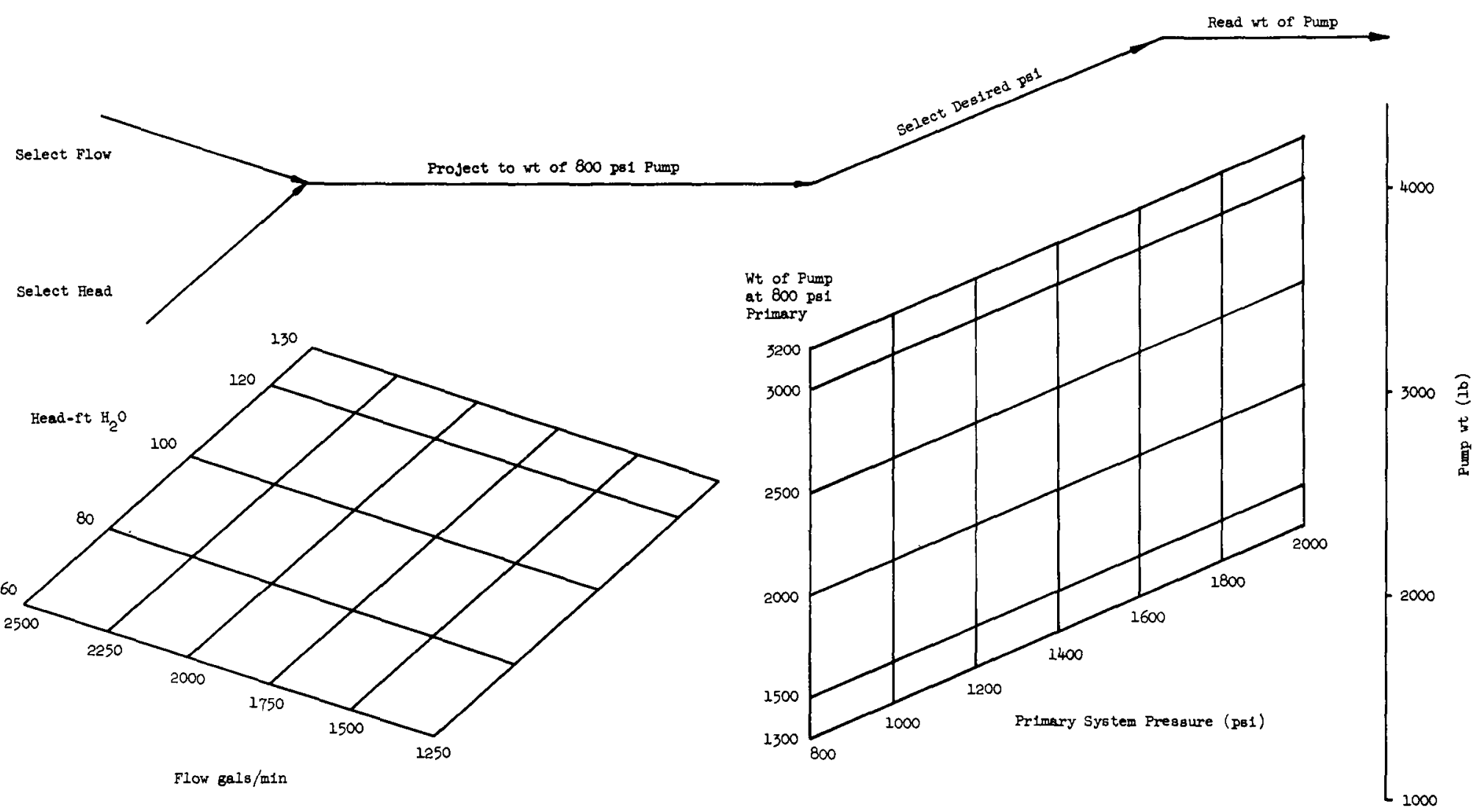

Fig. III-33. Primary Pump Welght as a Function of System Flow, Head, and Pressure--Canned Motor 


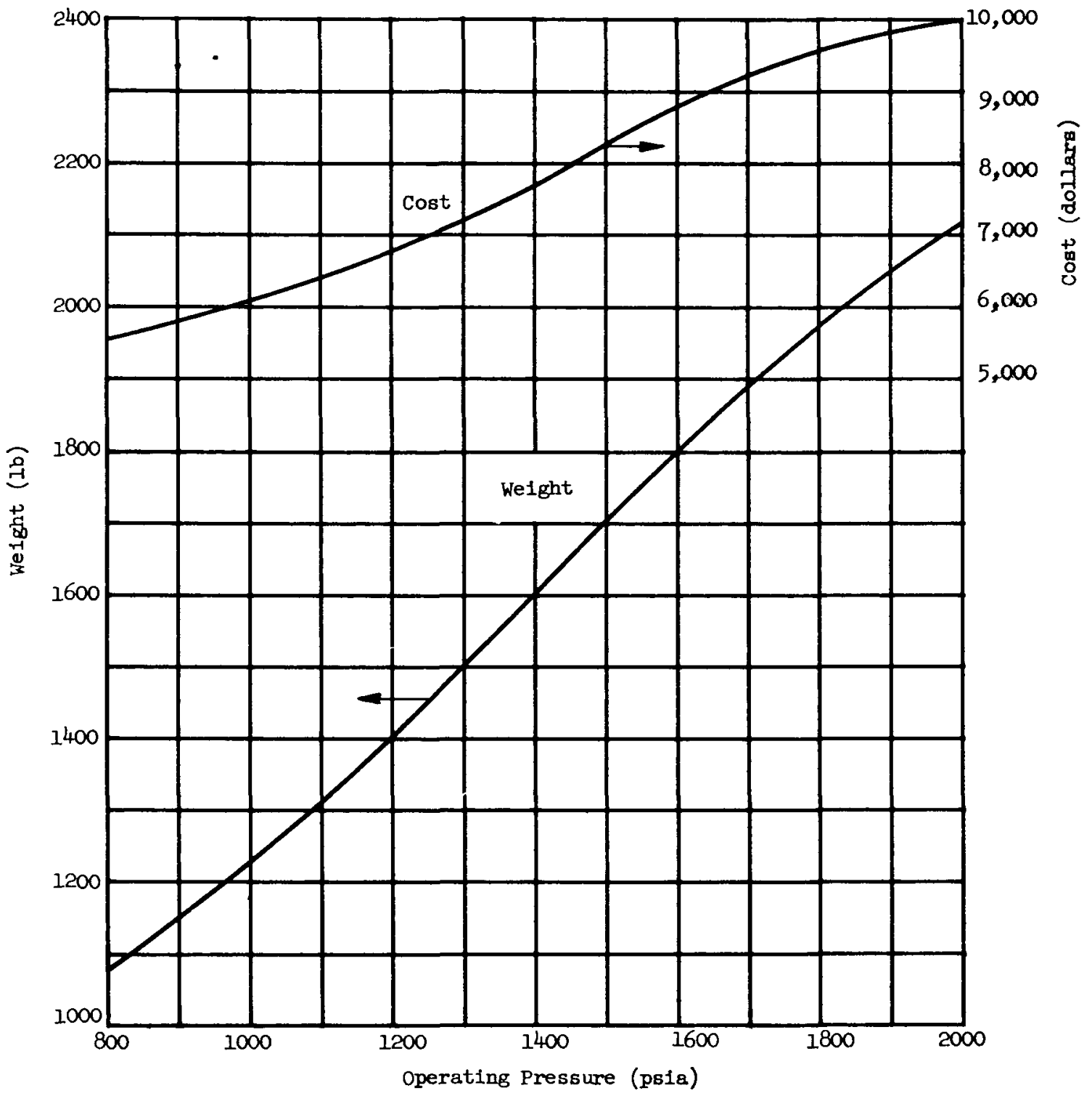

Fig. III-34. Primary Auxiliary Systems Weight and Cost vs Operating Pressure 

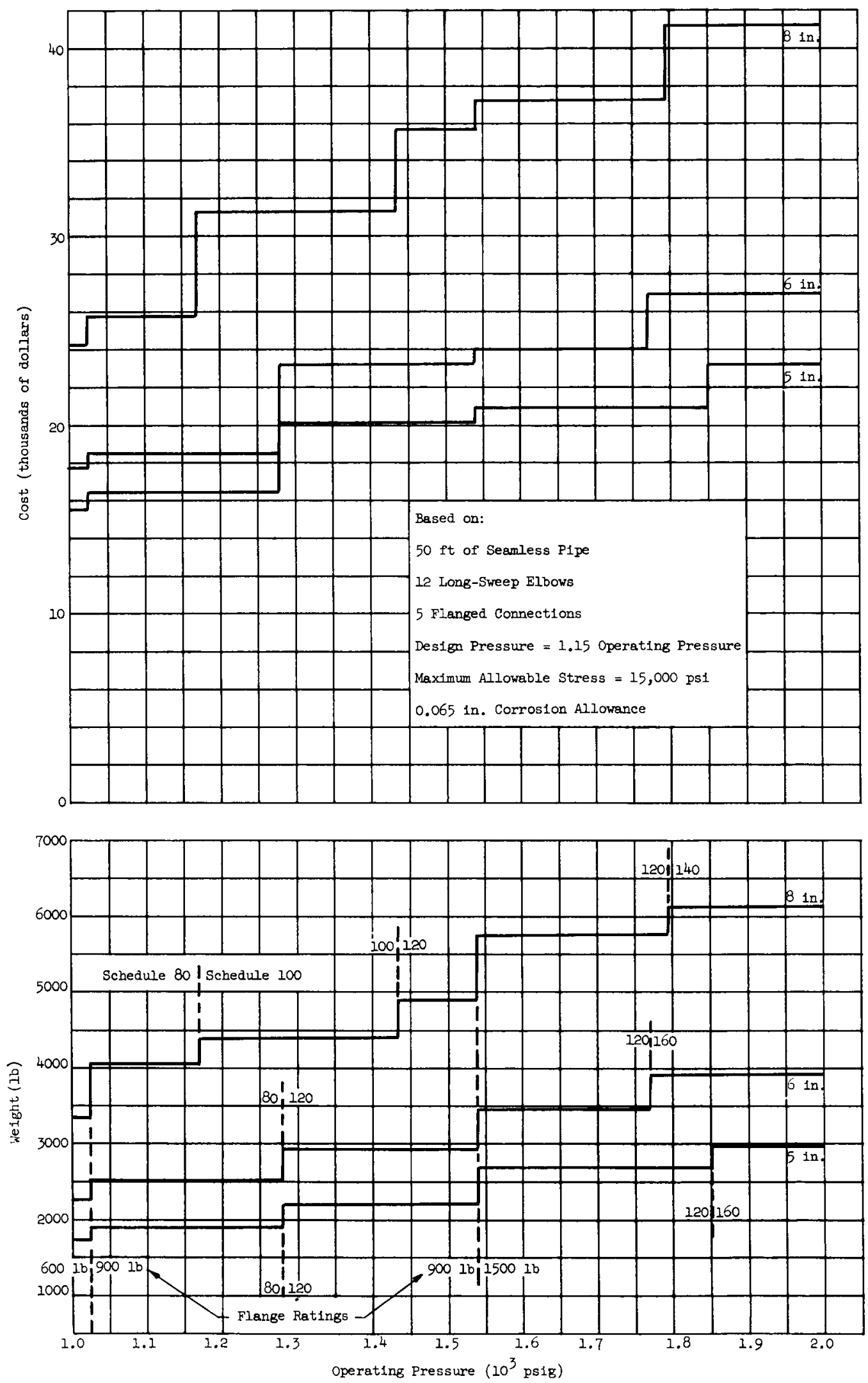
Fig. III-35. Primary Coolant Piping Weight and Cost as a Function of Operating
Pressure and P1pe Size 


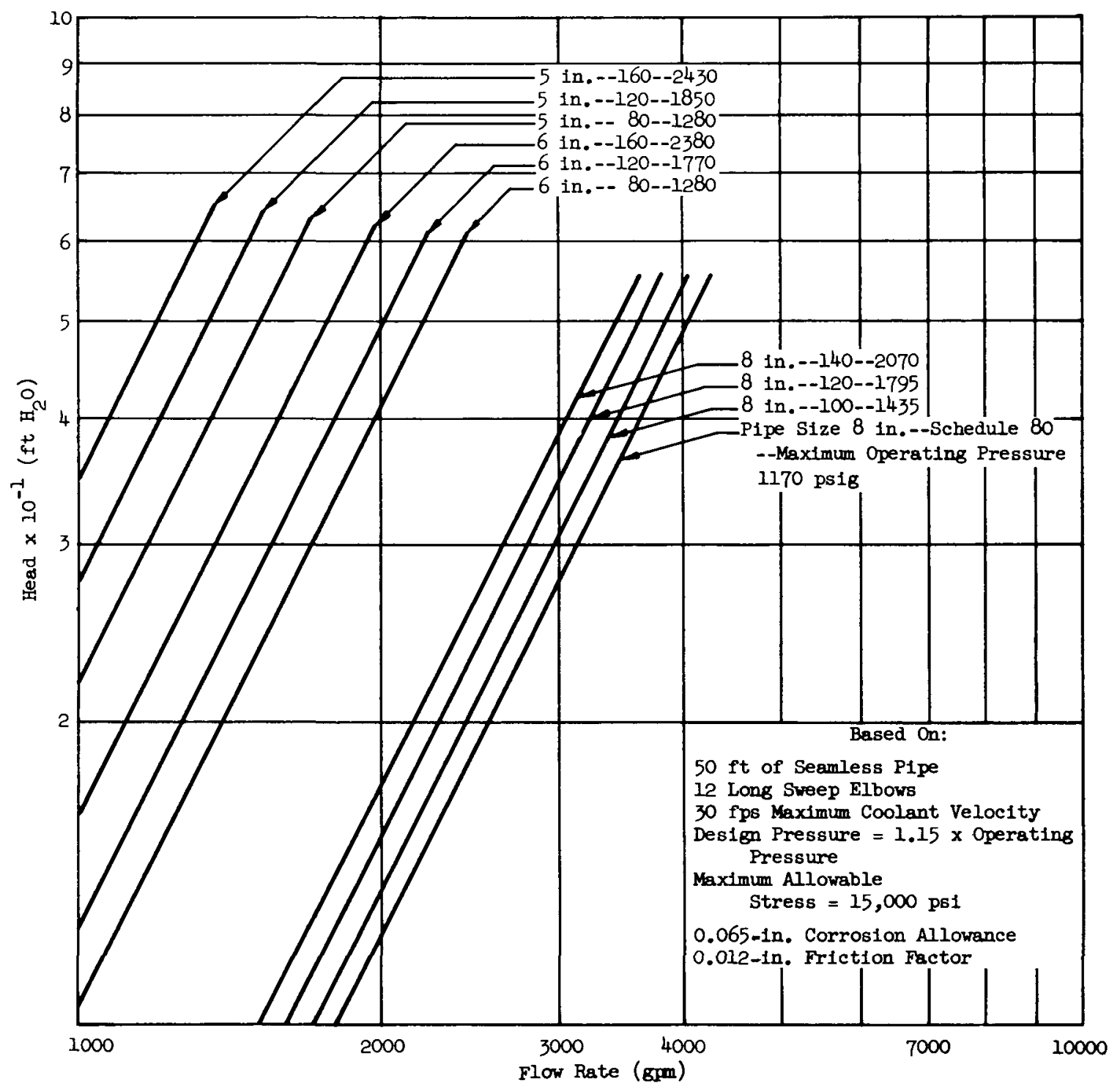

F1g. III-36. Primary Loop Coolant P1ping Head Loss as a Function of Flow Rate, Operating Pressure and Pipe Size 
of core, the portion of the pressure drop due to frictional losses is small (approx 10\%) and the major portion is due to contractions and expansions of the fluid.

The calculated pressure drop for the reference design nonboiling (two-pass) core was $11 \mathrm{psi}$ at $2000 \mathrm{gpm}$. This calculated value is in close agreement with values obtained experimentally in the laboratory. Since the major portion is due to contractions and expansions, the nonboiling two-pass core pressure drop was approximated by taking the ratio of the flows squared times the reference design drop of 11 psi.

The reactor pressure drop for a nucleate boiling single-pass core was approximated by taking two-thirds of the drop for a nonboiling core with the roxsame flow rate.

Results of this analysis are shown in Fig. III-37.

\section{System Head and Pumping Power}

The system head was determined by taking the summation of the reactor, primary piping, and steam generator pressure drops.

The piping, reactor, and steam generator pressure drops are shown in Figs. III-36, III-37 and Fig. IV-16 of Chapter IV, respectively.

Pumping power is calculated based upon a hot startup condition, since standby power will be provided for plant startup.

\section{Primary System Weight Study}

A study was made to estimate the shipping weight of the primary system, excluding packaging and the steam generator. The system was broken down into the categories of fixed and variable weight components. Fixed components are those whose weight essentially does not change with variations in primary system pressure. All the components were also located in one package of a two-package primary loop system. Figure III-38 shows the component weight (fixed plus variable) per package. Table III-6 lists the main components contained in each package.

Figure III-39 shows the effect upon primary system weight of variations in primary system pressure and flow.

\section{Table III-6}

Package Components

\section{$\underline{\text { Package A }}$}

Actuators

Vessel Head

Thermal Shield

Purification Cooler

\section{Package B}

Charging Pumps

Pressurizer (variable wt)

Primary Purm (variable wt) 


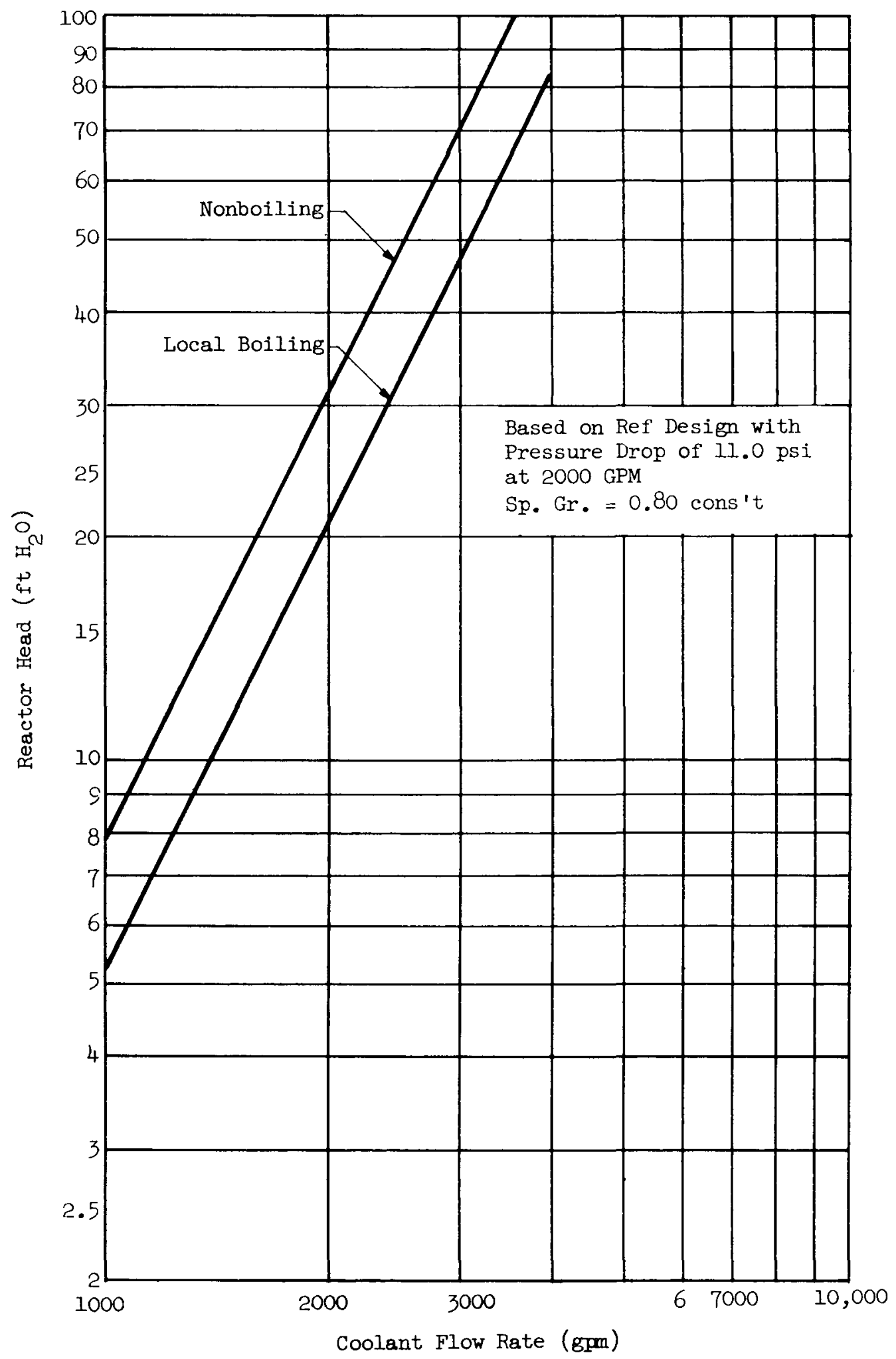

Fig. III-37. Reactor Head Loss as a Function of Coolant Flow Rate and Heat Transfer Mode 
Package A

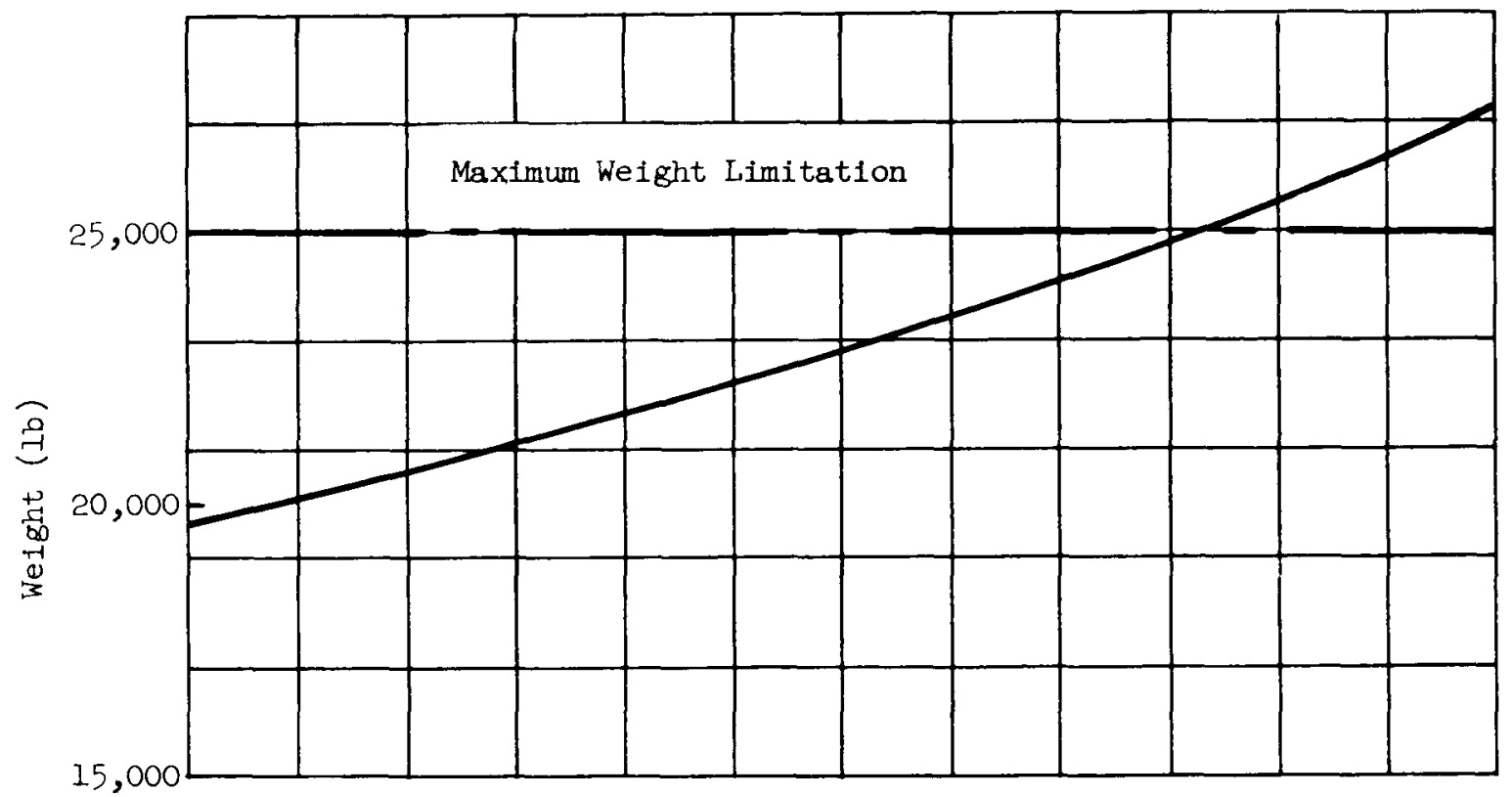

Package B

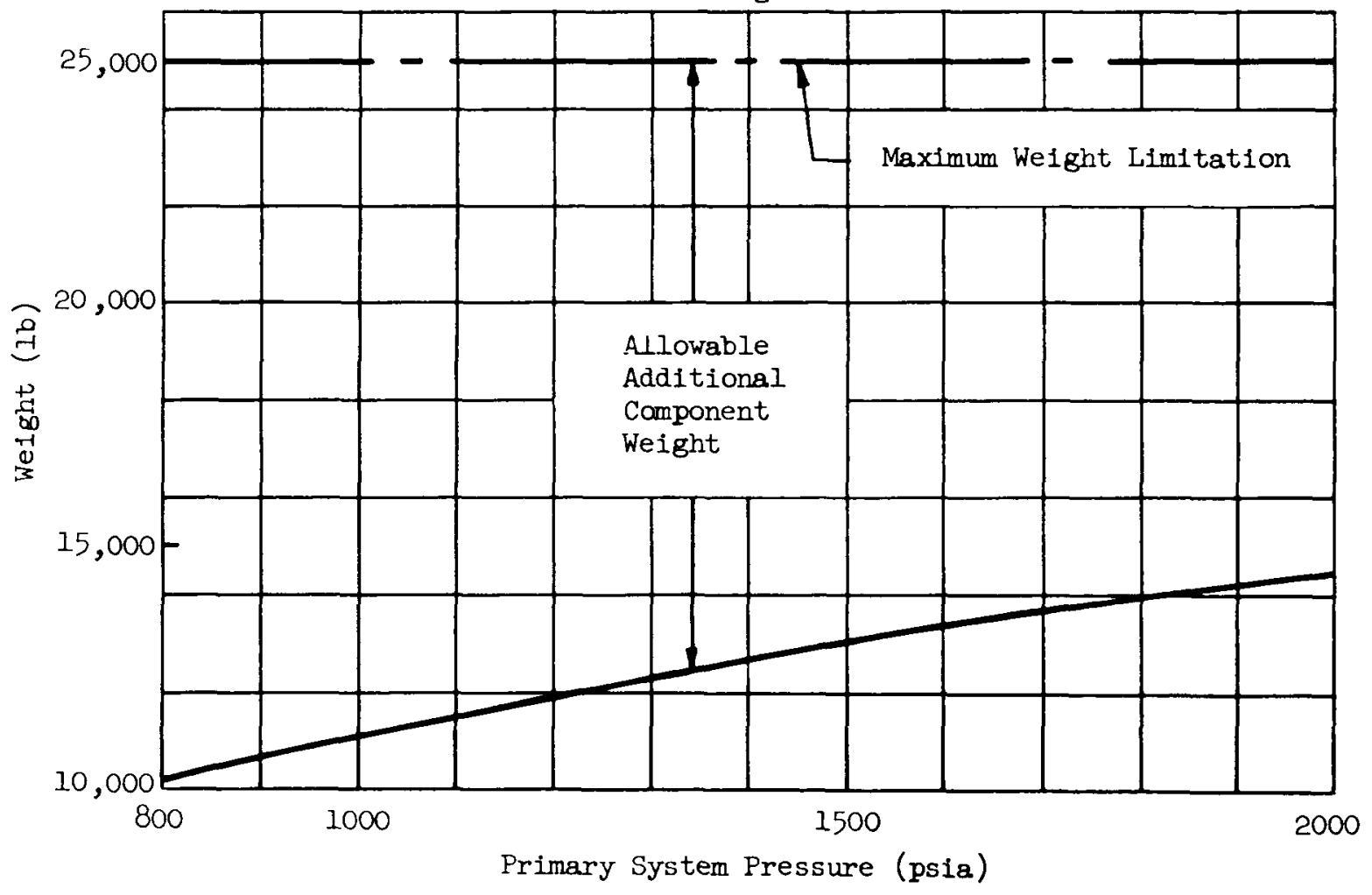

Fig. III-36. Primary System Component Weight as a Function of Pressure 


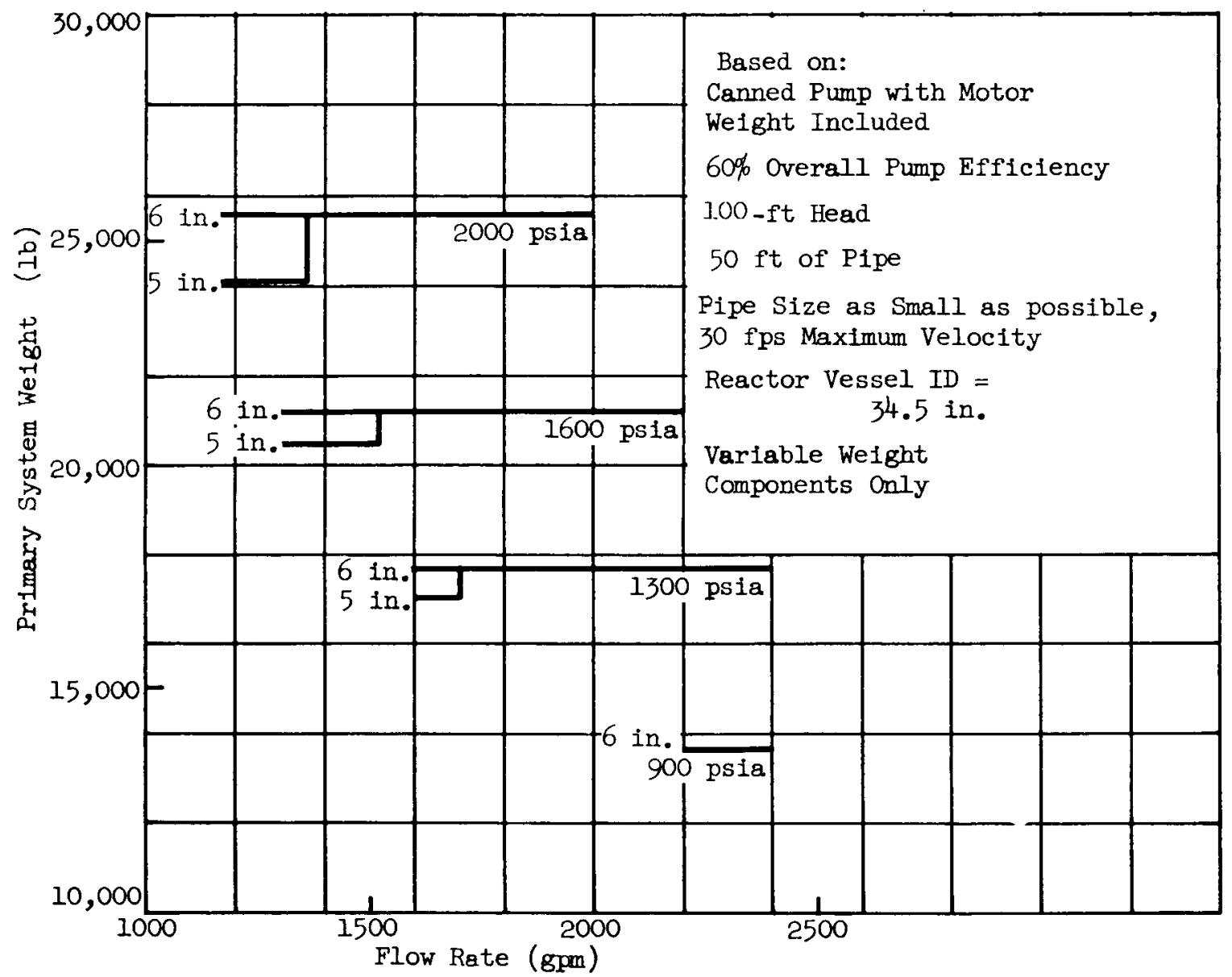

Fig. III-39. PM-1 Primary System Weight as a Function of Flow Rate and Pressure 
Table III-6 (continued)

Primary Piping (variable wt)

Auxiliary Systems (variable wt)

Primary Piping (variable wt)

Reactor Vessel (variable wt) 
Project Engineer: C. Fox

\section{A. SCOPE OF STUDY}

The PM-1 contract requires that the plant produce 1000 kwe net and $7 \times 10^{6}$ $\mathrm{Btu} / \mathrm{hr}$ in the form of low-pressure steam for process heat. The plant is to be capable of operating at ambient conditions of -60 to $70^{\circ} \mathrm{F}$ and of rejecting cycle heat to the atmosphere.

Based on previous experience, the auxiliary electrical power requirement for this plant was estimated at 250 kwe. For the purposes of the parametric study, a gross output requirement of 1250 kwe was assumed.

Inasmuch as pressurized water systems are well understood at this time, it was possible to establish several ground rules early in the study, namely:

(1) Secondary systems for pressurized water plants are of practical interest over the steam pressure range from 200 to 600 psia. Although steam at pressures below 200 psia is easy to produce, very inefficient cycles result. Also, the large volumetric steam flow associated with the lower pressures results in increased turbine size and weight. Steam pressures above 600 psia result in excessive primary loop temperatures (correspondingly excessive pressures) and require expensive and heavy primary loop equipment such as piping, pressure vessels, etc.

(2) The requirement that cycle heat be rejected to the atmosphere necessitates the use of higher turbine back pressures than are normally used with conventional water-cooled surface condensers. It was found, based on past experience, that turbine back pressures below 6 in. Hg abs (saturation temperature--141 $\mathrm{F}$ ) result in either excessively large aircooled heat exchangers or exorbitant fan power requirements for a $70^{\circ} \mathrm{F}$ ambient condition. It was also found that, with an intermediate fluid such as ethylene glycol in the condenser system, an economically-sized, reasonably-priced, condenser system could be designed to operate at a back pressure of $11.5 \mathrm{in.} \mathrm{Hg}$ abs. In view of these considerations, a turbine back pressure range of 6 to $11.5 \mathrm{In}$. $\mathrm{Hg}$ abs was established for study purposes.

(3) The production of substantial amounts of superheated steam by a pressurized water reactor system is not considered feasible. This is due to two factors: first, the relatively low temperatures avallable do not provide sufficient superheating to improve the cycle efficiency enough to justify the increased size and cost of the steam generator; second, steam generator moisture separators have been developed to a point where steam of $1 / 4$ to $1 / 2 \%$ moisture content can be guaranteed, thereby eliminating the moisture problem without superheating.

(4) It was found that a single-extraction secondary cycle with one closed heater is economical. Because of this fact, plus the size limitation of the PM-1 turbine, a single extraction was the maximum deemed feasible. 
Secondary system studies were divided into six sections:
(1) Turbine-generator studies
(2) Condenser studies
(3) Cycle studies
(4) Power quality studies
(5) Steam generstor studies
(6) Summary of equipment selection.

\section{B. TURBINE-GENERATOR STUDIES}
W. Koch
R. Groscup
L. Hassel

With the establishment of the gross electrical output of 1250 kwe for the PM-1 plant, the question of which size turbine-generator would be most suitable for this application was investigated. Both full- and one-half- capacity machines were studied using standard and oversized generators (see Section IV-E).

Figures IV-I, IV-2 and IV-j show some of the representative heat balances studied. Figure IV-1 shows the heat balance for a 1250-kw turbine, zero extraction, cycle cycle operating at 500 psia steam pressure and 9 in. Hg abs back pressure. Figure IV-2 shows the heat balance for a similar unit but with extraction.

F1gure IV-3 shows a two-turbine (625 kw each) cycle, with no extraction, operating at 200 psia steam and $11-1 / 2$ in. Hg abs back pressure.

The results of the heat balance studies for the three systems are plotted in Figs. IV -4, IV-5, and IV-6 as steam inlet pressure versus the steam generator thermal output required to generate required power at three turbine exhaust back pressures.

As expected, the most efficient cycle is the system using a 1250-kw turbine generator set with extraction to a closed feed water heater. The two-turbine cycle without extraction is the least efficient.

Table IV-I shows the weights of the various machines investigated. 


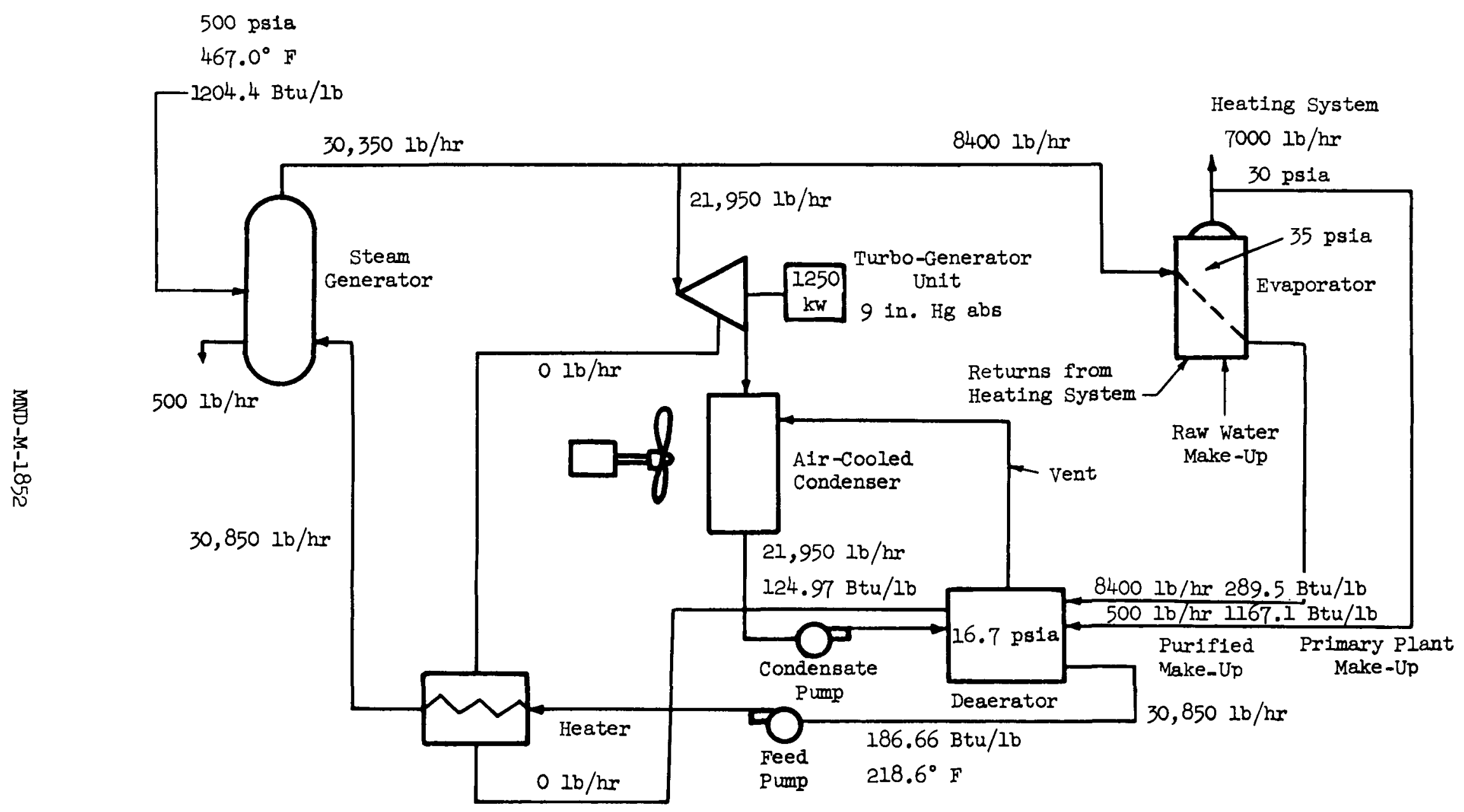




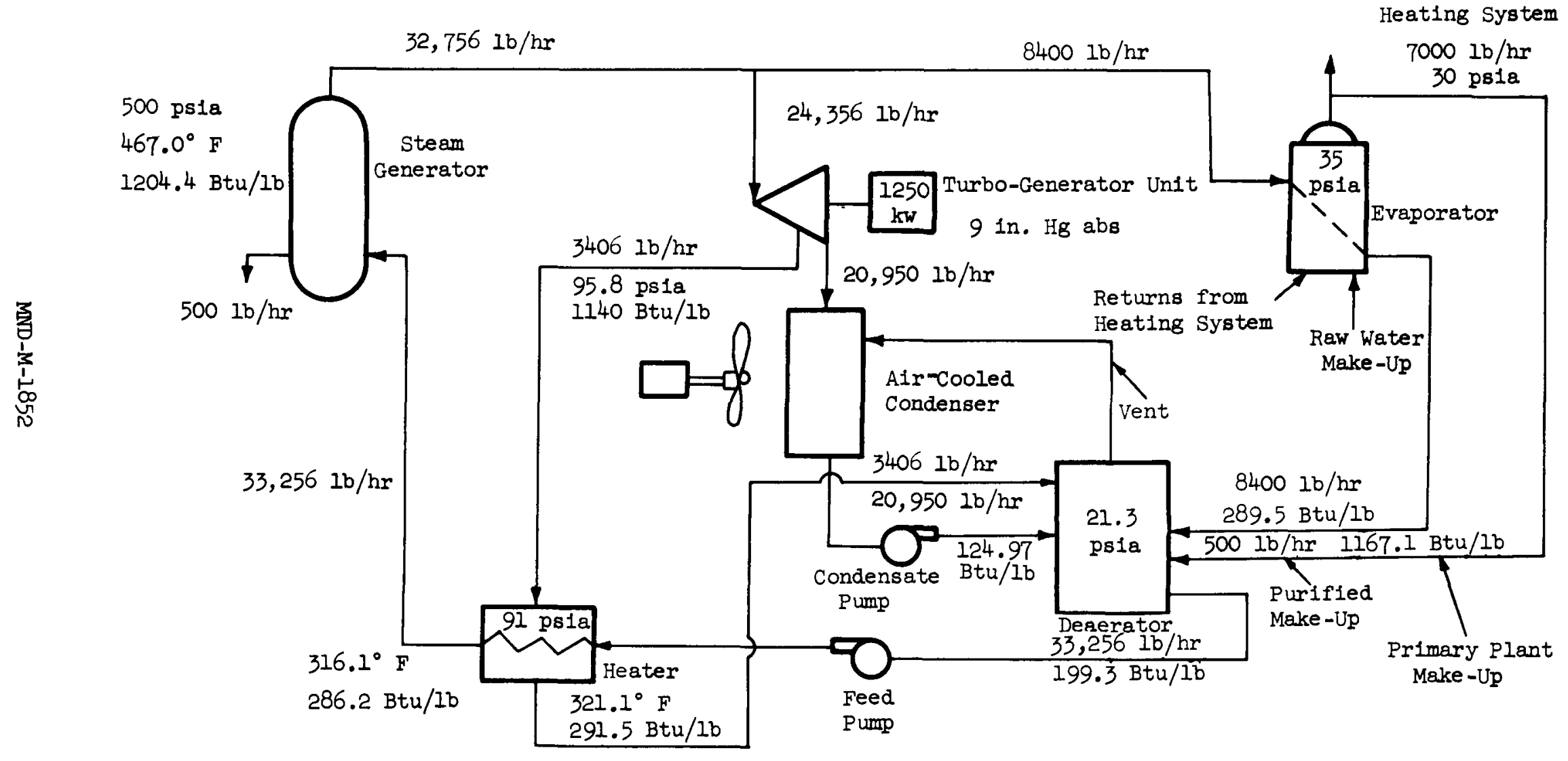

Fig. IV-2. Geared Turbine Generator Basic Heat Balance Extraction Unit 


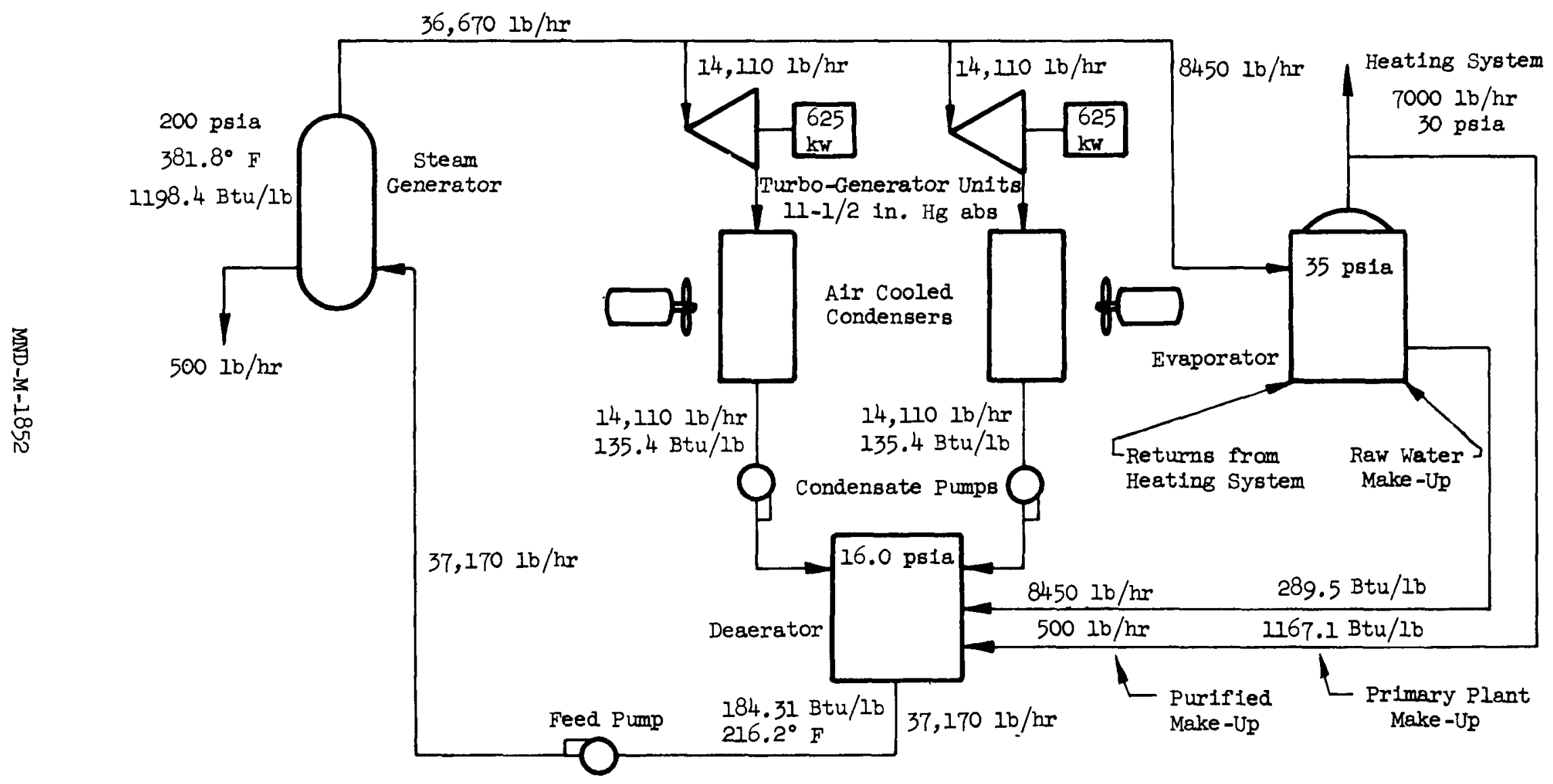

F1g. IV-3. Geared Turbine-Generator Basic Heat Balance 


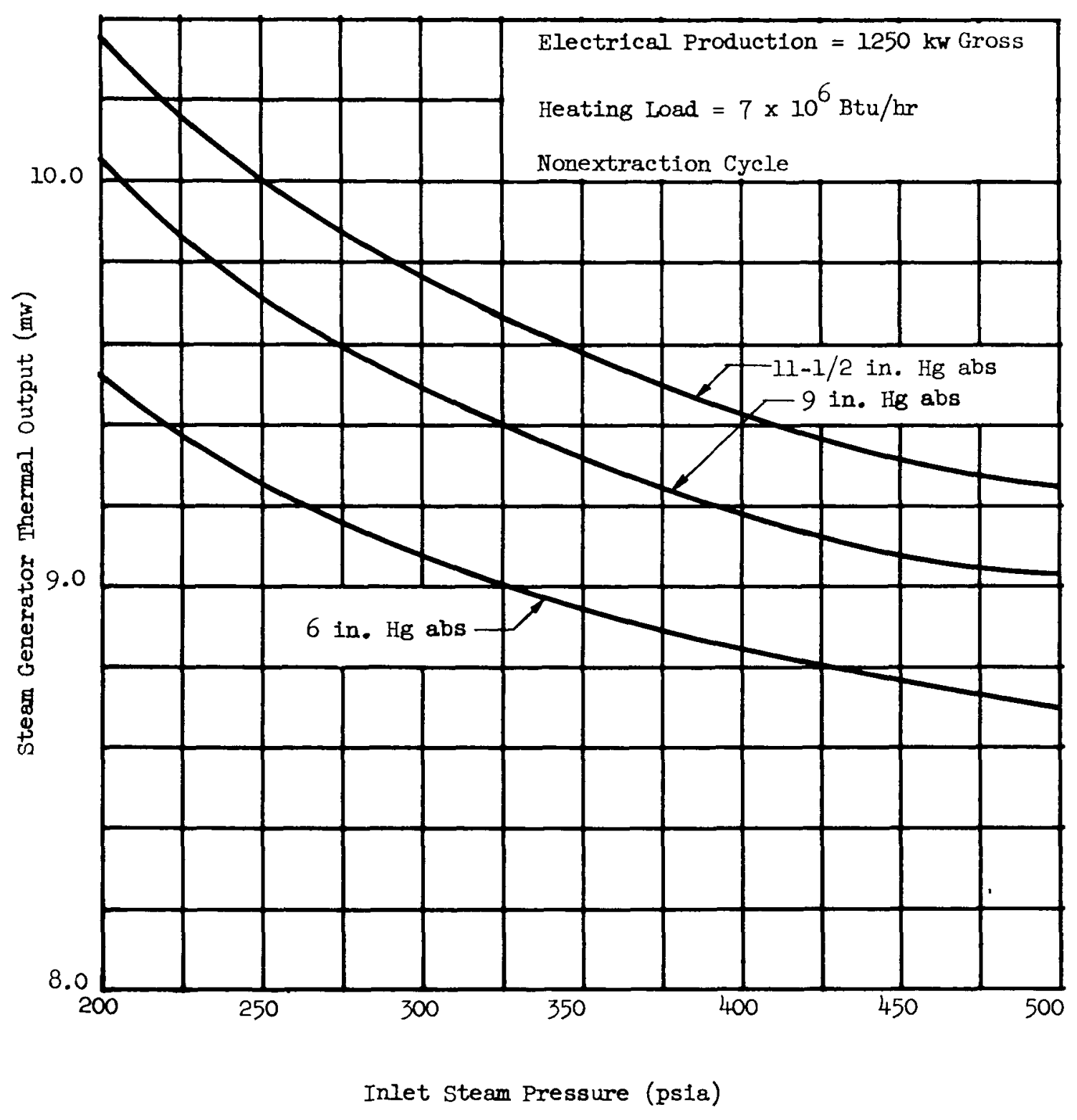

F1g. IV-4. Steam Generator Thermal Output as a Function of Inlet Steam Pressure and Exhaust Pressure--1250 kw Geared Turbine-Generator 


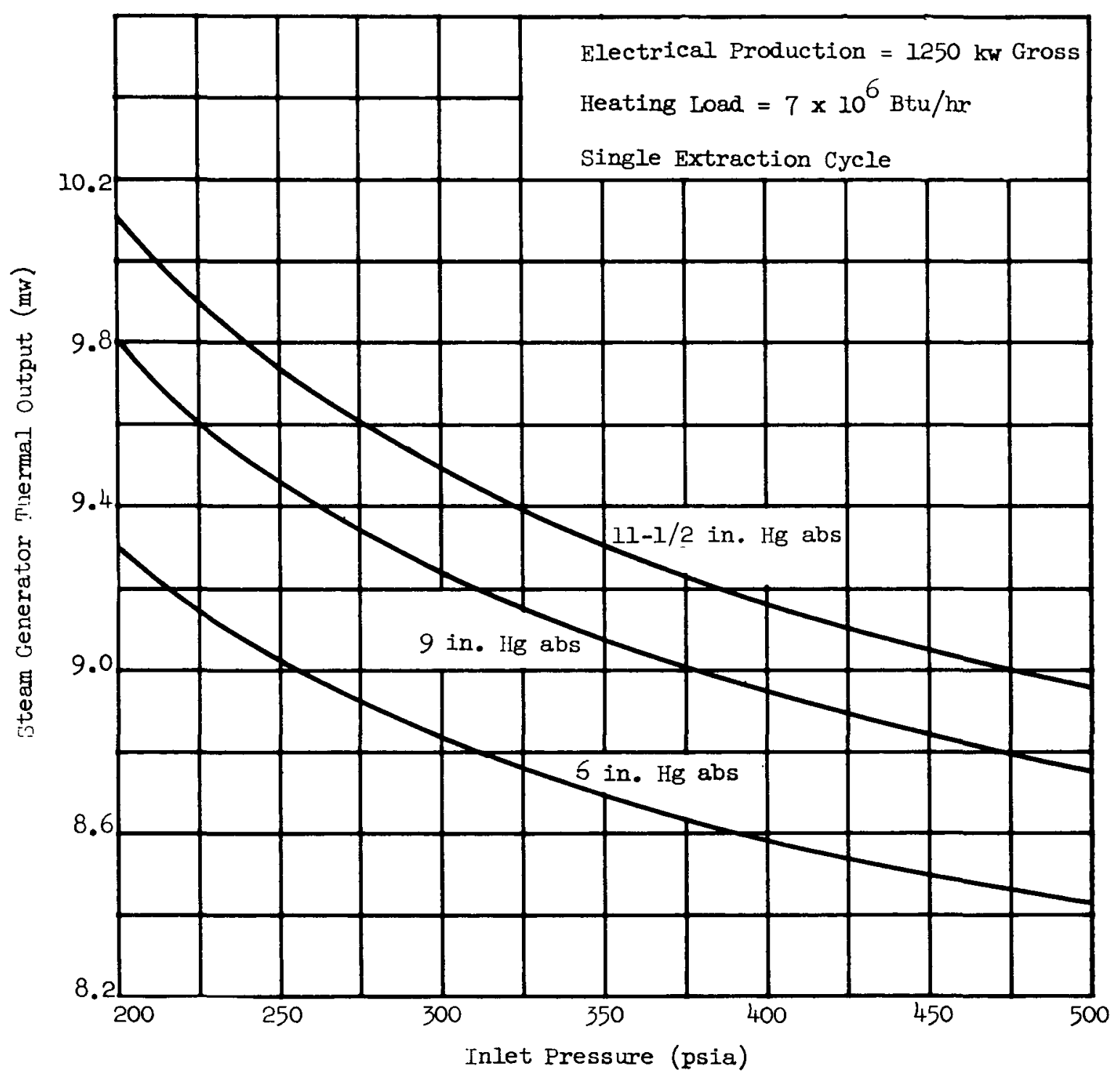

Fig. IV-5. Steam Generator Thermal Output as a Function of Inlet Steam Pressure and Exhaust Pressure--1250 kw Geared Turbine-Generator 


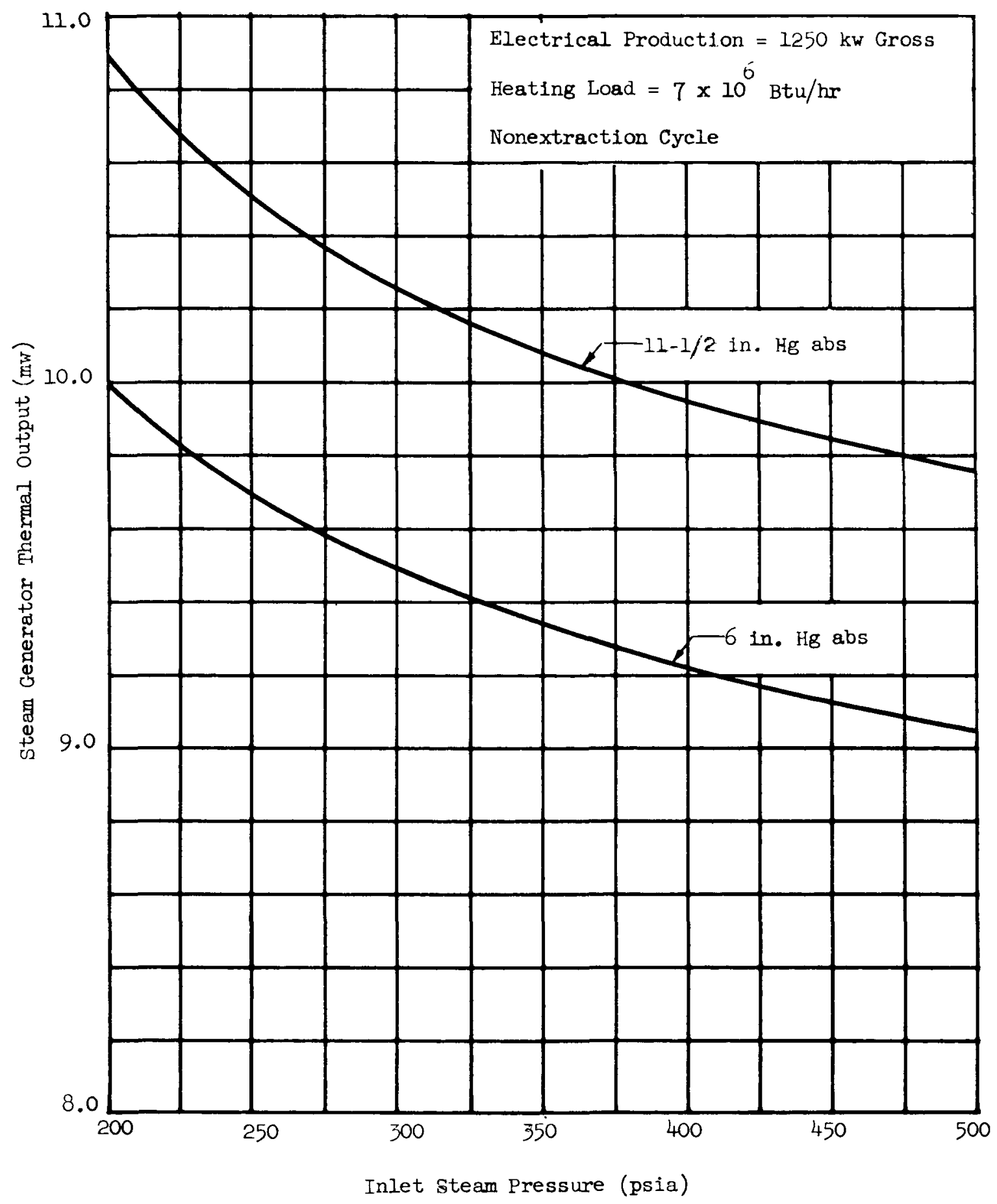

F1g. IV-6. Steam Generator Thermal Output as a Function of Inlet Steam Pressure and Exhaust Pressure--625 kw Geared Steam Turbine-Generator 
TABLE IV-I

60-Cycle Turbine-Generator Weights

$\begin{array}{ccccccccc}\begin{array}{c}\text { Rating } \\ (\mathrm{kW})\end{array} & \begin{array}{c}\text { Generator } \\ (\mathrm{RPM})\end{array} & \text { Drive } & \begin{array}{c}\text { Voltage } \\ \text { Dip }(\%)\end{array} & \begin{array}{c}\text { Turbine } \\ (\mathrm{lb})\end{array} & \begin{array}{c}\text { Gear } \\ (\mathrm{Ib})\end{array} & \begin{array}{c}\text { Generator } \\ (\mathrm{Ib})\end{array} & \begin{array}{c}\text { Bedplate } \\ (\text { Ib })\end{array} & \begin{array}{c}\text { Total } \\ (1 \mathrm{~b})\end{array} \\ 1250 & 1200 & \text { Geared } & 2 & 4700 & 4000 & 18,000 & 2000 & 28,700 \\ 1250 & 1200 & \text { Geared } & 6 & 4700 & 4000 & 9,400 & 2000 & 20,100 \\ 1250 & 3600 & \text { Direct } & 2 & 9000 & \ldots & 24,000 & 2500 & 35,500 \\ 1250 & 3600 & \text { Direct } & 5 & 9000 & -\ldots & 17,000 & 2500 & 28,500 \\ 625 & 1200 & \text { Geared } & 2 & 4280 & 1500 & 10,400 & 1800 & 17,980 \\ 625 & 1200 & \text { Geared } & 6 & 4280 & 1500 & 6,350 & 1800 & 13,930 \\ 625 & 1800 & \text { Geared } & 3 & 4280 & 1500 & 11,000 & 2000 & 18,780 \\ 625 & 3600 & \text { Direct } & 2 & 6150 & -\ldots & 18,000 & 1800 & 25,950 \\ 625 & 3600 & \text { Direct } & 4 & 6150 & \ldots & 8,200 & 1800 & 16,150\end{array}$

NOTE: Accessories and piping are not included; they will be shipped in another package if necessary.

A cost and packaging comparison of one full-capacity and two one-half-eapacity turbines, including auxiliaries and switchgear, was also made (see Table IV-2). It showed that the two-turbine system costs $\$ 131,000$ more than the single unit system.

The heat rate based on 280 psia steam and 9 in. $\mathrm{Hg}$ abs exhaust pressure is $26,260 \mathrm{Btu} / \mathrm{kw}-\mathrm{hr}$ for the single-unit system and $27,550 \mathrm{Btu} / \mathrm{kw}-\mathrm{hr}$ for the two onehalf-capacity unit system.

It is possible to ship the 1250-kw unit as a single package; however, the two 625-kw units require two packages for shipment. The two-625-kw-machine system also requires additional switchgear units and approximately twice as many piping interconnections. Further, the single-machine system does not pose the load balance problem which would be present with a two-turbine generator system. 
TABLE IV-2

Secondary Loop Packages and Estimated Cost Variation

\begin{tabular}{|c|c|c|c|c|c|c|c|c|}
\hline \multicolumn{5}{|c|}{ No. Turbine-Generator Sets } & \multicolumn{4}{|c|}{ Two Half-Capacity } \\
\hline $\begin{array}{c}\text { System Steam Pressure } \\
\text { (psia) }\end{array}$ & & to 275 & 275 & 500 & $200 t$ & - 275 & 275 & 0500 \\
\hline $\begin{array}{l}\text { Turbine Cost } \\
\text { Variation }(\$)\end{array}$ & \multicolumn{2}{|c|}{$-131,000$} & \multicolumn{2}{|c|}{$-131,000$} & \multicolumn{2}{|c|}{0} & \multicolumn{2}{|r|}{0} \\
\hline $\begin{array}{l}\text { No. of Condensers } \\
\text { (air-to-steam type) }\end{array}$ & \multicolumn{2}{|r|}{3} & \multicolumn{2}{|c|}{2} & \multicolumn{2}{|c|}{3} & \multicolumn{2}{|r|}{2} \\
\hline $\begin{array}{l}\text { Condenser Cost } \\
\text { Variation }(\$)\end{array}$ & \multicolumn{2}{|c|}{$+65,000$} & \multicolumn{2}{|c|}{0} & \multicolumn{2}{|c|}{$+65,000$} & \multicolumn{2}{|r|}{0} \\
\hline $\begin{array}{l}\text { Extraction System } \\
\text { Cost }(\$)\end{array}$ & 0 & +7000 & 0 & +7000 & $\begin{array}{c}\text { not } \\
\text { considered }\end{array}$ & $\begin{array}{c}\text { not } \\
\text { considered }\end{array}$ & $\begin{array}{c}\text { not } \\
\text { considered }\end{array}$ & $\begin{array}{c}\text { not } \\
\text { considered }\end{array}$ \\
\hline $\begin{array}{l}\text { Packages Required } \\
\text { (No.) }\end{array}$ & 7 & 7 & 6 & 6 & 8 & 8 & 7 & 7 \\
\hline $\begin{array}{l}\text { Package Cost } \\
\text { Variation }(\$)\end{array}$ & 0 & 0 & -5000 & -5000 & +5000 & +5000 & 0 & 0 \\
\hline $\begin{array}{l}\text { Total Cost } \\
\text { Variation }(\$)\end{array}$ & $-66,000$ & $-59,000$ & $-136,000$ & $-129,000$ & $+70,000$ & $+70,000$ & 0 & 0 \\
\hline
\end{tabular}


Table IV-3 sumarizes the turbine-generator study and includes the weights of oversized generators used to attain the desired power quality.

\section{TABLE IV -3 \\ Turbine-Generator Comparison One 1250-kw Unit}

Weight

Turbine only (Ib)

Total (1b)

Packages

Heat rate (Btu/kw-hr) based on 280 psia steam and 9-in.

Hg abs back pressure

Cost difference

Switchgear

Interconnections

Operation
4,700

28,700

One possible

26,260

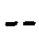

$\cdots$

$-$

-
Two 625-kw Units

$$
9,560
$$$$
35,950
$$

Two required

$$
27,550
$$

$+\$ 131,000$

More units

Approximately twice as many

Load balance problem

As a result of this study, the single turbine-generator system was selected.

\section{CONDENSER STUDIES}

\section{W. Koch}

R. Groscup

L. Hassel

Three types of condenser systems were investigated for the PM-I plant, namely: steam-to-ethylene glycol-to-air; a direct contact condenser using water coolant circulated through an air-cooler; and a direct air-to-steam condenser. Schematics of these three systems are shown in Figs. IV-7, 8 and 9.

It is well established that the ethylene glycol system (Fig. IV-7) is the safest from freeze-up. Studies of this system applied to the PM-l showed, however, that it required approximately $90 \mathrm{kw}$ more auxiliary power than the other two systems investigated. In addition, it required more equipment which resulted in additional weight and the need for more packages. Therefore, it was considered the least desirable, and will be used only if both of the other systems prove unfeasible.

The second system investigated was the direct contact water-type condenser, also known as the Heller System (Fig. IV-8). It is being used in Europe on several 10,000-kw conventional plants operating at ambient temperatures as low as $0^{\circ} \mathrm{F}$. It utilizes a direct contact condenser using feedwater-quality water and an aircooled heat exchanger. 


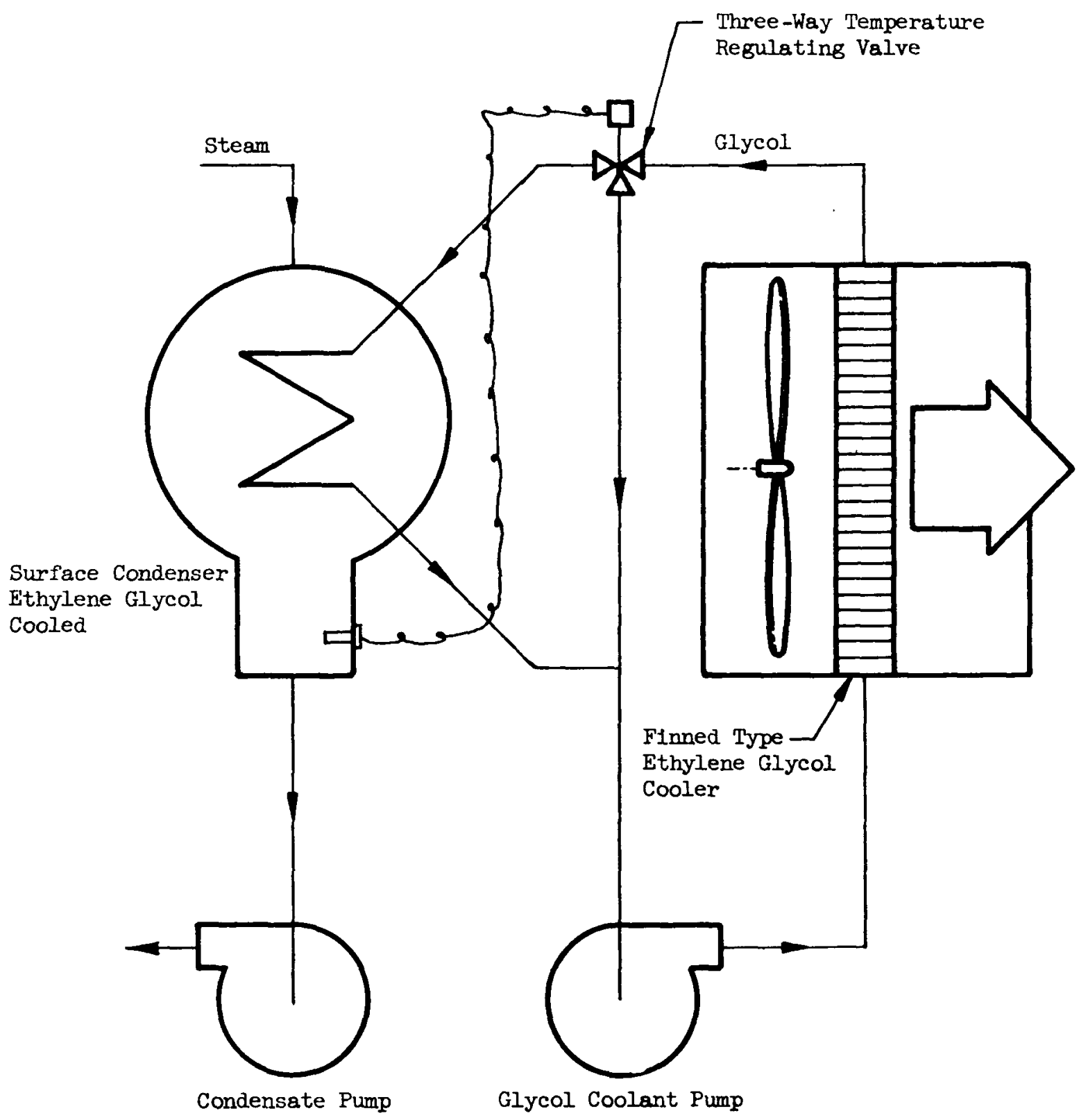

Fig. IV-7. Schematic of Steam-to-Ethylene Glycol-to-Air Condenser System (Tubular Surface) 


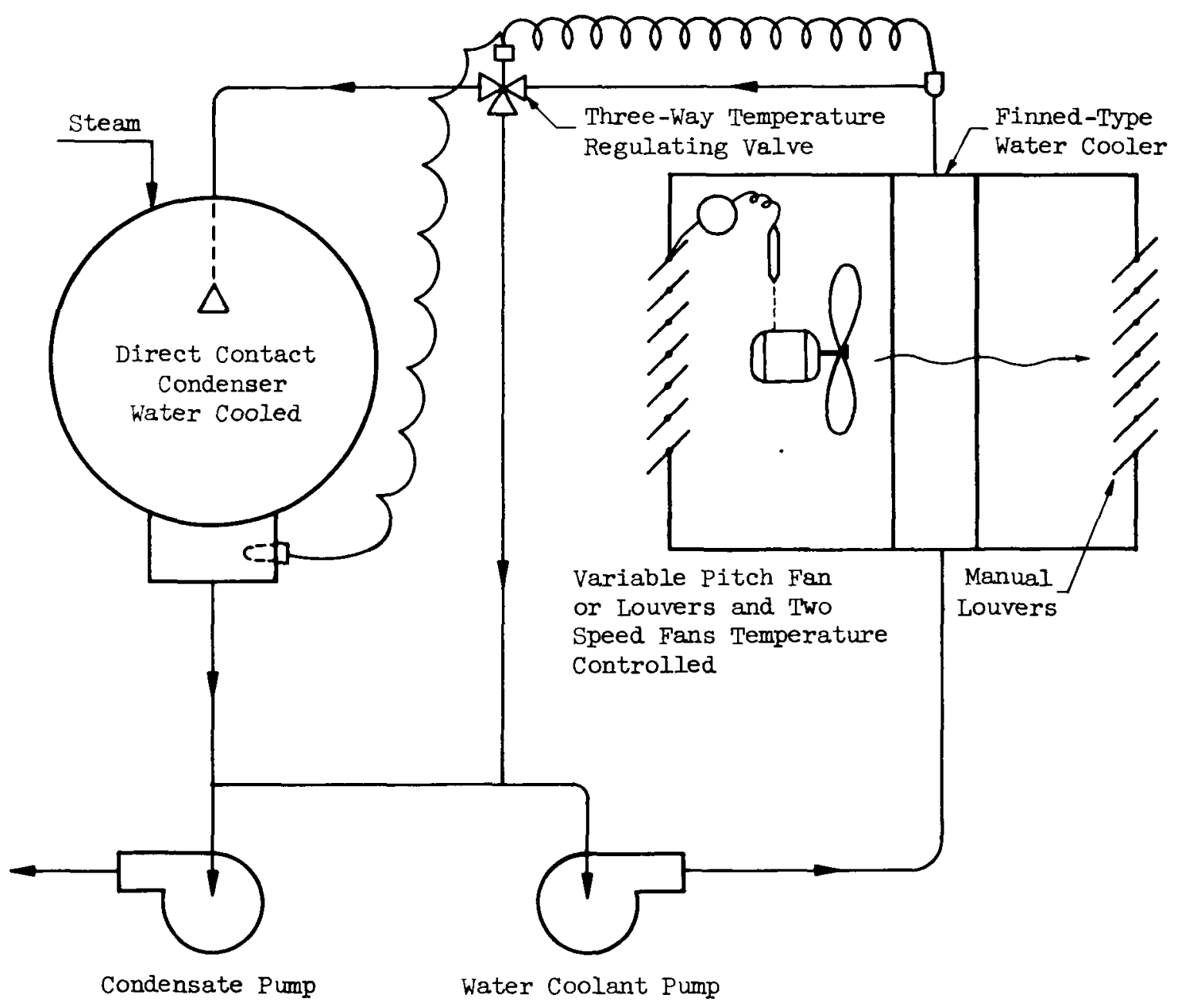

F1g. IV-8. Schematic of Direct Contact Water-Cooled Condenser System 


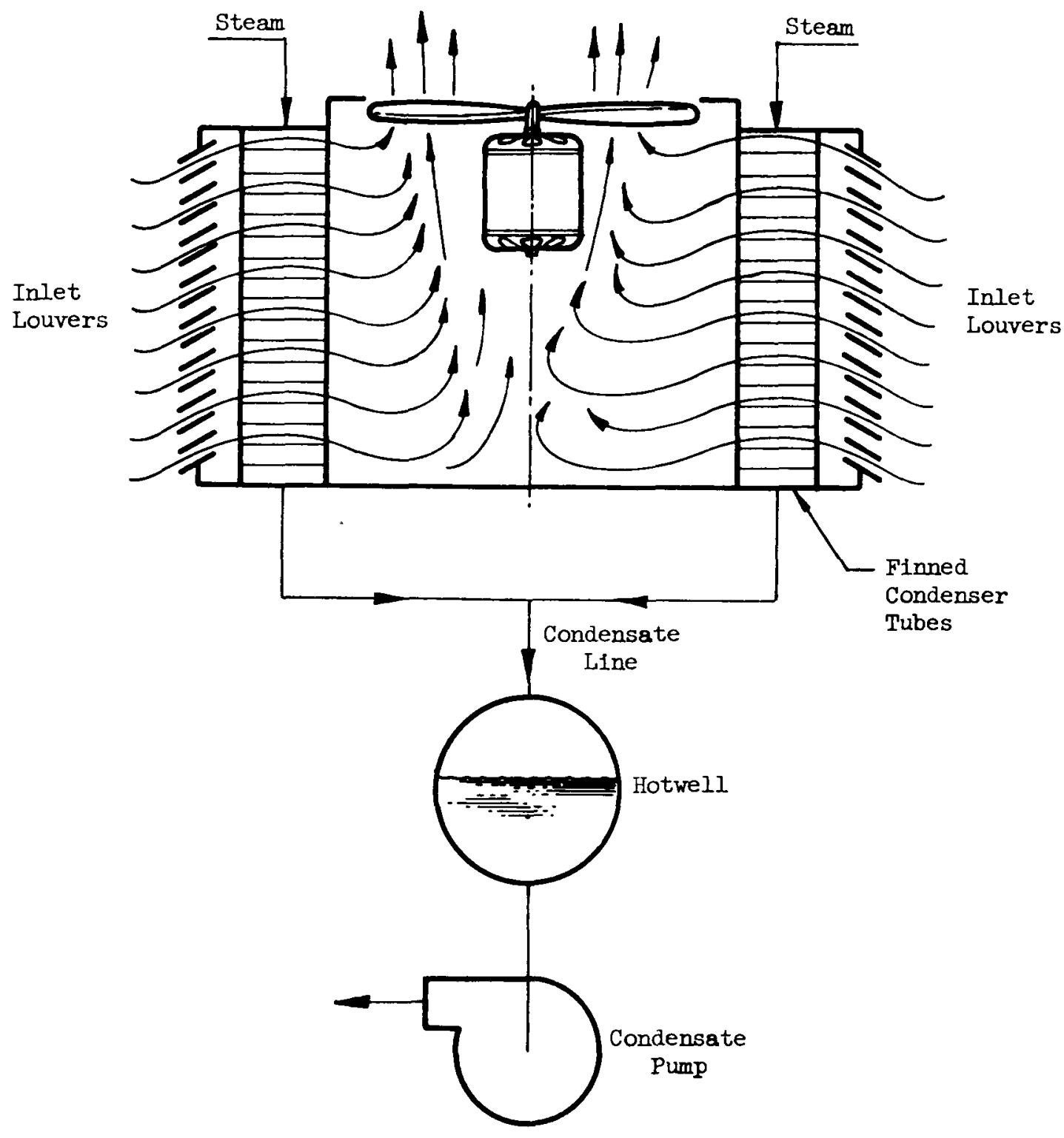

Fig. IV-9. Schematic of Direct Air-to-Steam Condenser System 
The third system investigated was the direct air-to-steam condenser system (Fig. IV-9). This has been used successfully in warm climates and to a limited extent in cold climates. The SL-l uses a direct air-to-steam condenser, the success of which has been limited by underdesign and poor configuration. An airto-steam condenser system designed for a warm climate proved unsuccessful at Eilson AF'B in Alaska. On the other hand, several direct air-to-steam condensers have been operated successfully for 15 yr in Germany at temperatures as low as $0^{\circ} \mathrm{F}$.

Table IV-4 compares the direct air-to-steam and direct contact water systems; the potential advantage of the direct air-to-steam system is clearly shown.

Experience

Cost

Auxiliary Power

Freeze-up Problem

Start-up Problem

Controls

Test Program

No. of Packages

\section{TABLE IV-4}

Condenser Comparison

\section{Air-to-Steam}

To approx $0^{\circ} \mathrm{F}$ with success SL-1 to $-24^{\circ} \mathrm{F}$ without trouble

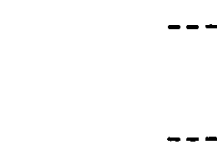

Can successfully design around problem

Uses steam for warmup

Approximately the same

Requires $1 / 2$ of a condenser section for a meaningful test - - total estimated cost of labor and materials $\$ 50,000$

Two

\section{Direct Contact Water}

To approx $0^{\circ} \mathrm{F}$--considerable experience in chilled water air-conditioning work

$\$ 4,000$ more (for contact condenser)

$10 \mathrm{kw}$ more (for water. circulating pump)

Solid water system presents severe freeze-up problem

Difficult to warm system with water

Approximately the same

Probably could use a very small test section involving less expense 
Three different sized air-to-steam condenser systems each operating at 6,9 , and $11.5 \mathrm{in.} \mathrm{Hg} \mathrm{abs} \mathrm{back} \mathrm{pressure} \mathrm{were} \mathrm{studied.} \mathrm{The} \mathrm{systems} \mathrm{studied} \mathrm{were} \mathrm{one}$ $52,000-s q$ ft unit, two 20,000-sq ft units and two 40,000-sq ft units.

Table IV -5 compares the cost of the three sizes of systems.

\section{$\underline{\text { TABLE IV }-5}$}

$\begin{array}{lccc}\text { System size, total sq ft } & 52,000 & 80,000 & 40,000 \\ \text { Number of units } & 1 & 2 & 2 \\ \text { Cost using } 40,000 \mathrm{sq} f t & -\$ 20,000 & +\$ 45,000 & 0\end{array}$

From a cost point of view the $52,000-s q$ ft unit looks very attractive, but study of fan power requirements (shown in Fig. IV-10) and the inability to add more area (due to configuration limitations) eliminated this system. The twounit system was, therefore, selected; its size will be determined by the results of the condenser test and the auxiliary power limitation $(135 \mathrm{kw})$ of the secondary loop. It is expected that the surface required for the two units will total approximately $60,000 \mathrm{sq} \mathrm{ft}$.

To eliminate problems that other direct air-to-steam condenser systems have experienced under cold ambient conditions, a test program has been planned. This test will use an oversized one-half section of one unit (approximately 26,000 sq ft surface area) and will be run in a climatic chamber, such as that of the Edgewood Chemical Center or of Eglin AFB, at temperatures as low as $-65^{\circ} \mathrm{F}$.

The purposes of these tests are to: determine the advisability of using reverstble fans for removing ice buildup; determine and eliminate freeze-up problems; determine the feasibility of a control system operating from condenser pressure; isolate other general control problems; investigate the feasibility of using louvers to control condensing rates in the cold tubes; determine air distribution with various louver and fan combinations; etc. The results of these tests will be utilized in the final design.

The tests are scheduled for January and February, 1960.

\section{CYCLE STUDIES}

W. Koch R. Groscup

L. Hassel

Investigations of secondary loop cycles and equipment during the first month of study showed that system weight and cost remained quite constant at initial steam pressures between 275 and 600 psia and turbine exhaust pressures between 6 and 11.5 in. $\mathrm{Hg}$ abs. Below 275 psia, a step increase in turbine weight occurs due to an increase in steam chest size resulting from increased volumetric steam flow and due to the requirement that nozzles be sized to limit the pressure drop across them. Above 600 psia, a step increase in turbine weight occurs because the turbine frame pressure and temperature design limitations are exceeded. Turbine back pressures within the range indicated allow the turbine exhaust to be sized in a manner consistent with the requirements for air transportability of the turbine-generator package. 


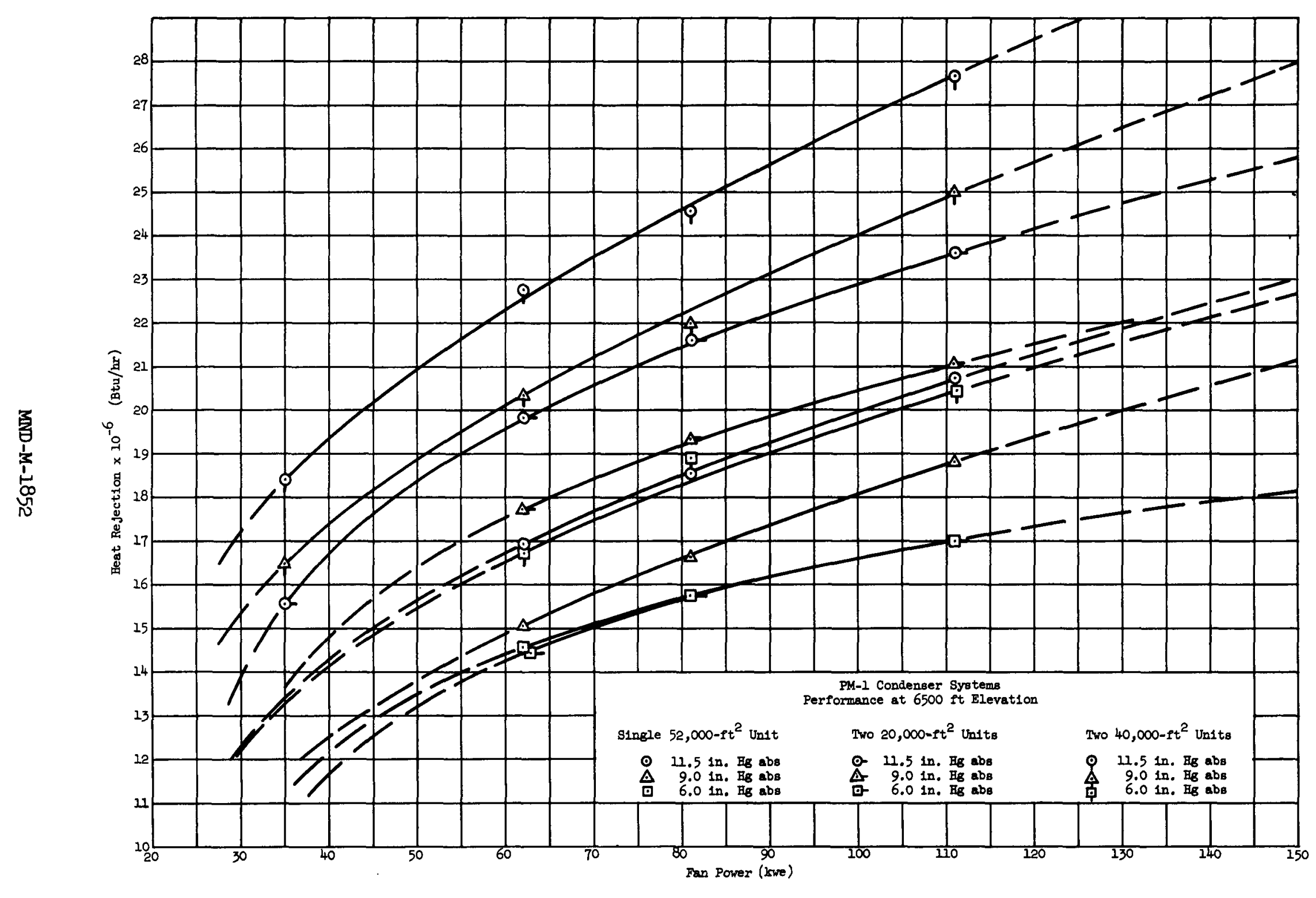

F1g. IV-10. A1r-to-Steam Condenser Heat Rejection as a Function of Fan Power, Exhaust Pressure, and Surface Area 
Based upon the considerations stated and in the scope of work, the systems considered were:

\section{(1) Straight Condensing}

(1) Electrically-driven auxiliaries

(2) Steam-driven auxiliaries

(2) Condensing--Single Regeneration Extraction

(1) Electrically-driven auxiliaries

(2) Steam-driven auxiliaries

A comparison of the thermodynamic requirements of a straight condensing cycle with those of a regenerative cycle, both with electrically-driven auxiliaries, indicates that, for a given set of steam conditions, the regenerative cycle is between two and three percent more efficient than the straight condensing cycle. A comparison of the savings in fuel costs (burnup plus inventory reprocessing considerations) with the increased capital cost of the regenerative cycle--approximately $\$ 7000--r e v e a l e d$ that the regenerative cycle capital costs were recovered in less than the five years arbitrarily chosen as the criterion for such evaluations. Packaging appears to pose no additional problems for the regenerative cycle since the heater is small and may be included in one of the existing packages. From the standpoint of maintenance, reliability and operation, the regenerative cycle appears feasible. The additional equipment consists largely of heat transfer surfaces and is relatively free from maintenance and simple to operate. Many years of industrial and power plant operation vouch for the system's reliability. A regenerative cycle will be incorporated into the plant design.

The desirability of using electrically-driven mechanical vacuum pumps rather than steam jet air ejectors to remove noncondensable gases from the condenser was evaluated. The characteristics of the two concepts were found to be:

(1) Vacuum Pumps

Power requirement Cost Weight

13 kwe $\$ 4000$ $2200 \mathrm{Ib}$ (including motors)

(2) Steam jet ejectors

Power requirement $\sim 300 \mathrm{lb} / \mathrm{hr}$ of steam (most of steam's energy

Cost recovered in after-condenser)

Weight $\$ 2250$ $800 \mathrm{lb}$ (including after-condenser)

After considering these characteristics, and the fact that the after-condenser may be made a functional part of the turbine gland seal condenser system, the steam jet air ejector system was selected for incorporation into the plant design.

The desirability of driving plant auxiliaries with steam turbines rather than with electric motors was examined, considering the following auxiliaries: 


\section{(1) Condenser fans \\ (2) Boiler feed pump \\ (3) Condensate pump \\ (4) Space heat boller feed pump}

It was not considered feasible to attempt to drive the condenser fans with a steam turbine because of the possibility that steam could condense or that the turbine exhaust could freeze when piping was exposed to low ambient temperatures.

The condensate and the space heat boller feed pumps were too small ( 1 kw) to be considered for steam turbine drives.

Heat balances indicated that, although straight condensing cycle efficiency could be improved by approximately one percent using a steam-driven boiler feed pump such was not the case for the regenerative cycle. In the regenerative cycle the energy delivered to the boiler feed pump turbine is not available to heat the feedwater in the closed heater. Thus, the increase in efficiency resulting from use of a turbine-driven feed pump is offset in part by a reduction of the efficiency gained through turbine extraction. An advantage the steam-driven pump has over the electric, is that an excess of approximately $25 \mathrm{kw}$ is available in station output. The advantage of diverting about $25 \mathrm{kw}$ of power from plant auxiliaries to station output appears to be more than offset by the advantages of simplicity, low maintenance and ease of operation offered by the electrically-driven pump. However, since the steam-driven pump must be supplied for purposes of maintaining steam generator water level during the core afterheat removal period, both systems are being supplied. It will be specifled that the electrically-driven pump is prime equipment and the steam-driven pump is standby.

Figures IV-II and IV-I2 illustrate the effect of steam conditions (turbine inlet and exhaust) on the secondary loop power consumption and net power available from the secondary loop.

\section{E. POWER QUALITY STUDIES}

W. Koch

R. Groscup

C. Hassel

Various means of meeting the PM- 1 power quality objectives within the PM-1 plant without utilizing control devices at the load were studied.

The PM-1 voltage objective is that the plant shall be inherently capable of limiting voltage fluctuations to within $\pm 2 \%$ between 10 and $120 \%$ of rated load, when subjected to an instantaneous load change of $30 \%$ of rated capacity at 0.80 power factor. Recovery time from initiation of the transient to steady-state conditions shall not exceed $1.5 \mathrm{sec}$. Under steady-state conditions the plant shall limit voltage fluctuations to $\pm 0.5 \%$.

Three methods were investigated to meet the voltage fluctuation objective, namely: an electric load dump system; a synchronous condenser system; an oversize electric generator.

An electric load dump system transforms a step load transient to a ramp transient on the generator. The ramp transient control requirements are such that the natural 
Turbine Exhaust Pressure (in. Hg abs)

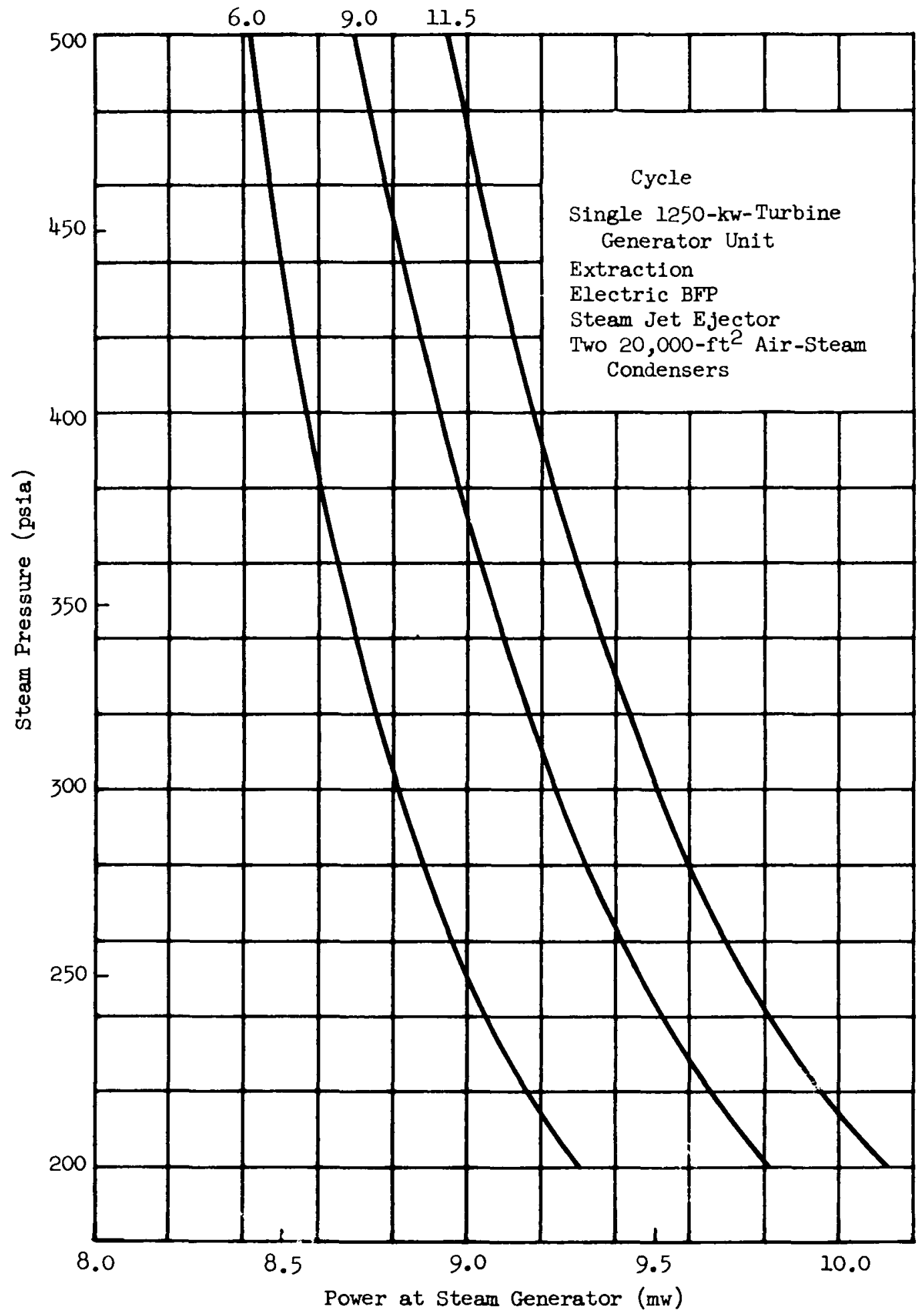

Fig. IV-11. Required Steam Generator Power as a Function of Secondary Steam Inlet and Exhaust Measure 


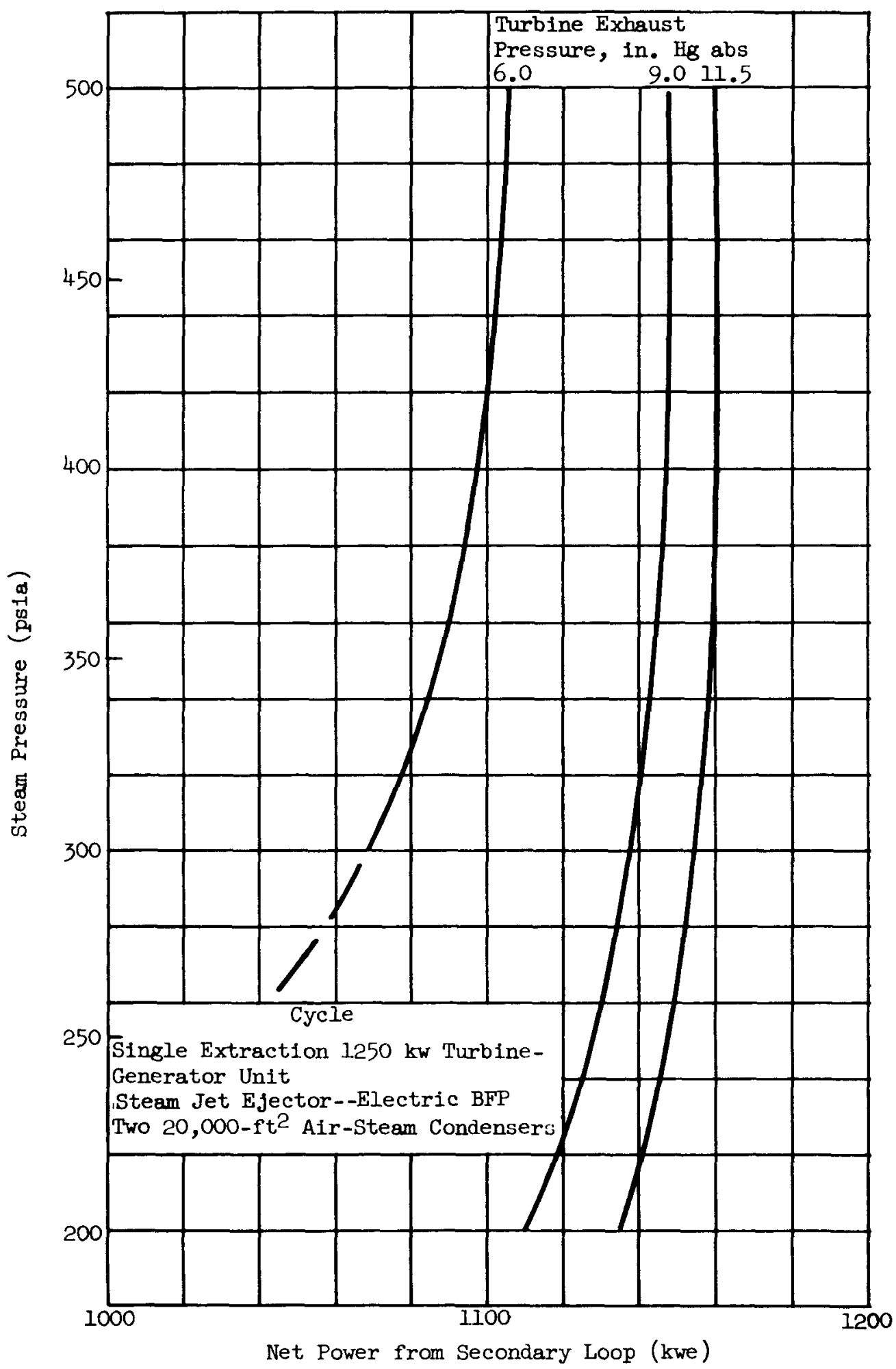

Fig. IV-12. Secondary Loop Power as a Function of Secondary Steam Inlet and Exhaust Pressure 
voltage regulation of the generator would maintain voltage fluctuations within the desired limits.

An analysis of the system necessary to accomplish such transient transformation. indicated that it was not feasible. First, it is not possible to determine when the load will change without adding anticipating devices at the load which involve information feedback to the generator and are not desired. Second, it is not possible to place a properly-sized load, in the form of an electric load dump, on the line at the exact instant that the prime load changes without knowing the size of each load increment and using some elaborate control system from each load increment. Therefore, no immediate solution of the transient problem can be feasibly obtained with an electric load dump system.

A synchronous condenser system converts the generator load power-factor to near unity and thereby increases the natural capacity of the generator to limit voltage fluctuations. Analysis of this approach revealed that the condenser would have to be energized or de-energized at the exact time that the load transient was applied; the same type of problems are present, therefore, with this system as those encountered with the electric load dump system.

The third method considered was the use of an oversize generator having enough Iron In its construction to lower the transient reactance and thus to maintain the desired voltage quality under the given transient conditions. In this study, three types of generators were considered: a 1200-rpm salient pole; an 1800-rpm salient pole; and a 3600-rpm non-salient pole. Table IV-ú shows the results of this study.

TABLE IV-6

$1250 \mathrm{kw}, 60$ Cycle Generator Weights

\begin{tabular}{llcccccr} 
rpm & $\begin{array}{l}\text { Geared } \\
\text { Direct }\end{array}$ & $\begin{array}{c}\text { Voltage } \\
\text { Dip }(\%)\end{array}$ & $\begin{array}{c}\text { Turbine } \\
(1 \mathrm{~b})\end{array}$ & $\begin{array}{c}\text { Gear } \\
(1 \mathrm{~b})\end{array}$ & $\begin{array}{c}\text { Generator } \\
(\mathrm{lb})\end{array}$ & $\begin{array}{c}\text { Bedplate } \\
(\mathrm{lb})\end{array}$ & Total \\
\hline 1200 & Geared & 2 & 4700 & 4000 & 18,000 & 2000 & 28,700 \\
1200 & Geared & 6 & 4700 & 4000 & 9,400 & 2000 & 20,100 \\
3600 & Direct & 2 & 9000 & -- & 24,000 & 2500 & 35,500 \\
3600 & Direct & 5 & 9000 & -- & 17,000 & 2500 & 28,500 \\
$1800^{*}$ Geared & 3 & 4280 & 1500 & 11,000 & 2000 & 18,780
\end{tabular}

* NOTE: These values are for a single 650-kw-capacity machine only. weight.

The 1800-rpm generator was dropped from consideration due to its excessive

It was determined that the oversize generator offered the most feasible solution to the voltage fluctuation portion of the power quality objective. Of the turbine generators studied, the 1200-rpm salient pole generator system is the only one that meets the voltage dip power quality requirements within the 30,000 $1 \mathrm{~b}$ weight limitation. This machine, with a fast-acting static excitation voltage regulator system, will be incorporated into the plant design.

Another portion of the power quality objective concerns the deviation factor and harmonic content of the generator voltage. It is a design objective that the 
deviation factor of the line-to-line voltage at zero load and balanced $4 / 4$ rated load at 0.80 power factor not exceed two percent. Further, the rms of all harmonics should be less than two percent, with any one harmonic less than 0.75 percent, at full-rated load.

The deviation factor and harmonic content voltage quality criteria cannot be met by system design since the characteristics of the load are not known. The noload deviation factor of the generators under consideration will not, however, exceed two percent, nor will the rms of all harmonics exceed two percent. Any single harmonic may exceed the objective of 0.75 percent, but will not exceed 1.5 percent. The harmonics that may exceed the stated 0.75 percent will probably be the 3 rd, $5 \mathrm{th}, 7 \mathrm{th}$, and $9 \mathrm{th}$, although the $3 \mathrm{rd}$ and $9 \mathrm{th}$ will be zero in the line-to-line voltage and appear to be of no concern. If there is reason to emphasize reduction of either the 5 th or 7 th harmonic at the expense of the others, this can be done. The remaining harmonic can be reduced by a filter, if necessary, after the generator design is complete.

The last portion of the power quality objective concerns frequency fluctuation. The objective is that the plant be inherently capable of limiting frequency fluctuations to within $\pm 2 \%$ between 10 and $120 \%$ of rated load, when subjected to an instantaneous load change of $30 \%$ of rated capacity at 0.80 power factor. Recovery time from initiation of the transient to steady-state conditions should not exceed 1.5 sec. Under steady-state conditions the plant should limit frequency fluctuations to $\pm 0.25 \%$.

It should not be difficult to meet this objective. At present, isochronous governors are being used on turbine drives for equipment such as paper dryers, nylon spinning machines, etc., in which speed must be maintained to $\pm 0.1 \%$. An isochronous governor will be used on the turbine.

\section{F. STEAM GENERATOR STUDIES}

W. Koch

$$
\text { R. Groscup }
$$

L. Hassel

The steam generator is affected by both primary and secondary loop pressures, temperatures, and flows; therefore this study was treated somewhat differently from the others. The following design conditions were applied.

\author{
Heat to be transferred \\ Maximum weight \\ Maximum length \\ Steam pressure \\ Primary loop design pressure \\ Primary loop flows \\ Log mean temperature \\ difference
}

\author{
$9.5 \mathrm{mwt}$ (middle of range) \\ 25,000 lb (shipping limitation) \\ $28 \mathrm{ft}$ (shipping limitation) \\ 250,375 , and 500 psia (covers range) \\ 2300 psi (conservative basis) \\ 1000,1700 , and $2500 \mathrm{gpm}$ (covers range) \\ 30,65 , and $100^{\circ} \mathrm{F}$ (covers range)
}

Previous investigations of steam generators for similar applications showed that horizontal types, in the capacity range required, weighed nearly twice as much and cost $65 \%$ more than similarly-sized vertical types. Since the more promising primary loop layouts were also those utilizing the vertical-type steam generator, it was selected for study. Table IV-7 shows the results of this study. Both type 304 SS and Inconel primary side constructions were investigated. Although the use of Inconel does not reduce the secondary loop water treatment program, it presently 
- 
TABLE IV-7

PM-1 Steam Generator Study

Heat Load 9.5 TMW, Steam Flow 31,900 1b/hr, Shell and Channel ID $=28-5 / 8 \mathrm{ln}$, 1/2-1n. OD Tubes

\begin{tabular}{|c|c|c|c|c|c|c|c|c|c|c|}
\hline $\begin{array}{l}\text { Steam } \\
\text { Pressure }\end{array}$ & $\begin{array}{c}\text { Estimated } \\
\text { Price } \\
304 \text { SS } \\
(\$)\end{array}$ & $\begin{array}{c}\text { Estimated } \\
\text { Price } \\
\text { Inconel } \\
(\$)\end{array}$ & $\begin{array}{l}\text { Primary } \\
\text { Flow } \\
\text { (gam) }\end{array}$ & $\begin{array}{l}\text { LMTD } \\
\left({ }^{\circ} \mathrm{F}\right) \\
\end{array}$ & $\begin{array}{l}\text { Estimated } \\
\text { Primary } \mathrm{T}_{\text {avg }} \\
\end{array}$ & $\begin{array}{l}\text { Shell Design } \\
\text { Pressure } \\
\text { (ps1) }\end{array}$ & $\begin{array}{l}\text { Surface } \\
\text { Area } \\
\left(\text { ft }^{2}\right) \\
\end{array}$ & $\begin{array}{l}\text { Pressure } \\
\text { Drop } \\
\text { (psi) }\end{array}$ & $\begin{array}{c}\text { Overall } \\
\text { Length } \\
(\mathrm{ft})\end{array}$ & $\begin{array}{c}\text { We1ght } \\
(1 \mathrm{~b})\end{array}$ \\
\hline $\begin{array}{l}250 \mathrm{ps} 1 \mathrm{a} \\
401^{\circ} \mathrm{F}\end{array}$ & $\begin{array}{l}86,500 \\
73,700 \\
69,100 \\
84,200 \\
72,700 \\
68,500 \\
81,900 \\
72,100 \\
68,100\end{array}$ & $\begin{array}{l}96,000 \\
81,000 \\
76,000 \\
92,500 \\
80,000 \\
76,300 \\
90,000 \\
79,300 \\
75,000\end{array}$ & $\begin{array}{l}1,000 \\
1,700 \\
2,500\end{array}$ & $\begin{array}{r}30 \\
65 \\
100 \\
30 \\
65 \\
100 \\
30 \\
65 \\
100 \\
\end{array}$ & $\begin{array}{l}431 \\
466 \\
501 \\
431 \\
466 \\
501 \\
431 \\
466 \\
501 \\
\end{array}$ & $\begin{array}{l}500 \\
700 \\
900 \\
500 \\
700 \\
900 \\
500 \\
700 \\
900 \\
\end{array}$ & $\begin{array}{r}1,840 \\
780 \\
475 \\
1,630 \\
700 \\
430 \\
1,520 \\
660 \\
410 \\
\end{array}$ & $\begin{array}{r}6.9 \\
5.0 \\
4.4 \\
12.1 \\
7.7 \\
6.4 \\
20.2 \\
12.0 \\
9.7 \\
\end{array}$ & $\begin{array}{l}23.5 \\
13.9 \\
11.1 \\
21.6 \\
13.1 \\
10.7 \\
20.6 \\
12.8 \\
10.5\end{array}$ & $\begin{array}{r}13,300 \\
9,400 \\
8,000 \\
12,400 \\
9,000 \\
7,800 \\
10,900 \\
8,800 \\
7,700 \\
\end{array}$ \\
\hline $\begin{array}{l}375 \text { psia } \\
438^{\circ} \mathrm{F}\end{array}$ & $\begin{array}{l}87,500 \\
74,000 \\
70,500 \\
73,000 \\
85,000 \\
72,700 \\
69,700 \\
96,400 \\
80,000 \\
72,100 \\
69,500 \\
\end{array}$ & $\begin{array}{r}96,200 \\
81,400 \\
77,500 \\
80,300 \\
93,500 \\
80,000 \\
76,600 \\
106,000 \\
88,200 \\
79,300 \\
76,500 \\
\end{array}$ & 2,500 & $\begin{array}{r}30 \\
65 \\
100 \\
65 \\
30 \\
65 \\
100 \\
20 \\
30 \\
65 \\
100 \\
\end{array}$ & $\begin{array}{l}468 \\
503 \\
538 \\
503 \\
468 \\
503 \\
538 \\
458 \\
468 \\
503 \\
538 \\
\end{array}$ & $\begin{array}{r}700 \\
900 \\
1,200 \\
900 \\
700 \\
900 \\
1,200 \\
600 \\
700 \\
900 \\
1,200 \\
\end{array}$ & $\begin{array}{r}1,840 \\
780 \\
520 \\
675 \\
1,630 \\
700 \\
470 \\
2,540 \\
1,520 \\
660 \\
460 \\
\end{array}$ & $\begin{array}{r}6.9 \\
5.0 \\
4.7 \\
14.6 \\
12.1 \\
7.7 \\
7.0 \\
30.2 \\
20.5 \\
12.4 \\
11.3 \\
\end{array}$ & $\begin{array}{l}23.2 \\
13.5 \\
11.2 \\
19.1 \\
21.3 \\
12.8 \\
10.7 \\
29.6 \\
20.3 \\
12.5 \\
10.6\end{array}$ & $\begin{array}{r}14,500 \\
9,700 \\
9,200 \\
11,500 \\
13,500 \\
9,200 \\
8,900 \\
16,900 \\
12,900 \\
9,000 \\
8,800 \\
\end{array}$ \\
\hline $\begin{array}{l}500 \text { psia } \\
467^{\circ} \mathrm{F}\end{array}$ & $\begin{array}{l}87,900 \\
75,000 \\
71,700 \\
85,300 \\
73,600 \\
70,500 \\
83,800 \\
73,000 \\
70,100\end{array}$ & $\begin{array}{l}96,500 \\
82,500 \\
78,900 \\
93,800 \\
81,000 \\
77,500 \\
92,000 \\
80,300 \\
77,100\end{array}$ & 1,000 & $\begin{array}{r}30 \\
65 \\
100 \\
30 \\
65 \\
100 \\
30 \\
65 \\
100\end{array}$ & $\begin{array}{l}497 \\
532 \\
567 \\
497 \\
532 \\
567 \\
497 \\
532 \\
567\end{array}$ & $\begin{array}{r}800 \\
1,200 \\
1,500 \\
800 \\
1,200 \\
1,500 \\
800 \\
1,200 \\
1,500\end{array}$ & $\begin{array}{r}1,840 \\
800 \\
550 \\
1,630 \\
720 \\
500 \\
1,520 \\
700 \\
480\end{array}$ & $\begin{array}{r}6.9 \\
5.2 \\
5.1 \\
12.1 \\
8.3 \\
8.2 \\
20.2 \\
13.5 \\
12.6\end{array}$ & $\begin{array}{l}23.0 \\
13.4 \\
11.2 \\
21.0 \\
12.7 \\
10.7 \\
20.0 \\
12.5 \\
10.5\end{array}$ & $\begin{array}{r}14,900 \\
10,900 \\
10,500 \\
13,700 \\
10,400 \\
9,900 \\
13,200 \\
10,300 \\
9,700\end{array}$ \\
\hline
\end{tabular}


does appear to add some "insurance." At present, several steam generators of Inconel-type construction are being fabricated. Since some difficulty is being experienced in getting a tube-to-tube sheet weld in these units, the stainless steel construction has been selected pending final resolution of the Inconel welding problems.

Figures IV-13, 14, 15, and 16 are graphic representations of the data presented in Table IV-7.

\section{G. SUMMARY OF EQUIPMENT SELECTION}

W. Koch

In summation, the selected secondary loop equipment may be described as follows:

(1) A single 1250-kw turbine-gear-generator. The generator is a 1200-rpm salient pole machine sized to give the two percent voltage dip. The turbine is a single-extraction type.

(2) Two direct air-to-steam condenser packages, each with approximately $30,000 \mathrm{sq}$ ft of heat transfer surface area.

(3) A single closed feed water heater.

(4) A steam jet air ejector.

(5) Electrically-driven condenser fans, boiler feed pump, condensate pump and space heat boiler feed pump. One steam-driven boiler feed pump furnished for standby.

(6) A vertical steam generator.

All plant operating conditions affecting the primary loop and overall plant performance were selected by integration of primary and secondary systems. These conditions are presented in Section VI of this report. 


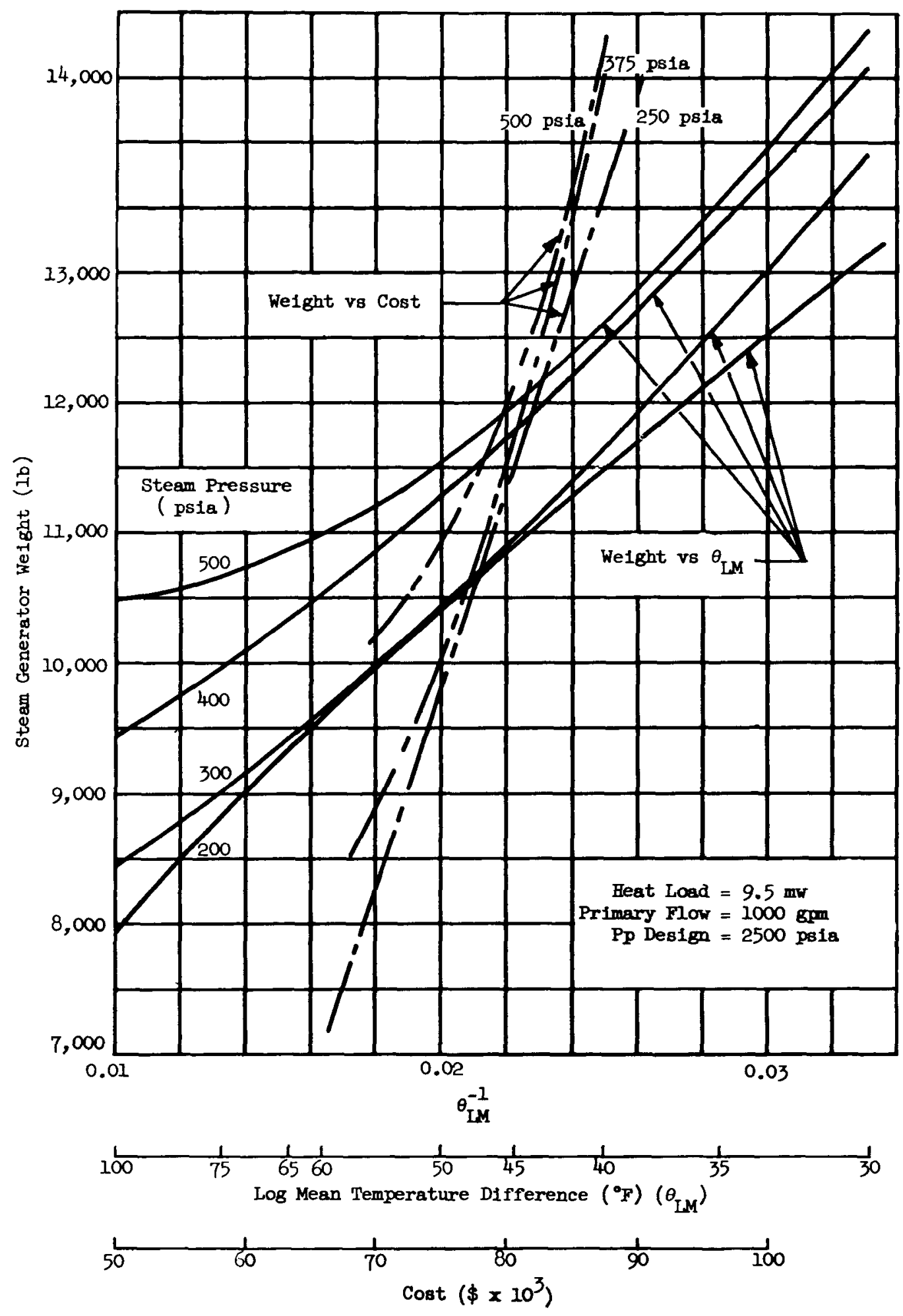

Fig. IV-13. FM-1 Steam Generator Data 
IV -28

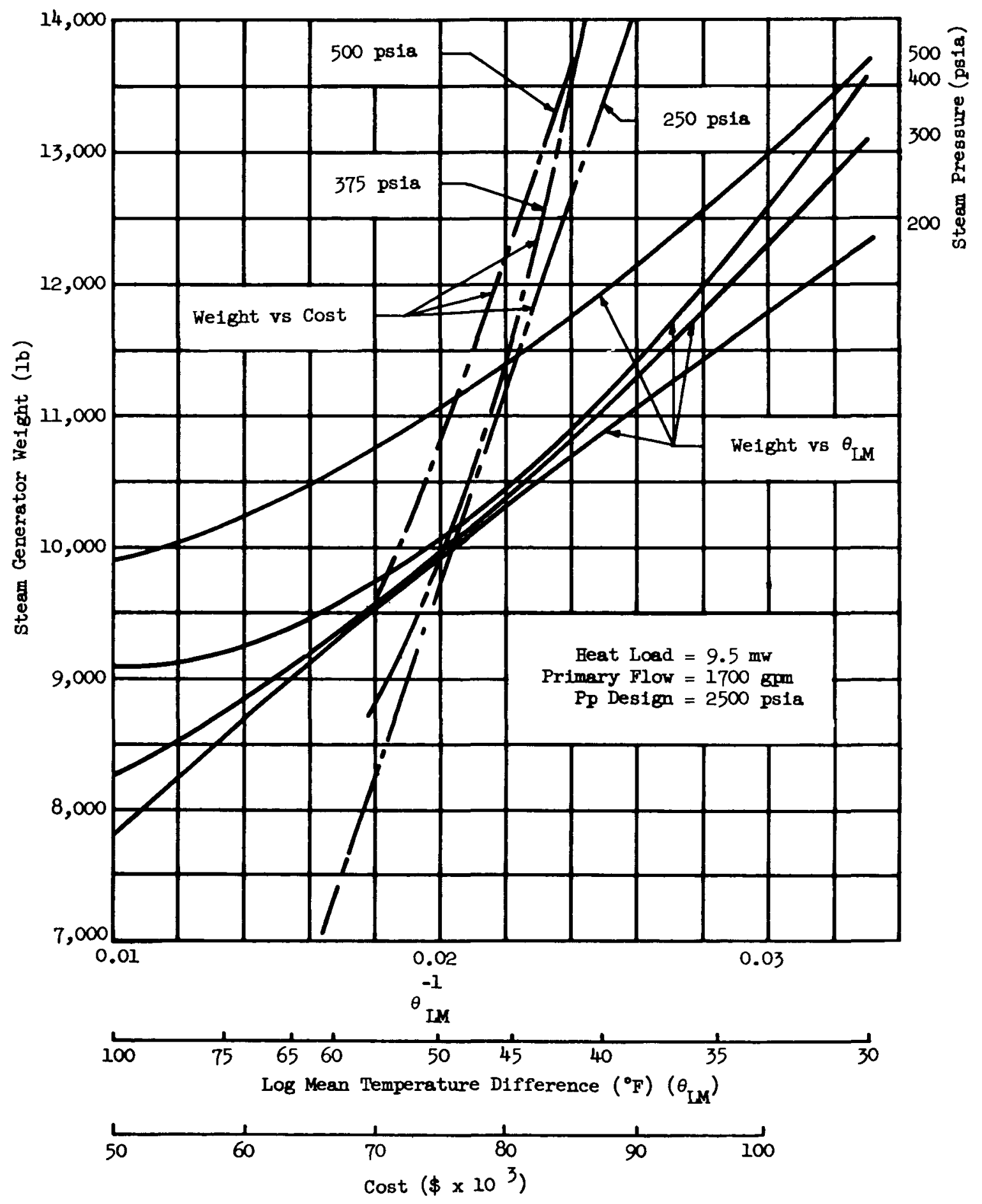

Fig. IV-14. PM-1 Steam Generator Data 


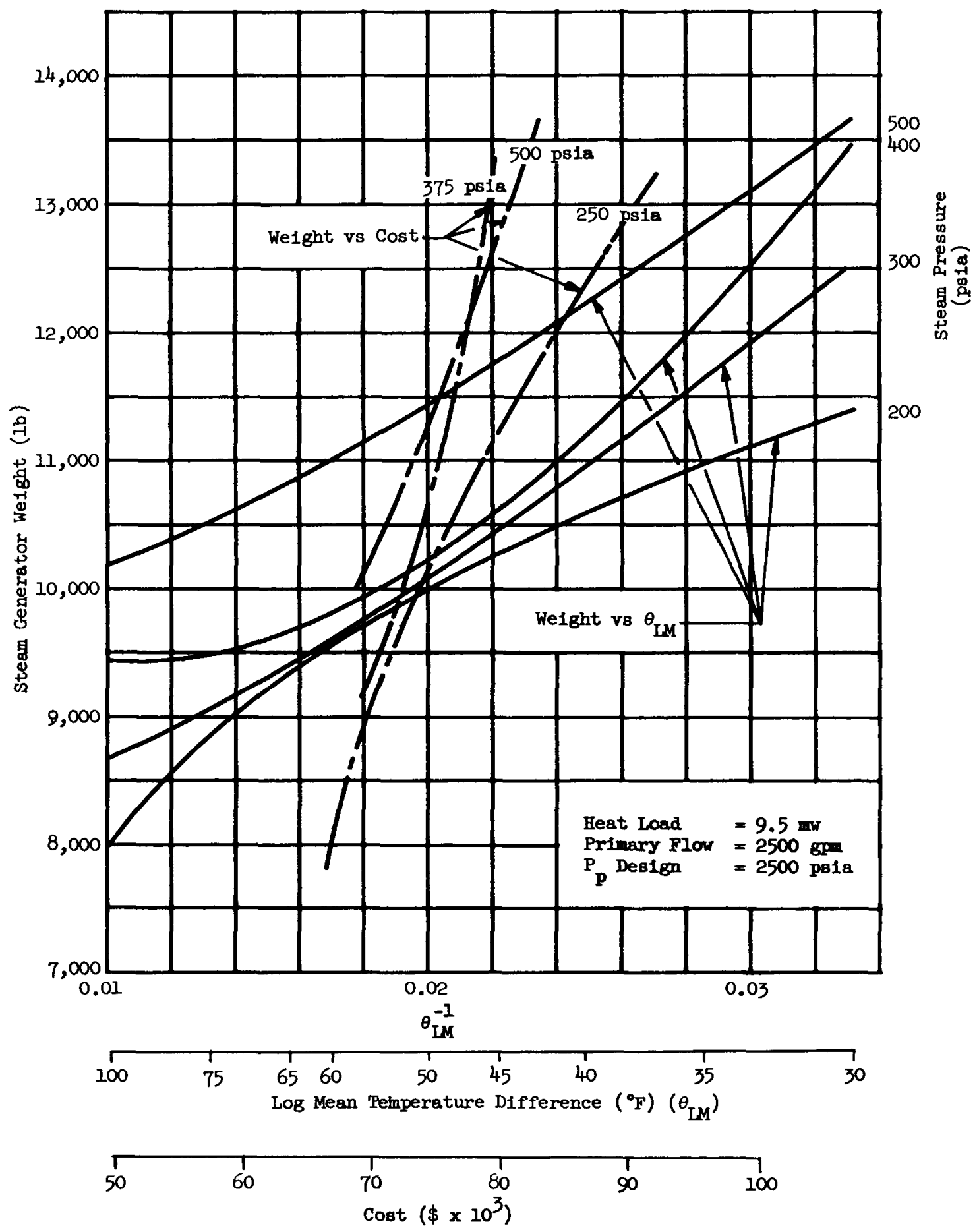

F1g. IV-15. FM-1 Steam Generator Data 


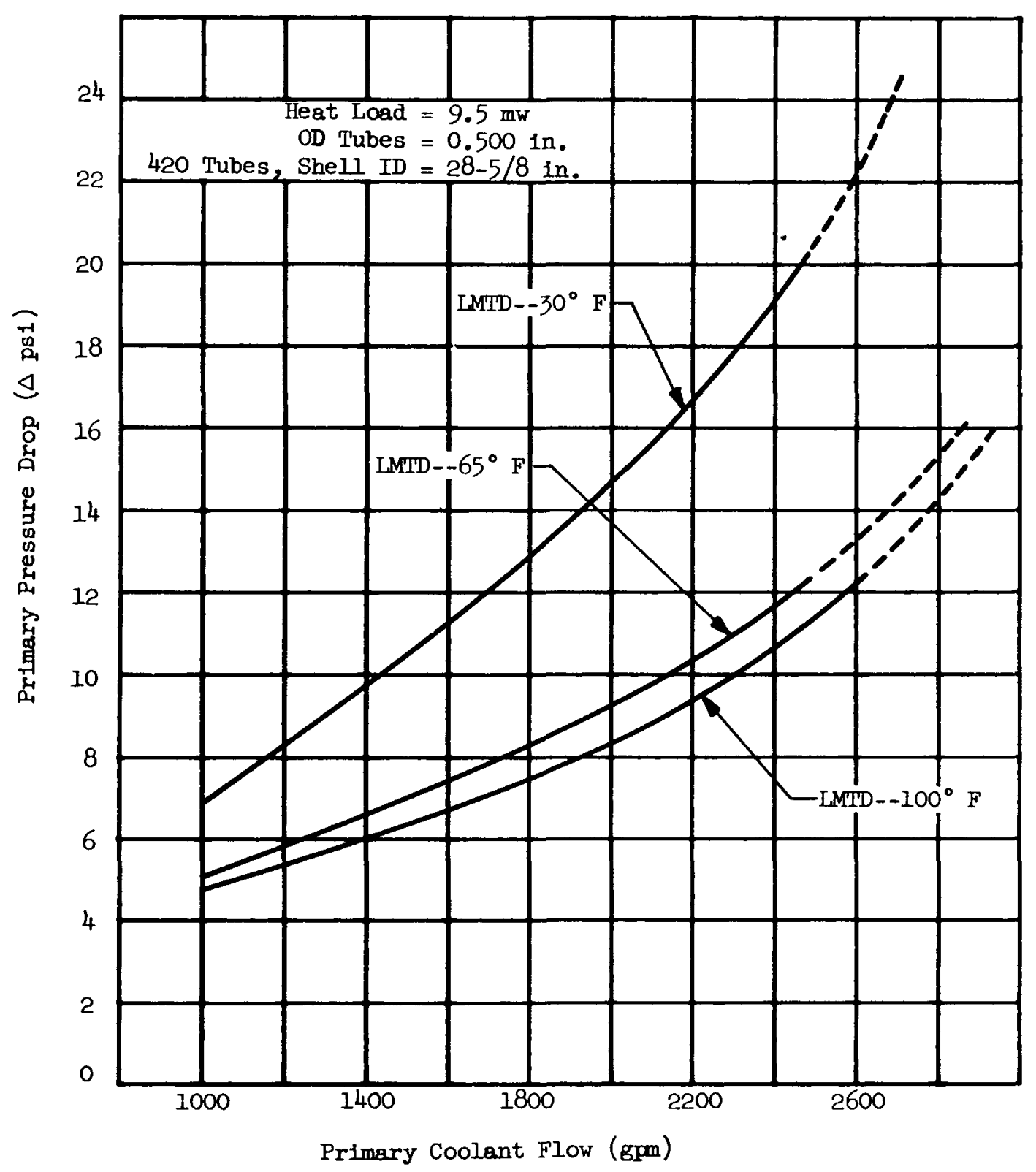

Fig. IV-16. PM-1 Steam Generator Data 
V. CONFIGURATION
Project Engineer--Sections B,C, and D: R. Akin
Section E: C. Fox

A. GENERAL CONSIDERATIONS

Parametric Studies of PM-1 plant configuration dealt with the following main technical areas:

(1) Primary loop configuration, which concerned the practical requirements of equipment arrangement, including access for maintenance, piping, stresses, access for reactor refueling operations, module center-ofgravity location during shipment and total weight per module during shipment.

(2) Primary loop containment, which concerned types of vessel design, including single and multiple vessels, both code and noncode; various materials of construction; and types of closure.

(3) Shielding, which concerned water level requirements for refueling, general biological shield studies, and general support of primary loop layout work.

(4) Packaging and shelter, which concerned PM-1 module design and types of shelter--including shipping requirements, panel design, rigid base design, and heat loss calculations.

These efforts are closely associated with the equipment and cycle characteristics of the plant. For this reason equipment conditions were assumed which would be somewhat conservative and. which generally conformed to the PM-I reference design set forth in MND-1558. The conditions chosen were as follows:

Primary loop pressure
Primary pipe size
Contained energy
Equipment weight limit
Package dimensions
$\quad$ available for equipment
No. of condenser packages
Steam generator size (vertical)
Maintenance access

Primary loop pressure

Package dimensions avallable for equipment

Steam generator size (vertical)

Maintenance access
2000 psi

6 in. ips, Sch 120

$2,094,000 \mathrm{Btu}$

$25,000 \mathrm{Ib}$

8 ft 2 in. $x 7$ ft 8 in. $x 29$ ft 6 in. 2

32 in. $D \times 15 \mathrm{ft}--11,000 \mathrm{lb}$

Steam generator tubes, refueling, pumps, resin, actuators

The conclusions reached in this area of study were necessarily general and must be implemented by additional study of the selected plant operating conditions. This wlll occur during preliminary design, Task 3.2 of the PM-1 program.

\section{B. PRTMARY LOOP CONFIGURATION}
H. Brainard
H. Clark
J. Todd

Scope of Studies

Primary loop configurations consistent with our containment philosophy were studied. All primary loop concepts were subject to the following considerations: 
(1) The primary loop is to be transported in a minimum number of shipping packages by air, rail, truck or ship.

(2) Shipping packages are to be either square or circular in cross section and desigmed according to the following specifications, which must be met if the plant is to be shipped in C-130-type aircraft.

(1) Square cross section package--8 ft 8 in. wide $x 8$ ft 8 in. high $x$ $30 \mathrm{ft} 0$ in. long.

(2) Circular cross section package--8 ft 8 in. diameter $\times 30$ ft 0 in. overall length.

(3) Total package weight, square or circular, including any primary loop components shipped within it, not to exceed $30,000 \mathrm{Ib}$.

(4) Square packages to be of noncode design using 50,000 1b/ in. ${ }^{2}$ allowable stress.

(5) Circular packages to be designed both for ASME code and noncode designs, the latter using a 50,000 1b/in. ${ }^{2}$ allowable stress.

(3) The primary loop is to be designed so that field welding is not necessary.

(4) Packages are to be capable of installation at the site either above ground or with minimum excavation.

(5) No concrete will be employed for shielding.

(6) Packages are to be adaptable to relocation.

(7) Personnel must have access to the reactor package for refueling operations within elght hours after shutdow.

(8) The arrangement of the primary system is to be such that minimum modification is required in switching between the contained and noncon tained versions.

Investigations were made of various basic primary loop arrangements. Those considered were:

(1) Square Package--In this arrangement, the primary loop is mounted and shipped in two flat-sided packages. Water is to be used as the biological shield. (See Fig. V-1.)

(2) Circular Package--In this arrangement, the primary loop is mounted and shipped in two cylindrical packages and employs site backfill as the blological shield. (See Fig. V-2.)

(3) A single package primary loop, containing both steam generator and reactor. (See Fig. V-3.)

Concept Evaluation

As a result of these layouts, the following practical points concerning the arrangement of the primary system were established: 

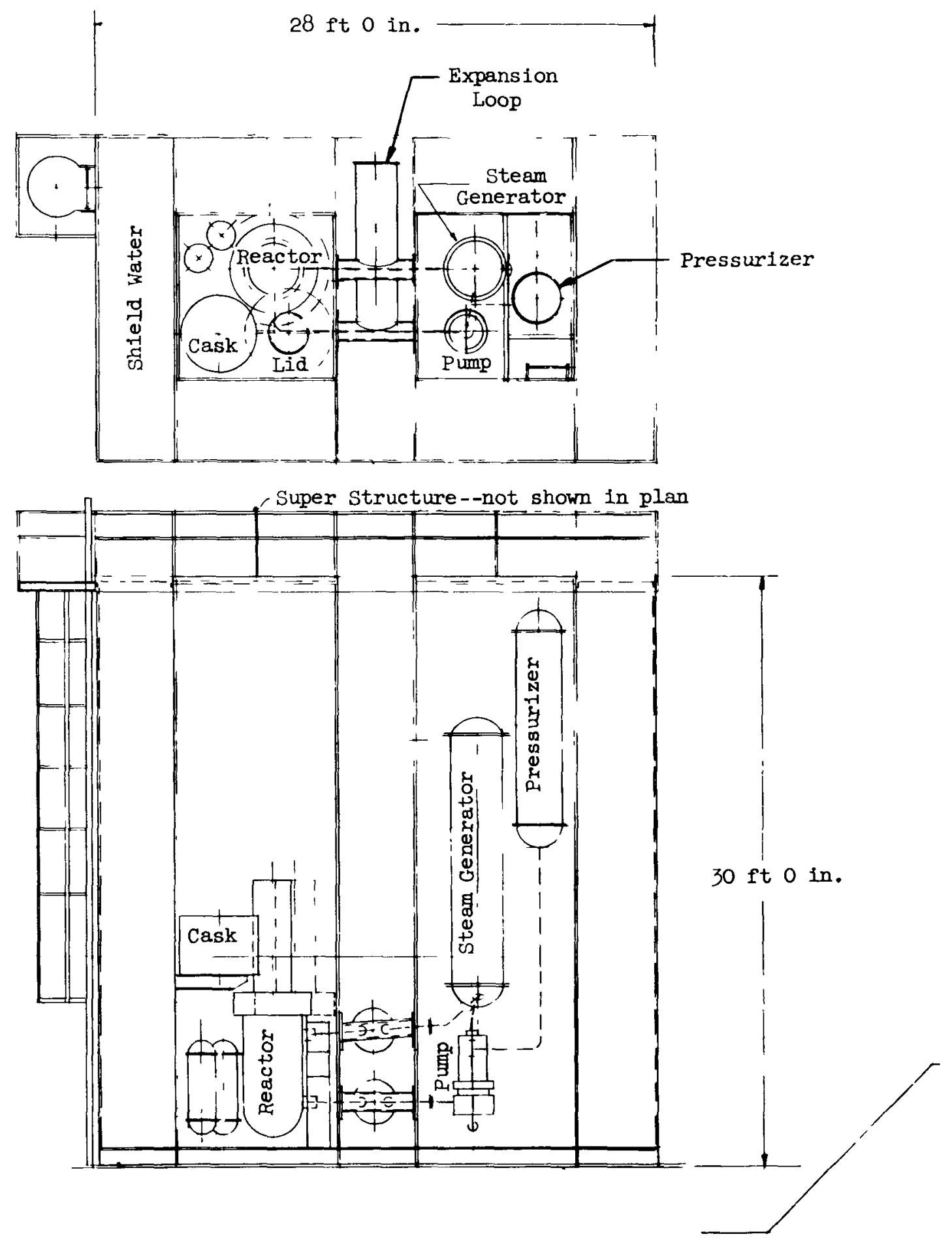

Fig. V-1. Primary Loop Arrangement--Two Square Packages 



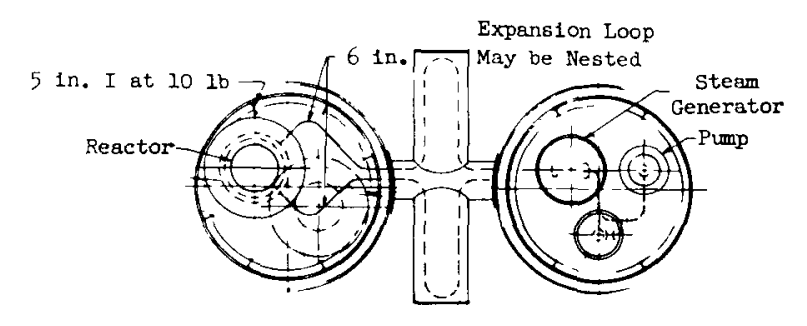

Plan - Local Bolling Reactor Plant

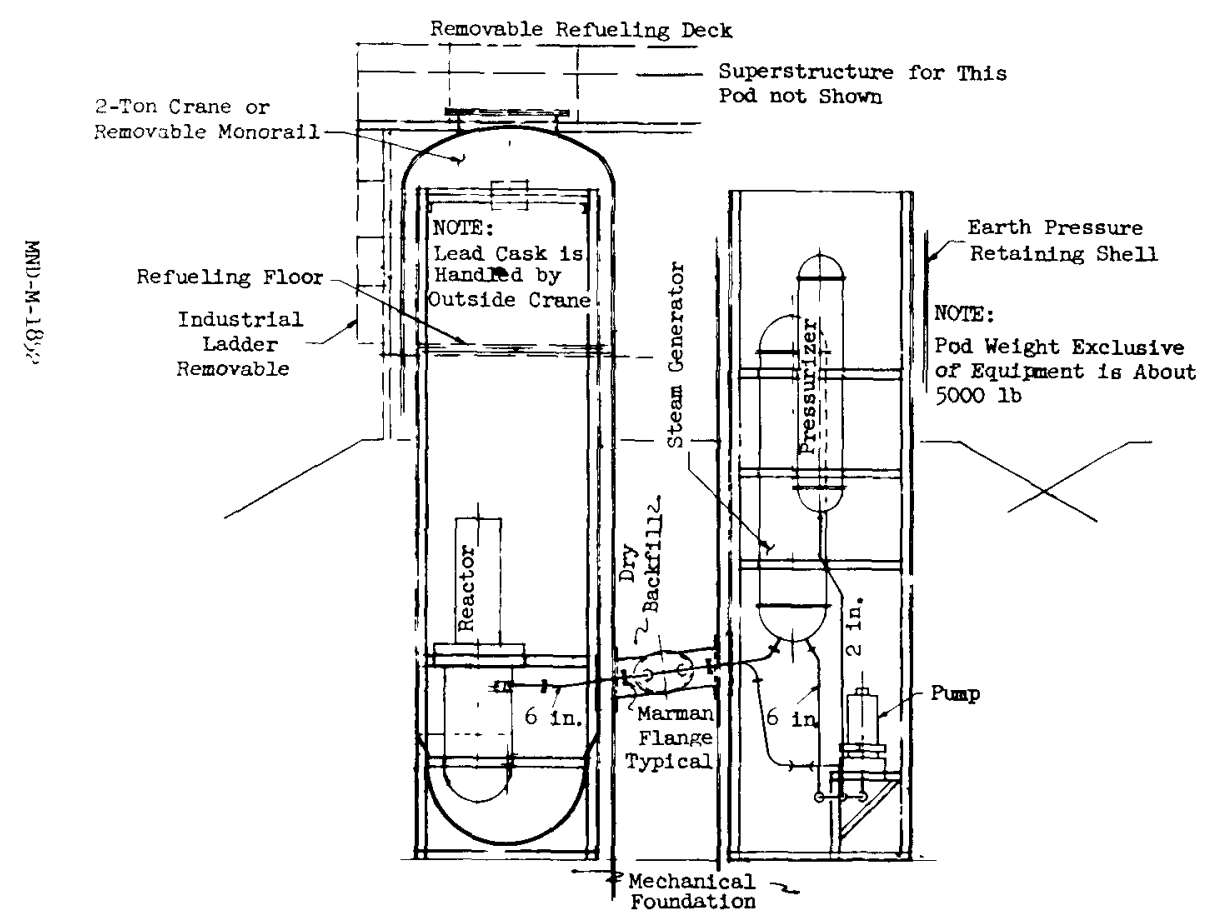

Elevation - Local Boiling Resctor Plant
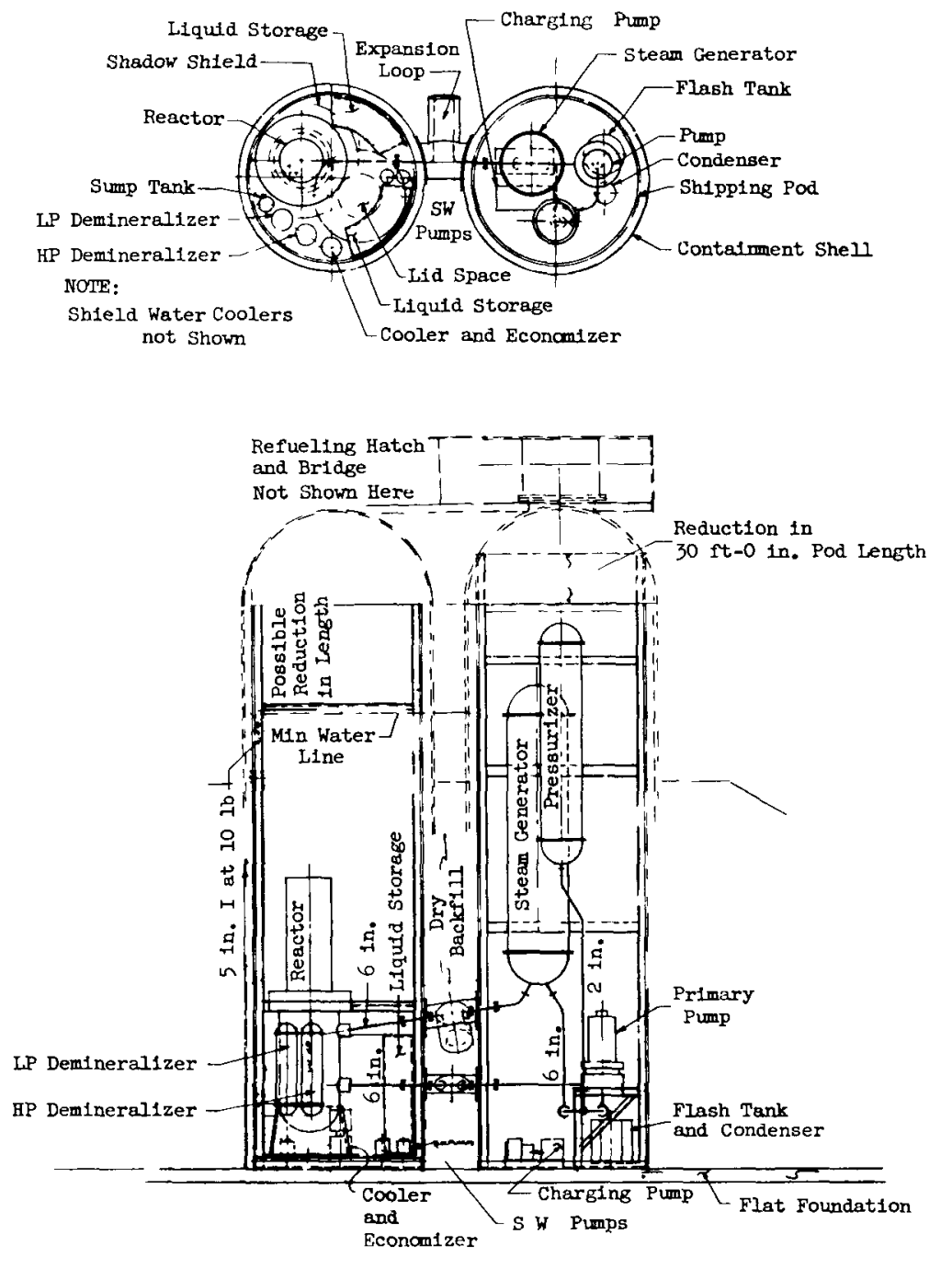

Fig. V-2. Circular Tank Complex--Dry Backfill 

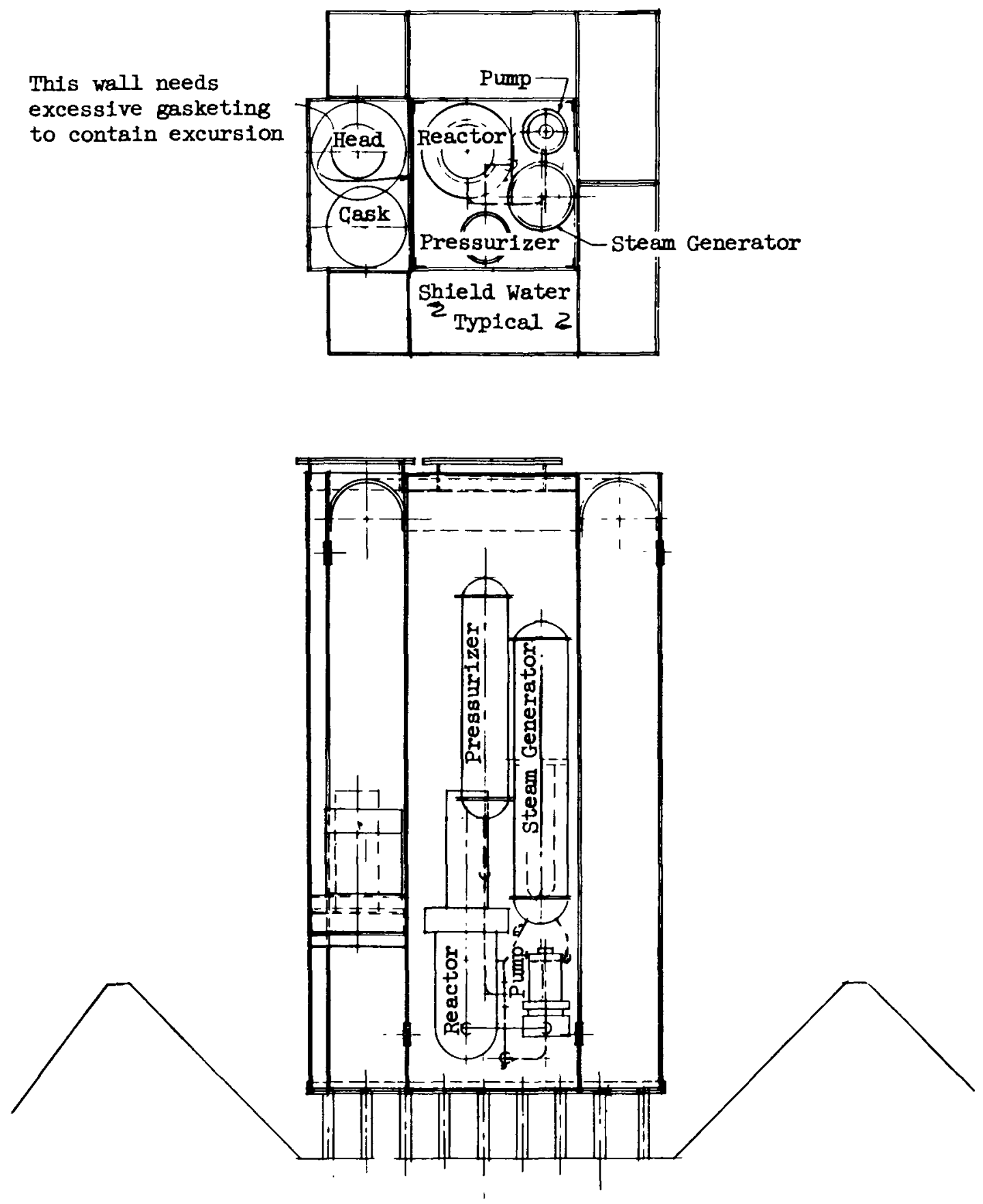

F1g. V-3. Primary Loop Arrangement--One Square Package 
(1) The concept of using water as the only biological shield material was abandoned. Site backfill is considered more desirable due to the limited water supply ( $6 \mathrm{gpm})$ at the proposed site, as well as the additional cost necessary for fabricating and shipping shield water tanks.

(2) Water, as an additional shield material placed in the tank containing the reactor vessel, is necessary for protection of personnel during refueling operations as well as for removing the afterheat of a spent core.

(3) The vessel to hold the shield water is to be a welded cylindrical tank constructed of steel plate. A flat-paneled tank is considered inefficlent both structuraliy and economically. Use of aluminum presents problems in strength and fabrication.

(4) Arrangement of primary system components within two cylindrical tanks of $8 \mathrm{ft} 8$ in. diameter by $30 \mathrm{ft}$ in length is possible with due regard given to space requirements needed for refueling operations, maintenance, pipe runs, spent fuel storage, etc.

(5) The tank containing the reactor vessel should be vertical to provide room for refueling operations and maintain approximately $9.7 \mathrm{ft}$ of water above the reactor core for the protection of personnel.

(6) The additional packages or tanks containing the steam generator, pressurizer and associated components may be either horizontal or vertical.

(7) Depending on the final containment parameters (i.e., excursion peak pressures as effecting tank strength and weight), an additional objective is to establish a primary system arrangement which permits shipment of a containment tank and its integrally mounted equipment as one package.

(8) Double shell construction against earth pressures induced by the backfill is unnecessary. The original intention of speeding plant installation and relocation is not enhanced by this means.

(9) Relocation of a single tank is not seriously impeded by the use of site backfill around the tank. Areas of serious activation can be predicted in advance and isolated through the use of cribbing, piling, etc.

(10) Shipping of the primary loop components integrally mounted within two $8 \mathrm{ft} 8$ in. cylindrical containment tanks which also serve as shipping packages will not be possible within package weight limitations. For the noncontained version, integral mounting of major equipment appears possible.

(11) Maximum adaptability to either contained or noncontained versions is gained through the use of the same tanks for containment and for retaining of the site backfill; however, due to minimum skin thicknesses of $1 / 4$ in., set by ASME code requirements, basic shell weight (without upper head and flange) is at least $8520 \mathrm{lb}$ using "T-1" material. The dual use concept limits, therefore, the permissible equipment weight per package.

During the early phases of the parametric study the most promising arrangement appeared to be the square two-package complex with a perimeter of rectangular shield water tanks (Fig. V-I). The units were intended for vertical installation above the ground line. The advantages were seen to be: 
(1) Maximum space within the limiting dimensions was available for equipment placement. Sufficient personnel access to components requiring maintenance was afforded.

(2) Maximum space was available for refueling operations.

(3) No excavation was required. Blological shielding was accomplished through the use of shield water tanks and metallic shadow shields adjacent to the reactor vessel.

(4) Minimum erection and site preparation effort was required.

(5) The primary piping layout was ideal with low wall stresses and minimum end moments applied to equipment.

On the other hand, the following disadvantages were inherent in this approach:

(1) Elaborate structural reinforcement was necessary to guarantee structural integrity of flat-sided tanks against hydrostatic pressure.

(2) Although the required structural reinforcement could be reduced using sandwich construction paneling (i.e., urethane core bonded to metallic faces), paneling of this type is relatively expensive and, when subjected to radiation, may not maintain bonding strength.

(3) Avallable water supply at the proposed site was insufficient to fill the shield water tanks in a reasonable time.

(4) At least two plane loads would have been required to transport the shield water tanks.

A single square package containing the reactor, steam generator, pump and pressurizer was laid out (Fig. V-3). This design had all of the disadvantages of the two square package design and in addition had three others:

(1) The radiation levels were too high for maintenance operations without extensive shielding.

(2) An extra package was required to ship the head and the refueling cask.

(3) The neutron radiation level at the pump was such that pump life would be impaired.

A third concept investigated (Fig. V-2) was the two-package circular tank arrangement using site material backfill as the biological shield. This concept proved satisfactory with regard to equipment arrangement, primary loop piping, refueling and supports and structural members necessary to withstand internal and external pressures.

Aluminum was seriously considered as a means for reducing overall package weight. The disadvantage of this alternative was that welding would reduce the allowable working stress to approximately $10,000 \mathrm{psi}$. Since thicker sections would be required, the welght situation would not be appreciably improved. 
From consideration of the containment tank welghts discussed in Section V-C, and of the allowable total package limit of $30,000 \mathrm{lb}$, it became apparent that all equipment could not, in a two-package primary system, be shipped in the tanks.

Infially, it was intended that the reactor shipping package include the following primary loop components having these estimated weights:
(1) Reactor vessel
9600
(2) Mount
1200
(3) Demineralizers
2000
(4) 6 in. S.s. piping
1000
(5) Insulation and condult
$\underline{250}$
Total 14,050 1b

The steam generator shlpping package was to include the following primary loop components having these estimated weights:
(1) Steam generator
11,000
(2) Pressurizer vessel
3,000 (3) 6 in. and 2 in. S.S.
piping
2,000
(4) Charging pumps
600
(5) Waste pumps
200
(6) Auxiliary piping
(7) Insulation
(8) Shield water pumps
(9) Primary pump

Total $\frac{2,500}{19,9301 b}$

It will be shown in the next section that, while the basic uncontained primary plant consists of two modules and the contained version consists of three modules, it may be necessary to ship the uncontained primary plant in three packages and the contained version in four packages. It should be noted, however, that the welght of the additional shipping package, in all cases other than that of the codedesigned contained configuration, is less than one-half of the allowable maximum; it may be possible to ship sufficient secondary system equipment in this additional package to eliminate a secondary system package. housing.

A separate package will be required in each case for the crane and above-grade 


\section{PRTMARY LOOP CONTATMMENT}

P. Mon

J. Todd

\section{Scope of Studies}

This study was concerned with the investigation of feasible containment concepts that were consistent with an optimum primary loop configuration. The following requirements and objectives were established as preliminary guides for the containment investigations :

(1) The vapor container shall be designed to be independent of the plant equipment housed therein to assure that there will be a minimum of changes in system and package design when switching between the contained and noncontained versions of the plant. The design of the vapor container shall permit removal of any components housed therein with minimum damage to the container; provisions for personnel access shall be included.

(2) The components of the vapor container must be transportable in C-130type aircraft. The vapor container shall be d signed to incorporate maximum prefabrication at the factory in order to reduce the on-site construction effort.

(3) The containment shall be capable of installation and test in a maximum of four weeks under conditions typical of arctic construction. A maximum number of containment components and structures shall be relocatable.

(4) The containment must provide access for personnel, small equipment and shielding for reactor and associated components sufficlent to permit the refueling of the reactor to begin not later than $8 \mathrm{hr}$ after shutdown. Personnel access is not required during reactor operation.

(5) Concepts involving leakage may be considered during the parametric study. Such leakage shall not expose military personnel at the base to more than 25 rem for a maximum incident. Dosage due to ingestion of activity may not exceed tolerance.

(6) Shielding concepts which may affect containment are as follows:

(1) To the maximum extent possible, plant arrangement will be such that shielding may be reduced in areas requiring little or no access during operation. In accord with AEC regulations, doses as high as 3 rem can be permitted for personnel activities required only a few times per year, provided dosage does not exceed 3 rem in any 13-week period or 5 rem in any one year.

(2) The use of local site materials such as soil and aggregate for shielding may be considered for those sites where substantial savings may be realized therefrom.

(3) Adequate water will be available for use as reactor shielding during refueling. It may not be assumed that large quantities of water will be available for "once-through usage." All water will be recirculated if water cooling is required. 
(7) Designs which are capable of installation with the prepackaged plant modules above ground level are preferred, since they are adaptable to the maximum number of sites.

(8) The containment must be insulated and/or heated to assure proper performance with ambient temperatures as low as $-60^{\circ} \mathrm{F}$.

(9) Containment designs which do not conform to the ASME unfired pressure vessel code may be considered during the parametric study. It is necessary, however, that a clearly stated exception be made and that AEC approval be obtained if a noncode design is used.

(10) The containment vessel(s) and structure shall have a design life of $20 \mathrm{yr}$.

(11) A means of absorbing or quenching the energy released by rupture of the primary loop shall be provided in order to reduce, after an incident, the time that the containment is exposed to peak pressure.

A maximum credible incldent was defined for purposes of parametric study efforts. The incident, selected to be conservative, was based on a 2000 psia system and the following assumptions:

(1) The primary loop will rupture and release all of the primary fluid into the containment vessel.

(2) The energy contained in the released fluid is $2,094,000 \mathrm{Btu}$, the total of three sources:

(1) Excursion energy due to a reactor power transient of approximately $300,000 \mathrm{Btu}$.

(2) Stored heat in the loop, calculated for approximately $88 \mathrm{ft}^{3}$ of water at $2000 \mathrm{psi}$ and $500^{\circ} \mathrm{F}$.

(3) Afterheat developed in the reactor during release of the fluid, at approximately $60,000 \mathrm{Btu}$.

During the parametric studies, an alternate incident was also defined, based on a 1500 psia primary system.

Numerous methods of containing the plant primary loop incident were investigated. Twelve configurations were developed to the point of making scaled sketches and determining design pressures, approximate weights, and number of airplane loads.

\section{Evaluation of Concepts}

Several important conclusions were reached during the parametric study perlod. These conclusions represent a consolidation of PM- 1 requirements and objectives and may be briefly sumarized as follows:

(1) A large, single-vessel containment is not to be used. Difficulties are foreseen in that the unit would have to be shipped in segments and would require a lengthy field assembly prior to equipment installation, additional shipping packages, and some primary system modifications for the noncontained version. Relocatability would be poor. 
(2) A containment concept utilizing three interconnected tanks with integrally shipped equipment is possible with the primary system operating pressure at approximately $1500 \mathrm{psi}$. This was determined fram consideration of the peak excursion pressures as a function of the total containment volume and the resulting tank weights. From Table V-1, the basic shell weight (code design) for "T-1" material is seen to be a minimum at 3 tanks, with a peak excursion pressure of 102 psig. Use of only two tanks for containment leads to excessive tank weight preventing integral mounting of all primary loop equipment during shipment.

(3) A containment concept utilizing four interconnected air-transportable tanks is required with the primary system operating significantly above $1500 \mathrm{psi}$. This is necessary to allow for larger and heavier loop components; a greater containment volume is also required to reduce tank weight.

(4) A containment concept utilizing two interconnected air-transportable tanks with integrally shipped primary loop equipment is not possible at any primary system operating pressure. Excessive tank weights would be required and the allowable weight of integrally-mounted equipment would be severely limited.

(5) No shield water will be utilized except in the reactor package. This is partly due to the limited supply of water at the site (6 gpm). In addition, site backfill will provide a more satisfactory biological shield. Water will serve as the shield material only in the immediate area of the reactor vessel and core, and will be maintained at a level of $9.7 \mathrm{ft}^{\mathrm{a}}$ above the core at all times. This will provide the required biological shielding for personnel during refueling operations, as well as provide a coolant reservolr for removal of spent core afterheat.

(6) Double-shell concepts are not to be used to retain earth backfill. Use of either cribbing for backfill retention or backfilling directly against the tank shell after erection allows each unit to meet the relocation criteria while enabling use of the $8 \mathrm{ft} 8 \mathrm{in}$. diameter shipping dimension to the maximum benefit for arrangement of primary loop equipment. For our use, ASME code requirements dictate a minimum shell thickness of $1 / 4$ in. This results in a basic tank suitable for backfill retention and/or pressure containment with only a nominal addition of structural members. It is also considered that site installation time would not be appreciably reduced by preinstallation of earth-retaining tanks. Backfill could be completed after placement of the equipment tanks, during interconnection and testing of primary loop components.

(7) Even in the cases described in 2 and 3 above, weights of tanks and equipment may not allow shipping fully assembled primary system components. Design efforts will emphasize maximum integral mounting of primary system components and shipment within the containment tanks. After considering the various primary loop arrangements, it is felt that the loop components can be installed and shipped within two of these $8 \mathrm{ft} 8 \mathrm{in}$. diameter tanks. 
TABIE V-I

Basic Shell Weight (ASME Code Design)

\begin{tabular}{|c|c|c|c|c|c|}
\hline $\begin{array}{l}\text { No. of } \\
\text { Tanks }\end{array}$ & $\mathrm{v}$ & $\mathrm{P}$ & $\mathrm{t}_{\text {Required }}$ & $\mathrm{t}_{\text {Actual }}$ & Wt/Pk \\
\hline 2 & 2,110 & 150 & 0.364 & 0.375 & 12,800 \\
3 & 3,800 & 102 & 0.247 & 0.25 & 8,520 \\
4 & 5,500 & 72 & 0.174 & $0.25^{*}$ & 8,520 \\
\hline
\end{tabular}

*Minimum of 0.250 Required by Code

$$
\begin{aligned}
& t_{\text {Required }}=\frac{P R}{S E-0.6 P}=\frac{P \times 52}{21,500-0.6 P} \\
& \text { wt }=P\left(2 \pi p h t+4 \pi R \times \frac{R}{2} \times t\right) \\
& \text { wt }=P t(2 \pi \times 52 \times 308+4 \pi \times 52 \times 26) \\
& \text { wt }=0.29(101,000+17,000) t \\
& \text { wt }=34,200 t
\end{aligned}
$$

where

$$
\begin{aligned}
& \mathrm{P}=\text { Pressure, psi } \\
& \mathrm{H}=\text { Height, in. } \\
& \mathrm{R}=\text { Radius, in. } \\
& \mathrm{t}=\text { Thickness of Shell, in. } \\
& \mathrm{wt}=\text { Weight, lb }
\end{aligned}
$$

NOTE

1. Maximum Allowable Stress 26,250 psi

2. Allowance of 5,000 psi Made for Discontinuities 
(8) If it is required that the reactor pressure vessel be shipped and relocated on a separate shipping pallet, a 7-ft diameter opening is necessary at the top of the containment tank for removal of this unit. Vessel dimensions and crane clearance for both refueling and reactor installation establish this as the minimum opening.

(9) If the reactor vessel does not have to be shipped separately, the minimum opening necessary at the top of the containment tank is 3.5 ft in diameter, which is required to accommodate the spent core shipping cask during refueling operations. A crane is also needed to position the core, reactor vessel head, and demineralizer cartridges during refueling and maintenance operations.

\section{Design Considerations}

Of the numerous containment concepts studied, four of the multiple-tank configurations will receive further study. A concept using three containment tanks is being developed under preliminary design (Task 3.2) and useful parts of the above configurations will be modified for use in this concept. Tables V-5 and V-6 describe all concepts considered and indicate those to be studied further.

The multiple tank configurations were chosen for further development because they lend themselves to conversion from contained to uncontained versions by either using or eliminating additional containment volume tanks. The multiple tank method is also adaptable to above or below-ground installations by supplying the necessary structure for either case. There is a distinct possibility of avoiding field welds and keeping leakage to a minimum with this type of configuration.

In order to keep the number of tanks required for containment to a minimum, the design pressures in the above concepts become high. The tanks then become heavy (See Tables V-2 and $\mathrm{V}-3$ ) and greatly restrict the weight of equipment that could be shipped within them. To overcome this difficulty, the equipment, in some cases, should be mounted on skids to be shipped separately. This procedure allows the full use of the 30,000-1b shipping limitation for equipment and skids.

The multiple-tank concept presents a problem in joining the tanks together. Conventional bolted flanges consume allowable shipping space and are extremely heavy. The Conoseal Division of the Marman Co. was contacted concerning the possibility of using clamp-type joints in sizes ranging from 40 to $96 \mathrm{in}$. In diameter and at pressures from 65 to $150 \mathrm{psig.} \mathrm{The1r} \mathrm{design} \mathrm{engineers} \mathrm{felt} \mathrm{that} \mathrm{clamps} \mathrm{in} \mathrm{ranges}$ from $36 \mathrm{in.} \mathrm{to} 40 \mathrm{in.} \mathrm{diameter} \mathrm{were} \mathrm{feasible,} \mathrm{but} \mathrm{anything} \mathrm{larger} \mathrm{would} \mathrm{require}$ extensive development. Large clamp-type joints tend to warp during welding and, if the parts were welded first and then machined, the overall machining would be costly.

Preliminary analysis using the ASME Pressure Vessel Code indicates that a single flange depth of about $7 \mathrm{in}$. will be required for an $8 \mathrm{ft} 8 \mathrm{in}$. diameter opening, presenting an additional welght problem. Furthermore, the code is not conservative, since flange stiffness, proper gasket seating and minimum flange deformation (rather than strength) are the important considerations. While code allowable stresses carry a safety factor of four, flange depth for proper gasket seating does not, and sealing requirements overshadow strength requirements.

An investigation was made to determine the minimum number of packages required to hold the reactor package and the steam generator package including integrally - 
mounted equipment within their allowable shipping weight limits of $30,000 \mathrm{Ib}$. Tables V-2 and V-3 show how the package weight becomes smaller as the number of packages increases. As the total contalnment volume increases, the maximum peak pressure decreases and hence the required package thickness. These designs are based on both code- and non-ASME-code designs for T-1 steel. It should be pointed out that a limiting factor for the number of packages used is the skin thickness. For a number of noncode packages greater than four, the skin thickness becomes too small if determined by contained pressure and is set by such other considerations as corrosion and handing.

The ASME code allowable for $\mathrm{T}-1$ is $26,500 \mathrm{ps} 1$ with the additional requirement of a minfmum skin thickmess of $0.25 \mathrm{in}$. This requirement automatically limits the use of many packages to reduce the design pressure. The welght allowance for intermal structure in Tables $\mathrm{V}-2$ and $\mathrm{V}-3$ is approximate and could increase. Such considerations as earth loads and erection loads may also require heavier internal structures.

Using Table V-l as a guide to selection of the optimum number of tanks for an ASME design, a three-tank concept was decided upon since the code requires a minimum shell of $0.250 \mathrm{in}$. and in a three-tank concept the requirement is $0.247 \mathrm{in}$. The estimated package welghts for a contained and noncontained three-tank configuration are tabulated in Table V-4 using the shell welghts from Tables VI-2 and VI-3 for a 1500 psi primary system pressure. The equipment welghts used in establishing the package weights are for an incident with primary system operating pressure at $1500 \mathrm{ps1}$. For a breakdown of equipment integrally mounted for shipment in the packages see Tables V-7 to V-10. Each table contemplates a threetank system with a primary operating pressure of $1500 \mathrm{psi}$ and temperature of $465^{\circ} \mathrm{F}$.

Further Investigation of vapor contalnment design will be required. Accordingly, areas of investigation during the preliminary design phases have been established as follaws:

(1) Welghts of code-built containment tanks (with and without cover heads for flanged or fleld-welded connection) will be determined. Consideration w1ll be given to necessary structural members for shell integrity, equipment support and shipping mounts.

(2) A feasible equipment layout will be developed meeting the primary loop conditions recently established (see Section VI-B). Due consideration will be given to flexible pipe runs, equipment size and weight, mounting and maintenance and refueling requirements.

(3) The feasibility of the following will be given detailed consideration:

(1) Mounting the primary loop components on structures which may be installed in two $8 \mathrm{ft} 8 \mathrm{in}$. dlameter $\times 30$-ft long tanks.

(2) Shipping the system in the form of: primary loop structures, coded containment tanks to house the structures and additional coded containment tanks.

Investigations will include consideration of structural supports, shipping limitations, site preparation, installation problems and system housings. Particular emphasis will be placed on the design of a three-unit system.

(4) The number of packages required to ship equipment integrally using the coded containment tank, less head, as a shipping package will be determined. 
TABLE V-2

Estimated Package Welght (Non Code Design)

\begin{tabular}{|c|l|l|l|l|c|c|}
\hline $\begin{array}{c}\text { No. } \\
\text { Package }\end{array}$ & $\begin{array}{c}\text { System } \\
\text { Pressure }\end{array}$ & $\begin{array}{c}\text { Basic } \\
\text { Shell }\end{array}$ & Flange & $\begin{array}{c}\text { Internal } \\
\text { Structure }\end{array}$ & $\begin{array}{c}\text { Weight } \\
\text { per } \\
\text { Package }\end{array}$ & $\begin{array}{c}\text { Possible Equip- } \\
\text { ment Weight }\end{array}$ \\
\hline 2 & 2,000 & 6,400 & 7,500 & 4,000 & 17,900 & 12,100 \\
3 & 2,000 & 4,260 & 6,000 & 4,000 & 14,260 & 15,740 \\
4 & 2,000 & 2,740 & 4,800 & 4,000 & 11,540 & 18,460 \\
2 & 1,500 & 5,100 & 6,000 & 4,000 & 15,100 & 14,900 \\
3 & 1,500 & 3,400 & 4,800 & 4,000 & 12,200 & 17,800 \\
4 & 1,500 & 2,200 & 3,900 & 4,000 & 10,100 & 19,900 \\
\hline
\end{tabular}

Material: T-1, Allowable Working Stress 50,000 psi

TABLE V-3

Estimated Package Weight (Code Design)

\begin{tabular}{|c|l|r|l|l|c|c|}
\hline $\begin{array}{c}\text { No. } \\
\text { Package }\end{array}$ & $\begin{array}{l}\text { System } \\
\text { Pressure }\end{array}$ & $\begin{array}{c}\text { Basic } \\
\text { Shell }\end{array}$ & Flange & $\begin{array}{c}\text { Internal } \\
\text { Structure }\end{array}$ & $\begin{array}{c}\text { Welght } \\
\text { per } \\
\text { Package }\end{array}$ & $\begin{array}{c}\text { Possible Equip- } \\
\text { ment Weight }\end{array}$ \\
\hline 2 & 2,000 & 12,800 & 7,500 & 4,000 & 24,300 & 5,700 \\
3 & 2,000 & 8,520 & 6,000 & 4,000 & 18,520 & 11,480 \\
4 & 2,000 & 8,520 & 4,800 & 4,000 & 17,320 & 12,680 \\
2 & 1,500 & 10,200 & 6,000 & 4,000 & 20,200 & 9,800 \\
3 & 1,500 & 8,520 & 4,800 & 4,000 & 17,320 & 12,680 \\
4 & 1,500 & 8,520 & 3,900 & 4,000 & 16,420 & 13,580 \\
\hline
\end{tabular}

Materlal: T-1, Allowable Working Stress 26,500 psi Minimum Thickness 0.250 in. 


\section{TABLE V-4}

Three-Tank Conf1guration--Estimated Welghts of Shlpping Packages

\begin{tabular}{|c|c|c|c|c|c|c|}
\hline \multirow{7}{*}{ 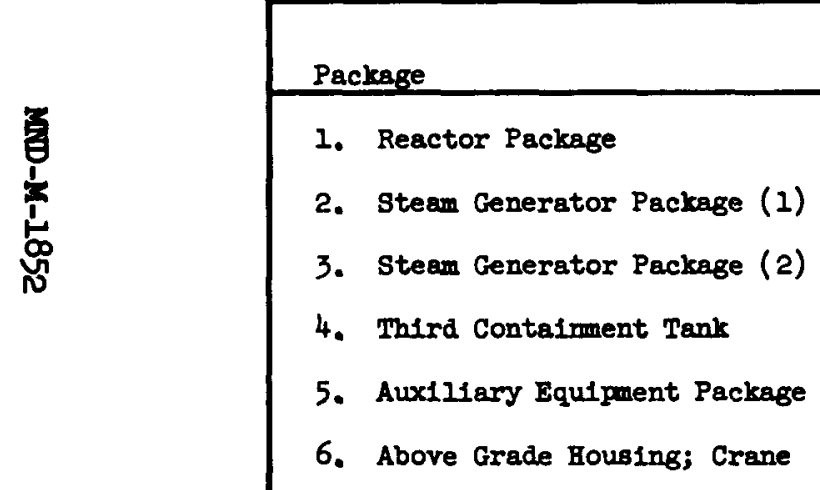 } & $\begin{array}{l}\text { Non Coded Contained } \\
\text { Flanged Welded } \\
\end{array}$ & \multicolumn{2}{|c|}{$\begin{array}{l}\text { Non Coded Non Contained } \\
\text { Flanged }\end{array}$} & $\begin{array}{l}\text { Coded Contained } \\
\text { Flanged Welded } \\
\end{array}$ & \multicolumn{2}{|c|}{$\begin{array}{l}\text { Coded Non Contained } \\
\text { Flanged Welded }\end{array}$} \\
\hline & 26,250 & 28,950 & 26,950 & $28,570 \quad 26,570$ & 28,570 & 26,570 \\
\hline & 29,600 & -- & -- & $27,320 \quad 23,320$ & -- & -- \\
\hline & -- 26,930 & 26,930 & - & -- 29,430-. & $\quad-\quad 29,430$ & -- \\
\hline & $12,200 \quad--$ & -- & -- & $25,020 \quad 19,020$ & -- & -. \\
\hline & -- & 11,900 & -- & $--\quad-$ & -- $\quad 14,900$ & -- \\
\hline & - $28,500 \quad \ldots$ & & $\cdots$ & $--28,500 \ldots$ & - 28,500 & \\
\hline
\end{tabular}




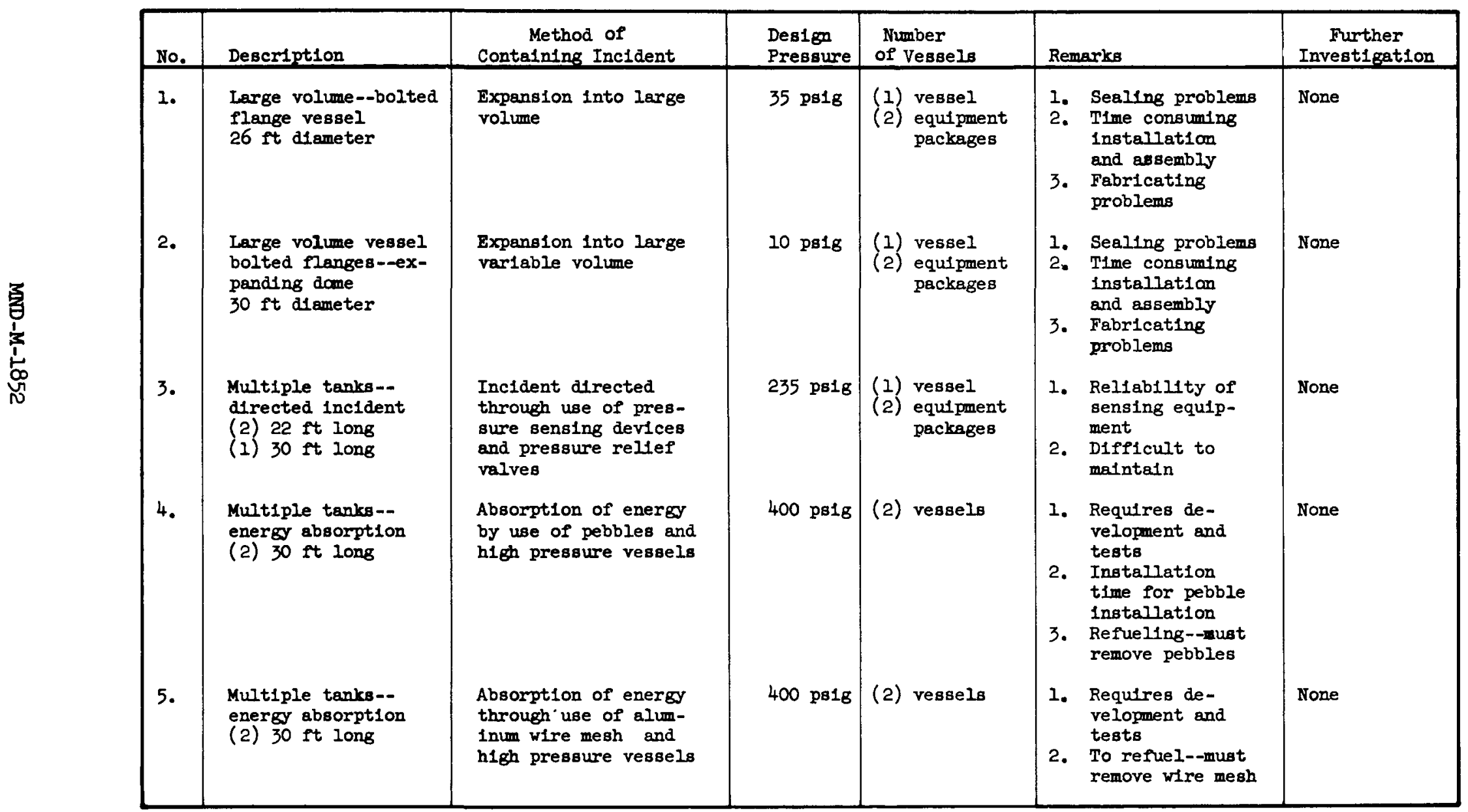




\section{$\underline{\text { TABLE V-5 (continued) }}$}

\begin{tabular}{|c|c|c|c|c|c|c|}
\hline INo. & Description & $\begin{array}{c}\text { Yethod of } \\
\text { Containing Inc1dent }\end{array}$ & $\begin{array}{l}\text { Des1gn } \\
\text { Pressure }\end{array}$ & $\begin{array}{c}\text { Number } \\
\text { of Vessels } \\
\end{array}$ & Remarks & $\begin{array}{c}\text { Further } \\
\text { Invest1gation }\end{array}$ \\
\hline 6. & $\begin{array}{l}\text { Multiple tanks } \\
\text { (2) } 25 \text { ft long } \\
\text { (1) } 30 \text { ft long }\end{array}$ & $\begin{array}{l}\text { Expansion through full } \\
\text { dlameter of tenks into } \\
\text { hlgh pressure vessels }\end{array}$ & $150 \mathrm{psig}$ & (3) ressels & $\begin{array}{l}\text { 1. Equipment skdd- } \\
\text { mounted } \\
\text { 2. Fleld assembly } \\
\text { problems }\end{array}$ & $\begin{array}{l}\text { 1. Tank 1nter- } \\
\text { connections } \\
\text { 2. Materlals } \\
\text { 3. Equi pment } \\
\text { arrangement } \\
\text { 4. Use of Innex } \\
\text { shells }\end{array}$ \\
\hline 7. & $\begin{array}{l}\text { Multiple tanks } \\
\text { (4) } 30 \mathrm{ft} \text { long }\end{array}$ & $\begin{array}{l}\text { Expansion through full } \\
\text { dfameter of tanks into } \\
\text { hlgh pressure ressels }\end{array}$ & 85 psig & (4) vesselo & $\begin{array}{l}\text { 1. Equipment skedd- } \\
\text { mounted } \\
\text { 2. Fleld assembly } \\
\text { problems }\end{array}$ & $\begin{array}{l}\text { 1. Tank 1nter- } \\
\text { connections } \\
\text { 2. Yaterials } \\
\text { 3. Equipment } \\
\text { arrangenent } \\
\text { 4. Use of Inner } \\
\text { she118 }\end{array}$ \\
\hline 8. & $\begin{array}{l}\text { Mult1ple tanks } \\
\text { (2) Horlzontal-- } \\
30 \mathrm{ft} \text { long } \\
\text { (2) Vert1cel-- } \\
15 \mathrm{ft} \text { long }\end{array}$ & $\begin{array}{l}\text { Expansion through full } \\
\text { dfameter of tanks and } \\
\text { through bullkeads with } \\
\text { pressure d1aphragas } \\
\text { Into high pressure } \\
\text { vessels }\end{array}$ & $150 \mathrm{psig}$ & (4) vessela & $\begin{array}{l}\text { 1. Skid-mounted } \\
\text { equipment } \\
\text { 2. Fleld assembly } \\
\text { not too diff1- } \\
\text { cult } \\
\text { 3. Pressure dis- } \\
\text { phragms required }\end{array}$ & $\begin{array}{l}\text { 1. Tank 1nter- } \\
\text { connections } \\
\text { 2. Katerlals } \\
\text { 3. Equi prent } \\
\text { arrangement } \\
\text { 4. Use of 1nner } \\
\text { shells }\end{array}$ \\
\hline 9. & $\begin{array}{l}\text { Multiple tanis } \\
\text { (2) Hor1zontal-- } \\
30 \mathrm{ft} \text { long } \\
26 \mathrm{ft} \text { long } \\
\text { (1) Verticel-- } \\
15 \mathrm{ft} \text { long }\end{array}$ & $\begin{array}{l}\text { Expansion through full } \\
\text { dlameter of tanks and } \\
\text { through bultheads if th } \\
\text { pressure dfaphroger } \\
\text { Into high pressure } \\
\text { vessels }\end{array}$ & 200 pasg & (3) vessels & $\begin{array}{l}\text { 1. Skfd-mounted } \\
\text { equipment } \\
\text { 2. Field assembly } \\
\text { not too diffi- } \\
\text { cult } \\
\text { 3. Pressure dia- } \\
\text { phragms re- } \\
\text { qufred }\end{array}$ & Trone \\
\hline
\end{tabular}


TABLE V -6

PM-1 Containment Concepts

Conventional

\begin{tabular}{|c|c|c|c|c|c|c|}
\hline No. & Description & $\begin{array}{c}\text { Method of } \\
\text { Containing Incident } \\
\end{array}$ & $\begin{array}{l}\text { Design } \\
\text { Pressure } \\
\end{array}$ & $\begin{array}{c}\text { Number } \\
\text { of Vessels } \\
\end{array}$ & Remarks & $\begin{array}{c}\text { Further } \\
\text { Invest1gat1on }\end{array}$ \\
\hline 1. & $\begin{array}{l}\text { Large volume welded } \\
\text { vessel } 34 \mathrm{ft} \text { d.- } \\
\text { ameter }\end{array}$ & $\begin{array}{l}\text { Expansion Into large } \\
\text { volume }\end{array}$ & $35 \mathrm{psig}$ & $\begin{array}{l}\text { (1) vessel } \\
\text { equipment } \\
\text { peckages }\end{array}$ & $\begin{array}{l}\text { 1. Requires fleld } \\
\text { welding } \\
\text { 2. Requires concrete } \\
\text { 3. Earth back-f1ll } \\
\text { 4. Time consuming } \\
\text { 1nstellation } \\
\text { and assembly }\end{array}$ & None \\
\hline 2. & $\begin{array}{l}\text { Multiple tanks } \\
\text { (4) } 30 \mathrm{ft} \text { long }\end{array}$ & $\begin{array}{l}\text { Expansion through small } \\
\text { dlameter tubes, with } \\
\text { diaphragms, Into h1gh } \\
\text { pressure vessels }\end{array}$ & $82 \mathrm{ps} 1 \mathrm{~g}$ & (4) vessels & $\begin{array}{l}\text { 1. No field welding } \\
\text { 2. Earth back-f1il } \\
\text { or } \\
\text { 3. } 8 \text { shleld water } \\
\text { tanks }\end{array}$ & $\begin{array}{l}\text { 1. Flange joints } \\
\text { 2. Materials } \\
\text { 3. Equi pment } \\
\text { arrangement } \\
\text { 4. Use of Inner } \\
\text { shells }\end{array}$ \\
\hline 3. & $\begin{array}{l}\text { Multtple tanks } \\
\text { (4) } 22 \text { ft long }\end{array}$ & $\begin{array}{l}\text { Expansion through small } \\
\text { dlameter tubes, w1th } \\
\text { diaphragms, Into h1gh } \\
\text { pressure vessels }\end{array}$ & $115 \mathrm{psig}$ & $\begin{array}{l}\text { (4) vessels } \\
\text { (2) } \text { shleld } \\
\text { water } \\
\text { supply } \\
\text { tank }\end{array}$ & $\begin{array}{l}\text { 1. No fleld welding } \\
\text { 2. Earth back-f111 } \\
\text {. }\end{array}$ & $\begin{array}{l}\text { None } \\
\text { Not enough } \\
\text { maintenance room }\end{array}$ \\
\hline
\end{tabular}


TABLE V-7

Package Welghts--Non-Coded Contained System

1. Reactor Package
a) Shell (with head)
b) Reactor vessel
c) Mount
d) Demineralizer systems
e) 1/3 Primary loop pipe
f) Insulation

$$
\begin{gathered}
12,2001 \mathrm{~b} \\
9,600 \\
1,200 \\
2,000 \\
1,000 \\
250 \\
\hline 26,2501 \mathrm{~b}
\end{gathered}
$$

2. Stean Generator Package (contaiment)
a) Shell (with head)
b) Reactor head
12,200
c) Primary coolant pump motor
7,000 and impeller
d) Actuators
e) Two air blast coolers for shleld water
2,500

\begin{tabular}{l}
3,000 \\
4,900 \\
\hline $29,6001 \mathrm{~b}$
\end{tabular}

3. Steam Generator Package (structure and cover)
a) She11
b) Steam generator (vertical)
c) Pressurtzer
d) 2/3 Primary piping
e) Two charging pumps
7,000
11,000
3,000
2,000
600
f) Waste pump
200
g) Auxdliary piping
250
h) Insulation
250
1) Two shield water pumps
130
j) Primary pump involute and mount
$\frac{2,500}{26,93010}$

4. Third Containment Tank

a) Shell (w1th head)

$$
\frac{12,200}{12,20016}
$$

5. Butlding and Support Structure Holst, "A" Frame Gantry Structure

$$
\begin{array}{r}
24,500 \\
4,000 \\
\hline 28,5001 \mathrm{~b}
\end{array}
$$

NOTE: Weight of packages $\dot{i}, 2$ and 4 will be reduced by 4,000 ib each if head welding replaces flanges. 
TABLE V-8

Package Weights--Non-Coded, Non-Contained System

1. Reactor Package
a) Shell
b) Reactor vessel
9,400
c) Mount
d) Demineralizer systems
1,200
e) $1 / 3$ Primary loop pipe
2,000
f) Insulation
1,000
g) Actuators
250
h) Primary coolant pump motor and impeller
2,500
$28,950 \mathrm{Ib}$

2. Steam Generator Package (structure and cover)
a) Shell
b) Steam generator (vertical)
c) Pressurizer
d) 2/3 Primary loop pipe
e) Two charging pumps
7,000
11, 000
3,000
2,000
f) Waste pump
600
g) Auxillary piping
200
h) Insulation
250
1) Two sinteld water pumps
250
130
j) Primary pump involute and mount

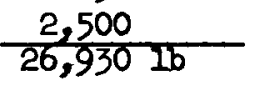

3. Auxdliary Skld Shipped Equipment
a) Reactor head
b) Two Air blast coolers for shleld water

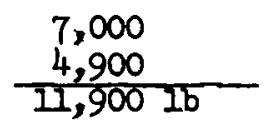

4. Buflding and Support structure

Ho1st, "A" Frame Gantry Structure

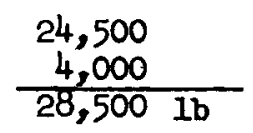

NOTS: Package 1 welght will decrease by 2,000 ib if head welds are used. 
TABLE V-9

Package Welghts--Coded Contained System

1. Reactor Package
a) Shell (less head)
b) Reactor vessel (less head)
c) Reactor vessel mount
d) Demineralizer systems
e) 1/3 Primary loop pipe
f) Insulation

$$
\begin{array}{r}
14,520 \\
9,600 \\
1,200 \\
2,000 \\
1,000 \\
250 \\
\hline 28,5701 \mathrm{~b}
\end{array}
$$

2. Steam Generator Package (containment)
a) Shell (with head)
b) Reactor head
c) Actuators

$\begin{array}{r}17,320 \\ 7,000 \\ 3,000 \\ \hline 27,3201 \mathrm{~b}\end{array}$

3. Steam Generator Package (structure and cover)
a) Shell
b) Steam generator (vertical)
c) Pressurizer
d) 2/3 Primary loop piping
e) Two charging pumps
f) Waste pump
g) Auxiliary plpe
h) Insulation
1) Two shield water pumps
j) Primary pump involute and mount
k) Primary coolant pump motor and impeller

$\begin{array}{r}7,000 \\ 17,000 \\ 3,000 \\ 2,000 \\ 600 \\ 200 \\ 250 \\ 250 \\ 130 \\ 2,500 \\ 2,500 \\ \hline 29,4301 \mathrm{~b}\end{array}$

4. Third Containment Tank
a) Shell (with head)
b) One head from package No. 1 above
c) Two air blast coolers for shield water

$$
\begin{array}{r}
17,320 \\
2,800 \\
4,900 \\
\hline 25,020 \mathrm{Ib} \\
24,500 \\
4,000 \\
\hline 28,500 \mathrm{Ib}
\end{array}
$$

5. Building and Support Structure Hoist, "A" Frame Gantry Structure

NOTE: Package 1 welght will decrease by 2,000 lb if head welds are used. Package 2 welght will decrease by $4,000 \mathrm{lb}$ if head welds are used. Package 4 weight will decrease by 6,000 lb if head welds are used. 
Package Welghts--Coded Non-Contained System

1. Reactor Package
a) Shell (less head)
b) Reactor vessel
c) Mount
d) Demineralfzer systems
e) 1/3 Primary loop pipe
f) Insulation

$$
\begin{array}{r}
14,520 \\
9,600 \\
1,200 \\
2,000 \\
1,000 \\
250 \\
\hline 28,5701 \mathrm{~b}
\end{array}
$$

2. Steam Generator Package (structure and cover)
a) Shell
b) Steam generator (vertical)
7,000
11, 000
c) Pressurizer
d) 2/3 Primary loop pipe
e) Two charging pumps
3,000
2,000
600
f) Waste pump
200
g) Auxiliary piping
250
h) Insulation
250
1) Two shield water pumps
130
j) Primary pump involute and mount
k) Primary coolant pump motor and impeller
2,500
2,500
$29,430 \mathrm{Ib}$

3. Auxiliary Skid Shipped Equipment
a) Reactor head
b) Actuators
7,000
c) Two alr blast coolers for shield water
$\frac{4,900}{14,9002 \mathrm{~b}}$
4. Building and Support Structure Hoist, "A" Frame Gantry Structure

NOTE: Package 1 weight will decrease by 2,000 lb if head welds are used. 
This method will allow the use of the containment tanks for both contained and noncontained versions with a minimum amount of change to the system and package design. Packages which exceed the 30,000lb allowable weight will be lightened by removing certain components. They will be shipped on a separate disposable skid or frame camplete with dust cover.

(5) For a noncode containment design, the number of shipping packages will be determined for integrally mounted and shipped equipment. Overweight packages will be lightened as mentioned above.

(6) For a noncode containment design, the weights of containment tanks with and without cover heads using flanged or welded openings will be compared. Consideration will be given to necessary structural members for tank shell integrity, supports, and mounts.

It should also be pointed out that non-ASME-code design will necessitate more rigorous analysis than has heretofore been used. This analysis could result in tank weight changes.

\section{SHIELDING}

\section{E. Divita}

W. Owings

General

This section presents a summary of the work performed on the effects of nuclear radiations. The main objectives of the study were as follows:

(1) To determine methods of providing primary and secondary shielding.

(2) To evaluate the effects of various vessel diameters and thermal shield designs on reactor vessel gamma heating.

Assumptions concerning the system geametry were made in order to estimate source strengths for shielding and gamma heating considerations. The primary loop of the PM-1 reference design (MND-1558) was chosen as the typical case and the core, reactor vessel, steam generator, and primary loop piping source strengths of this design were used in the studies. Minor variation of this design will not affect the conclusions presented in this report. The effects of major variations such as the utilization of a vertical steam generator are discussed. Analytical methods are presented in Appendix B.

\section{Biological Shield Studies}

The relatively high neutron fluxes present within and surrounding a compact 10-mw core produce intense sources of neutron and ganma radiation within the primary system. The primary objectives of this phase of the study were to determine methods of providing primary and secondary biological shielding, to estimate shield thickness requirements and to examine specific shielding problems encountered in primary system relocation. A preliminary investigation of several general shield configurations provided a background for analysis of the specific designs which are presented in this report. This investigation considered placement of the primary packages and utilization of various types of shield materials with the reactor and steam generator packages varying in placement from completely below 
to completely above the ground surface. Shielding materials utilized were water, lead, iron, plastics and earth. The most reasonable concepts were incorporated in the specific designs in this report.

Detailed shield analysis of three conceptual designs being considered are given in Fifs. V-4 and V-5. There were many other designs considered but these three show the baslc features of all designs. Shield water is shown on these drawings for comparison purposes only. Referring to design configuration No. I (Fig. V-4) the following camments can be made:

(1) A cylindrical lead shield 6 in. thick and 5 ft high surrounding the reactor would eliminate the need for the shield water tanks. The neutron radiation at certain points may be excessive but this can be reduced by $1-1 / 2 \mathrm{ft}$ of water or a plastic equivalent.

(2) The water tanks can be replaced by earth contained in a tank $4 \mathrm{ft} x$ $8 \mathrm{ft} \times 21.5 \mathrm{ft}$. Lead is not required. The, estimated earth volume is $15,500 \mathrm{cu}$ ft with this variation.

Referring to design configurations 2 and 3 (Fig. V-5) the following comments can be made:

(1) If the shield water tanks are replaced by contained earth and the lead thickness is reduced to 3 in., the gamma dose rates at the outer surface will be less than $100 \mathrm{mr} / \mathrm{hr}$. The fast neutron dose rates will be less than $25 \mathrm{mr} / \mathrm{hr}$.

(2) Air-scattered radiation is negligible.

(3) Radiation from pump and primary coolant piping will cause local high levels, approximately equal to those on the extended radial centerline of steam generator, at the outer surface of the water containment.

(4) Dose rates on containment surfaces from reactor radiation will be 100 $\mathrm{mr} / \mathrm{hr}$ or less; dose rates from steam generator radiation will be 250 $\mathrm{mr} / \mathrm{hr}$ or less.

(5) Without a lead shield around the reactor, dose rates are of about $10^{5}$ $\mathrm{mr} / \mathrm{hr}$ where the extended radial centerline of the core intersects the containment surfaces.

(6) A 2-in. lead shell around the active region of the steam generator will decrease the surface doses by approximately a factor of 10 .

(7) The amount of lead shielding required to shield the single package concept $8 \mathrm{hr}$ after shutdown would be excessive in volume and weight.

Dose rates were computed during reactor operation at full power and $8 \mathrm{hr}$ after shutdown for various points of interest. Shield optimization was not attempted. More detailed studies will be performed during preliminary design. Considerable weight reduction may be realized when the core, reactor vessel, and steam generator geometries are better defined. For the most part, high radiation levels exist in areas where little or no personnel access is expected. One exception to this occurs in the single package design of configuration 3 (Fig. V-5) where excessive dose rates from 

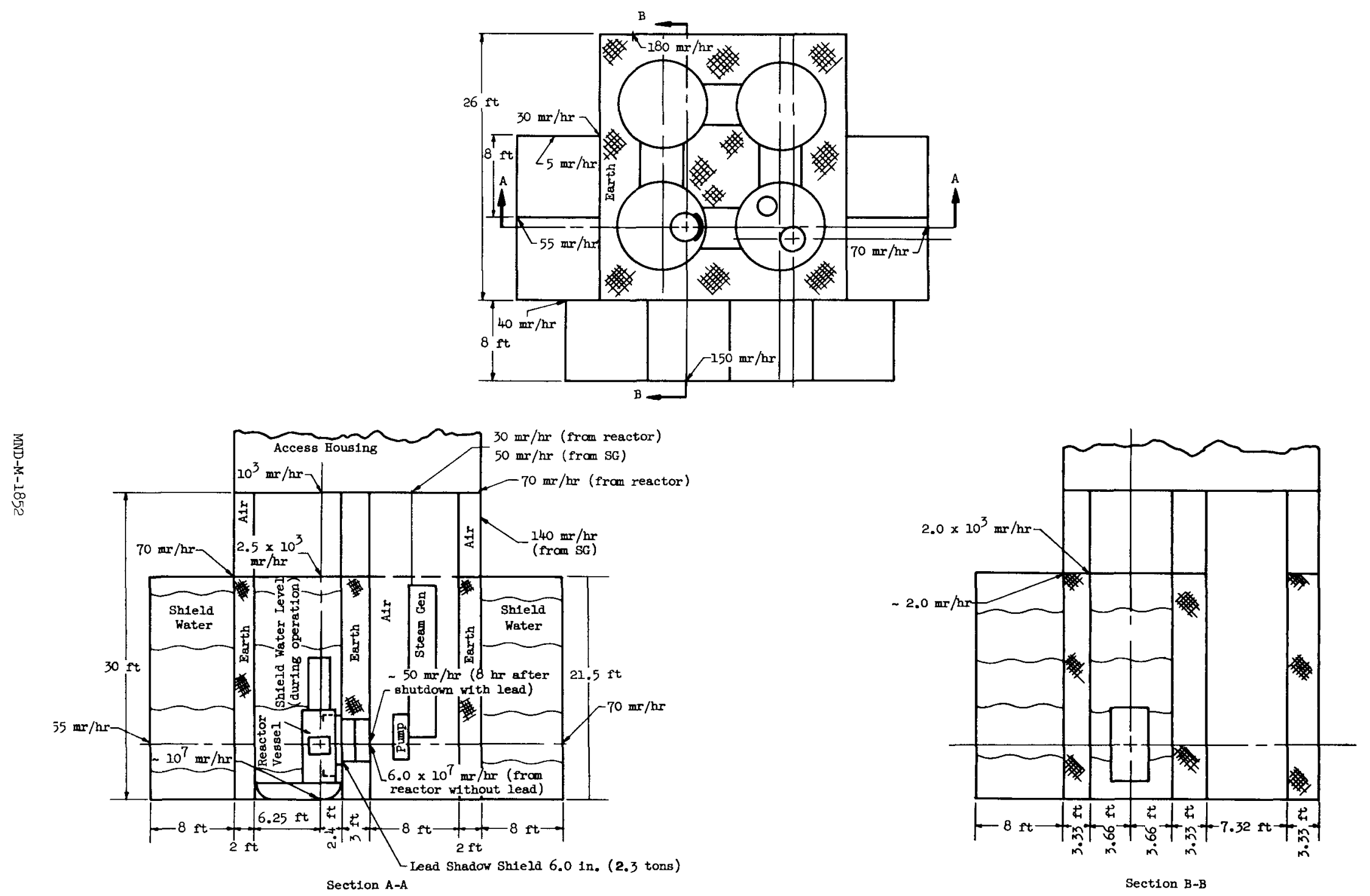

F1g. V-4. Preliminary Shleld Evaluation--Configuration 1 

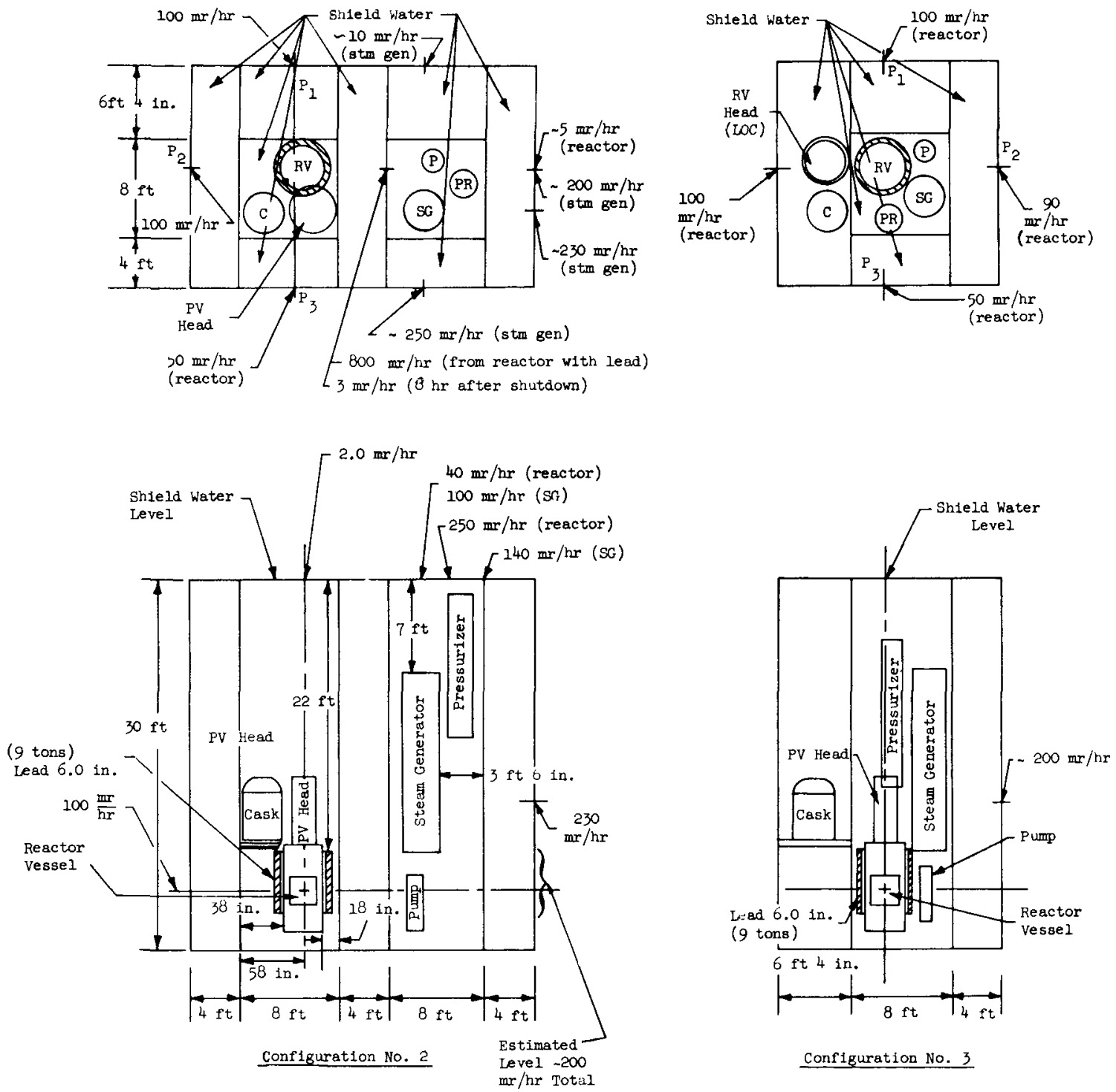

F18. V-5. Preliminary Shield Evaluation--Conf1gurations 2 and 3

MND-M-1852 
fission products and the activated pressure vessel occur in the vicinity of the steam generator, access to which is required after shutdown. The lead shielding required to reduce the dose rates to tolerable values would be excessive. Also, in this configuration, the primary loop pump is located in a region of high fast neutron flux; certain types of motor insulation would suffer excessive neutron damage. The single package concept is considered unacceptable from a shielding standpoint.

The following were true for all designs except that of the single package:

(1) Access is possible to the steam generator and coolant pump $8 \mathrm{hr}$ after shutdown.

(2) Adequate shielding of radiation from the core, pressure vessel and activated impurities in the primary loop piping is provided during operation.

(3) Adequate shielding is provided to prevent neutron activation of the earth and subterranean water.

(4) Adequate shielding is provided for refueling operations.

Preliminary shielding data for a vertical steam generator was developed assuming dimensions and wall thicknesses set forth in vendor data. Primary coolant activation was assumed to be the same as in the PM-1 reference design. Shielding requirements along the radial centerline were found to be approximately the same as in the horizontal version. Appreciably lower dose rates occur along the axial centerline because of material thickness, shielding effects of secondary water and the large vold area above the radioactive portion of the steam generator. The vertical design is, therefore, considered more acceptable from a shielding standpoint.

Gamma Heating of the Reactor Vessel

A general study of varying water gap and thermal shield thickness was performed to develop data for the determination of a reactor vessel configuration, including vessel inner diameter, wall thickness, thermal shield thickness and thermal shield placement within the vessel. Determination of the configuration involves consideration of the following:

(1) Maxtmum allowable stress in the reactor vessel during normal operation.

(2) Primary loop internal design pressure.

(3) Maximum integrated fast neutron flux within the reactor vessel wall.

(4) Vessel steel type.

The maximum allowable tangential stress is set by the ASME Boiler Code for any type of material. Internal operating pressure is determined by consideration of many plant operating and design factors other than stress. The maximum allowable integrated neutron flux is determined by consideration of radiation damage and expected life of the pressure vessel.

In view of the wide range of designs being considered during the parametric study, it was felt that the most useful data would be a presentation of gamma heating rates and fast neutron fluxes for various thermal shield thicknesses and pressure 
vessel inner diameters. Heating rates within the reactor vessel are a maximum along the core radial centerline and may be expressed as follows:

$$
Q(x)=Q_{0} e^{-\beta x}
$$

where: $Q(x)$ is the gamma heating rate (Btu/1n ${ }^{3}-h r$ ) a distance $x$ radially outward from the vessel inner surface.

$Q_{0}$ is the heating rate $\left(B t u / i n{ }^{3}-h r\right)$ at the vessel inner surface.

$\beta \quad$ is the attenuation coefficient (in. ${ }^{-1}$ )

Graphs of $Q_{0}$ and $\beta$ for gaps between the core and pressure vessel wall of from 4.0 to $28 \mathrm{in.,} \mathrm{and} \mathrm{thermal} \mathrm{shield} \mathrm{thicknesses} \mathrm{to} 1.5 \mathrm{ln}$. are given in Figs. V-6 through V-9. Integrated fast neutron flux at the inner surface of the pressure vessel for 1-yx operation at $10 \mathrm{mw}$ may be determined approximately from Fig. V-10.

The data presented in Figs. V-6 through V-10 were used in developing the plots of thermal stress versus water gap presented in the Core and Pressure Vessel Design Studies Section of Chapter III.

\section{E. PACKAGING AND SHELTER}

\section{A. Layman}

J. Reilly

Packaging and shelter studies for the PM-1 Power Plant have been directed toward the evaluation of existing methods and establishment of a shipping package and housing concept suitable for transportation of components by plane, rail, truck, or ship to a remote site. The requirement for plant relocation has placed emphasis on concepts in which shipping packages and site shelters use common housing panels. In addition, it was established early in the program that the plant shelter should provide true arctic housing. The typical arctic problems of eliminating through-metal and the need for an absolute moisture barrier are definitely involved because of the $\mathrm{PM}_{4}-$. requirement for operation at temperatures as low as $-60^{\circ} \mathrm{F}$ ambient.

Other important factors in the establishment of the concept for packaging and shelters were the limitations arising from shipment in the C-l30-type aircraft and the requirement for quick site erection.

\section{Shelter Concepts and Evaluation}

The factors investigated, such as package weight limitations, environmental conditions, external loadings and deflections, panel design and shelter configurations, all emphasized the desirability of utilizing the shipping packages in constructing the power plant shelter. The rigid, lightweight construction required for air shipment results in the design of a panel which can be made compatible with arctic requirements. The main disadvantage is that the panels may be subject to damage during shipment; this condition is a consequence of the stringent package weight limitations. If damage becomes a problem, protective plywood covers can be added to the packages when shipped (except by air), in which case additional weight would be allowable. In any event, the packages must be designed with an inherent capability of serving as shelters since they must be weatherproof, rigid, and lightweight for shipment and for storage prior to installation. 


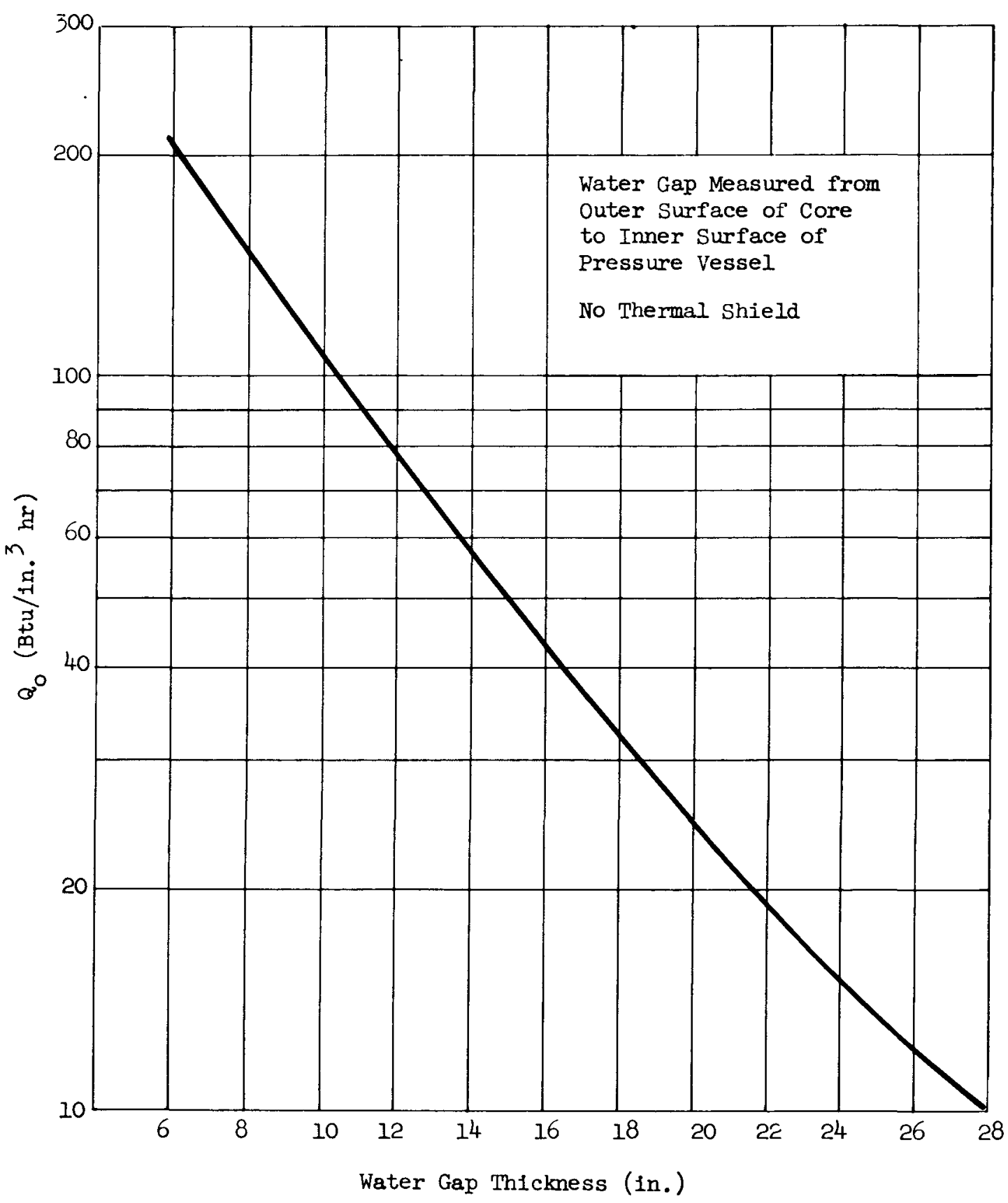

Fig. V-6. Pressure Vessel Gamma Heating 


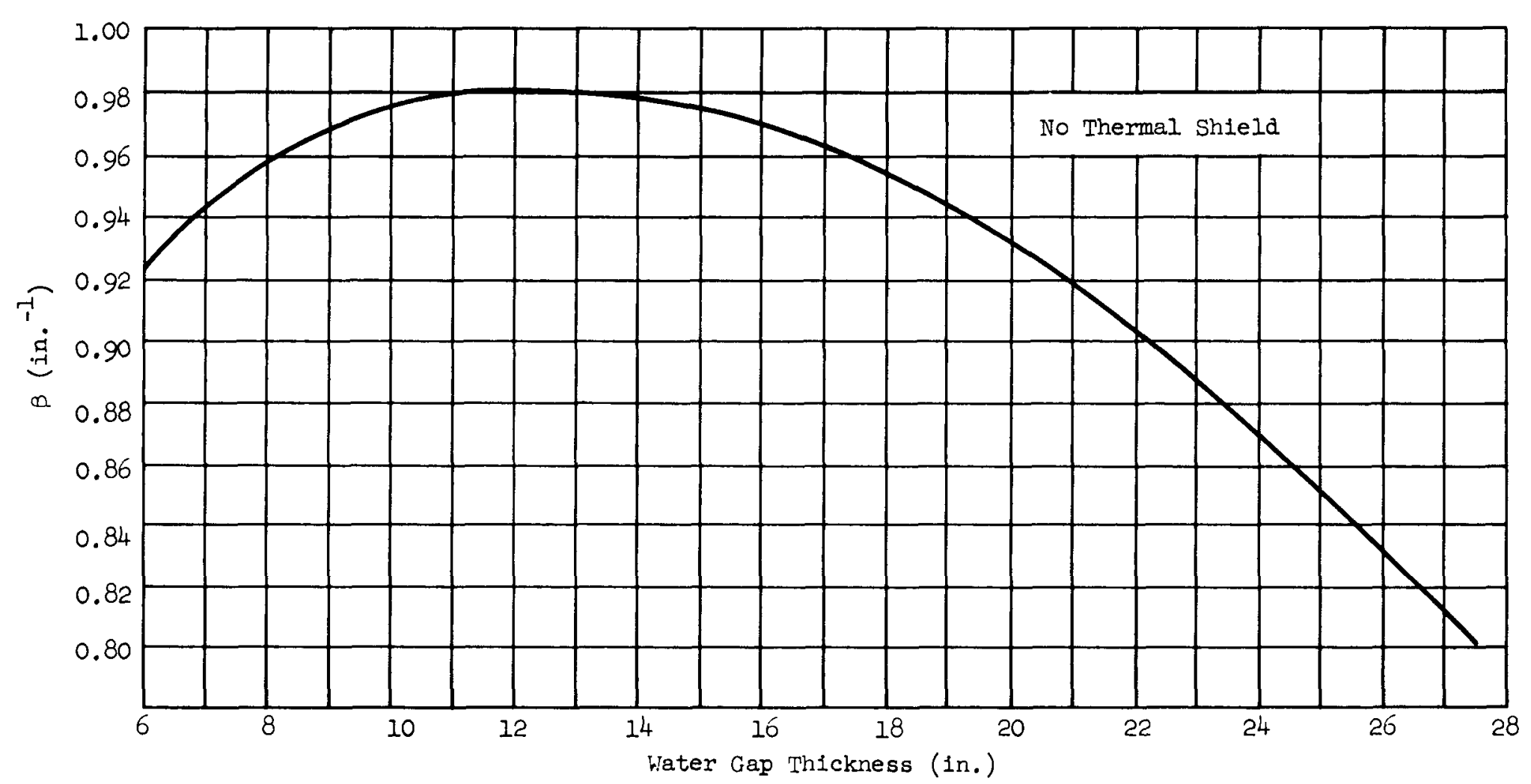

F1g. V-7. Pressure Vessel Gamma Heating 


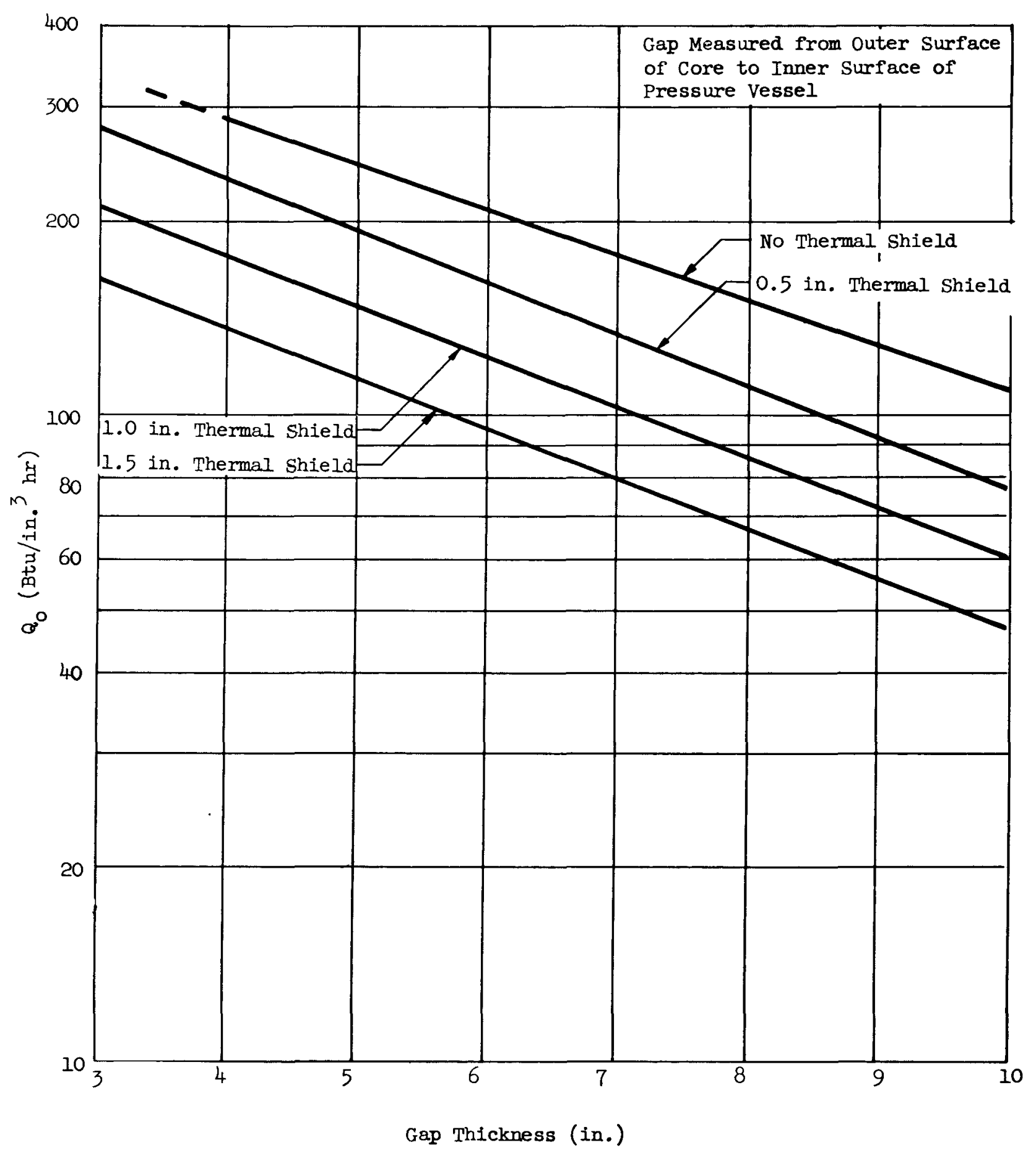

Fig. V-8. Pressure Vessel Gamma Heating--Q vs Gap Th1ckness 


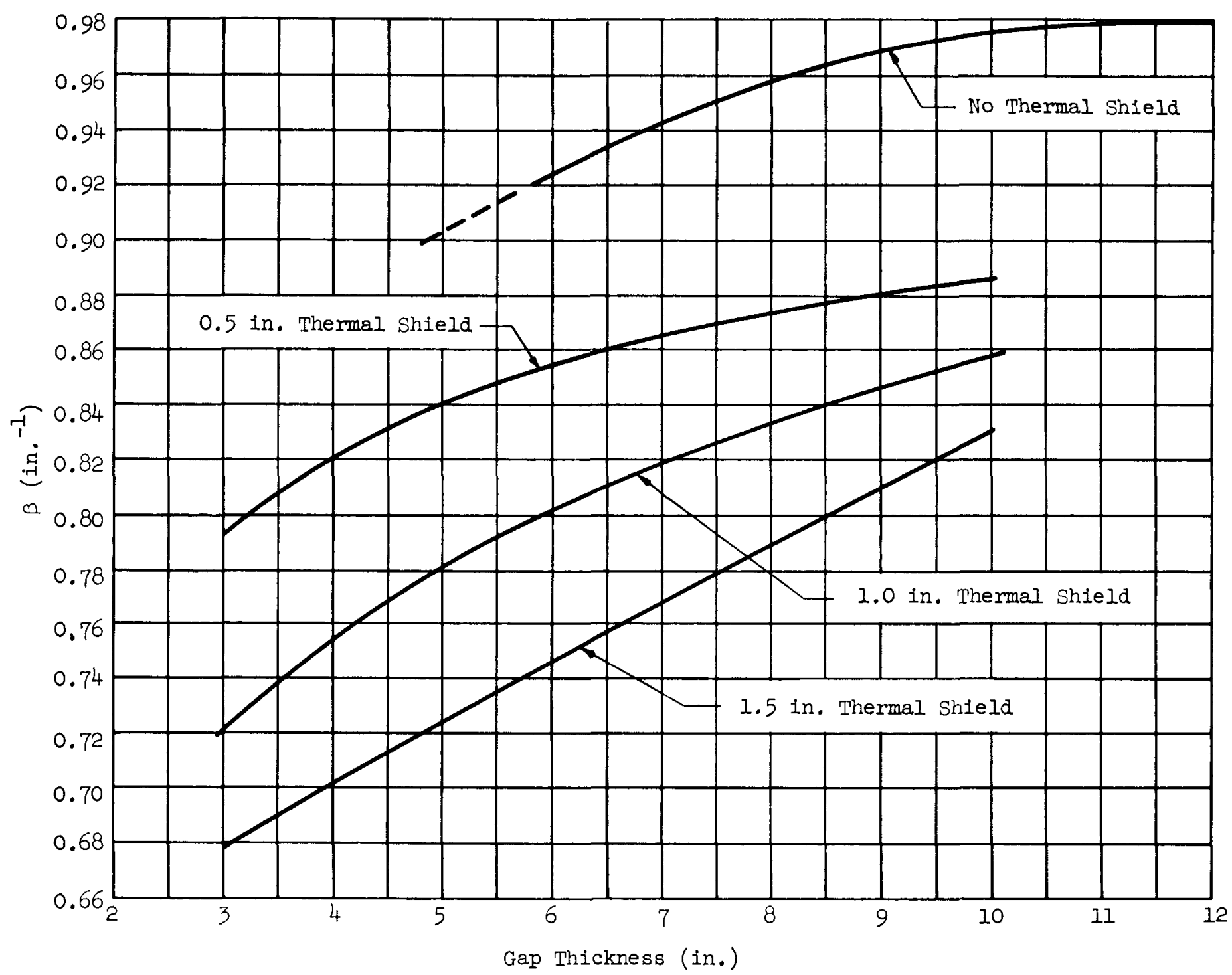

Fig. V-9. Pressure Vessel Gamma Heating 


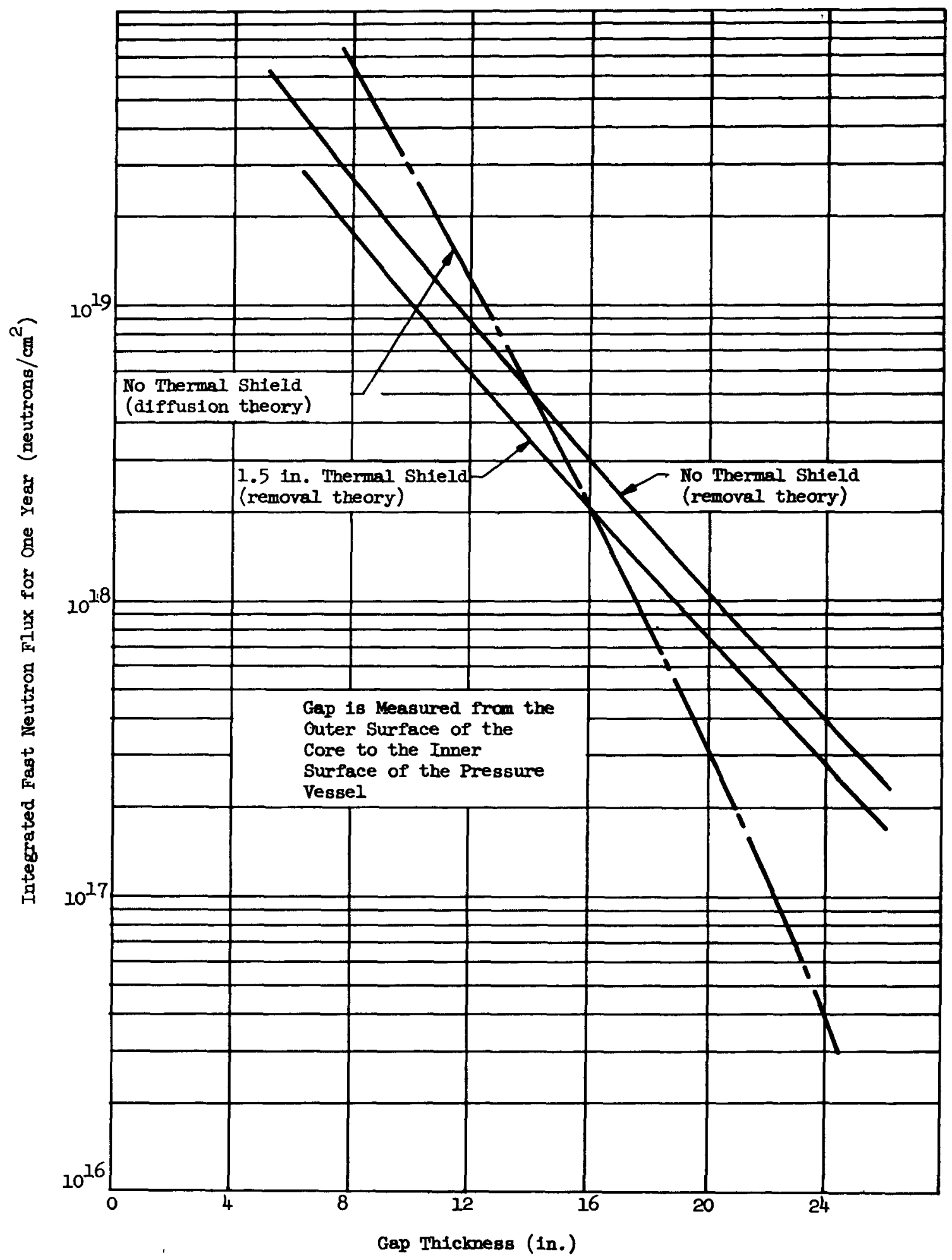

Fig. V-10. Integrated Fast Neutron Flux at the Inner Surface of Pressure Vessel for One Year Operation at $10 \mathrm{mw}$ 
The shelter for the secondary system can be constructed by arranging the shipping packages in a hollow square, and then swinging the lightweight inner side panels up to form a peaked roof. The area underneath this roof would provide ample access to equipment for maintenance and for placement of such additional equipment as the turbine generator. Strong, one-piece panels would make an excellent leakproof roof. A slope would be built into the package roof to allow run-off. Joints requiring seals are those points where the packages come together: the ends of adjoining packages, the peak, the shed roof and the roof ridge. This combination package-shelter configuration was selected after comparing these five possible methods of providing shelter.

Method 1. A standard prefabricated building, shipped in separate packages and erected on the site prior to installation of the equipment.

Method 2. A specially-developed arctic-type prefabricated buflding, constructed of structural sandwich panels, shlpped in separate packages and erected on the site prior to installation of equipment.

Method 3. A building constructed from the sides of the shipping packages prior to installation of the equipment.

Method 4. A building formed by arrangement and interconnection of shipping packages and removal or fold-out of some of the side panels, with equipment integrally mounted in packages.

Method 5. Each shipping package used as the shelter building for the contalned equipment, without modification.

Each of the above methods has advantages and disadvantages as summarized in Table V-ll.

TABLE V-11

Equipment Shelter Concepts

Method

1. Standard prefabricated building

2. Special prefabricated building, sandwich panels

\author{
Advantage \\ Low initial cost \\ Little $R$ and $D$ \\ expense \\ Readily avallable
}

Panels less apt to be damaged than methods 3, 4 and 5

True arctic building

Less maintenance than in method 1

Bullding can be set up before equipment arrives

\section{Disadvantage}

Not a true arctic building, difficult to insulate and vapor seal

Requires more packages than methods 3, 4 and 5

Heavier conventional packing crate required

Assembled with many small parts, nuts, bolts, plates, etc. Long erection and relocation time, high erection costs

More costly than method I

Requires more packages than 3, 4 and 5. Additional packaging material required for shipping

Longer erection time than 4 and 5. 
TABLE V-II (continued)

Method

3. Shelter building made of shipping package sides

4. Package interconnection to form a shelter building
5. Shipping package is shelter building

\author{
Advantage
}

May not require additional packages

Less maintenance than method 1

True arctic building

No pre-erection required before arrival of equipment

Does not require additional shipping packages

Shorter setup time

Shorter relocation

time

True arctic shelter

Less maintenance than method 1

More systems can be built in

Lighter weight packages than conventional packing crates

Minimum site erection time

Minimum relocation time

True arctic building

\section{Disadvantage}

Building cannot be set up until equipment arrives; then must be erected before equipment can be installed

Panels more subject to damage than 1 and 2

Sizing panels would be a problem

Less working space and access to equipment than 1 and 2

Requires development program

More costly than method 1

Panels subject to damage (but easily replaced)

Work area in the shelter would be too confining and equipment Inaccessible; no further consideration will be given this design

\section{Plant Module Shipping Requirements}

The PM-l Power Plant will consist of modular sections for quick assembly at a remote site. These sections will be packaged for shipment primarily by air in C-130 aircraft. Considerations have also been given to shipment by rail, truck and ship. In designing the packages for air shipment the following requirements were considered: weight, center of gravity, distribution of weight over the aircraft floor, cost, ease of setup, ease of relocation and rigidity (to minimize loads induced in equipment due to package bending). In designing the package so that it, or a portion of it, may be used to form an arctic-type shelter, consideration was given to fully insulating painels with absolute vapor barriers, eliminating through-metal penetrations, providing weather tightness at panel joints and providing construction sufficiently sturdy to withstand wind and snow loads. Figure V-ll summarizes the size and center of gravity requirements for shipment by C-130 cargo aircraft. 


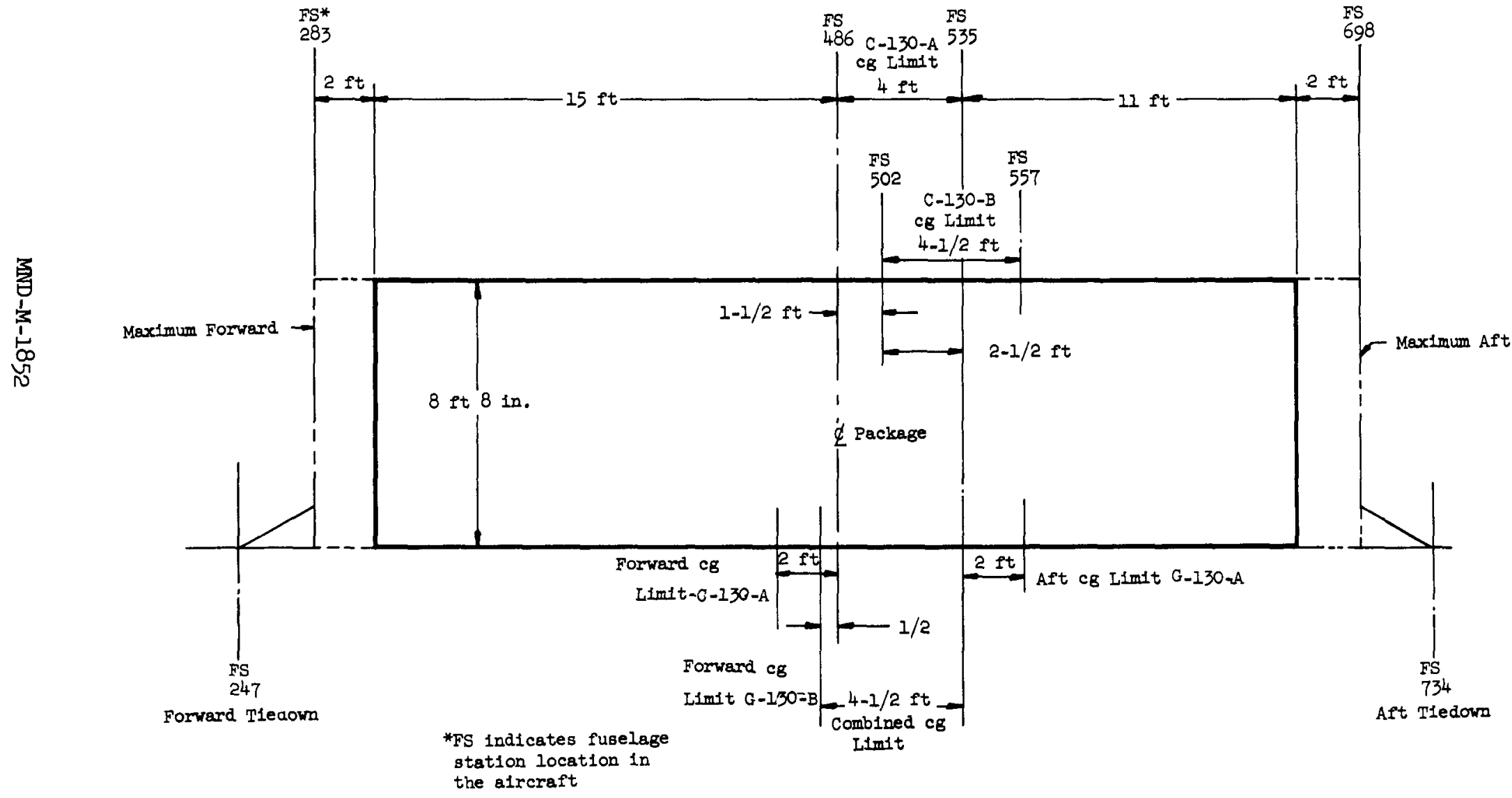

Fig. V-11. Center-of-Gravity Data--PM-1 Package 


\section{Package Weight}

Weight of the packages will depend upon the final materials selected. If the package, its panels, or a portion of the package is to serve as an Arctic shelter, then the panels must be of low density, hence lightwelght, and possess good insulating qualities. If the package is not to be used as a shelter, then more readily available materials might be used. However, a standard wood crate constructed in accordance w1th MIL-P-6057 would be excessively heavy for alr shipment. A crate 8 ft 8 in. $x 8$ ft 8 in. $x 30$ ft long, which is the maxtmum size shippable in the C-130, would weigh $8,800 \mathrm{Ib}$.

The maximum weight allowable in C-130 aircraft for the required 1000-mi mission was determined by running a mission anslysis and calculating fuel consumption for takeoff, climb, cruise at economical altitudes, let down, landing and a return mission with the aircraft empty. The results of the analysis showed that the C-130-A aircraft can carry $30,000 \mathrm{Ib}$ and the C-130-B aircraft can carry $33,000 \mathrm{lb}$. Since availability of the "B" aircraft is questionable, 30,000 $\mathrm{lb}$ has been established as the upper package weight limit.

Panel Requirements

Rigidity of the package to minimize bending will be the critical factor in determining the thickness or strength of the panels, rather than insulation requirements, snow losds, or wind loads. For balsa wood core panels, a minimum thickness of 2 in. was found to be adequate in both insulation qualities and in strength required for snow loads. Heat loss calculations were made for 2-in. and 3-in. panels using balsa as an insulator which has a " $K$ " factor of 0.025 . With a $\Delta T$ of $125^{\circ} \mathrm{F}$, the heat loss through the walls represents only 25 to $30 \%$ of the estimated heat gained by the shelter from the operation of equipment in the shelter. Deflections on a 2-in. panel were calculated with a $30 \mathrm{lb} / \mathrm{sq} \mathrm{ft}$ snow load. Using an 8-ft balsa core panel with 0.010-1n. stainless steel faces and supported at its ends, a 0.535-in. deflection was calculated.

\section{Rigid Base Design}

Design of the package must be such that minimum deflections occur during shipment and loading operations since bending induces loads into the equipment causing possible piping and structural fallures. Insufficient head room is available in the afrcraft to permit designing an equipment-mounting frame or skid of sufficlent depth to minimize bending and thus to distribute the load. It may, therefore, be required that the panel sides be utilized as structural bending members. In addition, the load on the aircraft floor cannot exceed $1000 \mathrm{lb} / \mathrm{ft}$ of length in the cargo campartment except for a section 14 ft 2 in. In length which can accomodate a floor loading of $3000 \mathrm{lb} / \mathrm{ft}$. This also requires that the package be designed as a rigid member.

\section{Panel Design}

As previously discussed, the package sides must be sufficiently rigid to minimize bending and also must be of lightweight construction for air shipment. Arctic-type panels were first considered for package sides. These panels were of sandwich construction providing insulation, vapor barrier and strength within themselves to support snow loads and to withstand wind loads without additlonal framework. These lightweight panels, approximately $4 \mathrm{ft} \times 8 \mathrm{ft}$ in size, are designed for quick assembly at the site and are held together by wedge fasteners. To handle the bending loads 
imposed by hoisting or moving over irregular surfaces, however, a continuous structural member within the package is required. Thus, the sandwich panels do not appear practical. In addition, the wedge and cam fasteners cannot take the shear loads. Wanigans, used as shelters for cross country antarctic expeditions, use large panels spliced together with shear strips. The most practical solution to the problem appears to be the use of one continuous panel with an integral truss constructed in a manner simflar to lightweight arctic panels for the sides and roofs of the packages. The following advantages are cited:

(1) A single panel would eliminate the problem of shear connections or fasteners between panels.

(2) Air leakage through the joints would be ellminated.

(3) A better vapor barrier is provided by using a continuous (metal) skin.

(4) Fewer roof joints will reduce leakage and heat loss.

(5) A more rigid beam is provided to distribute the load evenly over the aircraft floor, permitting heavier equipment and fewer packages.

(6) Bending is minimized which reduces loads induced into the equipment within the package.

(7) Large single panels are cheaper than individual panels of the same area.

(8) Single panels weigh $25 \%$ less than a group of individual panels.

(9) Large single panels are more readily adaptable to an integral truss member.

The main disadvantage may be difficulty in replacing panels in the event of damage during shipment. This will be evaluated in more detall during preliminary design. At the very worst, shipment damage could impose no greater penalty than that imposed by adopting the alternate design concept of shipping a prefabricated buflding in separate packages. 


\section{PLANTI SYNTHESIS AND DESCRTPIION OF SELECTIED DESIGN}

Project Engineer: R. Aktn; C. Fox

This section of the report presents the methods used and conclusions reached In the study of overall plant characteristics. Those design variables which are strongly interdependent are best studied in terms of their effects on the overall system. Thus the primary loop studies, secondary loop studies and steam generator studies were combined into total plant studies. The information developed in these overall studies included system pressures, temperatures and flows, types of steam cycles, auxiliary power requirements, plant welght, plant cost and fuel costs. Details of this work are presented in the following pages.

\section{A. PLANT SYNTHESIS STUDIES}
W. Koch
R. Baer
J. Beam
C. Smith

The net electrical production, process heat production, air transportability, and all other basic contract requirements were met by all of the designs that were formed through integration of the various primary and secondary systems. This integration process involved the following nine independent variables:

(1) Fuel element diameter $\left(D_{t}\right)$

(2) Fuel element pitch (s)

(3) Core diameter $\left(D_{c}\right)$

(4) Core length-to-diameter ratio (L/D)

(5) Primary system pressure $\left(P_{p}\right)$

(6) Steam generator $\log$ mean temperature difference

(7) Type of steam cycle

(8) Secondary system steam pressure $\left(P_{\mathbf{s}}\right)$

(9) Turbine exhaust pressure ( $P$ exh)

Other variables were either handled as dependent variables or established as constants for the plant integration effort. Selecting three values of each of the nine parameters and investigating all combinations would require consideration of about 20,000 cases. The engineering cost of such an investigation would probably exceed the maximum cost differential encountered in the study. Therefore, prior to the integration effort, the range of variables was reduced as far as possible through practical considerations such as relative weight, complexity or cost. Thus, most of the actual plant integration efforts were conducted with a single, nonextraction, turbine-generator, vertical steam generator, gross electrical production of $1250 \mathrm{~kW}$ and a single primary coolant pump in a 6-in. main coolant line. 
Furthermore, it was found by inspection of the early results that low welght, low cost and simplicity of design were nearly synonymous. Once the basic framework was established for the plant synthesis, the more detalled studies were directed toward finding the area of minimum capital cost. This was done for both nonbolling and local boiling systems. Finally, possible changes in the lowest cost systems were examined for their effect on layout, lower operating costs, etc., and a final selection was made. Thus the plant synthesis study consisted of three major steps:

(1) Determination of the approximate range of parameters which leads to a minimum capital cost, minimum welght system.

(2) A detailed study within the range of interest to determine the minimum-capital-cost system.

(3) Analysis of changes in system design which lead to improved design or reduced operating costs and evaluation of the effects on capital costs of such changes.

\section{Local Boiling System Studies}

In the first portion of the local bolling system studies, only secondary systems using a single, nonextraction, turbine-generator were considered because this is the lowest weight and lowest cost secondary system.

The core diameter was held constant at 22.5 in. since nuclear studies indicated that to be the minimum diameter required for a two-year core life. The minimum core diameter defines the pressure vessel and pressurizer of smallest size, weight and cost.

For the purpose of this study, a flxed core $L / D$ of 1.25 was assumed. This led to an active tube length of 28 in., which adequately meets both heat transfer and fuel loading requirements. If the core length changes, the absolute cost, weight, etc., of the pressure vessel and pressurlzer will also change, but this small change will not slgnificantly affect overall costs.

A fuel element diameter of $1 / 2$ in. was chosen as the best for this system, for the following reasons:

(1) Surface area is not a limiting criterion in a local boiling system, hence we are not restricted to small diameter tubes on close pitches.

(2) There is a limit to the thickness of the fuel cermet (approximately $0.030 \mathrm{in.}$ ) and the quantity of fuel ( $30 \mathrm{wt} \%$ ) that can be included in the cermet by the fuel element processes presently in use, hence we cannot use large heavily loaded tubes.

(3) Fabrication of elements having an active length of more than 30 in. is not feasible using available fuel element production facilities.

(4) Present fabrication methods have been successfully applied to elements up to $1 / 2$ in. in diameter.

(5) The space between fuel elements should be at least 0.10 in. for heat transfer considerations. 
(6) Nuclear studies showed little or no change in fuel inventory as tube size and spacing were changed.

(7) Assuming a fixed cermet thickness, wt $\% \mathrm{UO}_{2}$ and fuel inventary, and considering the fact that using tubes as colums limits their $\frac{\ell}{d}$ ratio to about 75 or less, a study of required core diameters far given values of tube diameter and tube spacing (FIg. VI-l) showed that a fuel element $1 / 2$ in. in diameter gives the smallest core diameter.

Only 6-in. primary piping was considered because of the cost and welght penalty involved in 8-in. pipe and the high head loss resulting from the use of 5-in. piping. This is discussed in more detail in Chapter III,Section $\mathrm{F}$. The schedule number of the pipe was varied with pressure in accordance with the ASA code.

In an effort to keep the number of cases to a minimum, only two values of steam pressure and steam generator logarithmic mean temperature difference were considered in the first portion of the study. The values selected were 300 and 500 psia and 30 and $60^{\circ} \mathrm{F}$ respectively; these represent the approximate limits of the range of interest.

Primary loop flow rates of 1400,1700 and $2000 \mathrm{gpm}$ were studied to permit coverage of the entire range of flows which are feasible using 6-in. pipe-considering the power requirements of the primary pump. Turbine back pressures of 6,9 and $11.5 \mathrm{in}$. of $\mathrm{Hg}$ abs were investigated. The resultant varlations of condenser fan power cover the entire range of available auxiliary power.

The values of all the parameters needed to determine the capital cost and weight of the system were established in the following manner. Uging FIg. VI-2*, the prlmary loop pressure was determined for the selected values of primary loop flow rate, steam pressure and steam generator logarithmic mean temperature difference. This pressure then determined the primary piping schedule number. The total head loss in the primary piping, reactor and steam generator was found using FIgs. VI-3, VI -4 and VI-5. The power requirement of the primary pump was then calculated, and added to the $1000 \mathrm{kw}$ output and the $80 \mathrm{kw}$ allowed for all other primary loop auxillary equipment in order that the net electrical production required from the secondary loop could be determined.

Then Figs. VI-6 through VI-16 were used to determine the weights and costs of the components listed below:

(1) Steam generator (F1gs. VI-6, 7 and 8)

(2) Reactor vessel (FIg. VI-9)

(3) Primary loop piping (Fig. VI-10)

This and many of the following curves appeared in Chapter III. They are duplicated here for the conventence of the reader. 
(4) Primary pump (Figs. VI-1I and 12)

(5) Pressurizer (Flgs. VI-13, 14 and 15)

(6) Auxillary systems (FIg. VI-16).

Figure VI-I7 shows the varlation with primary pressure of the total estimated capital costs of the six primary loop components set forth above. The cost of each of the six components, except the steam generator, varied with pressure. The breakpoints at 1300 and $1790 \mathrm{psia}$ are due to changes in primary piping schedules; the break at 1500 psis is due to the change of primary pump type from canned motor to mechanical seal. The increase in cost with decreasing pressure between breakpoints is due to the higher pumping rates required to maintain primary loop temperature with decreasing pressure. As was discussed in Section III of this report, the basis for cost evaluation of the pressurizer and the pressure vessel was cost per pound; the basis for evaluating the steam generator was Westinghouse-developed cost data; and the basis for evaluating the piping, pump and auxillary systems was a combination of vendorand published-information.

Costs of systems using 500 psia steam and $30^{\circ} \mathrm{F}$ log mean temperature difference were investigated and found to be higher than for the above case.

In view of the results obtained in this first phase of the local boiling study, the second portion of the study was restricted to primary system pressures of 1500 psia and below. Again only single turbine generator secondary systems were considered. It should be noted that the cost of secondary systems did not vary significantly over the ranges considered here and below; these costs are not included in the totals of the various figures.

The method of integration used in the second partion of the study was identical to that used in the first, with two exceptions. First, primary loop pressure was selected as an independent variable; Fig. VI-2 was used to determine the required primary coolant flow rate. Second, the turbine exhaust pressure was not treated as an independent variable. Instead, gross power production was held at $1250 \mathrm{ekw}$ and the condenser fan power was adjusted for each case to a value such that the total auxilliary power was exactly $250 \mathrm{kw}$. This method was used so that all systems compared would have equal auxilfary power requirements.

Initially, steam pressures of 250,300 and 400 psia and steam generator logarithmic mean temperature differences of $30,40,50$ and $60^{\circ} \mathrm{F}$ were studied at a primary pressure of 1500 psia. The resulting varlation in capital cost, shown in Fig. VI-18, clearly indicates that capital costs decrease as secondary steam pressures decrease. In the cases presented in Fig. VI-18, only two of the six primary loop components--the pump and the steam generator--vary in cost.

F1gures VI-19 and VI-20 were next obtained to attempt to find the minimum capital costs under varying conditions of primary and secondary system pressure, and log mean temperature difference. In these cases, the capital costs of all six of the primary loop components varied. The use of primary pressures below 1300 psia were briefly investigated and found to result (again due to increased pumping requirements) in increased capital cost. 


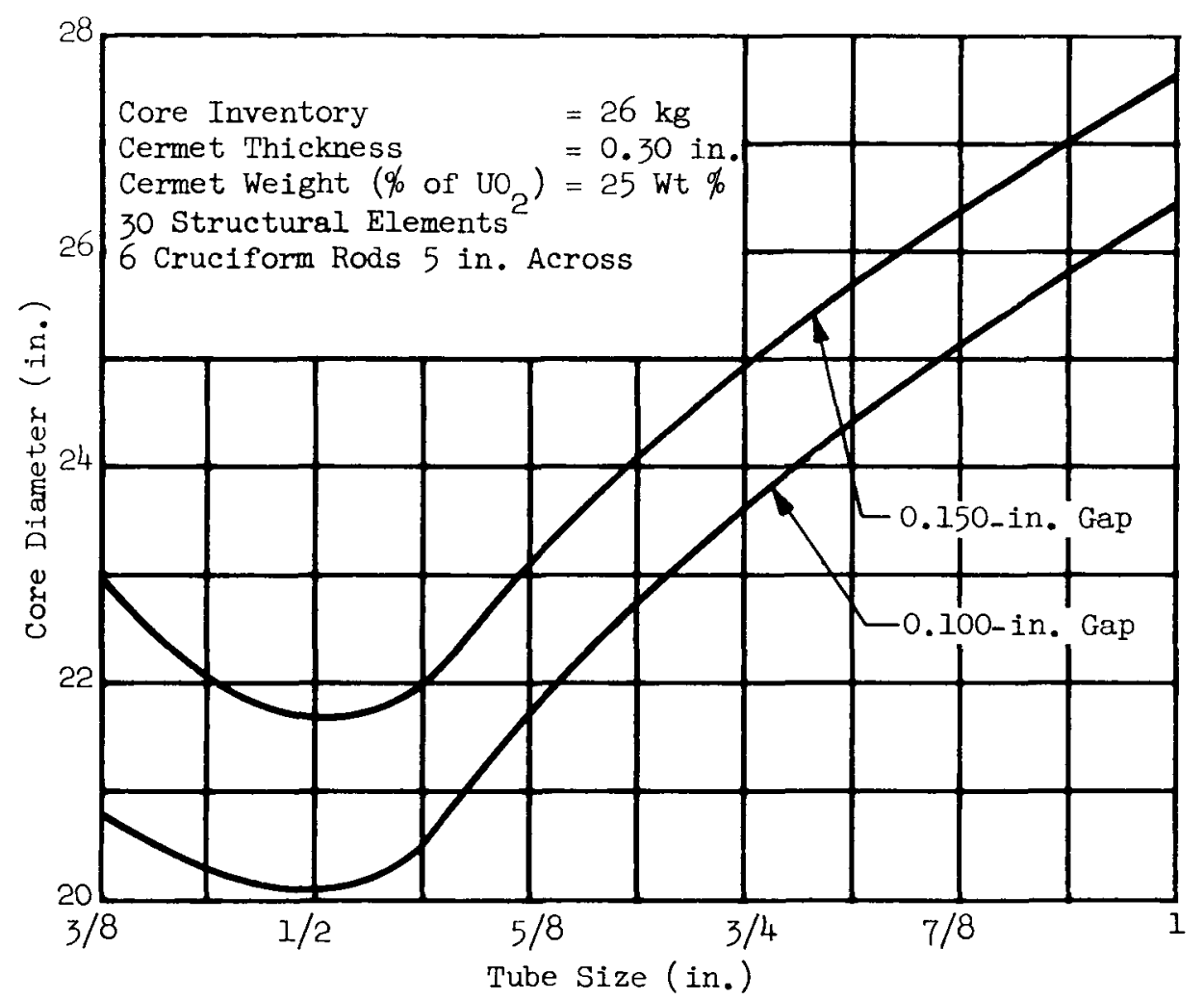

Fig. VI-1. Tube Size as a Function of Core Diameter--Local Boiling Core 
-

$\bullet$ 


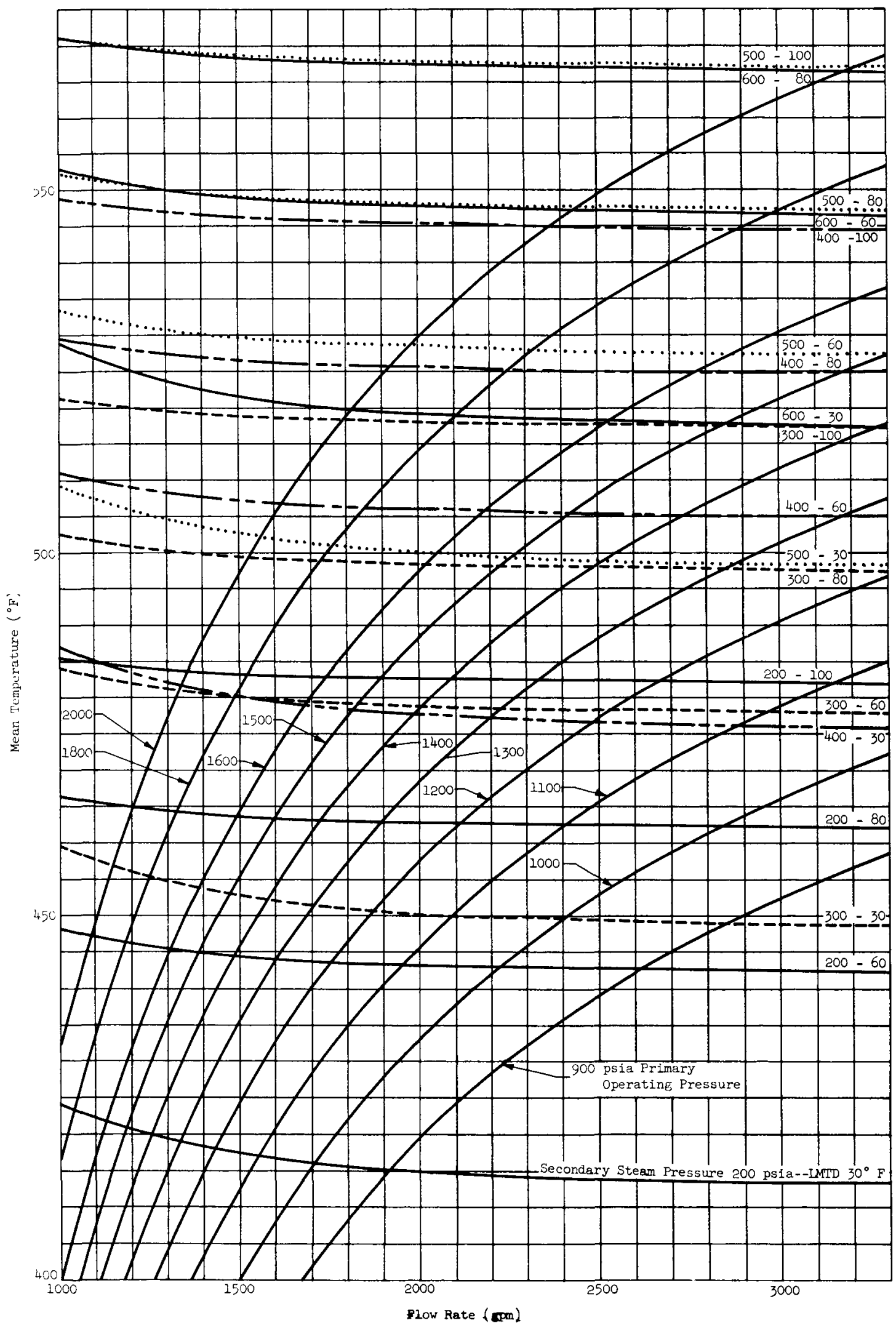

Fig. VI-2. Primary Coolant Mean Temperature as a Function of Primary Coolant Flow Rate--Locăl Bolling 


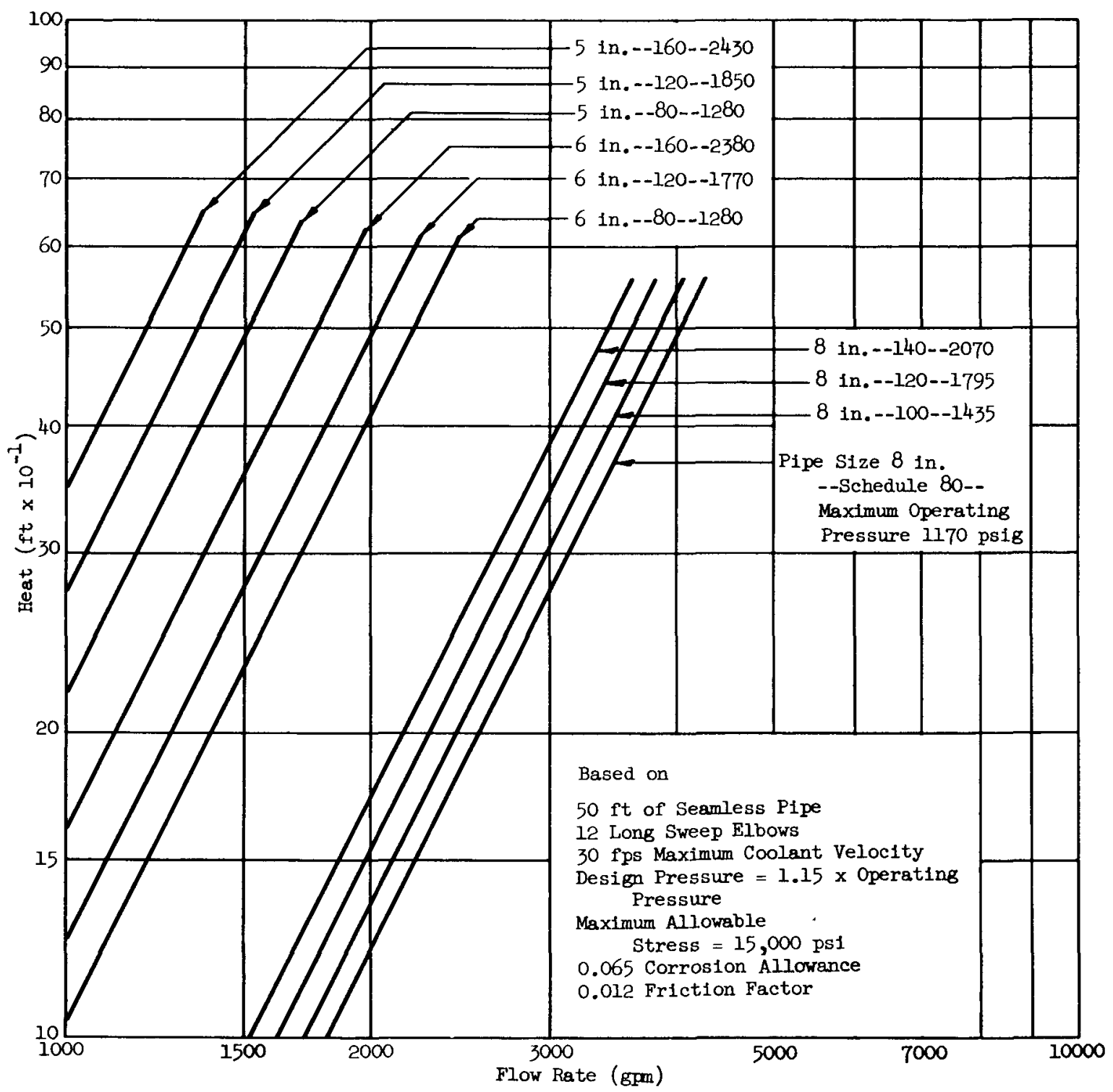

F1g. VI-3. Primary Loop Coolant Piping Head Loss, (ft),as a Function of Flow (gpm) 


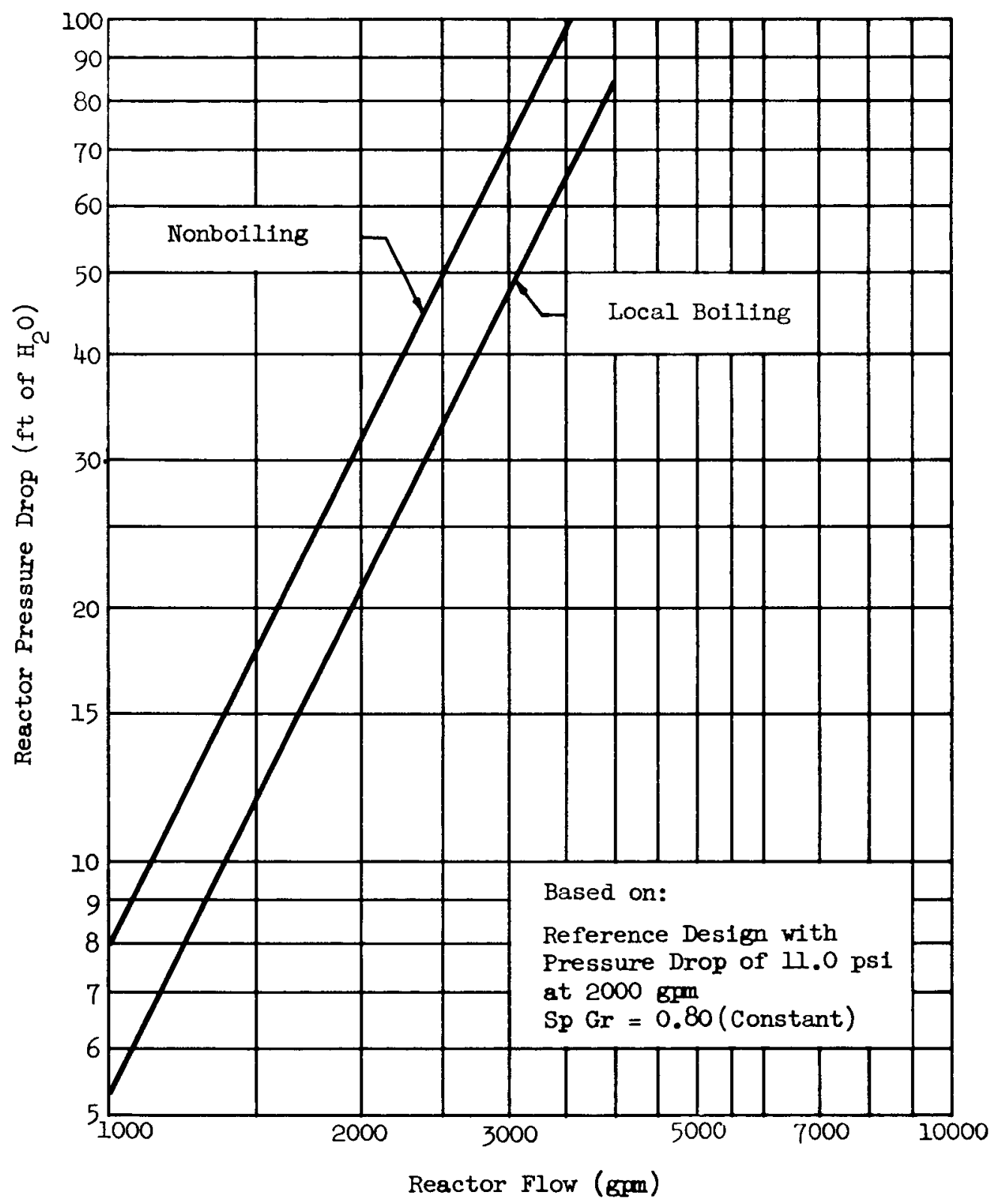

Fig. VI-4. Variation of Reactor Head as a Function of Flow Rate Under Non Boiling and Local Bolling Conditions 


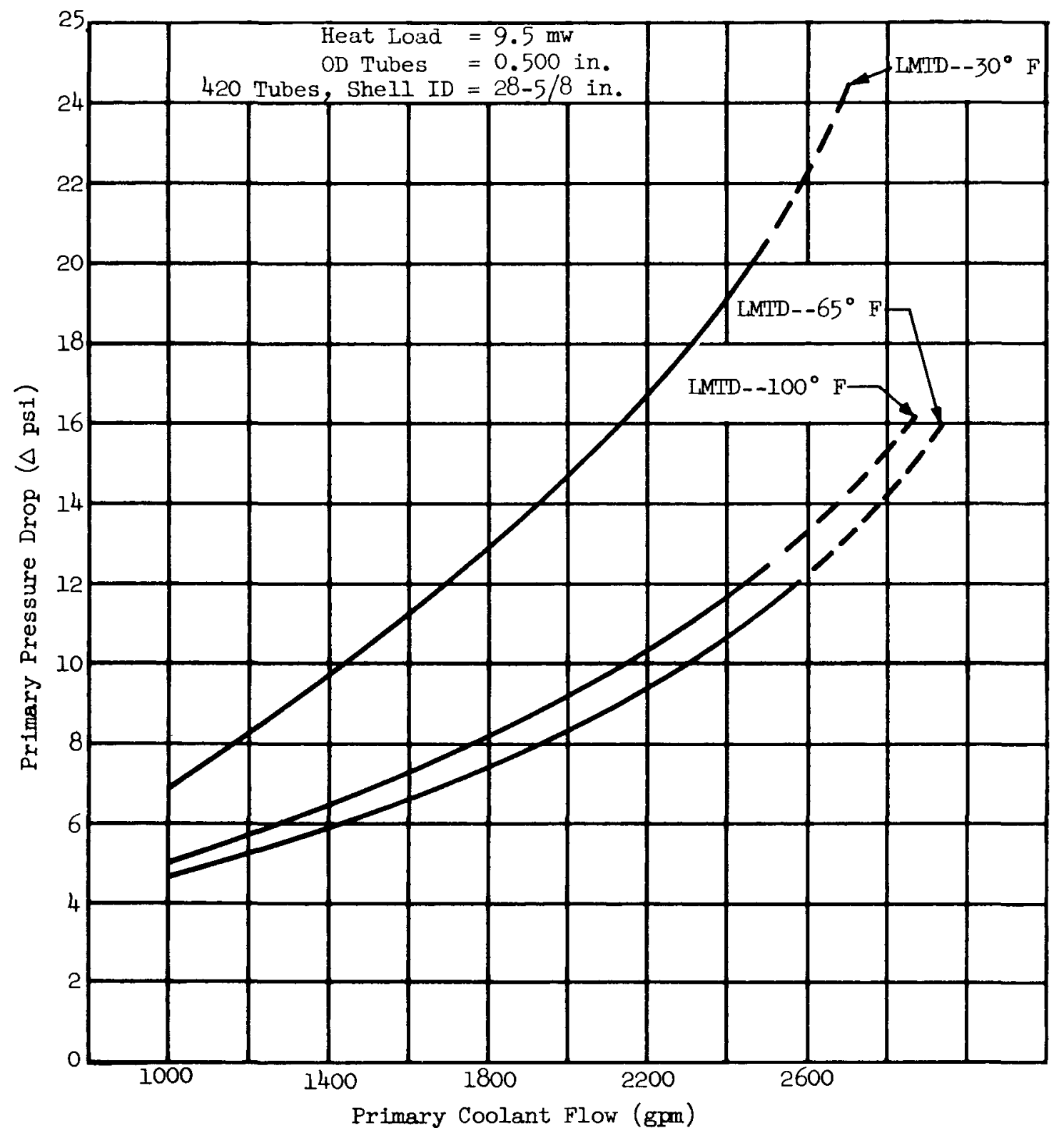

F1g. VI-5. PM-1 Westinghouse Steam Generator 

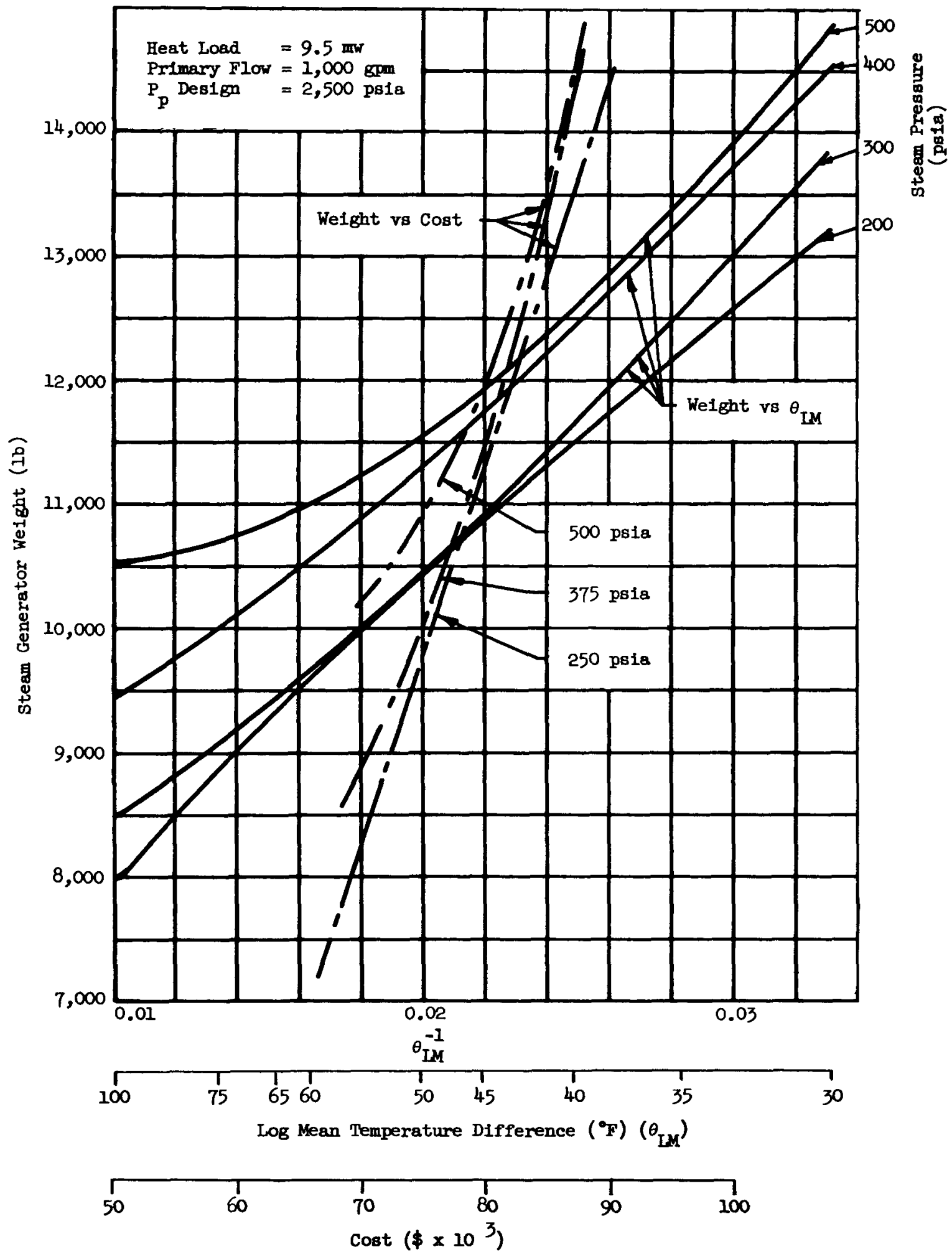

F1g. VI-6 PM-I Westinghouse Steam Generator 


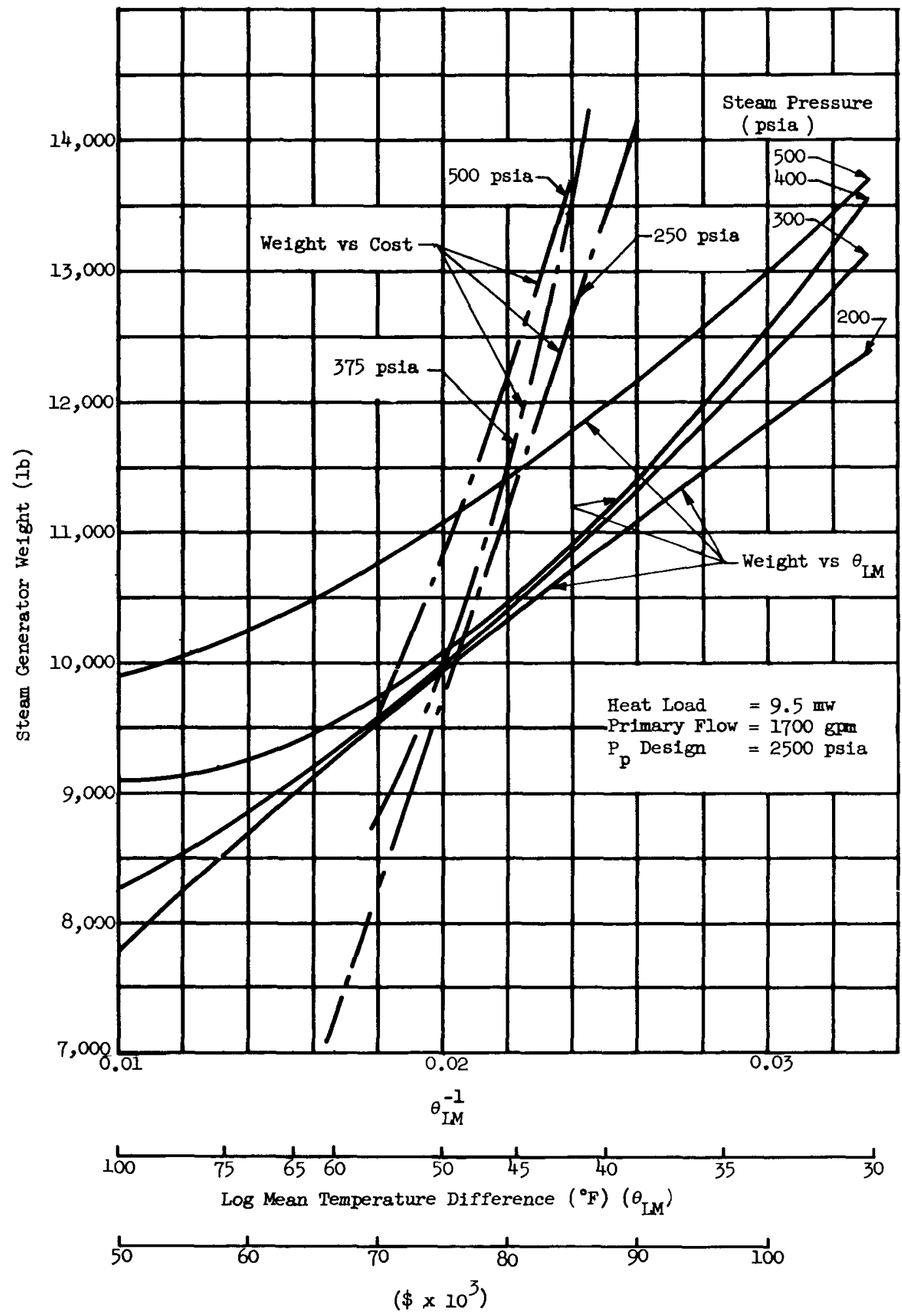

F1g. VI-7. PM-1 Westinghouse Steam Generator 


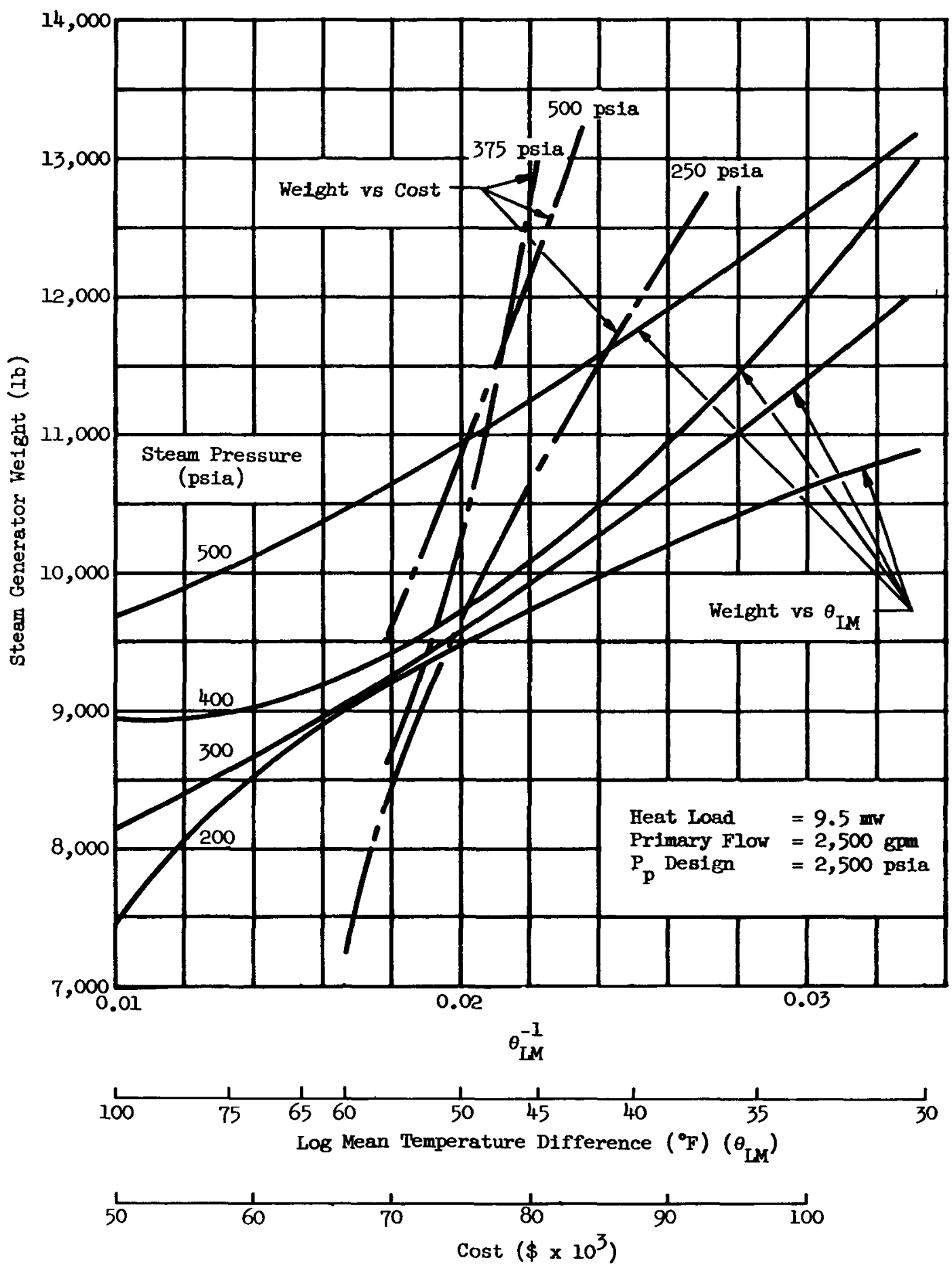

Fig. VI-8. PM-1 Westinghouse Steam Generator 


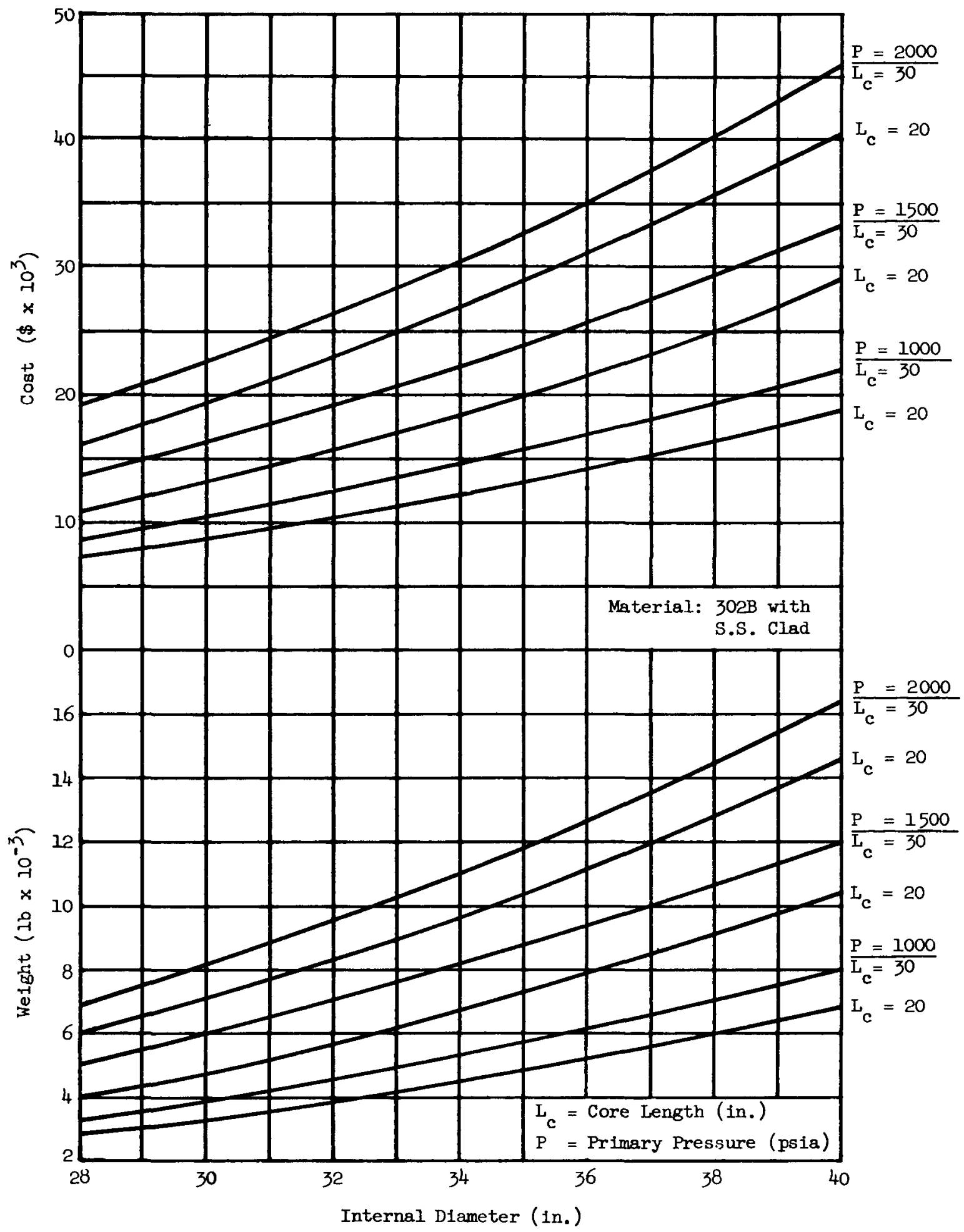

F1g. VI-9. Reactor Vessel Weight and Cost Variation 

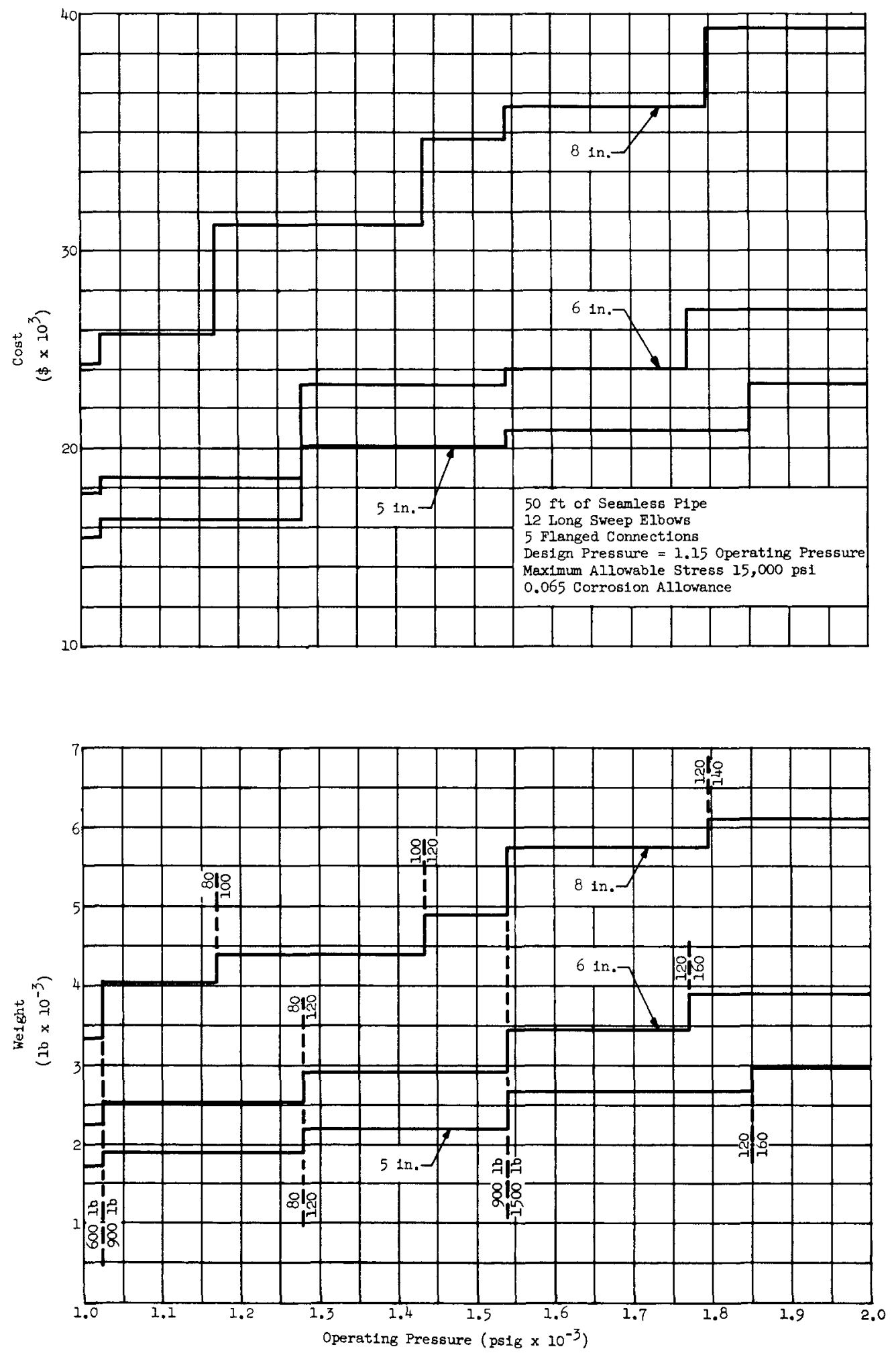

F1g. VI-10. Primary Coolant Piping Weight and Cost as a Function of Operating Pressure 
NOTE:

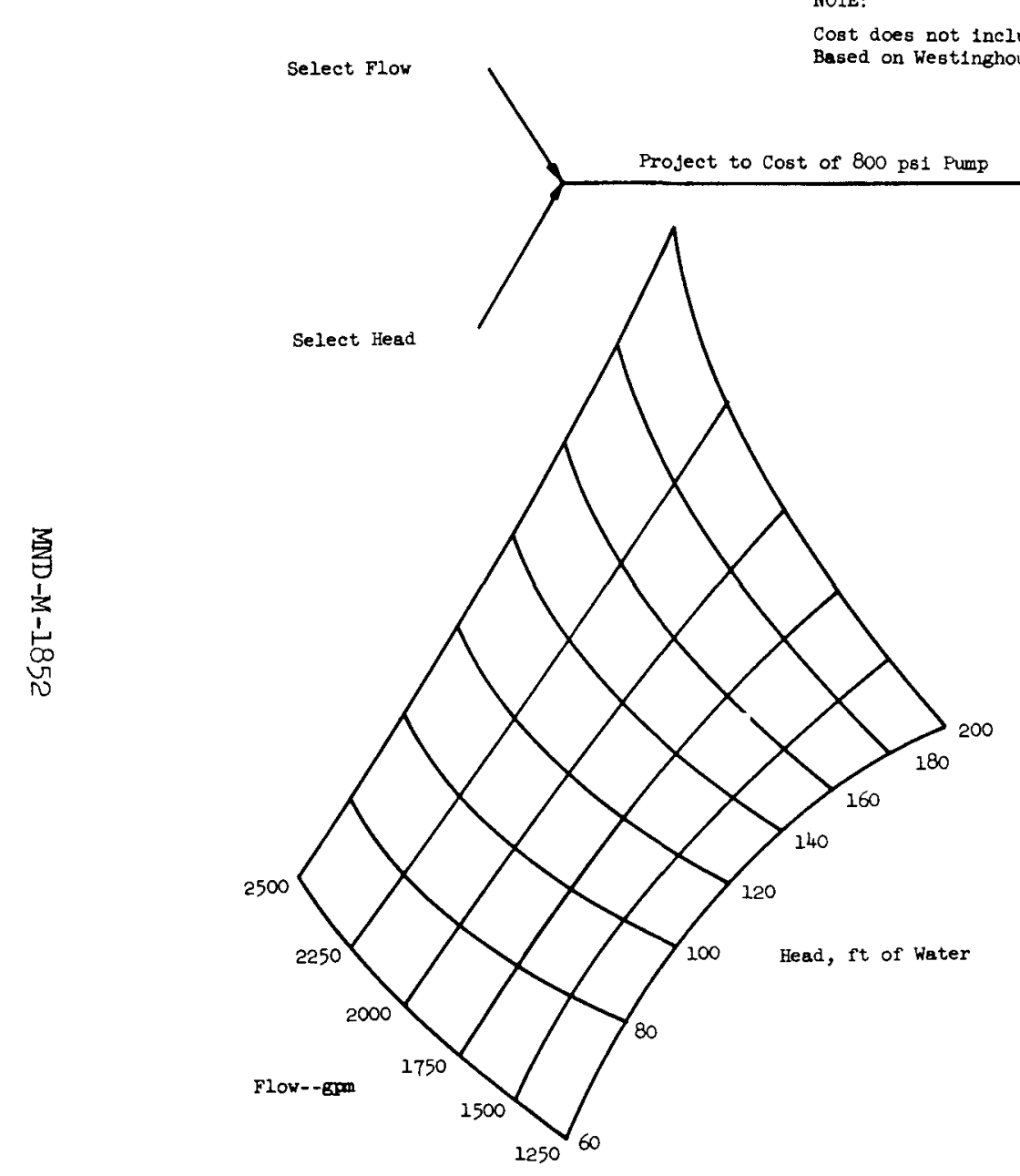

englneering and development

$$
\text { se data }
$$

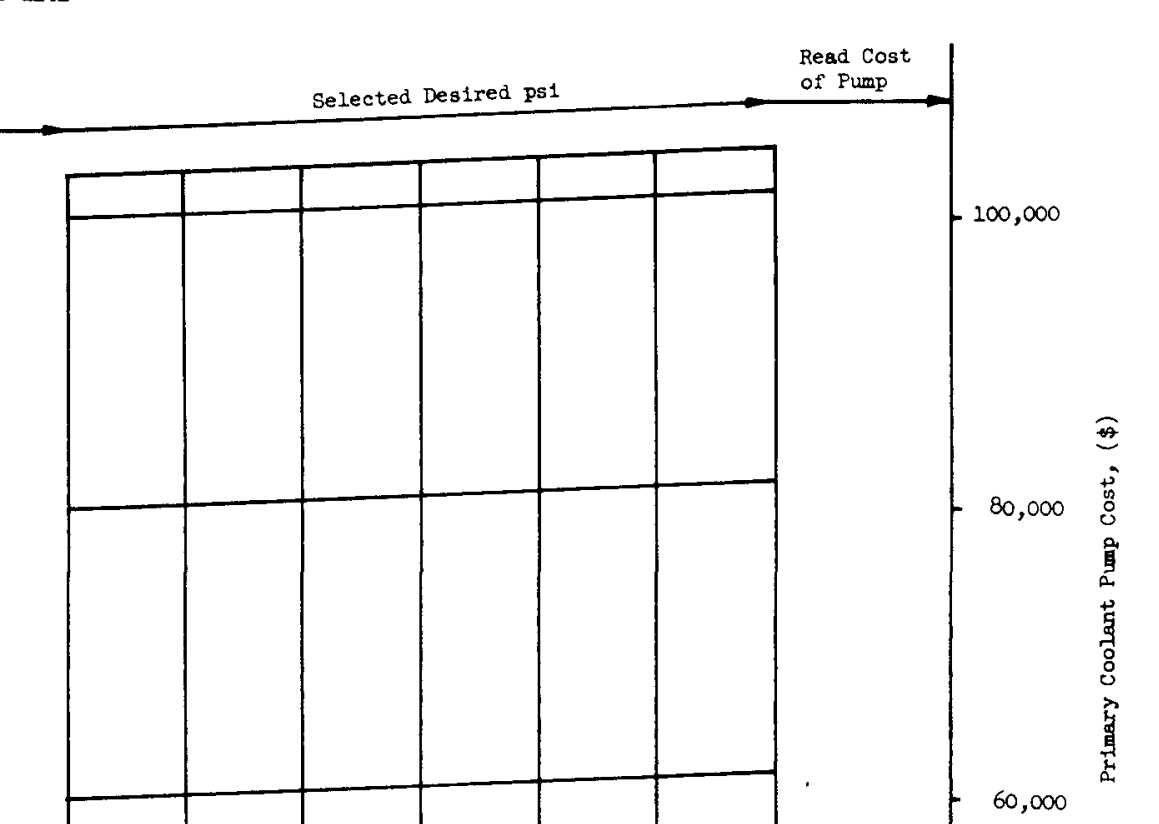

Fig. VI-11. Primary Coolant Pump Cost as a Function of System Flow, Head, and Pressure--Canned Motor 


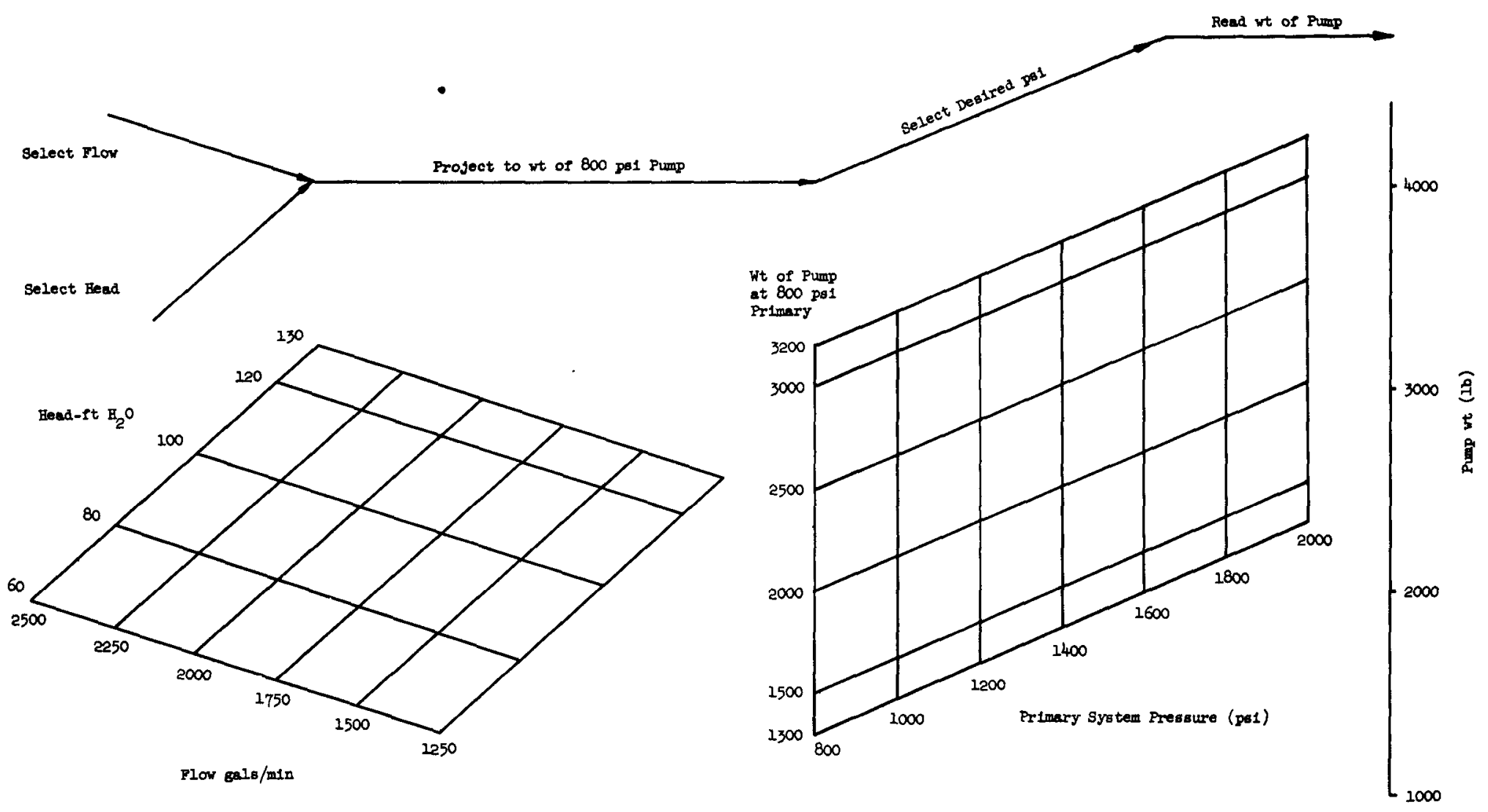

Fig. VI-12. Primary Pump Weight as a Function of System Flow, Head, and Pressure--Canned Motor 


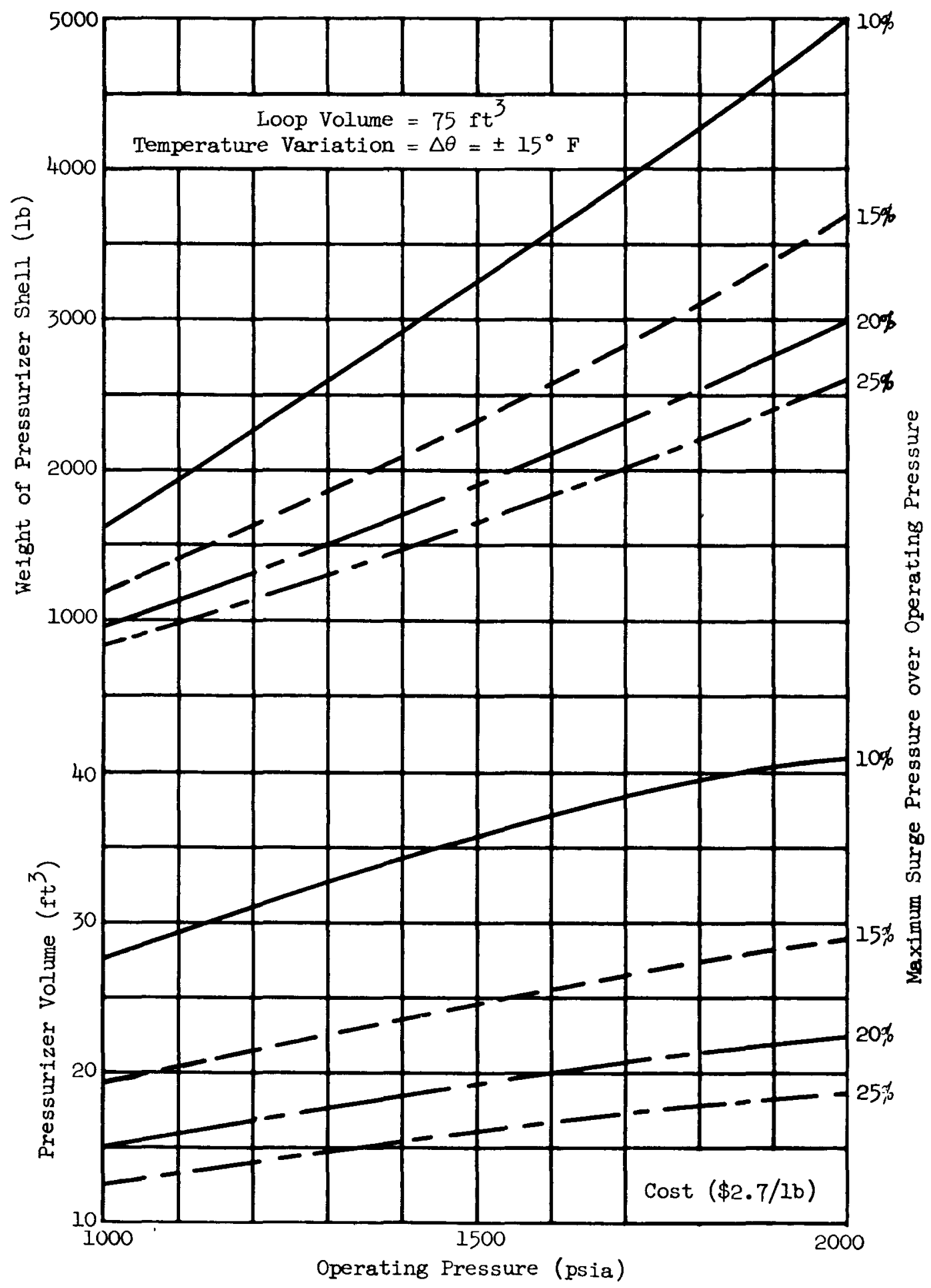

Fig. VI-13. Pressurizer Size as a Function of Operating Pressure 

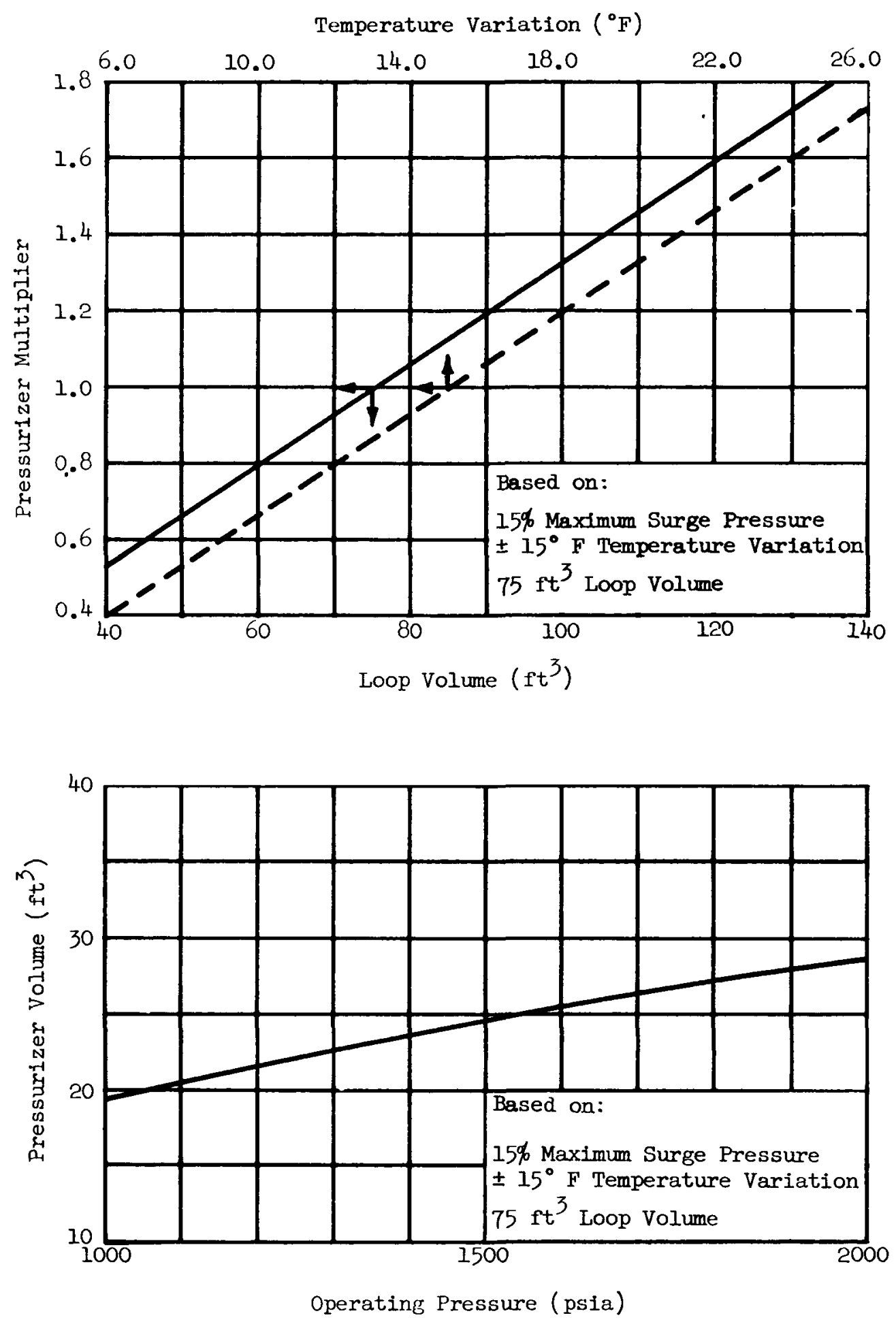

F1g. VI-14. Pressurizer Size as a Function of Operating Pressure, Loop Volume and Temperature Variation 


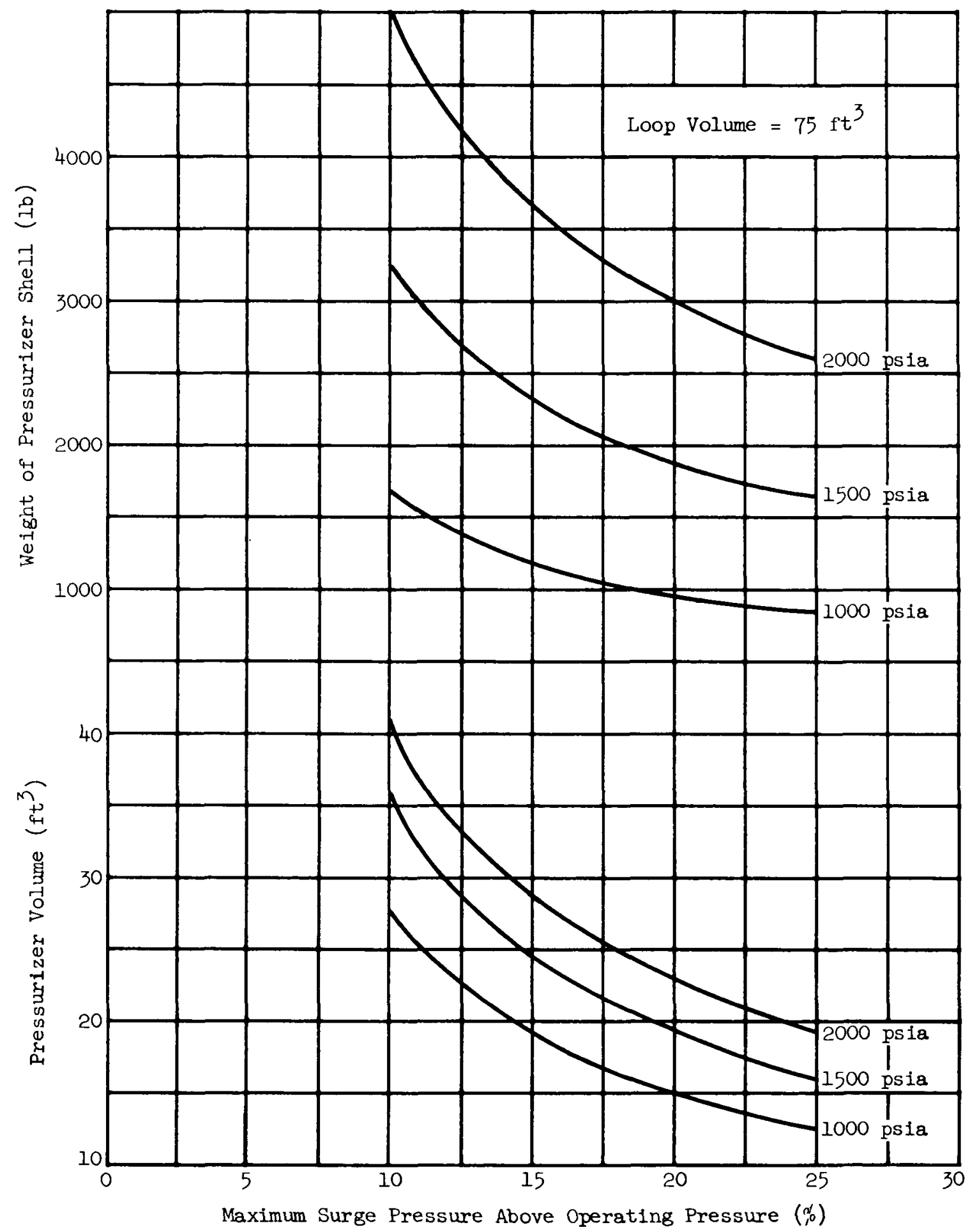

F1g. VI-15. Pressurizer Volume and Weight as a Function of Surge Pressure 


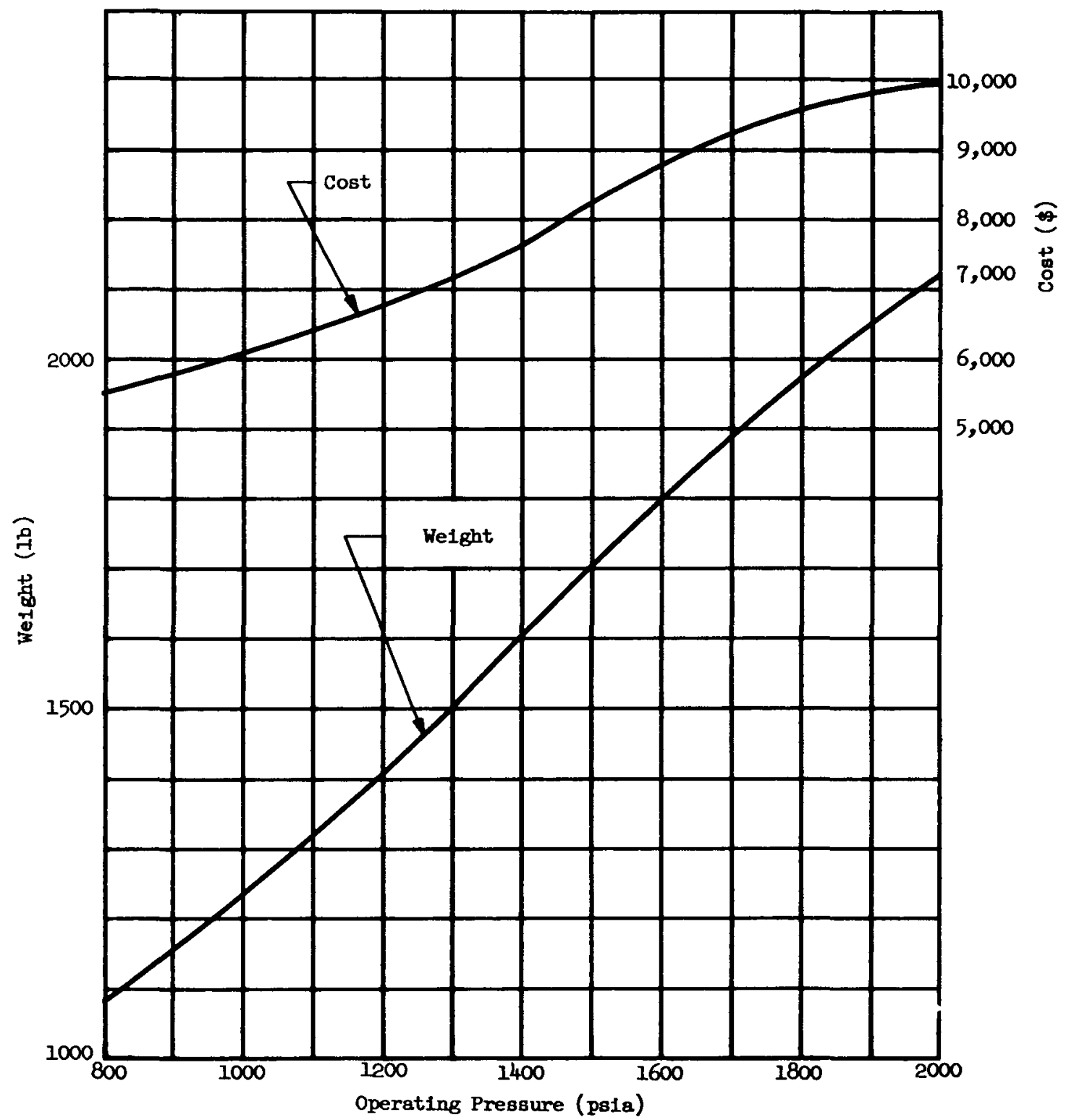

F1g. VI-16. Primary Auxdliary Systems Welght and Cost as a Function of Operating Pressure 


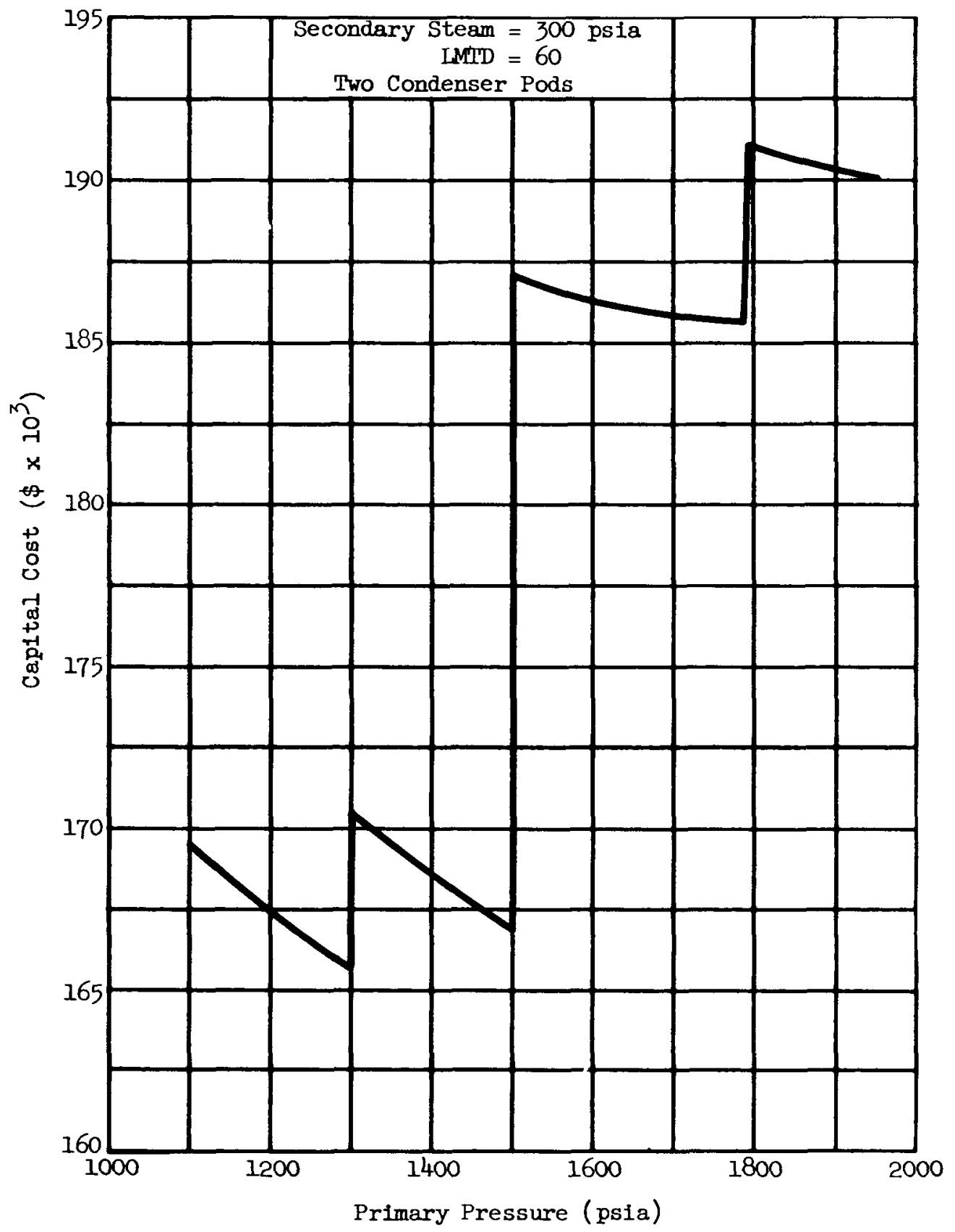

F1g. VI-17. Variation of Primary Loop Cost with Pressure 


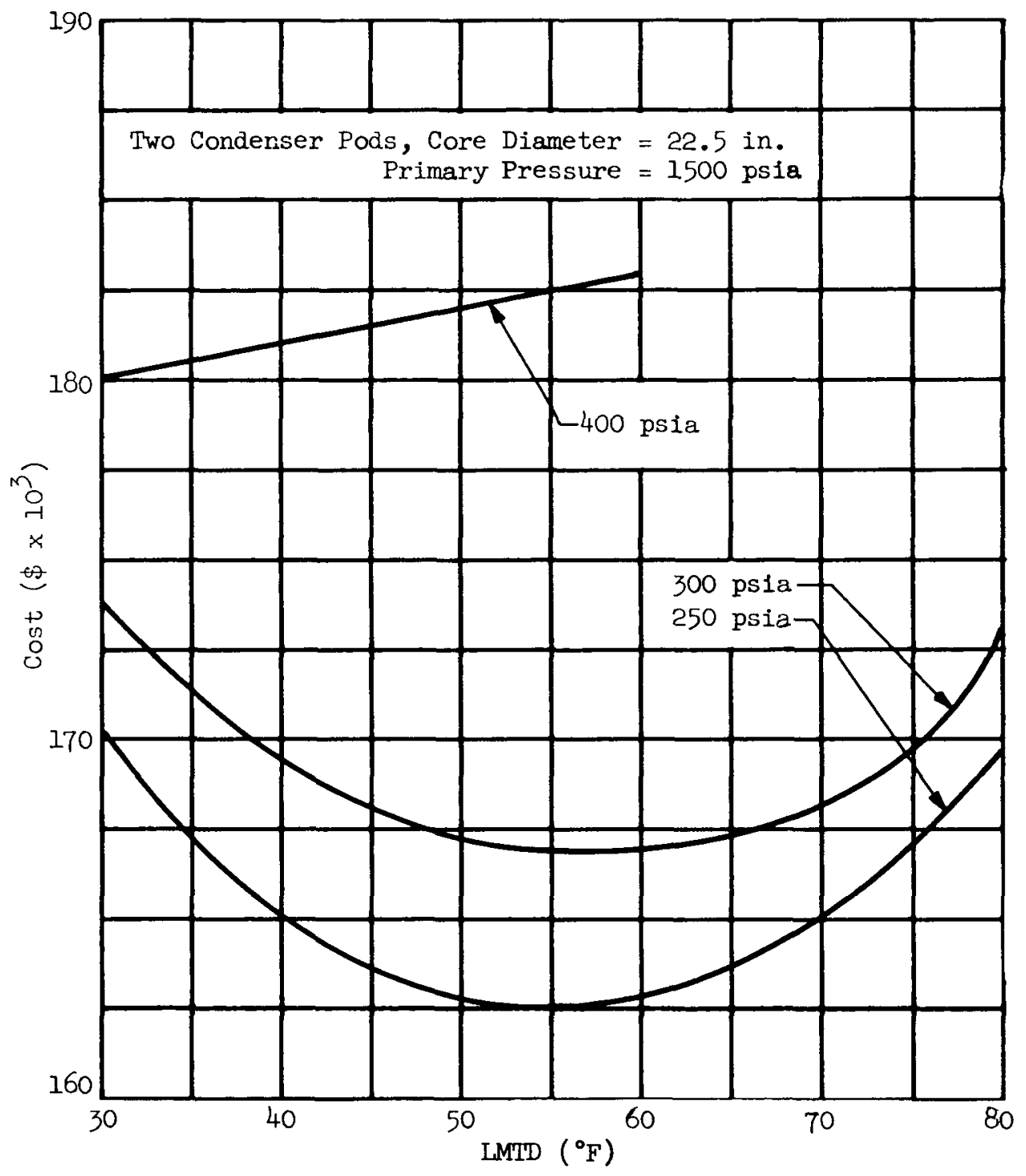

Fig. VI-18. Primary Loop Cost as a Function of LMTD and Secondary Steam Pressure--Local Boiling 


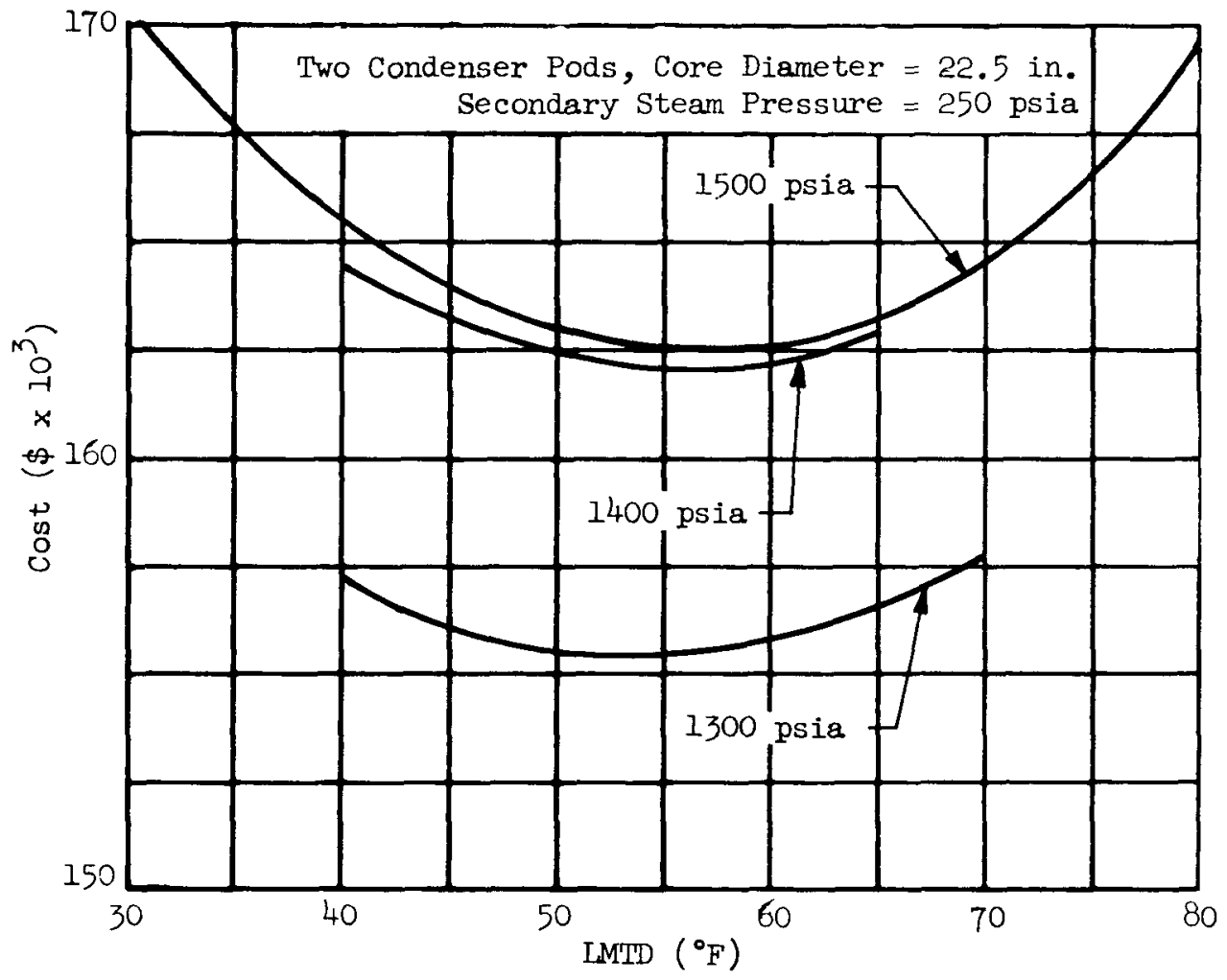

Fig. VI-19. Primary Loop Cost as a Function of LMTD and Primary Pressure-Local Boiling 


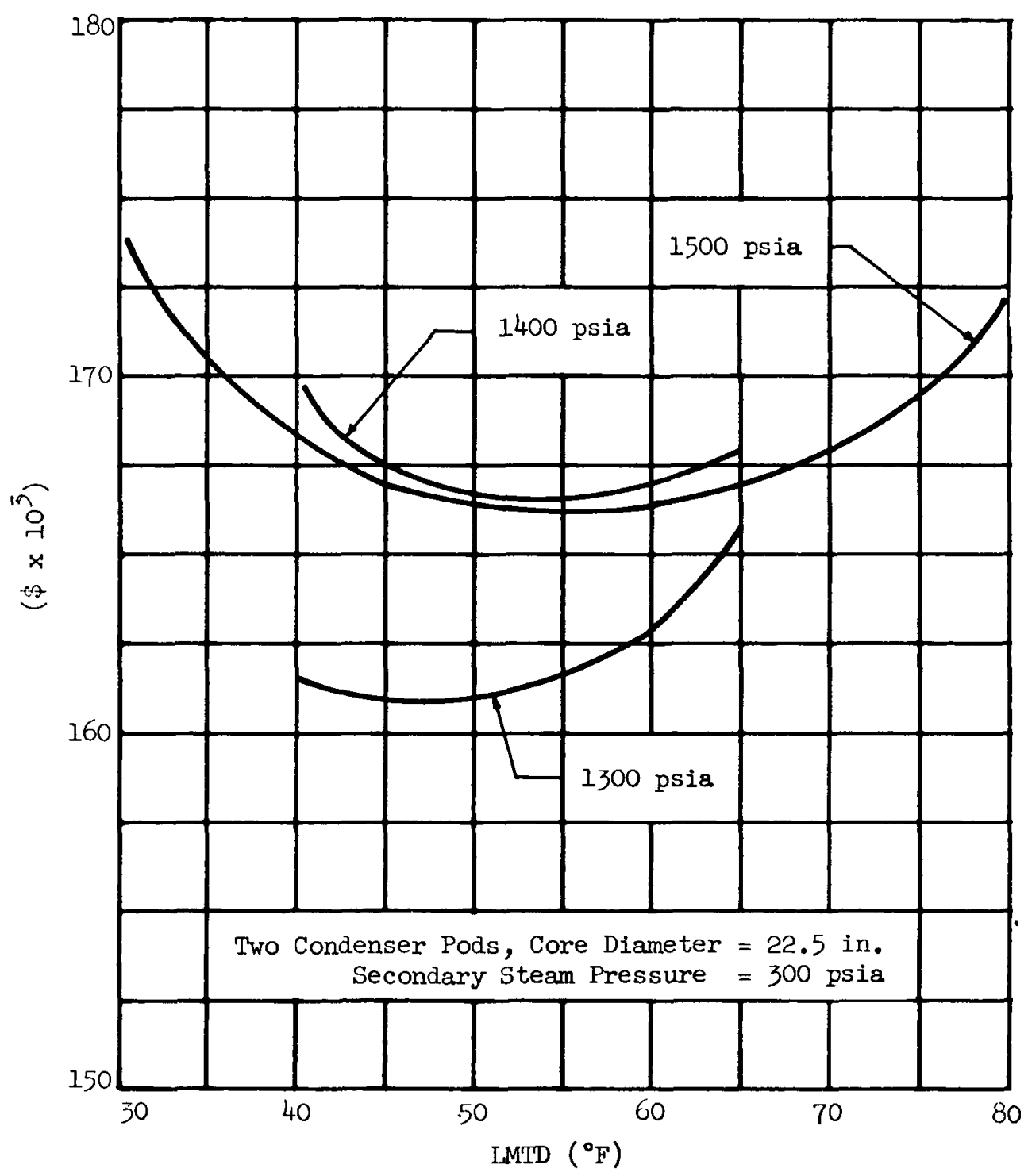

Fig. VI-20. Primary Loop Cost as a Function of LMTD and Primary Pressure--Local Bolling 
Minimum capital costs were found to occur at primary pressures of 1300 psia and with steam generator log mean temperature differences between 40 and $50^{\circ} \mathrm{F}$.

A number of additional considerations entered into the selection of the optimum case in the third phase of the study. The first consideration was that an increase in turbine weight occurs when the secondary steam pressure drops below 280 psia. Since the turbine-generator package is close to the maximum weight, a steam pressure of 280 psia was selected to avoid this increase. The next consideration concerned the steam generator. Since the package containing the steam generator is also close to the maximum weight, the logarithmic mean temperature difference of $50^{\circ} \mathrm{F}$ was selected to minimize steam generator weight. Finally, in order to account for uncertainties in the calculation of auxiliary power, the turbine exhaust pressure was raised from 7 to 9 in. of $\mathrm{Hg}$. This leaves a margin of $20 \mathrm{kw}$ in auxiliary power for sea level operation, and permits operation at $9 \mathrm{in.} \mathrm{back} \mathrm{pressure} \mathrm{at} \mathrm{an} \mathrm{elevation} \mathrm{of} 6500 \mathrm{ft}$.

In the third phase of the study, the following five different methods of changing from the minimum capital cost system were investigated.

(1) Increasing primary pressure and reducing primary coolant flow rate while maintaining the same secondary steam pressure and logarithmic mean temperature difference in the steam generator. The question here is whether the reduced pump cost and auxiliary power requirement overshadow the increase in pressure vessel, pressurizer and piping cost.

(2) Increasing primary loop and secondary steam pressures while maintaining primary coolant flow rate and logarithmic mean temperature difference in the steam generator. In this case, the advantage of increased secondary system efficiency is to be balanced against an increase in the cost of all of the six primary loop components except the pump.

(3) Increasing primary coolant flow rate and secondary steam pressure while maintaining primary loop pressure and logarithmic mean temperature difference in the steam generator. Here the increase in pump cost and power requirement, and steam generator cost is to be balanced against the worth of increased secondary system efficiency.

(4) Increasing secondary steam pressure and reducing logarithmic mean temperature difference in the steam generator while maintaining primary loop flow rate and pressure. The evaluation here is between increased steam generator cost and increased secondary system efficiency.

(5) Changing the type of secondary system while maintaining the primary loop pressure and flow rate, secondary steam pressure and steam generator logarithmic mean temperature difference (addition of a closed feedwater heater). The final case makes it possible to compare the effects of increased secondary system efficiency against the capital cost of an additional piece of secondary system equipment. 
The changes in capital costs were compared to changes in core fabrication, burnup and fuel reprocessing costs for the variations described above. Comparisons were made based on a five year pay-off period, since this was considered applicable to a military system designed for reliability, low cost and air transportability. The cost of core fabrication, burnup and fuel reprocessing was calculated to be $\$ 64,000$ per mw thermal of core power over the five year period. The method of calculation is shown below.

$$
\text { Burnup cost }=\frac{1.25 \mathrm{gm}}{\mathrm{mw}-\mathrm{day}} \times \frac{344 \text { operating days }}{\mathrm{yr}} \times 5 \mathrm{yr} \times \frac{\$ 15}{\mathrm{gm}}=\frac{\$ 32,000}{5 \mathrm{mw}-\mathrm{yr}}
$$

In the minimum capital cost case, the average burnup is approximately $33 \%$. Therefore, in order to burn up 1 gm of U-235, the initial loading must be increased by $3 \mathrm{gm}$. Cost of fabricating the three additional grams plus reprocessing the 2 gm left in the spent core is estimated at $\$ 5$ per gm.

$$
\begin{aligned}
\text { Fabrication + Reprocessing costs } & =1.25 \frac{\text { gm-burnup }}{\mathrm{mw} \text {-day }} \times 344 \frac{\text { operating days }}{\mathrm{yr}} \\
& \times 5 \mathrm{yr} \times \frac{3 \mathrm{gm}}{\text { gm-burned up }} \times \$ 5 / \mathrm{gm}=\frac{\$ 32,000}{5 \mathrm{mw}-\mathrm{yr}}
\end{aligned}
$$

of the five modes of design variation investigated, nnly the second and fifth paid over the $5 \mathrm{yr}$ period. The savings involved in method 2 only amounted to $\$ 2000$ and required a 1500 psia primary loop pressure. This made use of the mechanical seal pump rather marginal; it was felt that the small decrease in cost did not warrant the risk involved. The same method did not reduce costs with a 1400 psia primary pressure since the increased efficiency was not sufficient to overcome the increased piping cost.

The use of extraction feedwater heating reduced required thermal power by $0.24 \mathrm{mw}$, thus saving $\$ 15,300$ over the $5 \mathrm{yr}$ period. Since the additional weight was negligible and the additional capital cost was $\$ 7500$, this change was considered worthwhile.

The pertinent data summarizing the local boiling preliminary design case is tabulated in Table VI-l.

\section{Nonboiling Systems}

The method of integrating secondary systems and nonboiling core primary loops was very similar to that followed by local boiling cores.

The first portion of the local boiling study was completed before integration of the nonboiling cases began. It was found, after investigating several cases, that the pressure breakpoints obtained from the first portion of the local boiling study were also valid for nonboiling systems. Therefore, the integration of the secondary system with nonbolling primary systems considered only primary pressures of 1500 psia and below. 
The first phase of the nonboiling integration was essentially the same as the second phase of the nucleate boiling integration. That is, a detailed study of the range of parameters leading to the isolation of the minimum capital cost system. In this portion of the study, only single nonextraction turbine systems were considered.

Core diameters of 22.5 in. and 25 in. were studied since core size was expected to affect performance considerably. The smaller diameter again represents about the minimum core diameter in which a 2-yr life can be obtained. Unlike the nucleate boiling cores, the pressurized water cores are limited by heat transfer considerations. Larger core diameters permit lower primary coolant flow rates at the same operating pressure. A 25-in. core was studied to ascertain whether the reduction in pump cost would exceed the increase in reactor vessel and pressurizer cost. The same core length-to-core diameter ratio (1.25) studied for the local boiling cases was used in the pressurized water study. Only twopass cores were studied because of the heat transfer advantages discussed in Chapter III, Section C of this report.

The use of 0.5-in. diameter fuel elements in the inner pass of the core so restricts available heat transfer area that the range of operating pressures and flow rates which may be considered is severly limited. Therefore, smaller fuel element diameters were considered in the study despite the fact that this will involve additional problems of core design. The largest diameter fuel elements in the inner pass which allow full coverage of the range of interest of primary pressures and flow rates is 0.375 in.; this value was used throughout the study. The 0.5-in. diameter elements were used in all cases in the outer pass. A slight adjustment of tube pitch was made for each case in order to obtain equal values of the maximum fuel element surface temperature in both passes.

\section{TABLE VI -1}

System Comparison--Parametric Study Results

\begin{tabular}{|c|c|c|c|c|}
\hline & Nonboilir & ng System & Local Boi & ing System \\
\hline & $\begin{array}{c}\text { Lowest } \\
\text { Capital } \\
\text { Cost }\end{array}$ & Best Overall & $\begin{array}{r}\text { Lowest } \\
\text { Capital } \\
\text { Cost } \\
\end{array}$ & Best Overall \\
\hline Primary loop pressure (psia) & 1300 & 1500 & 1300 & 1300 \\
\hline Primary loop flow rate (gpm) & 2000 & 2000 & 1900 & 1900 \\
\hline Mean temperature $\left({ }^{\circ} F\right)$ & 463 & 483 & 463 & 463 \\
\hline Steam pressure (psia) & 280 & 350 & 280 & 280 \\
\hline Reactor power (mw) & 9.07 & $9.10^{(1)}$ & 9.01 & $9.21^{(1)}$ \\
\hline Extraction pressure (psia) & None & 100 & None & 100 \\
\hline
\end{tabular}


TABLE VI-I (continued)

\begin{tabular}{|c|c|c|c|c|}
\hline & \multicolumn{2}{|c|}{ Nonboliling System } & \multicolumn{2}{|c|}{ Local Boiling System } \\
\hline & $\begin{array}{c}\text { Lowest } \\
\text { Capital } \\
\text { Cost } \\
\end{array}$ & Best Overall & $\begin{array}{c}\text { Lowest } \\
\text { Capital } \\
\text { Cost } \\
\end{array}$ & Best Overall \\
\hline Exhaust pressure (in. of $\mathrm{Hg}$ ) & 5.8 & $9^{(1)}$ & 5.2 & $9^{(1)}$ \\
\hline IMIID of steam generator $\left({ }^{0} F\right)$ & 50 & 50 & 50 & 50 \\
\hline Capital cost ${ }^{(2)}$ (dollars) & 163,500 & 182,300 & 164,800 & 172,400 \\
\hline System weight $^{(3)}(\mathrm{Ib})$ & 26,800 & 29,800 & 26,940 & 26,940 \\
\hline
\end{tabular}

(1) Includes changes required for operation at an altitude of $6500 \mathrm{ft}$.

(2) Includes only items directly affected by variables studied--pressurizer, primary loop pump, primary loop piping, steam generator, auxiliary systems, pressure vessel and closed feedwater heater.

(3) Pressurizer, primary loop pump, piping, steam generator, auxiliary systems and pressure vessel.

The values of the other parameters considered in the pressurized water study were identical to those used in the integration of the local boiling cases. Figure VI -21 shows the same information for pressurized water cores that Fig. VI -2 does for nucleate boiling cores. Using Fig. VI-2l instead of Fig. VI-2 the procedure used in the second portion of the local bolling integration was repeated for the nonbolling cases.

Steam pressures of 250,300 and 400 psia were investigated at a primary pressure of 1500 psia with steam generator logarithmic mean temperature difference of $30,40,50$ and $60^{\circ} \mathrm{F}$; system weights and costs were determined. The cost results for both the 22.5-in. and 25-in. core diameter are shown in Figs. VI-22 and VI-23. Again the reduction in primary loop corponent capital cost with lower steam pressure is evident.

A comparison of Figs. VI-22 and VI-23 shows that using the 22.5-in. core yields the lower plant capital cost. Therefore only the 22.5-in. core was studied at lower primary system pressures. Since the local boiling study had already shown the relative cost difference between 250- and 300-psia steam, only 300-psia steam was studied at lower primary loop pressures. Primary pressures of 1200, 1300, 1400 and 1500 psia were investigated; the results are show in Fig. VI-24. As in the local boiling case, a primary pressure of 1300 psia results in the minimum capital cost system. 


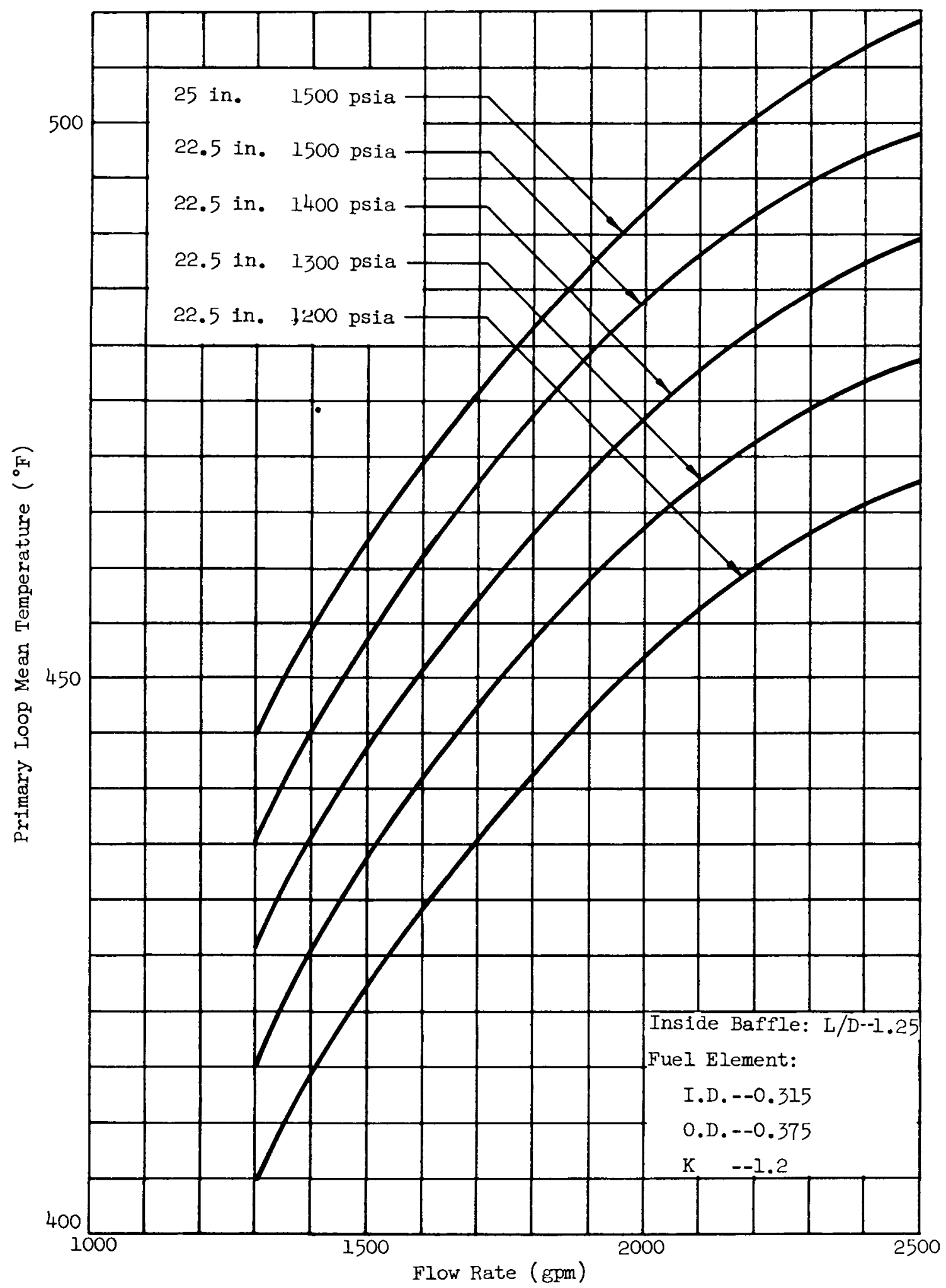

F1g. VI-2l. Primary Loop Mean Temperature as a Function of Flow 


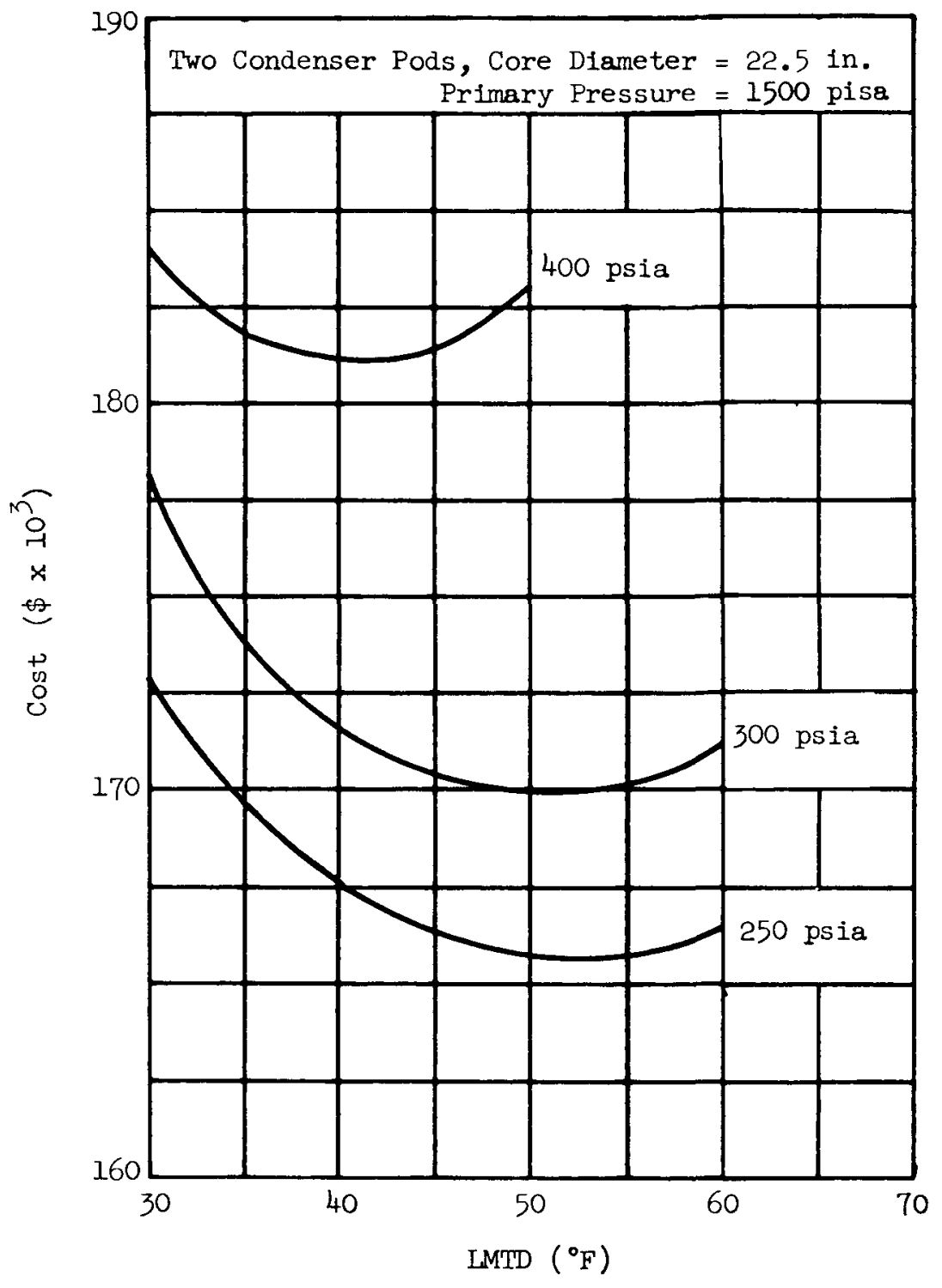

Fig. VI-22. Primary Loop Cost as a Function of LMID and Steam Pressure--Non Bolling 
Two Condenser Pods, Core Diameter $=25 \mathrm{in}$. Primary Pressure $=1,500$ psia

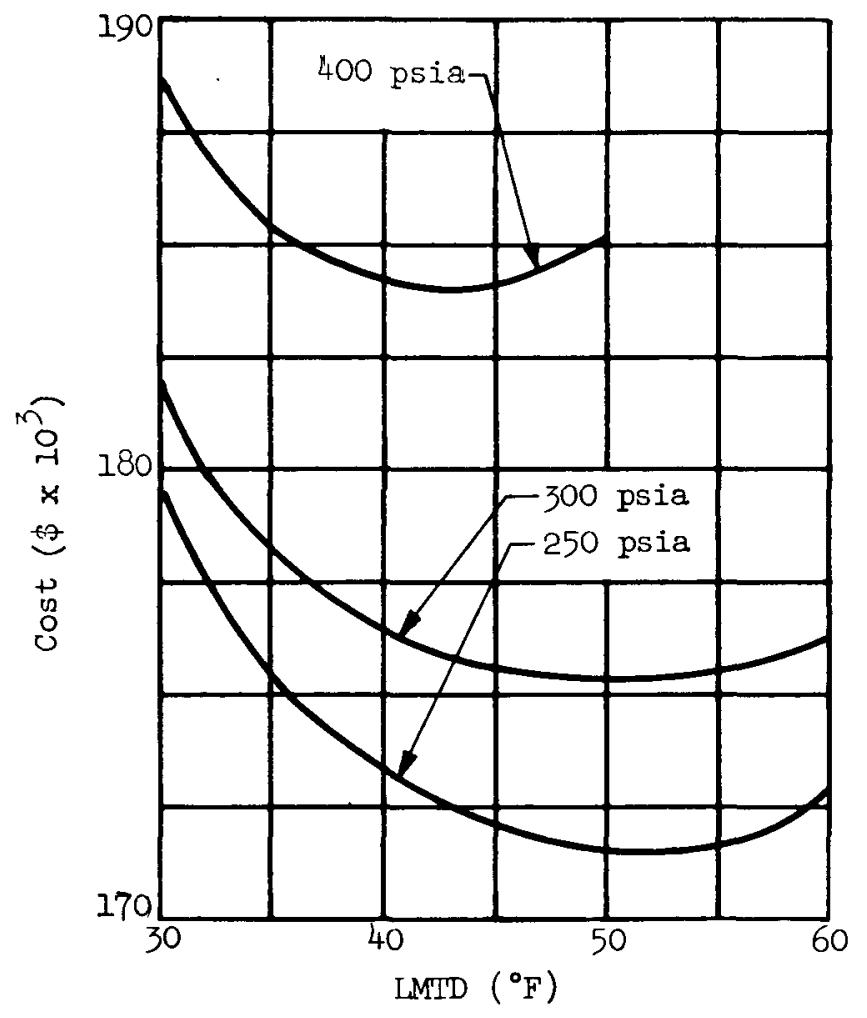

Fig. VI-23. Primary Loop Cost as a Function of IMTD and Secondary Steam Pressure--Non Boiling 
Two Condenser Pods, Core Diameter $=22.5$ in. Secondary Steam Pressure $=300$ psia

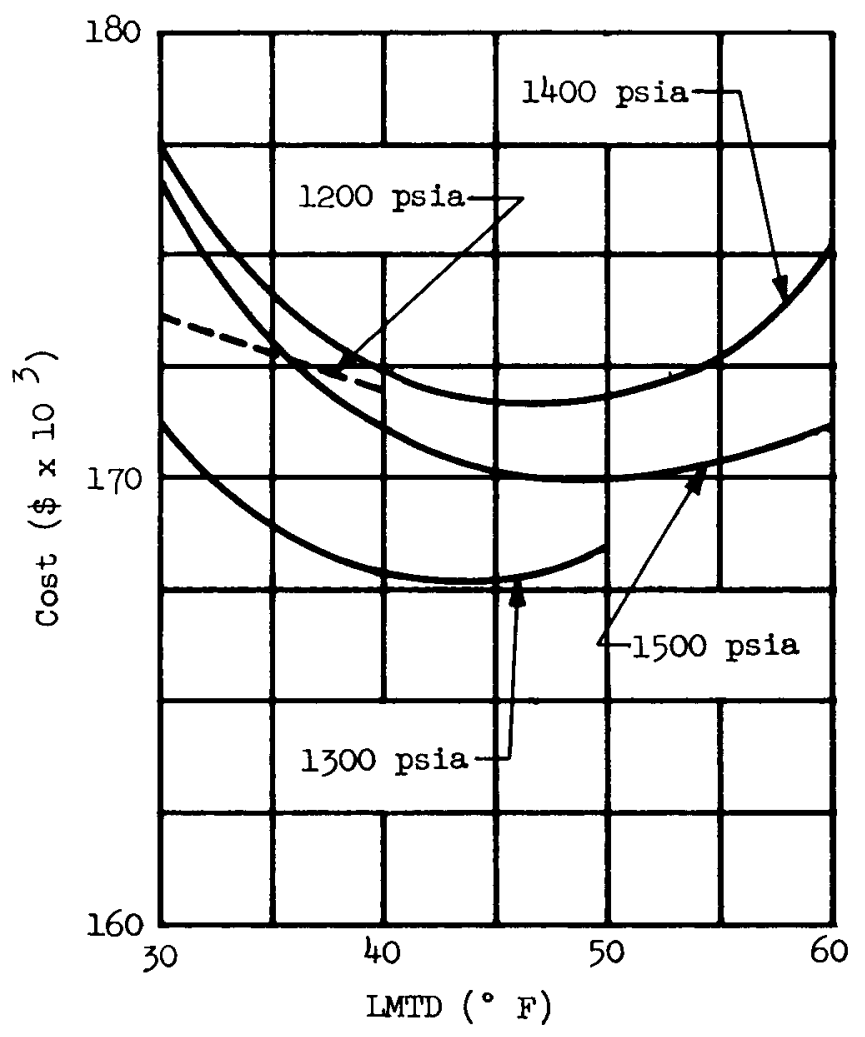

Fig. VI-24. Primary Loop Cost as a Function of Primary Resources and LMTD-Non Boiling 
The five design variations from the minimum capital cost system that were previously investigated with local boiling conditions were then investigated for nonboiling condition. Comparison was again based on a 5-yr period, with variations in operating cost computed on the basis of saving $\$ 64,000$ for every mW of thermal heat eliminated.

In the nonboiling case, all variations but the third result in a net reduction in overall system (capital-plus-operating cost). The most attractive of these variations is No. 2. By increasing the primary pressure to 1500 psia, a reduction of $0.30 \mathrm{mw}$ thermal can be achieved. This reduces operating cost by $\$ 19,200$ over the 5-yr period, while capital cost increases by $\$ 10,800$. It is felt that the $\$ 8400$ saving warrants the necessary increase in primary system pressure. In addition, the use of extraction feedwater heating reduces costs by approximately $\$ 7800$ as it did in the local boiling case. The pertinent data concerning the preliminary design case is tabulated in Table VI-I, including the effects of designing for 6500-ft elevation.

Comparison of Boiling and Nonboiling Systems

Comparison of the best overall local boiling and nonboiling water systems shows the local boiling system to have the following four principal advantages:

(1) Less Complex Core--The nonboiling core requires the use of a baffle, probably of complex geometry; provision of two types of fuel elements, differing in diameter; and supply of a significantly greater number of fuel elements, since more small-diameter tubes are necessary to provide the same inventory and since the addition of poison in the form of the baffle requires the introduction of more reactivity. Structural design is made more difficult by the use of small-diameter tubes.

The local boiling core may, on the other hand, require a degree of oriflcing that is not necessary with the nonboiling core.

It is felt that the capital and design cost of the nonboiling core, exclusive of fuel element fabrication, would exceed that of the local boiling core--even considering the cost of providing additional orificing.

Fabrication cost of the fuel elements to be used with the nonbolling core, a cost repeated every two years, is estimated to exceed that of the local bolling core by at least $\$ 40,000$. Reprocessing costs would also exceed those incurred with the local boiling core by a relatively small amount.

(2) Lesser Containment Problem--The energy stored in a 1500-psia non boiling primary loop is greater, and poses a greater hazard and containment problem than that stored in a 1300-psia local boiling loop. The estimated reduction of containment cost and weight is $5 \%$. 
(3) Greater Purmp Margin of Safety--The additional primary loop pressure in the nonboiling system makes the utilization of a mechanically sealed primary pump more questionable--although it was included for cost evaluation purposes.

(4) Lower Weight--The weight of the local boiling primary system is estimated to be about $2800 \mathrm{lb}$ less than that of the nonboiling system. Since it is anticipated that the package weight problem will become critical during preliminary design, this difference could eliminate an additional package.

(5) Lower Capital Cost--The capital cost of the local boiling primary system is estimated to be about $\$ 10,000$ less than that of the non boiling system.

A preliminary analysis of the degree of risks involved in building a local boiling system concluded that the principal problem was that of flow distribution. This problem was analyzed and, as indicated in Chapter III-C, it was concluded that no major difficulties will be encountered in the PM-1 system using local boiling.

In order to show the advantage of two-pass cores for pressurized water systems, the effect of converting the final pressurized water core from a two-pass to a one-pass core was investigated. It was found that in order to operate this core using one pass, without local boiling, and at a power level of $9.10 \mathrm{mw}$, an operating pressure of $2000 \mathrm{psia}$ and a primary loop flow of 2600 gpm are required. This compares to a pressure of 1500 psia and a flow of 2000 gpm required with a two-pass arrangement. These changes in pressure and flow would increase the capital cost of the system by approximately $\$ 70,000$.

\section{B. PLANT DESCRIPTION}

The plant design selected as a result of the parametric studies is one utilizing a local boiling core, with the primary loop pressure at 1300 psia. The steam generator is of the vertical type. The secondary system operates on 280-psi steam and uses a single turbine-generator unit and a direct airto-steam condenser. Parameters of the system are presented in Table VI-2.

\section{TABLE VI-2}

PM-1 Plant Design Summary

1. Overall Performance Data

Reactor Design Characteristics

Pressurized water, nominal operating pressure--psia . . . . 1300

Design pressure for heat transfer analysis--psia. . . . . . . . . . . . Design pressure for structural analysis--psia . . . . . . . . . . . . . . . . . Average core coolant temperature, nominal-- ${ }^{\circ} \mathrm{F} . . . . . . .463$ Reactor thermal power, nominal--mw. . . . . . . . . 9.21 Reactor thermal power, design--mw . . . . . . . . . 10.2

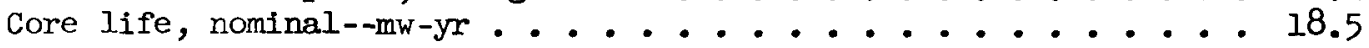




\section{TABLE VI-2 (continued)}

\section{Core Design Characteristics}

Geometry, right circular cylinder (approximately)

Diameter (average)--in. . . . . . . . . 22-25

Active length--in....................... 30

Overall length--in. . . . . . . . . . . 33-36

Core structural material................ Stainless

Fuel element data, tubular, cermet type

Steel

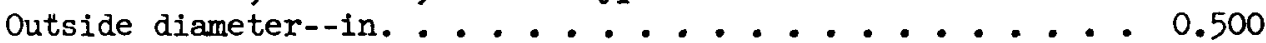

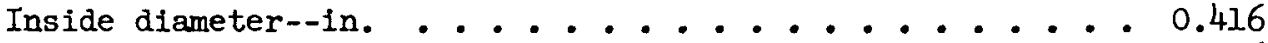

Clad thickness--in. . . . . . . . . . . . 0.006

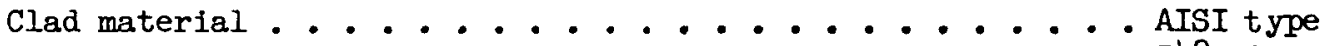
348 stainless steel; $\mathrm{Co}$ and $\mathrm{Ta}$ controlled

Pitch (approximately) in. .............. 0.65 Number of tubes ................. 725-750

$\mathrm{U}-235$ inventory--kg . . . . . . . . . 25-26

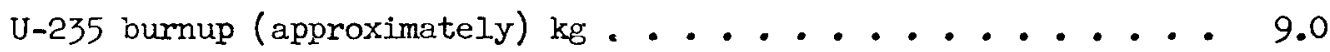
Meat composition

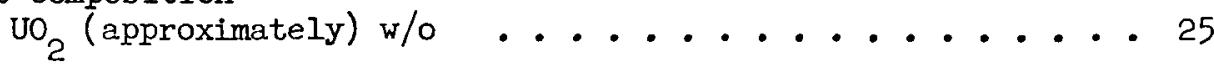

3. Core Heat Transfer Characteristics

Heat flux--Btu/ft ${ }^{2}-\mathrm{hr}$

Average (approximately) .................. 70,000

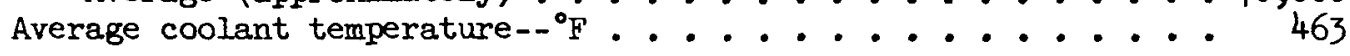

4. Reactor Hydraulic Characteristics

Coolant flow rate-grm ...................... 1,900

Systems Design

1. General Plant

Reactor power output, nominal--mw . . . . . . . . . 9.33

Steam generator power output, nominal--mw .......... 9.33

Steam pressure, full power, minimum--psia.......... 280

Steam conditions, full power....................... 1/4 moisture

2. Main Coolant System

Number of coolant loops . . . . . . . . . . . . . . 1

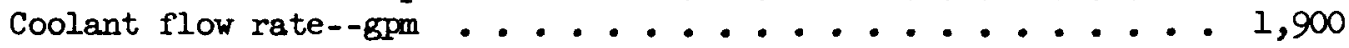

Coolant system destgn pressure--psia................ 1,500

Coolant velocity in piping (main loop)--fps . . ...... 23

Coolant pipe size, main loop, nominal, schedule 80 --in. . . . 6 
TABLE VI -2 (continued)

System basic material

Piping ................................... 304

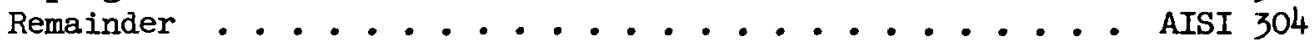

Main coolant pumps

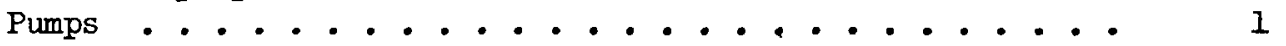

Steam generators

Number of units........................ 1

Design pressure (approximately) psi.......... 500

Type ..................... Vertical

with inte-

gral steam

drum and

separators

Temperature primary inlet, full power (approximately) ${ }^{\circ} \mathrm{F}$

Temperature primary outlet, full power (approximately) ${ }^{\circ} \mathrm{F}$

481

444

Temperature steam side outlet, full power-- ${ }^{\circ} \mathrm{F} . . . . .$.

411

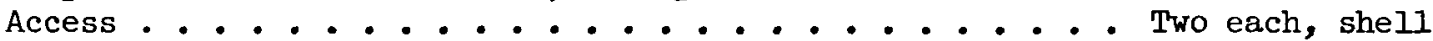
and tube side, bolted type

3. Pressurizing and Pressure Relief System

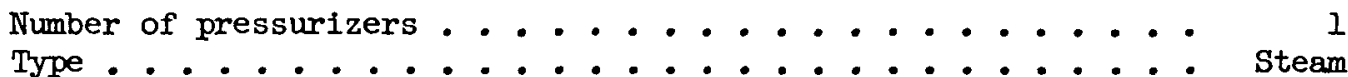

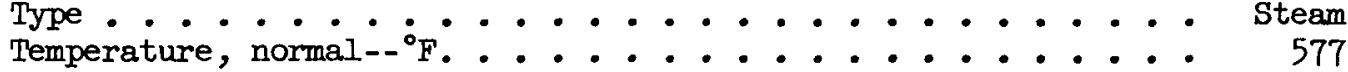

Pressure element (decreasing). ............ Water spray head

Pressure element (increasing)............ Electric immersion heater

4. Coolant Purification and Sampling System

Number of purification loops ...............

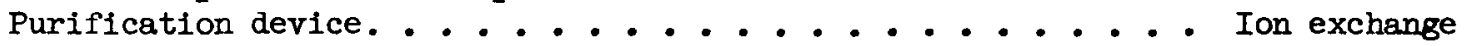
resin

Inlet temperature to ion exchanger (maximum) ${ }^{\circ} \mathrm{F}$. . . . . 120

Regeneration provisions............. Cartridge type, $1-y r$ Iife

\section{Primary Shield Water System}

Primary shield water cooler. . . . . . . . . . Air blast type

Purification loop. ................ Ion exchange resin

Regeneration provisions .............. Cartridge type, 1-yr life 
TABLE VI -2 (continued)

Secondary Loop

\section{General Plant}

Steam flow at full power--lb/hr (approximately). ..... 35,000 Steam temperature $\left({ }^{\circ} \mathrm{F}\right.$ ) at full power (280 psia, dry and saturated) 411 Feedwater flow at full power--lb/hr (approximately). . . . . 35,500 Maximum gross electrical output--kw at $0.8 \mathrm{pf} . . . . . . .1,250$ Maximum net electrical output--kw at $0.8 \mathrm{pf}$......... 1,000

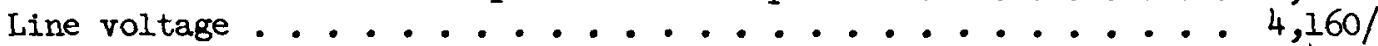
2,400

Cycle. . . . . . . . . . . . . . . 60

Phase................................ 3 Auxiliary equipment voltage. . . . . . . . . . . . 480 Process heat $7,000 \mathrm{lb} / \mathrm{hr}$ of 35 -psia dry and saturated

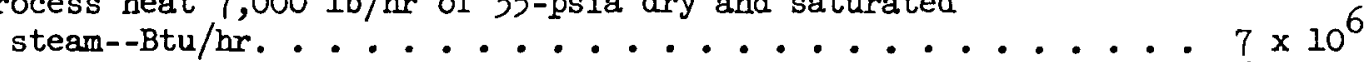

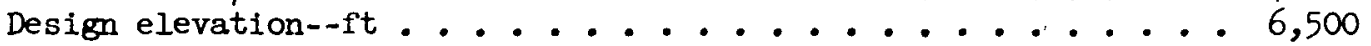

Auxiliary power--kw ................... 135

\section{Turbine Generator Set}

Type ...................... Single extraction turbine

Throttle flow, full power--lb/hr (approximately)....... 26,500

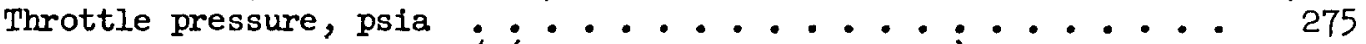
Throttle steam moisture--\% (moisture separator used) . . . . 0.5 Turbine steam exhaust conditions Pressure--in. Hg abs ............... 9 Moisture--\$ . . . . . . . . . . . . . 12.2 Lube oil cooler ......................... Air cooled Turbine speed--rpm (approximately) ........... 8,000 Generator capaci.ty --kva . . . . . . . . . . . 1,562.5 Generator capacity--kw at $0.8 \mathrm{pf}$. . . . . . . . . 1,250

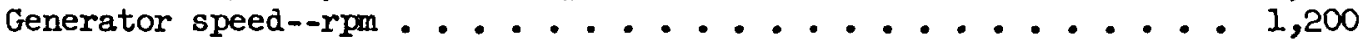

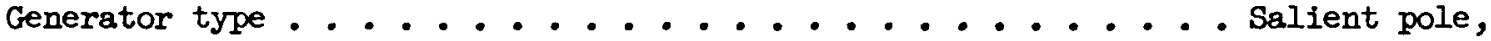
oversized for power quality considerations

\section{Condenser System (two furnished)}

Number .......................... . . . . . 2

Type ...................... D1rect alrto-steam

Duty--Btu/hr rejected (approximately)............ 1 x $10^{7}$ each Design elevation--ft above sea level .......... 6, ... 600

4. Feedwater Deaerating and Heating System

Deaerator

Type.................... Deaerator heater 


\section{TABLE VI-2 (continued)}

Flow--lb/hr (approximately). . . . . . . . 35,500

Design pressure--psia. . . . . . . . . . . . ..

Oxygen removal guarantee--cc/1 ...........

Storage--min

Boiler feed pump

Number . . . . . . . . . . . . . . . . .

Driver ........................

Closed Feedwater Heaters

Number . . . . . . . . . . . . . . . . . .

Extraction steam pressure--psia. ............

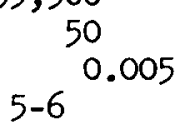

2

One steam driven

One electri-

cally driven

1

100

\section{Auxiliaries}

Evaporator--reboiler (combination)

Capacity--1b/hr ..................

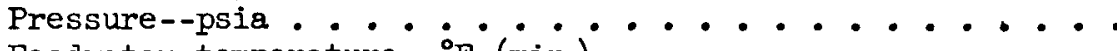

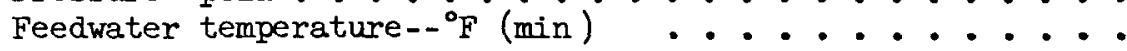

Type feedwater .................. Feedwater storage tank

Capacity--gal (approximately)............ 4,000

Secondary water treatment ............. Chemical

Turbine steam bypass system

Type ........................ Manual

Shop air compressors

Number ......................

Auxiliary diesel generator set

Number . . . . . . . . . . . . . . . . .

Capacity--kw .....................

Voltage. . . . . . . . . . . . . . . . . .

Type ......................

Emergency power

Type .................. Battery

Control system

Type .

Solid state electric 


\title{
APPENDIX A
}

\author{
REACTOR ANALYSIS CODES
}

In performing the parametric analysis, liberal use was made of the IBM-704 digital computer. The following are abstracts of the IBM-704 machine reactor design codes used.

\section{Program C3}

Program C3 provides a multigroup analysis for a bare, homogeneous, cylindrical reactor. The input data consists of geometric and composition variables defining the reactor configuration. Neutron cross section data are supplied on a nuclear data tape. Macroscopic cross sections are computed; flux and slowingdown density are then calculated for the homogeneous core. Flux at 19 lethargy levels plus a thermal group are used to compute 3 group constants. Thermal and epithermal cell corrections compensate for inhomogeneous cell structure. The leakage term includes a lethargy-dependent buckling and transport correction. Reactivity for an equivalent bare core and 3 group constants are the main output of the program.

Reference: XDC 58-3-178 "Three-Group Bare Reactor Program Using Epithermal Cell Corrections (704 Program C3)"

\section{Program F2}

Program F2 provides a multiregion, one dimensional, two-group diffusion calculation, in as many as 50 regions and at as many as 100 latice points. The input data consists of geometric variables defining the reactor and two-group constants for each of the regions. Output data includes reactivity, fast and slow flux and local-to-average power ratios.

Reference: "Two Group Neutron Diffusion--F2," General Electric Report, March 22, 1957.

3. Program I2

Program I2 solves the Boltzmann equation for cylindrical geometry by the $\mathrm{P}_{3}$ spherical harmonic approximation. The thermal flux distribution across a fuel element cell is calculated, thus providing an analysis of the fine flux perturbations in each of the regions of the fuel element cell. Output data includes average fluxes for each region from which a heterogeneity factor can be calculated for each material.

Reference: DC 58-1-158, "A 704 Program for the Solution of the Neutron Transport Equations in Fifty Concentric Cylindrical Annuli by the Weil Method (Program I 2)."

4. Cn--F2 Burnout

The burnout code provldes a one-dimensional two-group reactor core Iffe study. The code links Programs C2 and F2 and calculates fuel and burnable poison 
depletion and fission product formation. It permits output from several Program $C$ 's to be used as input for a Program F, thus providing a multiregion nonuniform burnup study. After completing Program $C$ and $F$ calculations, flux values obtained from the $F$ calculations are normalized to a specific power output. Then assuming flux and power constant for a given time interval, the isotopic densities are recomputed and used as input for Program $C$ at the next time interval. This process iterates to a $K_{\text {eff }}$ of 1.0 . Input data consists of the regular $C$ and $F$ input plus iteration parameter information. In addition to $C$ and $F$ output, burnout data are given.

\section{Fuel Recycling Program}

The fuel recycling program is a linkage of Program C3, a three-group burnout (including fission product and heavy isotope buildup), and a fuel processing and reactivity control program. The code provides a single region, uniform lifetime study of the reactor operating history. Input data given are the regular Program C3 input plus information concerning burnout and recycling iteration parameters. Output data consists of standard $C 3$ output, material withdrawal and recycling adjustments during reactor lifetime and a final summary of the time variation of Isotopic concentrations and $K_{\text {eff }}$.

\section{Synthetic Design Program (Syd II)}

Program Syd solves the equations set forth in APEX-303 to produce the coefficients of a quadratic equation in up to 25 independent varlables for any fractional factorial experiment design with less than 564 cases. The resulting quadratic equation then relates the effects of variations of independent variables upon a single dependent variable. A data point evaluation routine is included in the program to evaluate the quadratic for specific combinations of the independent variables and reduce this information to a form suitable for use on the Benson Lehner plotter machines. Input data consists of a set of explicitly evaluated dependent variable values and information concerning the number of independent variables and order of replication. Output data are the coefficlents of the quadratic equation, statistical measures of goodness of fit and point data evaluations.

References: APEX-303, "Synthetic Experiment Design Techniques in Reactor Analysis," J. M. Krosl and C. Cyl-Champlin. Synthetic Design 'Program" (Syd II), C. Cyl-Champlin--Unpublished Report.

\section{Data Preparation Programs}

Application of synthetic design techniques require numerous routine calculations to be performed. Several "data preparation" codes were programed to handle these computations. The programs generated during this parametric study are as follows:

DPl Computes geometrical and material density data, reflector savings and fuel $\overline{c e l l}$ regional cross sections for a nine varlable synthetic design. Sets up an input data tape for Program I2. Sets up input data tape for DP2.

DP2 Combines results of I2 and DPI (or DP3), computes material cell corrections, and sets up an input data tape for $\mathrm{C} 3$. 
DP3 Similar to DPI except for changes in several independent variables.

DP4 Solves a quadratic equation using synthetic design coefficients for a given core life at numerous points in the reactor Iifetime surface.

DP5 An extension of DP4, it also prepares cards for plotting cells vs inventory curves on Benson Lehner plotter.

8. $P D Q$

PDQ is a two-dimensional, reactor design code for the IBM-704 computer. It solves the few-group neutron diffusion equations for one- to four-lethargy groups over a rectangular region of the $\mathrm{x}-\mathrm{y}$ or $\mathrm{r}-\mathrm{z}$ plane. Input parameters are specifled regionwise, and complete variation of the mesh interval is allowed. Output includes reactivity and the flux at each point for each group.

Reference: WAPD-TM-70; "PDQ: An IBM-704 Code to Solve the Few-Group Neutron Diffusion Equations," August 1957. 


\section{APPENDIX B}

\section{METHOD OF CALCULATION--BIOLOGICAL SHIEID DESIGN}

Radiation emanating from the reactor core during operation consists of fast neutrons, prompt fission gammas, gammas from thermal neutron capture and inelastic scattering of fast neutrons and fission product gammas.

Capture gammas and inelastic scattering gammas created within primary water regions in the proximity of the core, thermal shield and pressure vessel are significant sources of radiation during operation. Source strengths for the above mentioned radiation were estimated from the data and standard methods of reference 1, chapter 3 . Where a gamma spectrum was involved, line energies at $0.5,1,2,3,4,6$ and 10 mev were used to approximate the spectrum. Dominant radiation omitted during operation from within the primary loop and components, excluding the reactor vessel, are fast neutrons (approximately $1.0 \mathrm{mev}$ ) and gammas (6.13 and $7.10 \mathrm{mev})$ resulting from the $0^{16}(n, p) N^{16}$ and $017(n, p) N^{17}$ fast neutron reactions, respectively. These occur in regions of high neutron flux. Activation cross sections, mode of decay and loop activation equations used to estimate this source are given by Rockwell (Ref. I).

After shutdown, major sources of radiation are fission decay products and activated constituents of the thermal shleld and pressure vessel. Fission product activity of the spent core was determined from the data of Perkins and King (Ref. 10) utilizing an IBM-704 code (Ref. 12) for computation of decay rates and gamma source strengths at seven line energies which approximate the spectrum. Activation of the steel was computed using standard activation equations and the data of Table 3.7, p. 46, Ref. 1. Values of the thermal neutron flux used in determination of gamma source strengths were taken from diffusion theory Program Fd radial and axial flux plots. Average fast neutron source strength $\mathrm{S}_{\mathrm{v}}$ (neutrons $/ \mathrm{cm}^{3}-\mathrm{sec}$ ) is given by

$$
\mathrm{S}_{\mathrm{v}}=\frac{\mathrm{PFWV}}{\mathrm{V}_{\mathrm{c}}}
$$

where $P$ is the operating power (watts), $F_{w}=3.1 \times 10^{10}$ fissions/watt-second, $D$ is the average number of neutrons emitted per fission event, $v_{c}$ is the volume of the core, and $v$ is the average number of neutrons released per fission.

Experimentally determined effective removal cross sections (Ref. 15) were used to compute fast neutron dose rates. Axial neutron dose rates $D_{N}$ (millirem/hr) are given by:

$$
D_{N}=\frac{S_{v}}{2 \Sigma_{R} C^{2}}\left[E_{2}\left(b_{1}\right)-\frac{E_{2}\left(b_{1} \sec \theta_{1}\right.}{\sec \theta_{1}}\right]
$$

where $S_{v}$ is the source strength given by equation $I-1, C$ is the conversion factor (millirem/hr per neutron $/ \mathrm{cm}^{2}-\mathrm{sec}$ ) for $8.0 \mathrm{mev}$ neutrons, $\Sigma_{R}$ is the macroscopic 
neutron effective removal cross section $\left(\mathrm{cm}^{-1}\right), b_{1}$ is the total number of mean free paths from source surface to dose point along the axis, and $\theta_{1}$, is the angle of the intersection of the axis and a line drawn from the dose point to the periphery of the cylinder top. The exponential integral $E_{n}(x)$ is defined as

$$
E_{n}(x)=x^{n-1}{\frac{e^{-t}}{t^{n}}}_{t t}^{\infty}
$$

where $\mathrm{n}$ is a positive integer greater than zero. Graphs and tables of this function are found in numerous standard references. Radial neutron dose rates are computed from the equivalent line source solution for a cylindrical source (Ref. I, Chapter 9) given by

$$
\mathrm{D}_{\mathrm{N}}=\frac{\mathrm{S}_{\mathrm{v}} \mathrm{R}_{\mathrm{o}}^{2}}{2(\mathrm{a}+\mathrm{z})_{\mathrm{c}}} \mathrm{F}\left(\theta, \mathrm{b}_{2}\right)
$$

where $R_{0}$ is the radius of the core $(\mathrm{cm})$, a is the distance measured from the core surface along the radial centerline to the dose point $(\mathrm{cm}), \mathrm{b}_{2}$ is the total number of mean free paths from the equivalent line to the dose point, $c$ is as previously defined for equation I-2 and $\theta=\tan ^{-1}$ of

$$
\left[\frac{\frac{H}{2}}{a+z}\right]
$$

where $\mathrm{H}$ is the height of the source $(\mathrm{cm})$. The self-absorption distance $\mathrm{z}(\mathrm{cm})$ determines placement of the line source within the cylinder and may be computed by the graphs and equations of pp. 362 and 363, Chapter 9, Ref. I. Graphs of tne function $F(\theta, b)$ are found in Chapter 9, Ref. I.

In order to consider a variety of radial shield configurations, all major sources within the reactor vessel during operation were lumped into a single surface source at the outside of the reactor vessel wall. A detailed description of the methods used to determine this equivalent surface source is given in Ref. 3 , pp. II-83 to II-86. The total surface source strength spectrum is given in Table II-21, p. II-86, Ref. 3. Brlefly, the core gamma contribution to the surface source strength was computed with an IBM-704 code which integrates over the entire cylindrical volume of the core and uses a single effective buildup factor represented by the sum of two exponentials in the mean free paths along the slant distance from the source volume element to the surface flux position. The infinite slab source IBM 704 code which computes the gamma flux from an infinite slab source with exponential representation of sources and buildup factor was used to determine capture garma contributions to the surface source strength at the outer surface of the pressure vessel. Ganma dose rates $D_{\gamma}($ mr $/ \mathrm{hr})$ are then computed by

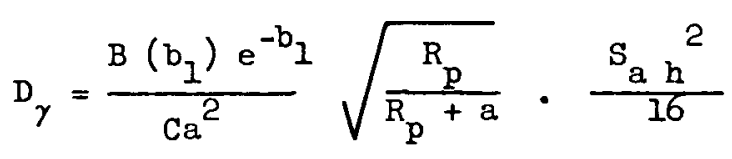


where

$C$ is the energy flux to dose rate conversion factor (mev/ $\mathrm{cm}^{2}-\mathrm{sec} / \mathrm{mr} / \mathrm{hr}$.

$B\left(b_{1}\right)$ is the buildup factor in media over $b_{1}$ mean free paths

$\mathrm{J}$

the number of mean free paths, $b_{1}=\Sigma \quad(\mu t)_{j}$ is the sum of the mean free $j=1$

paths through $J$ media interposed between the pressure vessel outer wall and point of interest

$R_{p}$ is the radius of the cylindrical outer pressure vessel surface $(\mathrm{cm})$

$h$ is the helght of the core (cm)

$\mathbf{J}$

$a=\Sigma t_{j}$ is the radial distance between the pressure vessel outer wall $j=1$

and the point of interest $(\mathrm{cm})$

$S_{a}$ is the total surface source strength assumed to be unfform over the surface $\left(\mathrm{mev} / \mathrm{cm}^{2}-\mathrm{sec}\right)$

Equation I-5 may be used as an approximation for the dose rate off the radial centerline by aligning the equivalent source normal to the line from its center to the point of interest.

The axial gamma dose from all sources within the reactor vessel were computed as:

$$
D_{\gamma}=\frac{B\left(b_{1}\right) e^{-b} 1}{C a^{2}}\left[\frac{R_{c}^{2} s_{v}}{\mu_{c}}+\frac{h / 2}{1+\frac{h}{a}} \sum_{i=1}^{I}\left(B e^{-\mu h}\right)_{i-1} \text { ri } s_{A_{1}}\right] \quad I-6
$$

where

$C$ is the energy flux to dose rate conversion factor (mev/ $\mathrm{cm}^{2}-\mathrm{sec} / \mathrm{mr} / \mathrm{hr}$ )

$B\left(b_{1}\right)$ is the buildup factor in media over $b_{1}$ mean free paths. $\mathrm{J}$

$b_{1}=\Sigma \quad(\mu t)_{j}=$ sum of the mean free paths through $J$ media interposed $j=1 \quad j$ between the nearer end of the core and the point of $\mathrm{J}$ interest.

$a=\Sigma \quad t_{j}=$ axial distance between the nearer end of the core and $j=1$

$R_{c}$ is the radius of cylindrical core $(\mathrm{cm})$. 
$\mathrm{S}_{\mathrm{v}}$ is the volume source strength assumed to be unfform over the entire core $\left(\mathrm{mev} / \mathrm{cm}^{3}-\mathrm{sec}\right)$

$\mu_{c}$ is the linear gamma absorption coefficlent for the core $\left(\mathrm{cm}^{-1}\right)$

$h$ is the helght of the core $(\mathrm{cm})$

$r_{1}$ is the inner radius of the $1^{\text {th }}$ cylindrical shell capture gamma region

$\mathrm{S}_{\mathrm{A}}$ 1s the surface source strength of capture gammas at the inner surface of the $1^{\text {th }}$ shell (mev/ $\left.\mathrm{cm}^{2}-\mathrm{sec}\right)$.

$\mathrm{B}_{\mathrm{e}}^{-\mu \mathrm{h}}$ is the attenuation factor through height of cylindrical shell or cylinder which is bounded on the outside by the capture gama source.

The volume source strength $S_{v}$ includes all sources within the core volume. The surface source strength $S_{a}$ for capture gammas was obtained by use of the previously mentioned slab source code by obtaining values of the gama flux at the inner surfaces of the various regions along the core radial centerline.

Radial and axial flux calculations of radiation from the steam generator and primary coolant in the piping were calculated by use of the equivalent line source solution for a cylindrical source (Ref. 1, Chapter 9). The following equations were used to perform calculations of dose rates off the radial centerline from the steam generator.

Above-the-top or below-the-bottom of the projected end surfaces of the source

$$
D_{\gamma}=\frac{B S_{v} R_{0}^{2}}{4(a+z)}\left[F\left(\theta_{2}, b_{2}\right)-F\left(\theta_{1}, b_{2}\right)\right]
$$

within the projected end surfaces of the source

$$
D_{\gamma}=\frac{B S_{v} R_{0}^{2}}{4(a+z)}\left[F\left(\theta_{1}, b_{2}\right)+F\left(\theta_{2}, b_{2}\right)\right]
$$

The angles $\theta_{1}$ and $\theta_{2}$ and the reglons of applicability of equations I-7 and I-8 are defined by the following drawing: 


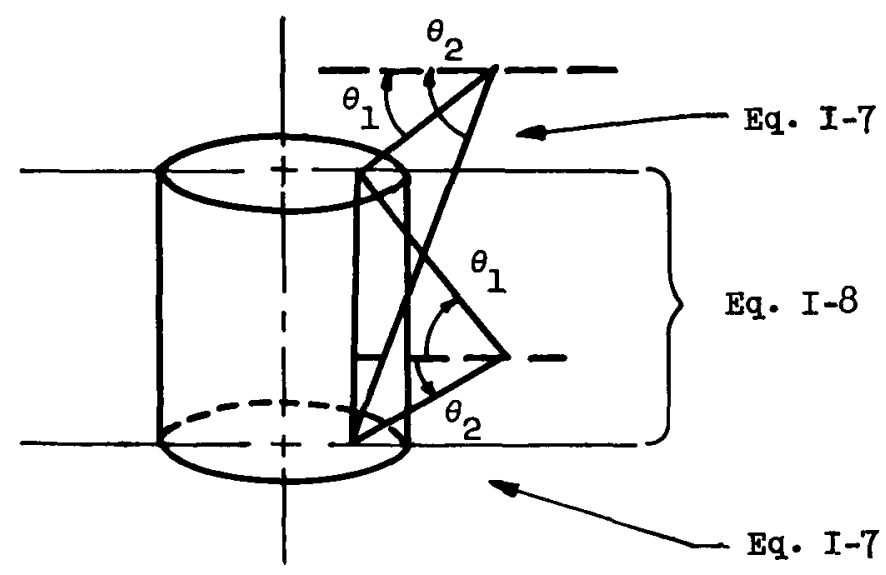

All other quantities are as previously defined for equations I-2 and I-4 with the exception that appropriate build-up factors, B were applied, the total linear gamma absorption coefficlent $\left(\mu \mathrm{c}^{-1}\right)$ was substituted for the neutron effective removal cross section $\Sigma_{\mathrm{R}}$ and $C$ is as previously defined for equation I-5. With

this substitution, equation I-2 and I-3 were used to calculate on axis and radiaI centerline steam generator ganma dose rates.

After shutdown, radiation from the core was computed using equation I-7 and I-8 and the above mentioned modified form of equations I-2 and I-3. Equation I-5 was used to estimate gamma dose rates from the activated pressure vessel. Source strengths were obtained from the preliminary date of Ref. 13.

N.D.A. dose build-up factors for a point isotopic source in an infinite medium were used for all gamma attenuation calculations. For shield media such as earth which may be assumed homogeneous, an effective $\mathrm{z}$ was determined by methods described in Ref. 1, Chapter 1 and the correspondingbuild-up factor was used. Where a single build-up factor was taken over the total number of mean free paths from source to dose point and through a variety of shield media, the conservative build-up factor was chosen. Garma absorption coefficients used were taken directly or computed from the $\mathrm{N}$ B S values given in Ref. 2. Estimated uncertainty of these theoretical values is within $\pm 2 \%$.

Alr-scattering of gamma radiation from the reactor vessel and dry-steam generator package was estimated by obtaining an equivalent point source for the actual volume source. The Klein-Nishima differential scattering cross sections were used with the standard equation of Chapter V, Ref. 5, for computations of dose rates. A graphical integration over various scattering angles (Ref. 14) were used as an ald to computation. Estimates of dose rates from air-scattered neutrons obtalned from the solutions of Ref. 9 showed this source to be negligible.

Equivalent thicknesses of Iron, lead and water for 6.0 mev gamma rays were calculated as: 
$B_{w}\left\{E_{0},\left[\mu\left(E_{0}\right) t\right]_{w} e^{-\left[\mu\left(E_{0}\right) t\right.}\right]_{W}=B_{1}\left\{E_{0},\left[\mu\left(E_{0}\right) t\right]_{1}\right\} e^{-\left[\mu\left(E_{0}\right) t\right] 1}$

where

$B_{w}\left\{E_{0},\left[\mu\left(E_{0}\right) t\right]_{1}\right\}=\begin{aligned} & \text { dose bulld-up factor for a point isotropic source in water } \\ & \text { over } \mu\left(E_{0}\right) t \text { mean free paths in water. }\end{aligned}$

$B_{1}\left\{E_{0},\left[\mu\left(E_{0}\right) t\right]\left\{\begin{array}{l}\text { dose build-up factor for a point isotropic source in the } 1^{\text {th }} \\ \text { media over the sum of mean free paths }\left[\mu\left(E_{0}\right) t\right]_{1} \text { through the } \\ 1^{\text {th media }}\end{array}\right.\right.$

$\mu\left(\mathbf{E}_{0}\right)$ is the mean ganma absorption coefficient $\left(\mathrm{cm}^{-1}\right)$ at energy
$\mathbf{E}_{0}$ (mev)

$t$ is the thickness of the shield media (cm) subscript 1 refers to iron or lead as the media.

The cholce of the single $6.0 \mathrm{mev}$ energy for derived surface source strengths was shown to be a good approximation by comparison with multienergy group computations.

A number of graphs were prepared from calculated data obtained by using the above equations. Elimination of the lengthy hand calculations in computation of dose rates and shield thickmesses was made possible through the use of these graphs.

Computed dose rates and shield thicknesses are conservative, possibly by as much as a factor of 10 . The uncertainty stems mainly from one or both of the following calculational techniques:

(1) A single average energy and source strength was used to estimate the dose rates in varlous media.

(2) A dose rate ratio approximation was used to obtain the attenuation through several different layers of shield media. For example, the dose rate beyond a combination of lead thickness $t_{1}$ followed by water of thickness $t_{w}$ is obtained by multiplying the dose rate in pure water at a distance $t_{1}+t_{w}$ by the ratio of the dose rate at $t_{1}$ in pure lead to the dose rate at $t_{w}$ in pure water.

Dose rates from the several sources in various shifeld media were prepared in graphical form as an aid to computation. The graphs included in this report (F1gs. B-I through B-7) may be used for quick estimates of shlelding required for components of the primary system. The graphs of FIg. B-I are gamma and fast neutron dose rates vs water thickness, taken along the radial centerline of the reactor core. The gamma flux was calculated using equation I-5 with the total reactor ganma radiation energy spectrm data given in Ref. 3. The neutron flux was calculated using fast neutron effective removal theory and equation I- 4 . 
Figure B-2 shows equivalent thickness of Iron and lead for water for 6.0 mev gamnas. The equivalent thicknesses were computed using equation I-9 with appropriate bulld-up factor.

Figure B-3 shows the attenuation along the core radial centerline of fast neutrons and gammas from the reactor vessel during operation in earth of density $2.075 \mathrm{~g} / \mathrm{cm}^{3}$. Neutron dose rates were computed using effective removal cross sections (Equation I-4). Gamma dose rates along the core radial centerline from fission products and induced activity in the core elght hours after shutdown, as a function of water shield thickness, are plotted in Fig. B-4. The data represents results of multigroup calculations over the energy spectrum of Ref. 4. The dashed curve was estimated from the two calculated points shown. Figure B-5 shows attenuation of gammas from the saturated pressure vessel activity, eight hours after shutdown, as a function of water thicloness. Equation I-5 was used with the data of Ref. 13 to compute these results. Dose rates from air-scattered gamas, originating in the steam generator during operation, are shown in Fig. B-6 for the illustrated horizontal and vertical package configuration. Package dimensions are:

$$
\begin{array}{ll}
\text { a. Horizontal } & 8 \mathrm{ft} 8 \mathrm{in} . \times 8 \mathrm{ft} 8 \text { in. } \times 20 \mathrm{ft} \\
\text { b. Vertical } & 8 \mathrm{ft} 8 \mathrm{in} \times 20 \mathrm{ft} \times 8 \mathrm{ft} 8 \mathrm{in} .
\end{array}
$$

Equivalent point sources (as illustrated) were assumed for the computation. Figure B-7 shows attenuation of radiation from the primary piping during operation through various shield media. The distance is measured from the inner surface of the pipe. 


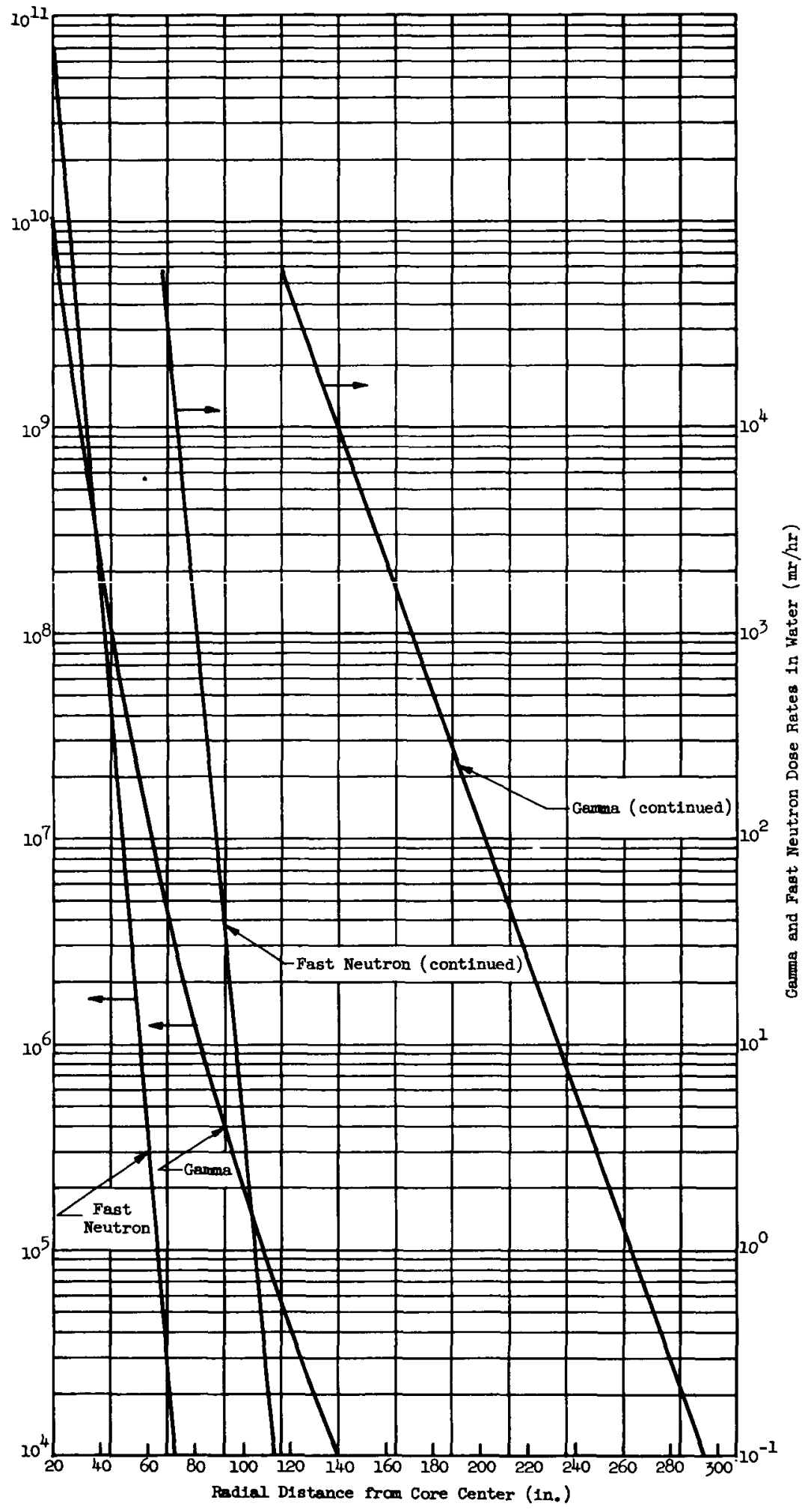

Fig. B-1. Attenuation by Water of Reactor Garma and Fast Neutron Dose Rates 


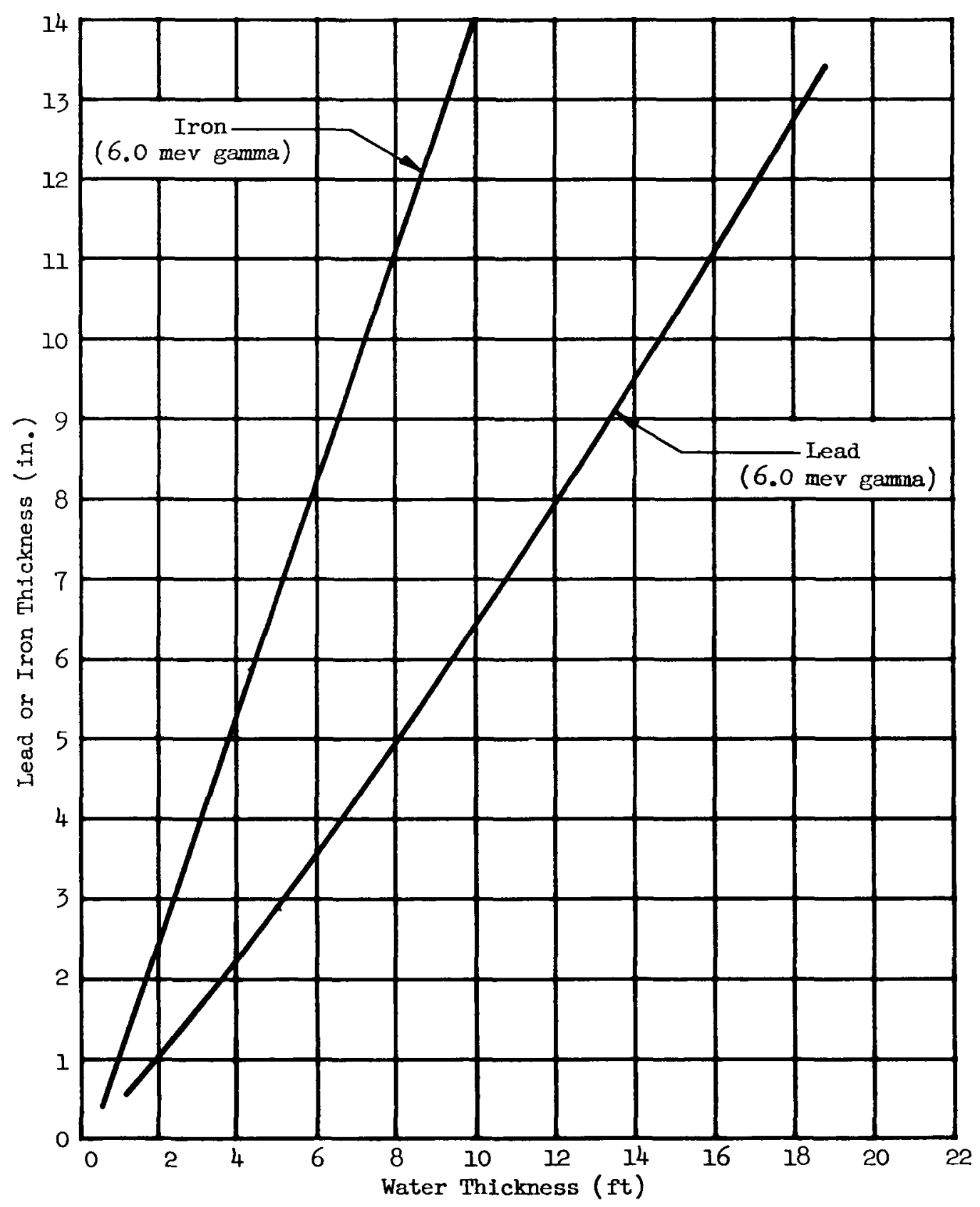

Fig. B-2. Equivalent Water Thicknesses of Lead and Iron for 6 mev Gammas 


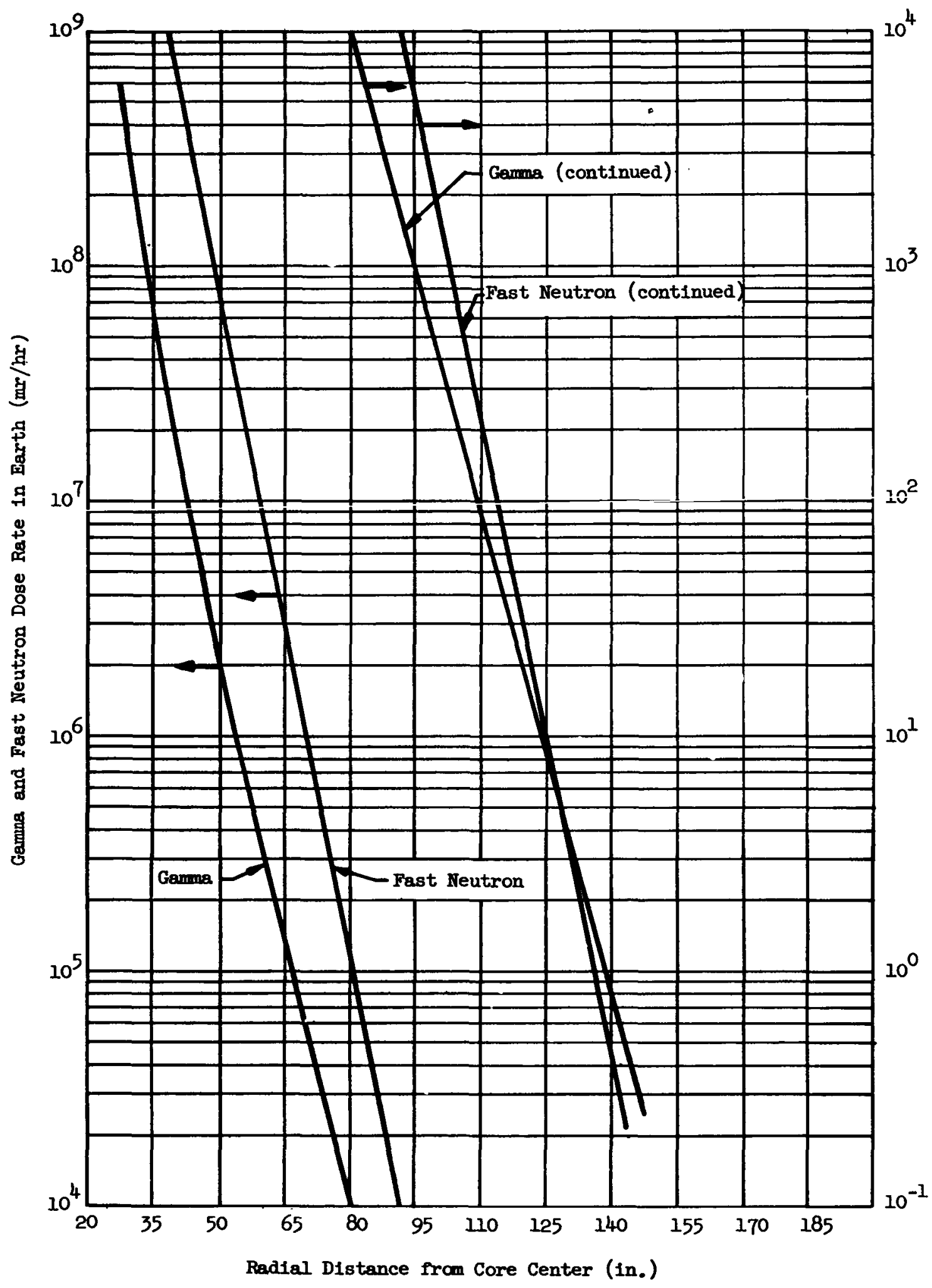

F1g. B-3. Attenuation by Earth of Reactor Gamma and Fast Neutron Dose Rates 


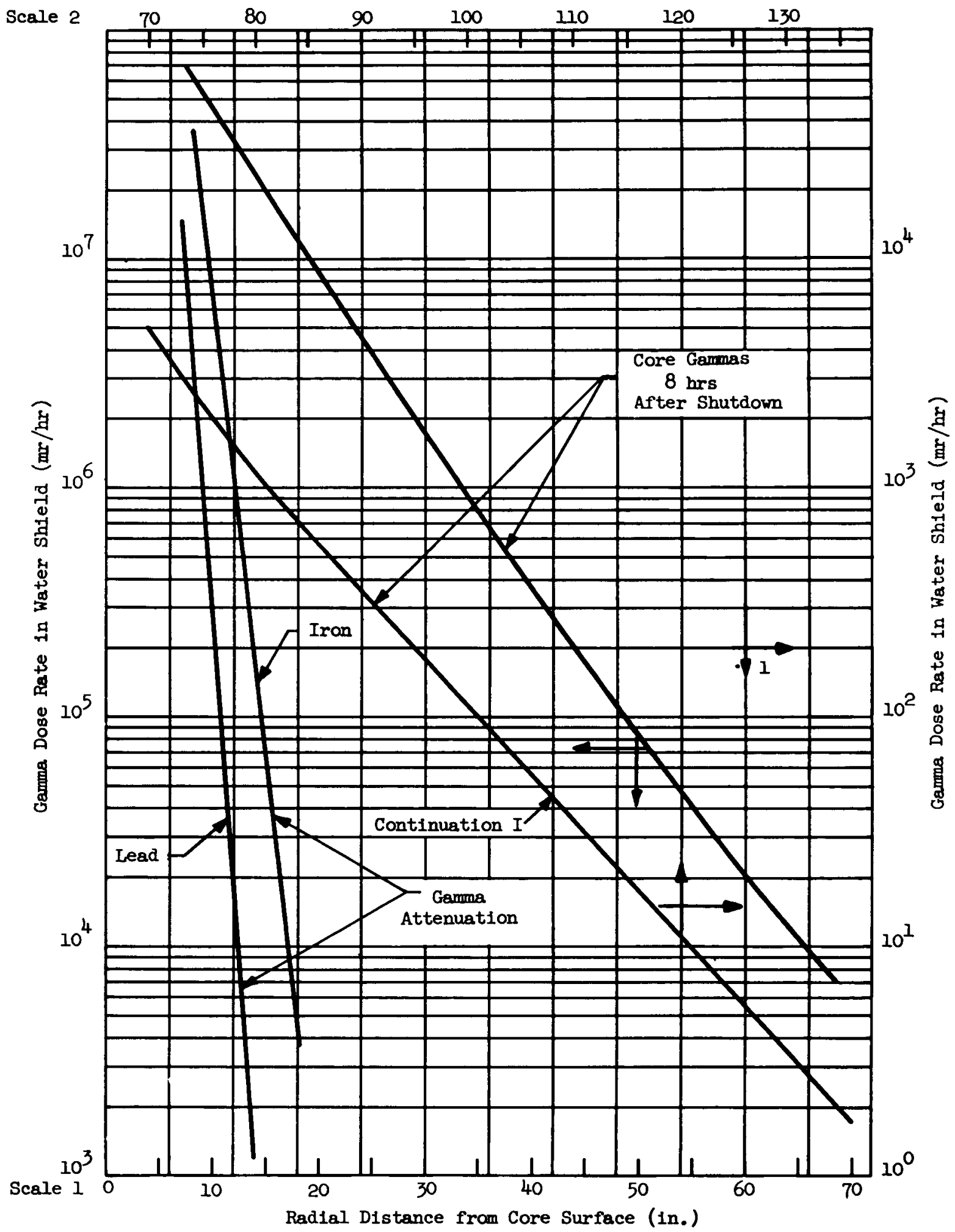

Fig. B-4. Attenuation by Water of Core Gamma Dose Rate--8 hr After Shutdown 


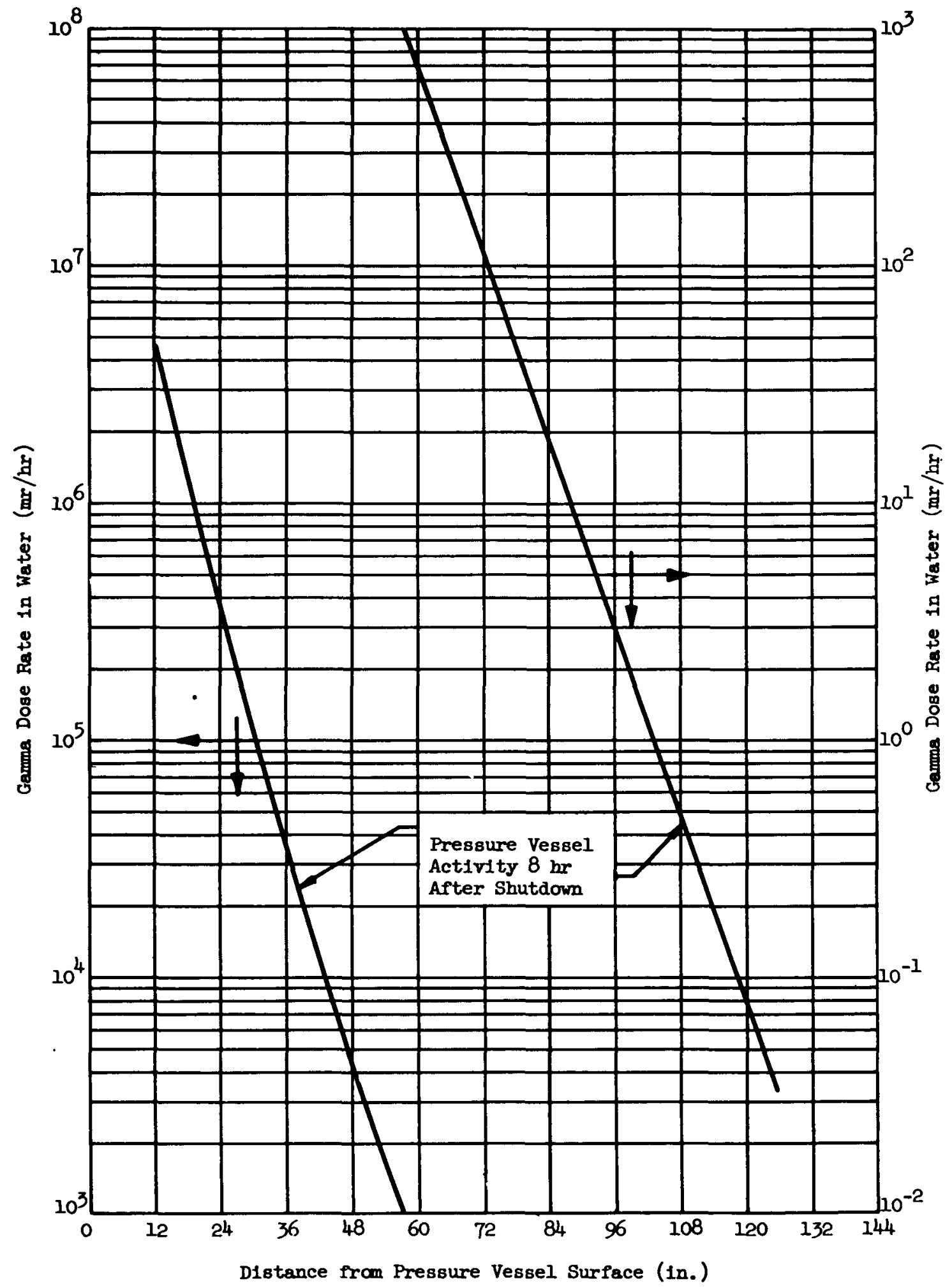

Fig. B-5. Attenuation by Water of Pressure Vessel Gamma Dose Rate-$8 \mathrm{hr}$ After Shutdown 

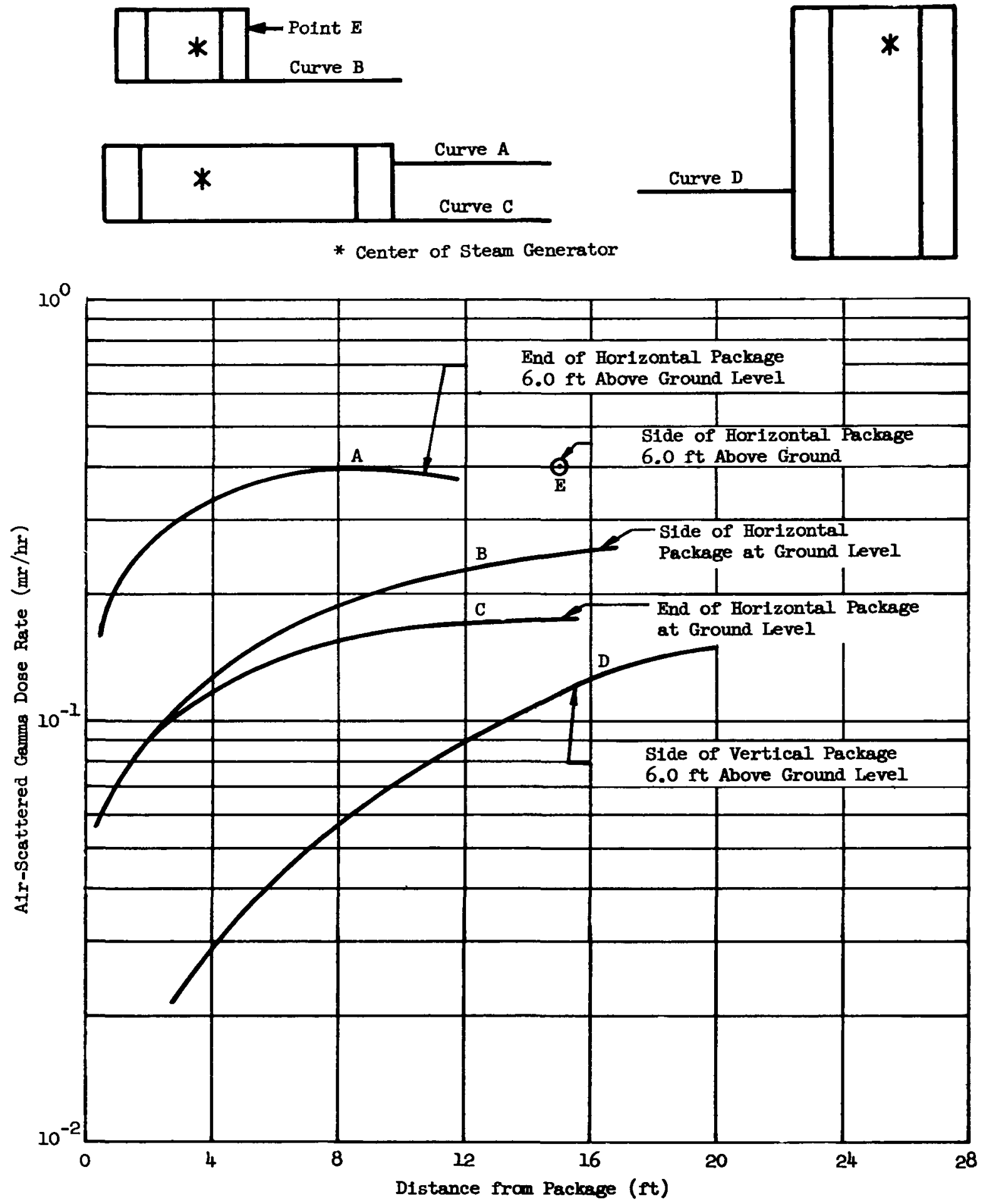

Fig. B-6. Variation of Air-Scattered Steam Generator Gamma Dose Rates with Distance from Steam Generator Package 


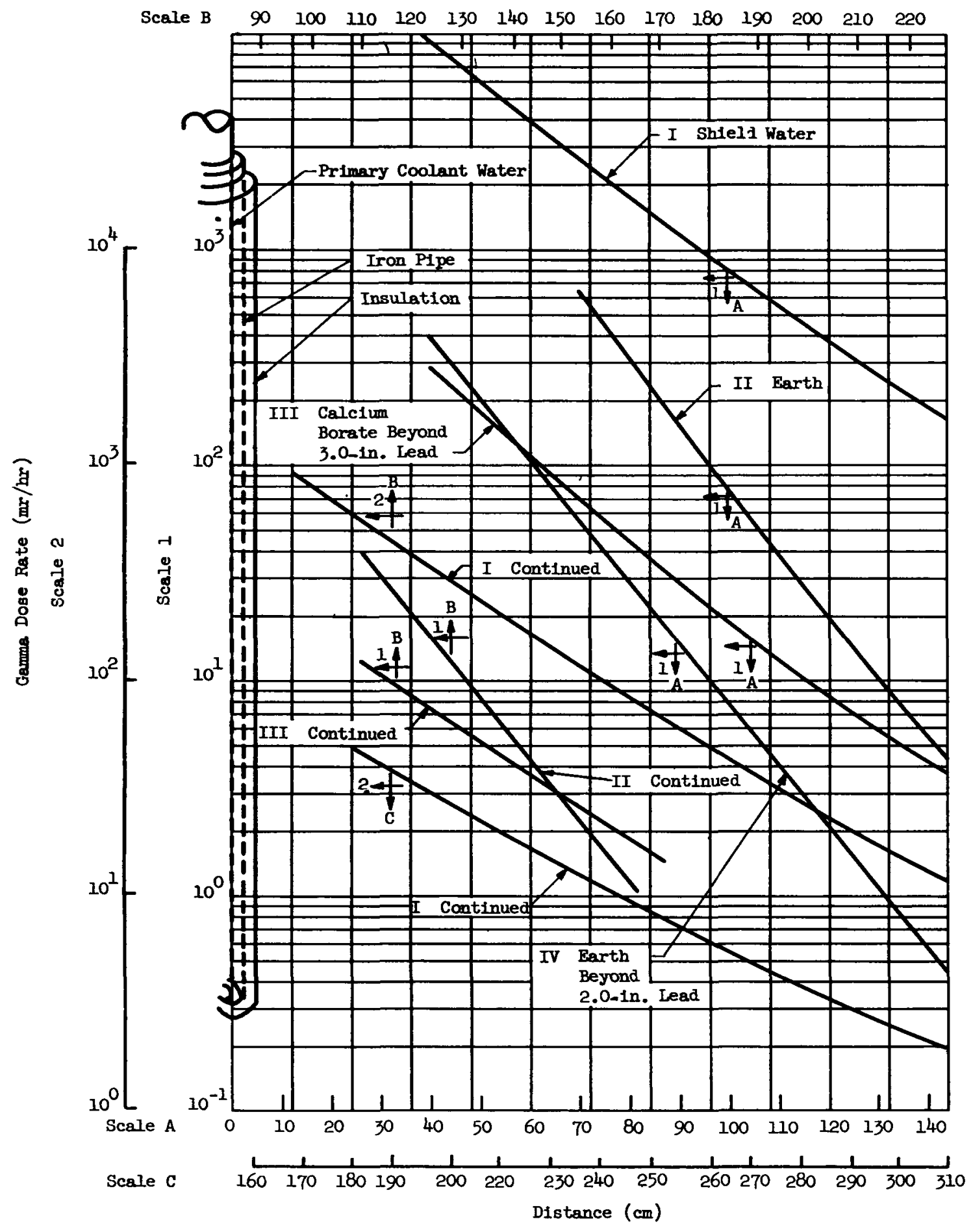

F1g. B-7. Attenuation of Primary Fluid Gammas by Various Media as a Function of Distance from Piping 


\section{APPENDIX $\mathrm{C}$}

HEAT TRANSFER ANALYTICAL ME'THODS

\section{Pressurized-Water Cores}

The IBM-704 code used to obtain data on the heat transfer performance of pressurized water cores treats the average element in each pass separately. The code performs the following operations:

(1) Computes an average film coefficient based on the equation

$$
h=0.023 \frac{\mathrm{K}}{\mathrm{D}}(\operatorname{Re})^{0.8}(\operatorname{Pr})^{0.4}
$$

(2) Divides the fuel element into a number of axial increments. The heat source in each increment is computed based on the input axial power distribution.

(3) Divides the element into a number of radial increments and solves the heat conduction differential equation by a finite difference technique. The coolant temperature rise and the element surface temperature are computed for the increment. The same procedure is used in each axial increment starting at the inlet of the pass and proceeding to the outlet. This information is then printed out.

The hot spot factors were then applied to the increment having the highest surface temperature computed by the code using the following equations:

First pass

$$
\mathrm{T}_{\max }-\theta_{\text {in }}=(P)\left(F_{q}\right)\left(F_{b}\right)(\beta)\left[\theta_{(x)}-\theta(\text { in })\right]+P\left(F_{q}\right)\left(F_{\varphi}\right)(\beta)\left[\left(T_{(x)}{ }^{-\theta}(x)\right]\right.
$$

Second pass

$$
\begin{aligned}
T_{\max }-\theta_{\text {In }} & =\Delta \theta_{O B}+(P)\left(F_{q}\right)\left(F_{b}\right) \beta\left[\theta_{(x)}-\theta_{(i n)}-\Delta \theta_{O B}\right] \\
& \left.+(P)\left(F_{q}\right)\left(F_{\varphi}\right)(\beta)\left[T_{\infty}-\theta_{\infty}\right)\right]
\end{aligned}
$$

Local Boiling Cores

The IBM-704 code used for obtaining data on the heat transfer performance of local boiling cores treats the hottest element in the core. The code performs the following operations.

(1) The bulk coolant temperature rise is computed along the hottest tube. The coolant inlet temperature required to prevent bulk boiling in this channel with a $50 \%$ power Increase is then calculated. 
(2) The nonboiling film coefficient is calculated based on the equation

$$
\mathbf{h}=0.023 \frac{\mathrm{K}}{\mathrm{D}_{\mathrm{e}}}(\mathrm{Re})^{0.8}(\mathrm{Pr})^{0.4}
$$

(3) Expressions for the fuel element surface based on local bolling and nonboiling conditions are equated and the code solves for the axial location where this situation occurs. This is the location where local boiling begins. The fuel element surface temperature under nucleate boiling conditions is defined by the equation:

$$
T_{\text {wall }}=\theta_{\text {sat }}+\frac{1.9}{e^{p_{p}} / 900} \quad \text { (q) }{ }^{1 / 4}
$$

(4) The burnout heat flux was then calculated at a location $65 \%$ of the way up the core. The correlation used was:

$$
\frac{9_{B .0}}{10^{6}}=c\left(\frac{G}{10^{6}}\right)^{m}\left(\theta_{\text {sat }}-\theta_{(x)}\right)^{0.22}
$$

At this location, the actual heat flux was calculated based on the assumed axial power distribution. The ratio of actual to burn-out heat flux was then computed. 


\section{APPENDIX D}

\section{PRESSURIZRR EQUATIONS}

Nomenclature:

W Mass, $1 \mathrm{~b}$

V Volume, cu ft

$\checkmark$ Specific volume, $\mathrm{cu} f \mathrm{ft} / \mathrm{lb}$

$\Delta \theta \quad$ Temperature variation, ${ }^{\circ} \mathrm{F}$

$B$ Coefficient of volumetric expansion, ${ }^{\circ} \mathrm{F}^{-1}$

Subscripts:

w Water

s Steam

sg Surge

p Pressurizer on at transient pressure

- Initial conditions

I Loop

Outsurge:

$$
\begin{aligned}
& \left(w_{w 0}-v_{s g}\right) v_{w p}+w_{s o} v_{s p}=v_{p} \\
& \frac{v_{w 0}}{v_{p}} \frac{v_{w p}}{v_{w 0}}-\frac{v_{s g}}{v_{p}} \frac{v_{w p}}{v_{I}}+\frac{v_{s o}}{v_{p}} \frac{v_{s p}}{v_{s o}}=1 \\
& \frac{v_{w p}}{v_{w o}}-2 \frac{v_{s g}}{v_{p}} \frac{v_{w p}}{v_{L}}+\frac{v_{s p}}{v_{s o}}=2\left[\text { since } \frac{v_{w o}}{v_{p}}=\frac{v_{s o}}{v_{p}}=1 / 2\right] \\
& v_{p}=2 v_{L} \beta \Delta \theta\left[\frac{v_{L}}{v_{w o}}+\frac{v_{L} v_{s p}}{v_{w p} v_{s o}}-2 \frac{v_{L}}{v_{w p}}\right] \\
& \text { Since } v_{s g}=\beta \Delta \theta v_{L}
\end{aligned}
$$


D-2

Insurge:

$$
\begin{aligned}
& \frac{\left(v_{s o}-v_{s g}\right)}{v_{s p}}=\frac{v_{\text {so }}}{v_{\text {so }}} \\
& \text { and } v_{p}=2 v_{L} \beta \Delta \theta\left[1-\frac{v_{s p}}{v_{\text {so }}}\right]
\end{aligned}
$$




\section{REFFERENCES}

1. TID 7004, "Reactor Shielding Design Manual," T. Rockwell (ed. ) March 1956.

2. "The Attenuation of Gamma Rays and Neutrons in Reactor Shields," H. Goldstein, May 1, 1957.

3. MND-MPR-1581, "Martin Design Report--Ice Cap Nuclear Power Plant," Martin Nuclear, January 1959.

4. MND-1558, "Modular Nuclear Power Plant, Volume II--Reference Design," Martin Nuclear, November 1958.

5. "Introduction to. Nuclear Engineering," R. Stephenson, McGraw-Hill, 1954.

6. APEX 407, "Ganma Ray Energy Spectra Fron Thermal Neutron Capture," F. E. Deloume, August 1958.

7. "The Physical Theory of Neutron Chain Reactors," A. Weinberg and E. P. Wigner, University of Chicago, Press, 1958.

8. MND-MPR-1711, "Integrated Fast Neutron Flux on the MPR Pressure Vessel," E. L. Divita, February 1959.

9. WKNL-90 "Shielding Characteristics of Air, Soil, Water, Wood and Other Common Materials--Volume I: Air-Scattering." Walter Kidde Nuclear Lab. Inc., February 28, 1957.

10. "Energy Release From the Decay of Fission Products," J. F. Perkins and R. F. King, Nuclear Science and Engineering, Volume 3 (1958) pp. 726 to 746

11. APAE 29, "Corrosion Product Activity in the Primary System of the Primary System of the Army Package Power Reactor, ALCO Products, Inc., April 15, 2958.

12. MND-1721, "A Program for the Computation of Fission Product Activity", W. 0. Owings, March 2, 1959.

13. MND-MPR-1747, "Thermal Neutron Activation of the MPR Type Pressure Vessel," E. Divita, J. Leffler, D. Owings, March 10, 1959.

14. Republished Data, "Air Scattering of Gamma Radiation, Shield Analysis Unit," April 1959.

15. AECD 3978, "Effective Neutron Removal Gross Sections for Shielding," Chapman and G. L. Storrs, September 19, 1955. 
1. ASME Boiler and Pressure Vessel Code, "Unfired Pressure Vessel," Section VIII, 1956.

2. "Tentative Structural Design Basis for Reactor Pressure Vessels and Directly Associated Components," Navy, April 1, 1958

3. The International Nickel Company, Inc., Technical Bulletin T-5 on Monel, May 1953.

4. Graphs of $\beta$ and $Q_{0}$ vs water gap, obtained from Mr. Don Ownings of The Martin Company, Nuclear Division.

5. Telephone conversation between Mr. Mounce of INCO in New York City and Mr. C. Canitz of The Martin Company, June 10, 1959, resulting in the following information:

$$
\begin{aligned}
& \mathrm{K}=0.34 \frac{\text { watts }}{\mathrm{cm}{ }^{\circ} \mathrm{C}}=19.64 \frac{\mathrm{Btu}}{\mathrm{hr} \mathrm{ft}^{\circ} \mathrm{F}} \text { at } 600^{\circ} \mathrm{F} \\
& \alpha=5.8(10)^{-6} \frac{\text { in }}{\text { in }^{\circ} \mathrm{F}} \text { at } 600^{\circ} \mathrm{F}
\end{aligned}
$$

6. ASME Boiler and Pressure Vessel Code Ruling Case No. 1234. 


\section{NOMENCLATURE}

c Empirical constant dependent on pressure

$\mathrm{D}_{\mathrm{e}} \quad$ Equivalent diameter

$F_{b} \quad$ Hot spot factor to account for variation in bulk coolant temperature

$F_{q} \quad$ Hot spot factor to account for varlation in power

$F_{\varphi} \quad$ Hot spot factor to account for variation in temperature differences across film

h Film coefficlent

k Thermal conductivity

m Empirical constant dependent on pressure

$P_{p} \quad$ Primary loop pressure

P Perturbation factor for local flux peaking

Pr Prandtl number

q Heat $\mathrm{flux}$

$\mathrm{q}_{\mathrm{BO}} \quad$ Burnout heat flux

Re Reynolds number

$\overline{\mathrm{T}}_{\mathrm{p}} \quad$ Mean temperature

$T_{\max } \quad$ Maximum fuel element surface temperature

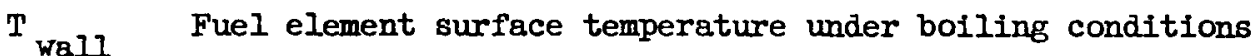

B Radial maximum to average flux ratio

$\theta$ in. Coolant inlet temperature

$\theta$ sat. Coolant saturation temperature

$\Delta \theta_{\mathrm{p}} \quad$ Coolant temperature rise across core

${ }^{\Delta \theta}$ OB Coolant temperature rise in first pass 


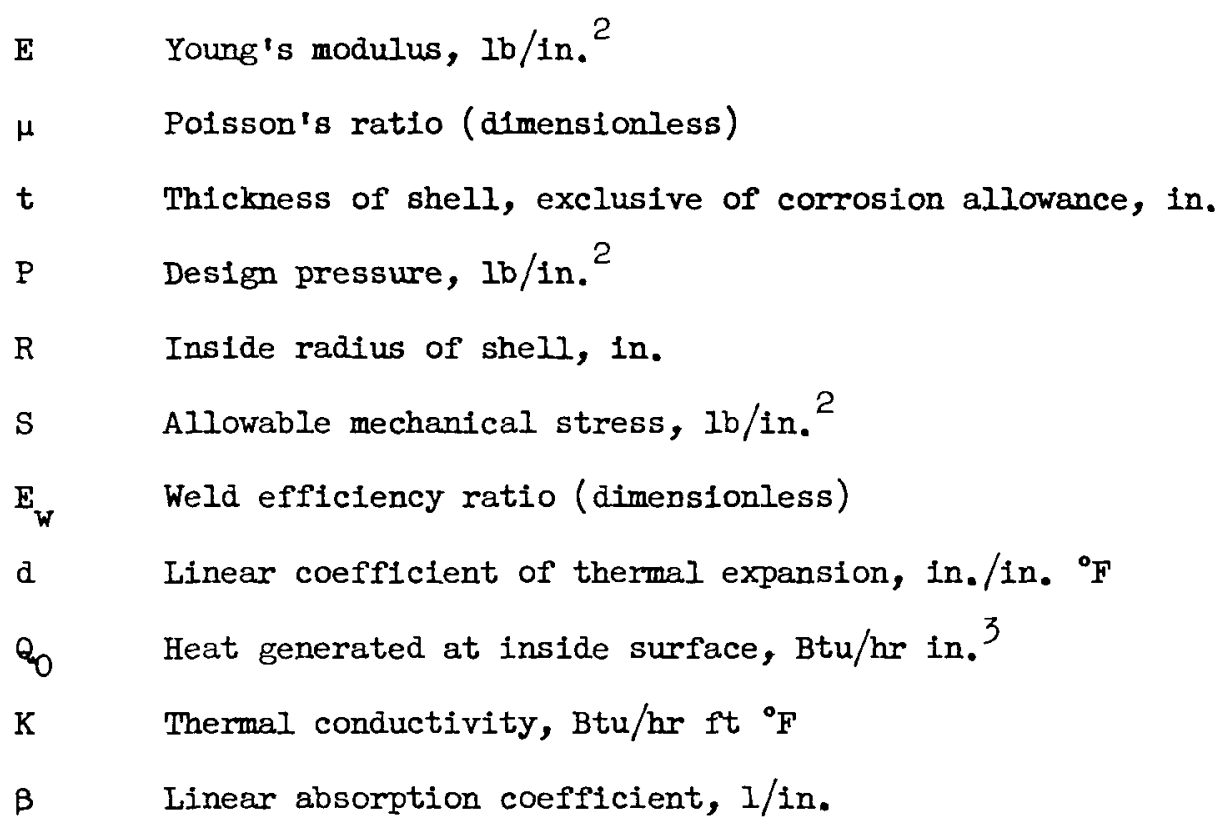

